\title{
Poverty, Inequality, and Growth in Developing Countries
}

Theoretical and empirical approaches

Edited by Atsushi Maki 


\section{Poverty, Inequality, and Growth in Developing Countries}

There are many problems regarding poverty, inequality, and growth in developing countries in Asia and Africa. Policy makers at the national level and at international institutions such as the United Nations, World Bank, International Monetary Fund, and others have implemented various policies in order to decrease poverty and inequality. This book provides empirical observations on Asian countries and Africa. Each chapter provides theoretical and empirical analysis on regional case studies with an emphasis on policy implications.

The book will be of use to many who wish to assess and improve policies in developing countries, mitigate poverty and inequality, and stimulate growth by drawing on relevant empirical research and economic theory. Clearly, there have been numerous policy failures, and the book aims to provide a basis for improving policies and outcomes based on relevant empirical observations.

Atsushi Maki is presently with the Department of Economics, Tokyo International University, Japan. He is professor emeritus of economics at Keio University, Japan. Previously, he was professor of economics (1987-2009) at the Faculty of Business and Commerce, Keio University. He has been a visiting scholar at several universities such as Harvard University and Australian National University and has taught at several universities and institutions such as Osaka University, ESSEC (France), KSMS (Kenya), and Willamette University as a visiting professor. His main fields are empirical analysis of consumer behaviour and market behaviour. 


\section{Routledge Studies in the Modern World Economy}

116 The Role of Informal

Economies in the

Post-Soviet World

The end of transition?

Colin C. Williams, John Round

and Peter Rodgers

117 Demystifying the Chinese

Miracle

The rise and future of relational capitalism

Yongqin Wang

118 Globalism and Regional Economy

Edited by Susumu Egashira

119 Russia's Changing Economic and Political Regimes

The Putin years and afterwards Andrey Makarychev and André Mommen

120 Innovation and Regional Development in China

Edited by Ingo Liefner and Yehua Dennis Wei

121 International Trade

Negotiations and Domestic

Politics

The intermestic politics of trade liberalization

Edited by Oluf Langhelle
122 Emerging Knowledge

Economies in Asia

Current trends in ASEAN 5

Edited by Dessy Irawati and Roel

Rutten

123 The Internationalization of the Renminbi

International Monetary Institute, Renmin University of China

124 Financial Globalization and Regionalism in East Asia Edited by Takuji Kinkyo, Yoichi Matsubayashi and Shigeyuki Hamori

125 Successful Business Dealings and Management with China Oil, Gas and Chemical Giants EurIng. Henry K. H. Wang

126 State Building and Development

Edited by Keijiro Otsuka and Takashi Shiraishi

127 International Economic Development

Leading issues and challenges

Edited by Fu Lai Tony Yu, Wai Kee Yuen and Diana

S. Kwan 
128 Innovation, Globalization and Firm Dynamics

Lessons for enterprise policy

Edited by Anna Ferragina, Erol Taymoz and Kamil

rilmaz

129 International Remittance

Payments and the Global

Economy

Bharati Basu with

James T. Bang

130 The Open Society and its

Enemies in East Asia

The relevance of the Popperian framework

Edited by Gregory C. G. Moore

131 The Economics of

Knowledge Generation

and Distribution

The role of interactions in the

system dynamics of innovation and growth

Edited by Pier Paolo Patrucco

132 Japan's Aid

Lessons for economic growth, development and political

economy

Edward M. Feasel

133 The Geographical

Transformation of China

Edited by Michael Dunford and

Weidong Lui

134 The Economics of Cooperative Education

A practitioners' guide to the theoretical framework and empirical assessment of cooperative education rasushi Tanaka
135 Comparing Post War Japanese and Finnish Economies and Societies

Edited by Yasushi Tanaka, Toshiaki

Tamaki, Jari Ojala and Jari

Eloranta

136 Measuring National Income in the Centrally Planned Economies

Why the west underestimated the transition to capitalism William Jefferies

137 Crises in Europe in the Transatlantic Context

Economic and political appraisals Edited by Bruno Dallago and John McGowan

138 The International Monetary System, Energy and Sustainable Development Edited by Sung Jin Kang and rung Chul Park

139 Capitalism and the World Economy

The Light and Shadow of Globalization

Edited by Toshiaki Hirai

140 Irish Economic Development Serial Under-achievement or High-Performing EU State? Eoin O'Leary

\section{Banking on Equality}

Women, work and employment in the banking sector in India Supriti Bezbaruah

142 Poverty, Inequality and Growth in Developing Countries Theoretical and empirical approaches

Edited by Atsushi Maki 
This page intentionally left blank 


\section{Poverty, Inequality, and Growth in Developing Countries}

Theoretical and empirical approaches

Edited by Atsushi Maki

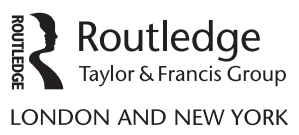


First published 2015

by Routledge

2 Park Square, Milton Park, Abingdon, Oxon OX14 4RN

Simultaneously published in the USA and Canada

by Routledge

711 Third Avenue, New York, NY 10017

Routledge is an imprint of the Taylor \& Francis Group, an informa business

\section{(C) 2015 Atsushi Maki}

The right of the editor to be identified as the author of the editorial material, and of the authors for their individual chapters, has been asserted in accordance with sections 77 and 78 of the Copyright, Designs and Patents Act 1988.

All rights reserved. No part of this book may be reprinted or reproduced or utilised in any form or by any electronic, mechanical, or other means, now known or hereafter invented, including photocopying and recording, or in any information storage or retrieval system, without permission in writing from the publishers.

Trademark notice: Product or corporate names may be trademarks or registered trademarks, and are used only for identification and explanation without intent to infringe.

British Library Cataloguing-in-Publication Data

A catalogue record for this book is available from the British Library

Library of Congress Cataloging-in-Publication Data

Poverty, inequality and growth in developing countries : theoretical and empirical approaches / edited by Atsushi Maki. - 1 Edition.

(Routledge studies in the modern world economy)

1. Poverty-Developing countries. 2. Equality-

Developing countries. 3. Urbanization-Developing

countries. 4. Developing countries-Economic conditions-

21 st century. I. Maki, Atsushi, 1948- editor.

HC59.72.P6P6834 2015

$339.4 ' 6091724-\mathrm{dc} 23$

2014046582

ISBN: 978-1-138-02326-0 (hbk)

ISBN: 978-1-315-69605-8 (ebk)

Typeset in Galliard

by Apex CoVantage, LLC 


\section{Contents}

List of Figures $\quad$ xi

List of Tables $\quad \mathrm{xv}$

Preface xxi

Notes on Contributors xxiii

1 Introduction 1

ATSUSHI MAKI

Overview 1

Structure of the book 3

Overview of the chapters 3

2 Are luxury goods really luxuries? The validity of the Törnqvist-Wold hypothesis

ATSUSHI MAKI AND MLEMBA ABASSY KAMWE

1. Introduction 10

2. Data used for the analysis 15

3. Estimating demand functions for nineteen commodities in the food category 23

4. The linear expenditure system (LES) and the quadratic expenditure system (QES) 29

5. The Törnqvist-Wold hypothesis regarding necessities and luxuries 32

6. Comparisons of empirical findings conducted by Deaton (1987, $1988,1990)$ and Maki $(1998,2002)$ regarding the validity of the Törnqvist-Wold hypothesis 36

7. Conclusion 40 
3 Engel's Law in Vietnam and the Philippines: effects of in-kind consumption on inequality and poverty

ATSUSHI MAKI AND SATOSHI OHIRA

1. Introduction 44

2. Data used for empirical analysis of consumer behavior in Vietnam and the Philippines 46

3. Engel curves in Vietnam and the Philippines 55

4. The role of in-kind transactions 63

5. Implications 65

6. Conclusion 68

4 Informal agriculture sector in Indonesia: big in size, small in contribution, and full of the working poor

KADARMANTO

1. What is the informal economy? 73

2. The gap between the formal and informal sectors 76

3. Poverty: households engaged in informal employment in agriculture or nonagriculture sectors 83

4. Case study of regional differences between the two provinces 91

5. Summary and policy implications 98

5 Effects of remittances on income inequality and poverty in the Philippines

SATOSHI OHIRA AND KAREN VILLAQUER FIRSHAN

1. Introduction 104

2. Income, inequality, and poverty profile 107

3. Determinants of the migration decision 111

4. Effects of remittances on inequality and poverty 119

5. Conclusion 125

6 Area disparity of income and expenditure in Sri Lanka: based on micro-data sets of the Household Income and Expenditure Survey of 2006-2007

YASUMASA BABA, YUKO ARAI, HIROKO YASUI, AND KAORI YONEZAWA

1. Introduction 128

2. Overview of Household Income and Expenditure Survey of Sri Lanka 131

3. Income and expenditure 136

4. Income and expenditure of specific households 143

5. Conclusion 150 
7 The agricultural sector in Thailand's middle-income stage $\quad 153$ SATOSHI OHIRA AND ATSUSHI MAKI

1. Introduction 153

2. Economic development in Thailand 154

3. Theoretical models 160

4. Estimation 168

5. Conclusion 179

8 The possibility of a border economic zone: Asian Golden Quadrangle

SATOKO OKUYAMA

1. Introduction 182

2. The Golden Quadrangle 183

3. Progress of the Greater Mekong Subregion Program 192

4. Enhancing partnerships with foreign countries 199

5. Policy recommendations for the development of the GQ 206

6. Conclusion 207

9 Development of the fishery systems in modern Taiwan NOBUTAKE KOIWA

1. Introduction 211

2. Introducing Japanese fishery systems in Taiwan 212

3. Development of fisheries in modern Taiwan 216

4. Characteristics of fishery systems in Taiwan 223

5. Conclusion 227

10 Conclusion

ATSUSHI MAKI

Index 
This page intentionally left blank 


\section{Figures}

\section{Chapter 2}

Figure 1 Scatter between Engel's coefficient and total expenditure 18

Figure 2 Nonparametric regression 20

Figure 3 Graphic representation of necessities and luxuries 35

\section{Chapter 3}

Figure la All households in Vietnam 56

$\begin{array}{ll}\text { Figure lb Very poor households in Vietnam } & 57\end{array}$

Figure lc All households in the Philippines $\quad 58$

Figure ld Very poor households in the Philippines 59

\section{Chapter 4}

Figure 1 Contribution to GDP by sector and industry

Figure 2 Informal sector production in the agriculture and nonagriculture sectors

Figure 3 Labor productivity by industry in the formal and informal sectors

Figure 4 Nature of employment by production unit

Figure 5 Labor force characteristics by gender, nature of employment, and sector

Figure 6 Labor force characteristics by gender: agriculture and nonagriculture

Figure 7 Structure of informal employment in Yogyakarta 95

Figure 8 Structure of informal employment in Banten 95

Figure 9 Employment by occupation and nature of employment in Yogyakarta

Figure 10 Employment by occupation and nature of employment in Banten 


\section{Chapter 5}

Figure 1 Family income composition, 2000-2009

Figure 2 Proportion of agricultural GDP and regional poverty $P(\operatorname{sen})$

Figure 3 Percentage of families that send members to foreign countries and per capita income

Figure 4 Probability of migration and Gini coefficient

Figure 5 Poverty index and probability of migration

Figure 6 Per capita income and the proportion of remittances to household income

Figure 7 Theoretical value of the probability of migration and per capita income

Figure 8 Kernel regression result

\section{Chapter 6}

Figure 1 Household map

Figure 2 Distribution of monthly income of Sri Lanka

Figure 3 Distribution of monthly income by area

Figure 4 Distribution of monthly expenditure of Sri Lanka

Figure 5 Distribution of monthly expenditure by area

Figure 6 Engel's coefficient by number of household members and area

Figure 7 Engel's coefficient and consumption

Figure 8 Monthly income and expenditure per household by family nuclei

Figure 9 Monthly income and expenditure per household by family nuclei and area with children under the age of seventeen who attend school

Figure 10 Engel's coefficient by family nuclei and area

Figure 11 Engel's coefficient of family nuclei by area with children under the age of seventeen who attend school

Figure 12 Monthly income and expenditure per household by elderly household

Figure 13 Monthly income and expenditure per household by elderly household and area

Figure 14 Engel's coefficient by elderly household and area 


\section{Chapter 7}

Figure 1 Economic growth in Thailand

Figure 2 Trend of Gini index in Thailand 156

Figure 3 Trend of poverty in Thailand

Figure 4 Trend in the relative share of agricultural GDP in East Asian countries

Figure 5 Relative incomes of agricultural workers across different stages of economic development: Thailand $\quad 159$

Figure 6 The basic framework of the model

Figure 7 Agricultural GDP (left); nonagricultural GDP (whole kingdom) (right)

$\begin{array}{lll}\text { Figure } 8 & \text { The change in prices } & 172\end{array}$

Figure 9 Population (whole kingdom) 172

$\begin{array}{lll}\text { Figure } 10 & \text { The ratio between agricultural GDP and total GDP } 173\end{array}$

$\begin{array}{ll}\text { Figure } 11 \text { Production function } & 174\end{array}$

$\begin{array}{ll}\text { Figure } 12 \text { Production function } & 176\end{array}$

$\begin{array}{lll}\text { Figure } 13 \text { Histogram of } \varphi(\cdot) & 177\end{array}$

\section{Chapter 8}

Figure 1 The Golden Quadrangle

Figure 2 Monthly wages of workers and middle managers 190

Figure 3 Comparing the average monthly wages between big cities and local cities

Figure 4 Economic corridors being built under the GMS Program 193

$\begin{array}{lll}\text { Figure } 5 \text { Road expansion in Mae Sai } & 196\end{array}$

$\begin{array}{lll}\text { Figure } 6 & \text { The New Mae Sai customs house } & 197\end{array}$

Figure 7 Trade volume with Laos by customs in northeastern Thailand

$\begin{array}{lll}\text { Figure } 8 & \text { Trade volume of Thailand by region } & 198\end{array}$

Figure 9 Comparing GDP 200

Figure 10 Comparing population 200

Figure 11 FDI inflows to ASEAN by country 201

Figure 12 FDI stocks of GMS Program countries 202

Figure 13 FDI inflows in Thailand, Laos, and Myanmar 203

Figure 14 FDI stock-GDP ratio 203

Figure 15 Export and import shares of GT countries 204

Figure 16 China's trade share in Thailand, Laos, and Myanmar 205

Figure 17 Japan's trade share in Thailand, Laos, and Myanmar 205 
xiv Figures

\section{Chapter 9}

Figure 1 Provinces of Taiwan 214

Figure 2 Yield of fishery products in Taiwan from 1899 to $1942 \quad 216$

Figure 3 Yield of fishery products in Taiwan from 1912 to $1939 \quad 217$

Figure 4 Fish catches after 1940 in Taiwan by fishing ground 220

Figure 5 Fishery trade data in the 1930s in Taiwan 221 


\section{Tables}

\section{Chapter 2}

Table 1 Adult equivalence scale

Table 2 Movement of Engel's coefficient from the lowest to the highest total expenditure classes

Table 3 Estimation results: the QUAID system

Table 4 Total expenditure elasticity of demand at different total expenditure levels: the QUAID system 23

Table 5 Estimation results 24

Table 6 Elasticity of demand 28

Table 7 Estimation results 30

Table 8 The classification between necessities and luxuries based on the Törnqvist-Wold hypothesis and the alternative hypothesis

Table 9 Necessities or luxuries based on elasticity of demand: the Törnqvist-Wold hypothesis versus the alternative hypothesis

Table 10 Comparison of the present analysis with past findings

\section{Chapter 3}

Table la Basic statistics from the 2006 Household Living

Standards Survey in Vietnam

Table lb Basic statistics from the 2006 Household Living

Standards Survey in Vietnam focusing on very poor households

Table lc Basic statistics of the 2006 Family Income and Expenditure Survey in the Philippines

Table ld Basic statistics of the 2006 Family Income and Expenditure Survey in the Philippines focusing on very poor households 
Table 2 Differences of the values between adult equivalence scales

Table 3 Gini coefficient using different definitions of the adult equivalence scale

Table 4a Engel's coefficient including and excluding in-kind consumption: very poor households in Vietnam

Table 4b Engel's coefficient including and excluding in-kind consumption: very poor households in the Philippines

Table 5

Gini coefficient including and excluding in-kind consumption

Table 6a Estimation results: the QUAID system food share function in Vietnam (including in-kind consumption) 60

Table 6b Estimation results: the QUAID system food share function in the Philippines (including in-kind consumption)

Table 7a Estimation results: the QUAID system food share function in Vietnam (excluding in-kind consumption) 61

Table 7b Estimation results: the QUAID system food share function in the Philippines (excluding in-kind consumption)

Table 8a Income elasticity of demand at different income levels in Vietnam (including in-kind consumption): the QUAID system

Table $8 \mathrm{~b} \quad$ Income elasticity of demand at different income levels in the Philippines (including in-kind consumption): the QUAID system

Table 9a

The role of in-kind consumption in Vietnam

Table $9 \mathrm{~b}$ The role of in-kind consumption in the Philippines

Table 9c Summary table on the role of in-kind consumption

Table 10 Numerical example of inverse U-shaped Engel curves

Appendix A.1 All households in Vietnam

Appendix A.2 All households in the Philippines

\section{Chapter 4}

Table 1

A conceptual framework: the informal economy

Table 2 Average wage and earnings by employment status and nature of employment

Table 3 Productivity and wage/earnings

Table 4 Working poverty rate by employment status,

Table 5 nature of employment, and industry

Working poverty rate by employment status, nature of employment, and industry 
Table 6 Proportion of working poor of each employment status to total employment

Table 7

Table 8

Poverty ratios among individuals in households sustaining themselves on informal employment by household employment income type and industrial sector (poor)

Poverty ratios among individuals in households sustaining themselves on informal employment by household employment income type and industrial sector (very poor)

Table 9

Poverty ratios among individuals in households sustaining themselves on informal employment by urbanity

Table 10

Average wage and earnings by nature of employment, urbanity, sector, and class of workers

Table 11 Number of informal jobs/employment by province and production unit

Table 12

Percentage of type of enterprise and nature of employment

Appendix A.1 Primary sampling unit (PSU) distribution for LFS and Phase 2 of the informal sector survey:

Indonesia

\section{Chapter 5}

Table 1

Change in the distribution of inequality, 2000-2009

Table 2

Distribution of inequality and poverty, 2009

Table 3

Table 4

Distribution of families receiving remittances and proportion of remittances to income by region, 2009112

Table 5

Determinants of receiving remittances

Table 6

Determinants of poverty status

Changes in inequality with and without remittances, 2009

Table 7

Per capita income with and without remittances

Determinants of per capita income

Table 9

Theoretical Gini coefficients

\section{Chapter 6}

Table 1

Population of Sri Lanka and districts

Table 2

Sample allocation (for twelve months) for districts

Table 3

Sample allocation (for twelve months) for sectors

Table 4

Average income and expenditure 
xviii Tables

Table $5 \quad$ Income Gini coefficients 137

Table 6 Expenditure Gini coefficients 139

Table $7 \quad$ Engel's coefficients 139

Table 8 Income and expenditure of family nuclei with children under the age of seventeen who attend school $\quad 145$

Table 9 Income and expenditure of family nuclei by area with children under the age of seventeen who attend school $\quad 145$

Table 10 Rearrangement of Table 6.9

Table 11 Monthly income and expenditure per household by elderly household

\section{Chapter 7}

Table $1 \quad$ Classification of the models

Table 2 Regions and provinces in Thailand in the analysis

Table 3 The average ratio between nonagricultural employment

Table 4 Variables

Table 5 Estimation results (production function) 173

Table 6 Estimation results (production function) 175

$\begin{array}{lll}\text { Table } 7 & \text { Estimation results (marginal productivity) } & 177\end{array}$

Table 8 Estimation results (consumer optimization) 178

$\begin{array}{ll}\text { Table } 9 & \text { Estimation results }\end{array}$

$\begin{array}{lll}\text { Table } 10 & \text { Estimation results (Matsuyama model) } & 179\end{array}$

\section{Chapter 8}

Table 1 Distances between the GQ and the major cities 185

Table 2 Population, land area, and poverty (2010) 187

Table 3 Income levels and economic structure (2010) 189

\section{Chapter 9}

Table 1 Data from 1907 for fisheries in Taiwan

Table 2 Data from 1907 for Japanese fishing vessels operating in Taiwan

Table 3 Top fish catches in Taiwan in 1925

Table 4 Number of fishing vessels in Taiwan from 1918 to 1929

Table 5 Total production in Taiwan from 1931 to 1942 by fishing ground

Table 6 Fish catches and numbers of fishery workers and motorized vessels in Taiwan in the 1920s 
Table 7 Taiwan's fishery exports (excluding Japan) in 1934 and 1935

Table 8 Taiwan's fishery imports (excluding Japan) in 1934 and 1935

Table 9 Taiwan's fishery exports to Japan in 1934 and $1935 \quad 221$

Table 10 Taiwan's fishery imports from Japan in 1934 and 1935

Table 11 Taiwan's fresh fish exports to Japan from 1920 to 1929

Table 12 Number of fishery associations in Taiwan in 1930 by area

Table 13 Fishery organizations in Taiwan in 1937 225

Table $14 \quad$ Number of fishery markets in Taiwan in 1935 by type of operator

Appendix A.1 Value of fishery products in Taiwan from 1899 to 1942

Appendix A.2 Total fishery products in Taiwan from 1912 to 1939

Appendix A.3 Fishery workers engaged in catching fish in Taiwan from 1900 to 1929

Appendix A.4 Fishery workers engaged in aquaculture in Taiwan from 1900 to 1929 
This page intentionally left blank 


\section{Preface}

Developing countries in Asia and Africa suffer from many problems due to poverty, inequality, and growth. Government policy makers and economists at international financial institutions such as the World Bank and International Monetary Fund advocate various policies aimed at stimulating economic growth in order to lessen and mitigate poverty and inequality while improving the standard of living. The record is mixed.

The present book focuses on analyzing poverty, inequality, and economic growth in developing countries from diverse perspectives, ranging from historical and theoretical to empirical observations. To properly assess the implications and impact of policies regarding poverty, inequality, and growth in developing countries, we analyze empirical findings and conduct empirical research based on economic theory in order to understand what is happening in affected households.

The issue of poverty in developing nations has been a focus at the Graduate School of Economics, Tokyo International University (TIU) for more than a decade. The program includes many graduate students from developing countries in Africa, the Middle East, South Asia, Southeast Asia, and East Asia. Students in master's and $\mathrm{PhD}$ programs must complete all coursework and submit their theses in English. The United Nations Statistical Institute for Asia and the Pacific (UNSIAP) plays a role in screening students who enter this program as part of an effort to improve the collection and study of statistics in the region. Thus, many of the candidates are mid-career government officials at agencies responsible for statistics collection and analysis in their home countries. After finishing the course at UNSIAP, the Institute recommends qualified candidates to apply to the Graduate School of Economics at TIU who want to study advanced economics and econometrics at TIU and earn an advanced degree. After obtaining a degree at TIU, they return to their home countries to work at Statistics Bureaus or at international institutions. Three contributors to this collection are TIU graduates from Indonesia, the Philippines, and Tanzania. Almost all the graduate students from developing countries I have taught at TIU are interested in analyzing poverty, inequality, and growth to improve the standard of living of in their home country. During the past decade, we have accumulated knowledge about poverty, inequality, and growth through lectures and discussion between faculty 
members and graduate students. The present monograph is a culmination of this collaborative research project.

We acknowledge financial support from the Ministry of Education, Culture, Sports, Science and Technology (MEXT) (Japanese Government)-Supported Program for the Strategic Research Foundation at Private Universities, 2010-2012 (S1002006; Principal Investigator: Atsushi Maki). The project includes faculty members who belong to the Graduate School of Economics at TIU, academics from other universities and research institutes, and former overseas graduate students at the Graduate School of Economics who are employed at the Statistics Bureaus of their home countries and/or at international institutions.

Our preliminary meeting was held in December 2010 to discuss our research agenda. In December 2012, we organized an international conference on poverty, inequality, and growth in developing countries at TIU. The present monograph includes some of the papers presented at this conference. The selected papers included in the present monograph were revised according to the comments and suggestions of the participants at the conference.

The editorial work for the final drafts submitted by the authors was conducted during my stay as a visiting scholar at the Harvard-Yenching Institute in Cambridge, Massachusetts, for four months beginning from September 2014. I appreciate the support of Professor Elizabeth J. Perry, the director of the Institute, who invited me to stay at the Institute, and Professor Dale W. Jorgenson, who kindly gave me comments and advice on the monograph during my stay at Harvard. Finally, I am indebted to Professor Yukihiko Kiyokawa at TIU for his support and suggestions regarding the three-year project funded by the MEXT-Supported Program for the Strategic Research Foundation at Private Universities. 


\section{Notes on contributors}

Yuko Arai is a researcher at the Statistical Information Institute for Consulting and Analysis, Japan.

Yasumasa Baba is professor at the Institute of Statistical Mathematics, Japan.

Karen Villaquer Firshan is an economics and statistics specialist (national consultant) at the Asian Development Bank, Philippines.

Kadarmanto is head of the Food Crops Statistics Division at BPS Statistics Indonesia.

Mlemba Abassy Kamwe is a senior statistician at the National Bureau of Statistics (NBS), Tanzania.

Nobutake Koiwa is professor of economics at Tokyo International University, Japan.

Atsushi Maki is professor of economics at Tokyo International University, Japan.

Satoshi Ohira is associate professor of economics at Keio University, Japan.

Satoko Okuyama is assistant professor of economics at Kanagawa University, Japan.

Hiroko Yasui is a researcher at the Statistical Information Institute for Consulting and Analysis, Japan.

Kaori Yonezawa is a researcher at the Statistical Information Institute for Consulting and Analysis, Japan. 
This page intentionally left blank 


\title{
1 Introduction
}

\author{
Atsushi Maki
}

\section{Overview}

Developing countries experience many problems stemming from poverty, inequality, and growth. Government policy makers and economists at international financial institutions such as the World Bank and the International Monetary Fund advocate many kinds of economic growth policies to lessen and mitigate poverty and inequality while increasing the standard of living. The present project focuses on analyzing poverty, inequality, and growth in developing countries based on economic theory and empirical observations.

It is generally believed that analysis of economic statistics such as macroeconomic statistics, cross-sectional data, market data, or micro-data is the basis of empirical analysis. However, while acknowledging that the analysis of statistics is a necessary condition for empirical analysis, it is not a sufficient condition in the field of sciences because empirical analysis must be informed by theoretical considerations.

We embrace empirical research in economics based on a seminal paper by Koopmans (1947) entitled "Measurement without Theory." In his paper, Koopmans introduced the contributions of Tycho Brahé, Johannes Kepler, and Isaac Newton to the field of celestial mechanics. Koopmans described the Kepler stage and the Newton stage in the development of celestial mechanics and identified the difference between the two stages. In the Kepler stage, Tycho Brahé collected accurate data about the movement of planets, while Johannes Kepler used this data to posit empirical regularities called Kepler's Three Laws regarding the motion of planets around the Sun. During his research, Kepler tested many kinds of hypotheses and conducted numerous calculations to verify his hypotheses. Thus, the Kepler stage, and Kepler's Three Laws, involves obtaining accurate values through observations and determining empirical regularities by testing various hypotheses. Based on the empirical regularities obtained in the Kepler stage, the Newton stage exists. We know that Newton's Law of Gravitation builds on the Law of Inertia, the Law of Motion, and the Law of Action and Reaction. In addition, he introduced the Law of Universal Gravitation as $F=G\left(M m / r^{2}\right)$. The difference between the Kepler stage and the Newton stage is in its general applicability. ${ }^{1}$ 
When we conduct empirical analysis in economics, we have to bear in mind three key considerations. The first stage of empirical analysis is to gather accurate observations. Processing observations as raw data, we find empirical regularities in the observations. During the process, we sometimes observe contradictory findings to existing empirical regularities. For example, we have observed an empirical regularity in many countries over many periods that as income increases in cross-sectional data, Engel's coefficient - namely, the ratio of food expenditure to income - decreases monotonically. This is a famous empirical law called Engel's Law. However, in poor households in developing countries, Engel's coefficient increases as income increases, defying existing expectations. When we obtain such kinds of observations repeatedly, we have to reconsider the existing model specification to describe empirical regularities in order to explain real-world observations.

The second stage of empirical analysis requires the selection of a model specification that can be explained in terms of economic theory. Constructing an analytical model, we have to choose suitable specifications consistent with theory.

The third stage is to evaluate empirical models in terms of their power of explaining the real world. Whether or not the model specification is suitable is judged by forecasting and/or making simulations after constructing the model. If the model specification is wrong, we will fail to forecast correctly and/or obtain unsuitable simulation results. In such cases, we have to return to the choice of the model specification and recalibrate it.

It is important to understand key differences between the natural sciences and social sciences and to explain the reason why the accumulation of knowledge about empirical regularities is thick in natural sciences, while it is thin in social sciences. One of the main reasons is the possibility of controlled experiments. In the natural sciences, it is relatively easy to conduct controlled experiments in a laboratory under the same conditions repeatedly. Even so, in natural sciences, a prediction of an earthquake, tsunami, or volcano eruption is difficult. This is mainly due to the difficulty of conducting a controlled experiment regarding seismic events. In fields in which it is difficult to repeatedly conduct controlled experiments, theory plays a critical role.

Another reason why the accumulation of knowledge on empirical regularities is thin in social sciences has to do with the degree of stability of the object of study. When we consider celestial mechanics as an example, it is relatively stable compared to economic fluctuations in the real world. Through observing the sky, we can record the appearance of new stars and that of comets. However, such events are relatively rare. In history, we experience the disappearance of nations and transformation in economic systems. We also experience relatively frequent crashes of financial markets and contend with the transformative power of war. Such events make it difficult for social scientists to discern empirical regularities.

Stability is necessary for identifying the first approximation of the general interdependence of the system. Regarding celestial mechanics, it is easy to approximate a model of a two-body problem under the assumption of ceteris paribus, other conditions remaining the same. Let us consider Newton's apple. The apple 
fell because the Earth's gravity pulled it. It is true that the Moon and the Sun also pulled the apple, but such effects are too small to perceive. In the case of the Law of Universal Gravitation, the Law is described by the relationship of the two bodies as $F=G\left(M m / r^{2}\right)$. In the real world of space, there are eight planets around the Sun, and therefore the system is specified by the N-body problem in nature. But without introducing the N-body problem, observation is well explained namely, we obtain suitable forecasting power by applying the two-body problem in the real world. As we mentioned previously, the Law of Universal Gravitation is specified by the two-body problem.

If we consider the collective gravitational effect of the Earth, the Moon, the Sun, and other planets on the apple, the problem ascribed to the N-body problem cannot be solved except in special cases. However, because of the Law of Universal Gravitation, natural scientists ignore the effects from the Moon and the Sun, and therefore the N-body problem is reduced to a two-body problem when considering the fall of Newton's apple. Thus, it can be solved analytically, and we can obtain good forecasting power using such approximations.

In the social sciences, notably regarding economic activities in the real world, observations are generated by the results of interdependence among many economic factors and markets. This creates a similar problem to that discussed previously regarding celestial movements in natural sciences - i.e. determining what to consider and what to disregard. The essence of empirical analysis in economics consists of finding suitable models to explain the real world in terms of first approximation with the assistance of economic theory.

Our fundamental approach in the present monograph is to:

(1) discover empirical regularities in observations

(2) explain empirical regularities by applying economic theory

(3) examine policies and assess their implications based on empirical models

(4) reconfirm the stability of the empirical model used.

\section{Structure of the book}

We divided the volume into two parts: the first section analyzes poverty and inequality using micro-data sets from Indonesia, Sri Lanka, the Philippines, Tanzania, and Vietnam. The second section analyzes economic growth in developing countries, mainly using time series data for China, Laos, Myanmar, Taiwan, and Thailand.

\section{Overview of the chapters}

The present monograph has eight substantive chapters and an introduction and conclusion. Chapter 2 analyzes consumer behavior in Tanzania, one of the developing countries in Africa. This chapter focuses on the validity of Engel's Law using the micro-data of the 2007 Tanzania Household Budget Survey (HBS). The 
National Bureau of Statistics in Tanzania conducted the survey. We found that the inverse U-shaped or quadratic Engel curve is suitable to explain the observation contrary to standard Engel's Law that has the characteristic of monotonically decreasing Engel's coefficient as income increases. Our finding means that the Engel curve is upward sloping in very poor households and that after reaching the peak value of Engel's coefficient, the curve is downward sloping monotonically.

The Engel curve is upward sloping in very poor households in Tanzania, indicating that the total expenditure elasticity for food in very poor households is elastic. This behavior is well described by the specification of the quadratic almost ideal demand (QUAID) system. However, food expenditure is classified as a necessity because own-price elasticity for the food category as a whole is inelastic, as verified by many empirical analyses using time series data and the present cross-sectional data. Based on the previous findings regarding the inverse U-shaped Engel curve, we consider the characteristics of necessities and luxuries utilizing not only total expenditure elasticity but also own-price elasticity in the theory of consumer demand.

Our basic question is: when a commodity is price inelastic (elastic) and total expenditure elastic (inelastic), is the commodity a necessity or a luxury? We proposed the Törnqvist-Wold hypothesis and tested the hypothesis empirically based on past empirical results. We found that the Törnqvist-Wold hypothesis does not contradict past empirical results and observations regarding the classification of necessities and luxuries using the relationship between price and income elasticities.

This information is important for the government to target subsidies and other transfer payments to maintain the standard of living and support the most vulnerable populations. During bad harvests, because of price increases in necessities, the standard of living in the nation decreases. When we have information regarding the price elasticity of demand, it is possible to fine-tune subsidies and the distribution of necessities in order to mitigate the negative impact of inflation and shortages.

Chapter 3 focuses on the Philippines and Vietnam, where poverty alleviation programs play a critical role in maintaining minimum living standards, making it essential to understand how impoverished households make ends meet through in-kind transactions. In the present analysis, we use the micro-data set of the 2006 Vietnam Household Living Standards Survey compiled by the Statistics Bureau in Vietnam and the 2006 Family Income and Expenditure Survey compiled by the National Statistical Office of the Philippines.

Using Engel curves including and excluding in-kind consumption, we found that when we included in-kind consumption in consumption expenditure, the Engel curve was monotonically downward sloping in Vietnam and the Philippines. On the other hand, when we excluded in-kind consumption from consumption categories, the Engel curve was hump-shaped or inverse U-shaped. Contrary to the standard Engel's Law, we found that the Engel curve excluding in-kind consumption was upward sloping in very poor households - namely, paid food consumption increases with cash income. This result is due to the different 
characteristics of consumption items between in-kind and cash consumption. In very poor households, there is a strong distinction between in-kind and cash consumption, with the latter treated as a luxury.

Our findings are also suggestive about the different effects of in-kind consumption depending on the stages of economic development that may be relevant in terms of economic and social policies in developing countries, especially those targeting improvement in the standard of living of poor households.

Chapter 4 explains the importance of the role of the informal sector in developing countries using Indonesian micro-data. Indonesia is essentially an agrarian society. This chapter compares the job structure of the Banten (West Java) and Yogyakarta (Central Java) provinces, focusing on the informal economy. Banten encompasses manufacturing and agriculture, while Yogyakarta features services and agriculture. We use the micro-data set of the informal sector collected in 2009 by BPS (Statistics Indonesia).

Since having multiple jobs is common practice in Indonesia, total employment in terms of the number of jobs is greater than that of the working-age population. In Yogyakarta, about 44 percent of total jobs are in the agricultural sector, while the wholesale and retail trade sector accounts for 15 percent of the total number of jobs, followed by the manufacturing sector at 11 percent. In Banten, about 21 percent of total jobs are in the manufacturing sector, while the wholesale and retail trade sector provide 21 percent, followed by the agricultural sector at 17 percent. In both provinces, the incidence of informal employment is higher in rural areas. Informal employment in Yogyakarta's rural areas is 95 percent namely, almost every person has two or more jobs - in comparison to 83 percent in urban areas. In Banten, the incidence of informal employment in rural areas reaches 91 percent, while in urban areas it is only 67 percent. Jobs in the agriculture sector are predominantly informal in both provinces.

In Yogyakarta, the estimated contribution of the informal sector to total gross value added (GVA) is 37 percent, while approximately 27 percent of Banten's GVA can be attributed to the informal sector. Yogyakarta's informal sector in agriculture contributes Rp5.7 trillion (about US \$555 million; \$1 = Rpl 0,255), while the nonagricultural informal sector generates Rp9.8 trillion. On the other hand, Banten's informal sector in agriculture contributes Rp9.8 trillion (about US \$956 million), while the nonagricultural informal sector contributes Rp25.6 trillion.

Households that sustain themselves on informal employment, especially if they are dependent on agricultural work, are most vulnerable to poverty in Yogyakarta, while casual workers in Banten are most likely to live in poverty.

Chapter 5 tests the validity of the new economics of labor migration (NELM) theory using data from the Philippines. Three implications of the NELM theory are examined using the Family Income and Expenditure Survey conducted by the National Statistics Office in 2009.

Remittances from overseas are one of the most important sources of income in the Philippines. The Survey of Overseas Filipinos conducted by the National Statistics Office defines remittances as the amount of cash and in-kind transfers 
received by families from overseas Filipino workers (OFWs). Remittances during the period of April to September 2013 sent by OFWs amounted to 163.2 billion PHP, with OFWs from Asia remitting the largest proportion. About 2.3 million OFWs worked abroad during that period, including countries such as Saudi Arabia, the United Arab Emirates, Singapore, Qatar, Hong Kong, and other countries in western Asia. Just over half of OFWs were men; male OFWs were generally older than female OFWs. Almost one third were laborers or unskilled workers, followed by employment in the retail/service sector, tradespeople, plant and machine operators and assemblers, and professionals. The majority of OFWs came from Calabarzon on the main island of Luzon near Manila.

The NELM theory claims that income inequality is likely to cause more relative deprivation and that a relatively more deprived person is expected to have a higher tendency to migrate. Migration decisions are often decided jointly by the family members left behind and the migrating person. Remittances from a migrating family member form an important component of direct returns to non-migrating family members. Based on the NELM theory, therefore, it is assumed that remittances increase family income and decrease inequality and poverty.

This study investigates the following three claims of the NELM theory by using micro-data derived from the Family Income and Expenditure Survey (FIES) of the Philippines and presents empirical findings on their validity: (1) poorer families are more likely to send members to a foreign country; (2) remittances decrease poverty; and (3) remittances decrease inequality. These three claims are all true if the NELM theory holds.

We have observed that: (1) very poor families are less likely to send their members to foreign countries; (2) remittances reduce poverty; and (3) remittances increase inequality. The second observation is consistent with the NELM theory, while the first and third observations are inconsistent with this theory.

Chapter 6 analyzes poverty and inequality in Sri Lanka. We explain the sampling design of the Household Income and Expenditure Survey (HIES) compiled by the Department of Census and Statistics of Sri Lanka. The economy in Sri Lanka has traditionally depended on agriculture - mainly rice and the three major plantation crops (tea, rubber, and coconuts) - but recently clothing has become the biggest export item.

The HIES 2006/07 provides household data and personal data collected through personal interviews. This report gives estimated values based on the twelve-month period from July 2006 to June 2007. A two-stage stratified random sample design was used in the survey. Each district is classified into three types of areas. The Urban, Rural, and Estate sectors of the district are the domains for stratification. An area governed by either a Municipal Council or an Urban Council is considered an Urban sector. Plantation areas that comprise more than twenty acres and have no less than ten residential laborers are classified as Estate sectors. Other residential areas that are not Urban or Estate sectors are considered Rural sectors. This sample design is characteristic compared to those conducted in other countries.

Data was separated according to the sections of the questionnaire. Therefore, we needed to connect files to analyze variables belonging to different sections. 
Some household variables were calculated from individual information. Then, household and individual information was integrated. Outliers were removed to protect the confidentiality of personal information.

During the period under study, it is important to consider the broader economic context. Unemployment rates in 2006 and 2010 were 6.5 percent and 4.9 percent, respectively. The poverty head count index declined from 15.2 percent to 8.9 percent between 2006 and 2010 and further decreased to 6.5 percent in 2012. One key factor in considering such trends is that the civil war ended in 2009 .

The average income of Estate workers is lower than that of Urban or Rural workers. The Gini coefficient is relatively large because the income of a few managers is high and the income of the majority of workers is low as a result of plantations being privatized after independence in 1948 .

It is important to bear in mind that the prolonged civil war in Sri Lanka between 1983 and 2009 left the northern and eastern regions relatively backward and undeveloped because that is where the fighting was most intense, and the government excluded these areas from development initiatives. The World Bank is now involved in addressing these issues by focusing on the improvement of infrastructure in these regions, ranging from health care, education, and irrigation to improving legislation on labor and land markets and improving access to public services and water supply. These projects are grouped under three themes: (1) the consolidation of peace; (2) growth; and (3) the promotion of equality.

Chapter 7 analyzes the changes in the sectoral structure due to economic development in Thailand. We test which type of model is suitable to explain the changes in sectoral structure using the data from Thailand.

The role of agriculture has long been one of the most important topics in economic development. Country-level economic development can be interpreted as the change from an agriculture-based sectoral structure to an industry-based sectoral structure. The role of agriculture usually decreases during the economic development process. On the other hand, agriculture is the most important sector in the sense that it provides food for subsistence and, at least in the first stage of economic development, provides the largest proportion of employment. Thailand has been facing the middle-income trap, creating a challenge for policy makers who are trying to maintain development momentum.

Thailand experienced rapid economic growth in the 1990s. Before that time, it was an agriculture-based country. Particularly during the period of economic growth in the 1990s, many people moved from the agricultural sector to the nonagricultural sector. Agricultural employment decreased from 70.8 percent in 1980 to 39.6 percent in 2012 .

In this chapter, we examine which type of model explains the data from Thailand. We find that neither a Harris-Todaro model nor a neoclassical-type model explain the actual data in Thailand. A hybrid of the two models is necessary. The theoretical model that best explains the current Thailand economy is a hybrid model of a wage-difference model and a neoclassical model. This conclusion is consistent with the observation that the country is now facing the middle-income trap. 
Chapter 8 focuses on economic growth prospects in Asia's Golden Quadrangle (AGQ). The AGQ is a zone adjacent to the borders of Thailand, Myanmar, Laos, and Yunnan (China). The poverty incidence of this area is comparatively high in each of these countries due to the remote, mountainous location; a history of violence; warlords; and the opium trade. In this chapter, we show the economic features of the AGQ and how it might be developed. This analysis might then be useful for the potential development of other impoverished areas in Association of Southeast Asian Nations (ASEAN).

The economic environment of the AGQ has improved drastically over the last decade, mostly due to Chinese influence. In addition to the surge of Chinese firms into the region, the infrastructure has been upgraded; peace has been consolidated; and the ASEAN Free Trade Agreement has created an attractive business-operating environment in Thailand, Myanmar, and Laos.

The AGQ is the border zone of four countries, and each country has different income levels and economic structures. To further encourage development in the AGQ, liberalization of the movement of people, capital, and goods is critical to facilitate establishment of a global supply chain in the area. Promotion of foreign direct investment (FDI) is also important for the formulation of a global supply chain since managing that depends on knowledge, experience, and information technology skills that developing countries typically lack.

Chapter 9 considers economic development due to legal and institutional changes affecting the fishery industry in pre-WWII Taiwan. The Taiwanese islands once belonged to the Qing dynasty of mainland China, but following the Sino-Japanese War of 1894-1895, they became a Japanese colony until 1945. Under Japanese rule, the fisheries of Taiwan were modernized, and the foundation of Taiwan's contemporary fishery industry was established.

The Japanese fishery system had three main characteristics: (1) the fishery rights system, which enabled the traditional and local fishery communities to manage the local fishery resources; (2) the adjustment of the operation of modern fisheries to avoid conflicts with traditional fisheries; and (3) an increase in the number of fishing villages.

In 1924, the Japanese Fishery Law was enforced in Taiwan, and fishery associations were gradually established to regulate development of this sector. The government supported the institutionalization of the fisheries sector and created a network involving the fishers, fishery merchants, and fishery processing firms.

Fisheries in Taiwan were developed through modernization, including the spread of motorized vessels. This is a good example of how sound policy can promote development.

\section{Note}

1 Koopmans $(1947$, p. 161) wrote in his paper that, It is not easy to specify precisely what is the difference between the two stages. Newton's Law of Gravitation can also be looked upon as describing an empirical regularity in the behavior of matter. The conviction that this "law" is in some 
sense more fundamental, and thus constitutes progress over the Kepler stage, is due, I believe, to its being at once more elementary and more general. It is more elementary in that a simple property of mere matter is postulated. As a result, it is more general in that it applies to all matter, whether assembled in planets, comets, Sun or stars, or in terrestrial objects - thus explaining a much wider range of phenomena.

\section{Reference}

Koopmans, Tjalling (1947), "Measurement without theory," Review of Economics and Statistics, 29, 161-172. 


\title{
2 Are luxury goods really luxuries?
}

\section{The validity of the Törnqvist-Wold hypothesis}

\author{
Atsushi Maki and Mlemba Abassy Kamwe
}

\section{Introduction}

In recent literature regarding empirical analysis of consumer behavior, the use of micro-data prevails in both developed and developing countries, applying not only parametric but also nonparametric approaches. In the present chapter, we report a variety of empirical findings using micro-data in Tanzania and applying nonparametric and parametric approaches. Based on theoretical and empirical findings, we propose a hypothesis regarding the definition of luxuries and necessities utilizing the concept of elasticities of demand for total expenditure, own prices, and cross prices and verify the validity of the Törnqvist-Wold hypothesis in light of past empirical observations.

The topics discussed in this chapter are the validity of Engel's Law, the elasticity of demand for total expenditure and prices, and the definition of luxuries and necessities regarding goods and services based on the Törnqvist-Wold hypothesis.

In economics, one of the enduring truths is Engel's Law; i.e. the ratio between food expenditure and total expenditure decreases monotonically as total expenditure increases. But does Engel's Law hold for developing countries where absolute poverty is endemic? We tested the validity of Engel's Law using cross-sectional micro-data in Tanzania. Applying a nonparametric approach to the micro-data set, our results suggested a U-shaped Engel curve. In addition, we estimated the inverse U-shaped Engel curve by applying parametric methods - namely, specifying the quadratic almost ideal demand (QUAID) system to the micro-data set. Our estimations indicated that the coefficient of the quadratic term of the QUAID system is negative and is statistically different from zero, meaning that we obtained the inverse U-shaped Engel curve for both nonparametric and parametric approaches. ${ }^{1}$

Our findings regarding the inverse U-shaped Engel curve raise questions about Engel's Law regarding the tendency of a monotonically downward-sloping curve. Based on Engel's Law, the share of food expenditure to total expenditure decreases monotonically, indicating that total expenditure elasticity is inelastic. Our findings, however, indicate that in some range of total expenditure, as total expenditure increases, the share of food expenditure to total expenditure actually increases, indicating that the total expenditure elasticity for food is elastic. Thus, 
Engel's Law may not be valid in developing countries where absolute poverty is endemic and consumption patterns may vary.

What do we know from standard textbooks about the total expenditure elasticity of demand? When it is greater than unity (or elastic), the commodity is classified as a luxury good. When it is less than unity (or inelastic), the commodity is classified as a necessary good. Although the contents of food expenditure as a whole are similar for all the households in Tanzania, the characteristic of total expenditure elasticity for the food category is different depending on the level of total expenditure. ${ }^{2}$ When the level of total expenditure is low, the total expenditure elasticity of food is elastic, but as total expenditure increases, the total expenditure elasticity of food becomes inelastic. The tendency of the Engel curve in Tanzania is different from that found in developed countries. How can we explain this variation that the food category is classified as luxury goods in very poor households, while it is classified as necessary goods in poor and non-poor households?

To solve the question, we consider not only total expenditure elasticity but also the own-price and cross-price elasticities of demand in the theory of consumer behavior. Regarding the definition of necessary and luxury goods, we have different definitions using own-price elasticity - namely, when own-price elasticity is inelastic (or the value of own-price elasticity is between -1 and 0 ), the commodity is classified as a necessary good. However, when own-price elasticity is elastic (or the value is less than -1 ), the commodity is classified as a luxury good. According to Gregory King's Law, the own-price elasticity of demand for wheat is inelastic, and therefore wheat is classified as a necessary good (cf. Stigler 1954).

To solve the discrepancy we found in terms of the Engel curve in Tanzania, we rely on the standard theory of consumer behavior. We derive the relationship among total expenditure and own-price and cross-price elasticities in consumer demand theory. We introduce the theoretical relationship between total expenditure and own-price and cross-price elasticities and propose the Törnqvist-Wold hypothesis and an alternative hypothesis. The Törnqvist-Wold hypothesis suggests that, as a rule, income elasticities of necessities are smaller than their price elasticities, whereas income elasticities of luxuries are greater than their price elasticities (Wold and Juréen 1953, p. 115). On the other hand, the alternative hypothesis against the Törnqvist-Wold hypothesis suggests that, as a rule, income elasticities of necessities are greater than their price elasticities, whereas income elasticities of luxuries are smaller than their price elasticities. In theory, we have two possibilities regarding the relationship between total expenditure and own-price elasticities in conjunction with the characteristic of cross-price elasticities. We checked the plausibility of the Törnqvist-Wold hypothesis in the real world by estimating demand functions using the Tanzanian micro-data set. ${ }^{3}$

In order to estimate demand functions, we used cross-sectional data. Regarding estimating demand functions using cross-sectional data, Deaton (1987, $1988,1990)$ conducted a series of interesting analyses. Deaton devised a method to change cross-sectional data into time series data. He divided the national market into regional markets in the cross-sectional data for a particular year. 
Usually, the observation period of cross-sectional data is one year, but sampling households report their monthly consumption expenditure, and they are rotated, say, every three months. We converted the cross-sectional data into time series data by using micro-data from the cross-sectional data. We estimated the Working-Leser demand functions, including total expenditure and prices for nineteen commodities within the food category, using the Tanzanian data. We also segmented markets by region (there are twenty-one in Tanzania) and by month. Therefore, we have the market data for the quantities demanded, their corresponding prices, and the average household total expenditure for 252 sample points - namely, twelve months times twenty-one regions. The twenty-one regions are Arusha, Dar es Salaam, Dodome, Iringa, Kagera, Kilimanjaro, Kigome, Lindi, Mara, Mbeya, Mtwara, Mwanza, Morogoro, Coast, Rukwa, Ruvuma, Singida, Shinyanga, Taboro, Tango, and Manyara. To estimate own-price elasticity and total expenditure elasticity, nineteen commodities are selected, focusing on the food category: (1) rice; (2) wheat; (3) burns (wheat); (4) white maize attains; (5) maize flour white; (6) beef with bones; (7) fresh, chilled, or frozen fish; (8) dried small fish; (9) fresh cow milk; (10) sunflower oil; (11) oranges; (12) broad beans; (13) beans (dried); (14) tomatoes; (15) cooking bananas (plantains); (16) brown sugar; (17) white sugar; (18) tea; and (19) Coca-Cola.

To double-check the estimated results for these nineteen commodities, two types of complete demand systems were used. One is the linear expenditure system (LES) demand function, and the other is the quadratic expenditure system (QES) demand function. Both specifications have the property of a minimum subsistence level (or committed expenditure that is obtained by a minimum required quantity multiplied by its price introduced by Stone [1954]) indicated by the parameters of the model. Usually, own-price inelastic goods are classified as necessary goods, and the parameters in the LES model directly determine the characteristics of goods - whether they are necessary or luxury goods.

After estimating the demand functions for nineteen commodities, we checked the possibility of the Törnqvist-Wold hypothesis regarding the distinction between luxuries and necessities related to total expenditure and own-price elasticities in the real world. As mentioned previously, we have two possibilities for the definition of luxuries and necessities regarding the relationship between total expenditure and own-price elasticities in conjunction with cross-price elasticities. We evaluate the empirical validity of the Törnqvist-Wold hypothesis and the alternative hypothesis.

Based on the aforementioned empirical findings, we further tested the validity of our present conclusion that the Törnqvist-Wold hypothesis is reasonable, referencing different empirical results obtained by a series of analyses by Deaton $(1987,1988,1990)$ and Maki $(1998,2002)$. Deaton $(1987,1988$, 1990) used household survey data for Cote d'Ivoire and Indonesia. In Deaton (1987), the data is derived from five categories of food expenditure: Meat, Fresh Fish, Other Fish, Starches, and Cereals. In Deaton (1988), the total expenditure and price elasticities of demand for eight categories of food are analyzed: Beef, Fish, Imported Rice, Domestic Rice, Maize, Yams, Plantain, and Cassava. 
In Deaton (1990), using Indonesian household survey data, the author estimated total expenditure and own- and cross-price elasticities for eleven clusters of commodities: Rice, Wheat, Maize, Cassava, Roots, Vegetables, Legumes, Fruits, Meat, Fresh Fish, and Dried Fish. Maki (1998, 2002) used household data of eight broader items within total expenditure such as Food, Beverages, and Tobacco; Clothing and Footwear; Gross Rent, Fuel, and Power; Household Equipment and Operation; Medical and Health Care; Transport and Communication; Education, Recreation, and Culture; and Miscellaneous Goods and Services for Japan. Maki $(1998,2002)$ also used household data of seven broader items such as Food, Housing, Household Operation, Apparel, Transportation, Other Goods, and Other Services for New Zealand. Finally, we proposed our conclusion regarding the definition of luxuries and necessities based on our empirical findings that the Törnqvist-Wold hypothesis is reasonable based on the real-world data.

The structure of the present chapter is as follows: Section 2 focuses on the validity of Engel's Law using the 2007 Tanzania household survey. This section explains the data used for the analysis, how to calculate the adult equivalence scale, how to estimate the food poverty line based on caloric measure, and how to derive the basic needs poverty line. This section also reports the movement of Engel's coefficient regarding three categories of households: the very poor, poor, and non-poor households. We calculated averages of Engel's coefficient for total expenditure classes that were divided into deciles (ten classes) of total expenditure adjusted by the adult equivalence scale for the very poor, poor, and non-poor households, respectively. Then, we tested whether or not the downward-sloping tendency of Engel's coefficient is observed in Tanzania.

Using the entire sample of the household survey data, we estimated the Engel curve applying nonparametric regression, and we estimated the Engel curve parametrically based on the utility maximizing behavior of households. We specified the QUAID system in the price-independent generalized logarithmic (PIGLOG)-type utility class that is a generalization of the almost ideal demand (AID) system proposed by Deaton and Muellbauer (1980).

Our empirical findings are as follows: contrary to Engel's Law, we found the inverse U-shaped Engel curve in Tanzania. It is upward sloping in the very poor households but downward sloping in the poor and non-poor households as total expenditure adjusted by the adult equivalence scale increases. The caloric intake of very poor households for the daily food expenditure evaluated by the adult equivalence scale is less than 2,200 calories. When the total expenditure adjusted by the adult equivalence scale increases, the share of food expenditure for the very poor households increases more. Therefore, the total expenditure elasticity for the very poor households is greater than unity. This behavior is well described by the specification of the QUAID system. As indicated in Table 2.4, the total expenditure elasticity shows a value greater than unity when the level of total expenditure is less than 10,000 Tanzania Shillings (TS).

Regarding micro-data analysis, nonparametric regression plays an important role in estimating econometric models based on economic theory conducting 
parametric analysis. We obtain much more information by utilizing not only the ordinary least-squares (OLS) regression but also quantile regressions. By using first-quartile, median, and third-quartile regressions, we can clarify the data dispersion in much more detail.

Regarding economic and social policy, the upward-sloping Engel curve for very poor households suggests that poverty alleviation and economic development programs have not had an impact on the poorest households and that more targeted assistance is crucial.

Section 3 focuses on estimating the Working-Leser demand functions for nineteen commodities within the food category to obtain total expenditure and own-price elasticities of demand. Using the same cross-sectional data, we estimated demand functions for finely classified commodities in the food category considering monthly and regional variations in prices. When we use the micro-data set from the cross-sectional data, we observe monthly and regional variations in prices reported by each individual household.

We use micro-data for the family expenditure survey based on cross-sectional data for households and market data classified by month and region. The objective of this section is to estimate the total expenditure and own-price elasticities of demand for food categories. This information is important for the government to target subsidies and other transfer payments to maintain the standard of living and support the most vulnerable populations. During bad harvests, because of price increases in necessities, the standard of living in the nation decreases. When we have information regarding the price elasticity of demand, it is possible to fine-tune subsidies and the distribution of necessities in order to mitigate the negative impact of inflation and shortages.

Section 4 double-checks the relation between necessary goods and own-price elasticity in conjunction with the subsistence level derived from the model. We specified two types of complete demand systems as testing models: the LES and the QES. These two systems use the concept of committed expenditure, and the sign of the committed expenditure determines their own-price elasticity as inelastic or elastic in the LES.

Our findings indicate that the characteristics of total expenditure elasticity and own-price elasticity derived from the Working-Leser demand functions - the LES and the QES - are similar, indicating that the estimation results are stable among different specifications of demand functions.

Section 5 considers the theoretical relationship among total expenditure and own- and cross-price elasticities. This section explains the Törnqvist-Wold hypothesis for luxuries and necessities. Usually, the distinction between luxury and necessary goods is evaluated in two ways: one is based on total expenditure elasticity, and the other is based on own-price elasticity. When the total expenditure elasticity is elastic, the commodity is classified as a luxury good, while the commodity is classified as a necessary good when the total expenditure elasticity is inelastic. On the other hand, the commodity is classified as a necessary good when the own-price elasticity is inelastic. When the own-price elasticity is elastic, the commodity is classified as a luxury good. 
If a commodity indicates elastic total expenditure elasticity and inelastic own-price elasticity, is the commodity classified as a necessary good or a luxury good? In this case, the Törnqvist-Wold hypothesis is a tool to define whether a good is classified as a necessity or a luxury. The Törnqvist-Wold hypothesis is that as a rule, income elasticities of necessities are smaller than their price elasticities, whereas income elasticities of luxuries are greater than their price elasticities.

We consider the Törnqvist-Wold hypothesis in detail using the theory of consumer behavior. We proved that we have two possibilities theoretically regarding the relationship between total expenditure elasticity and own-price elasticity. The important point of empirical analysis is to determine what is reasonable to explain real-world observations.

Section 6 evaluates the empirical findings by Deaton $(1987,1988,1990)$ and Maki $(1998,2002)$ based on the results theoretically obtained in Section 5 . This section evaluates luxuries and necessities using the Törnqvist-Wold hypothesis and the alternative hypothesis. We confirmed that the Törnqvist-Wold hypothesis is better than the alternative. Finally, Section 7 concludes the present analysis.

\section{Data used for the analysis}

In the present analysis, we use the 2007 Tanzania Household Budget Survey (HBS). The survey was conducted by the National Bureau of Statistics in Tanzania. The total number of the sample households exceeds 10,000. The Bureau conducted a household budget survey three times in the 21 st century, and the latest survey was in 2007.

Here, we explain the methodology of obtaining the food poverty line and the basic needs poverty line after defining the adult equivalence scale in Tanzania. These figures are determined by the age and gender of household members. Table 2.1 provides the adult equivalence scale defined by the 2007 Tanzania HBS.

The adult equivalence scale is an adjustment technique that takes into account the difference in caloric intake among the members in a household by age and gender. In a household, a male who is between 13 and 14 years old or who is between 19 and 59 years old or a female who is between 13 and 18 years old is normalized as unity. Depending on their age, for males the adult equivalence scale is between 0.40 and 1.20 , while for females the range is between 0.40 and 1.00 .

Now we explain the measurement of the food poverty line derived by the Tanzania Bureau of Statistics. The Bureau constructs a food basket representing foods typically consumed by the poorest 50 percent of households. Among food categories, alcoholic drinks and related items are excluded in Tanzania. The food poverty line is derived under the condition that the sum of calories obtained by food consumption expenditures per adult equivalence scale is 2,200 calories per day. The level of 2,200 calories per day is defined by the Food and Agriculture Organization (FAO) of the United Nations as the minimum necessary for survival. 
Table 2.1 Adult equivalence scale

\begin{tabular}{lcc}
\hline Age group & \multicolumn{2}{c}{ Gender } \\
\cline { 2 - 3 } & Male & Female \\
\hline $0-2$ & 0.40 & 0.40 \\
$3-4$ & 0.40 & 0.48 \\
$5-6$ & 0.56 & 0.56 \\
$7-8$ & 0.64 & 0.64 \\
$9-10$ & 0.76 & 0.76 \\
$11-12$ & 0.80 & 0.80 \\
$13-14$ & 1.00 & 1.00 \\
$15-18$ & 1.20 & 1.00 \\
$19-59$ & 1.00 & 0.88 \\
$60+$ & 0.80 & 0.72 \\
\hline
\end{tabular}

To estimate the basic needs poverty line, the Tanzania Statistics Bureau uses diary-based data for food consumption expenditures and recall-based data for non-food consumption expenditures. According to the HBS 2000/01 Report, the basic needs poverty line is obtained in the following manner: after calculating the share - say, $\alpha$ - of the food expenditure to the total of food and non-food expenditures in the poorest 25 percent of all households, the basic needs poverty line is obtained as the value of the food poverty line multiplied by the reciprocal of $\alpha{ }^{4}$

The 2007 Tanzania HBS cross-sectional data distinguishes between three household types - very poor, poor, and non-poor - according to the level of total expenditure adjusted by the adult equivalence scale as estimated by the Tanzania Statistics Bureau. The very poor households are defined as their total expenditure adjusted by the adult equivalence scale being below the food poverty line. The poor households are those whose adjusted total expenditure is between the food poverty line and the basic needs poverty line. The non-poor households are those whose adjusted total expenditure is above the basic needs poverty line. We divided the households for each category into ten classes (deciles) according to the level of total expenditure adjusted by the adult equivalence scale. Table 2.2 indicates the results for the averages of total expenditure, Engel's coefficient and its standard error, and the minimum and maximum of Engel's coefficient in each total expenditure class.

The number of households classified as very poor households is 968 , that of poor households is 1,096 , and that of non-poor households is 8,342 , totaling 10,406 households. About 10 percent of the households are classified as very poor households, while about 80 percent are categorized as non-poor households. Within the same category - for example, the very poor households - the sample households are divided equally into ten classes (deciles). We calculated average values for the total expenditure adjusted by the adult equivalence scale, Engel's coefficient, its standard error, and the minimum and maximum of Engel's coefficient. In the original book by Engel (1895), Engel's coefficient for 
Table 2.2 Movement of Engel's coefficient from the lowest to the highest total expenditure classes

(a) Very poor households (sample size: 968)

\begin{tabular}{llllllll}
\hline Class no. Sample & $\begin{array}{l}\text { Total } \\
\text { size } \\
\text { expenditure } \\
(\text { TS) }\end{array}$ & $\begin{array}{l}\text { Engel's } \\
\text { coefficient } \\
(\%)\end{array}$ & $\begin{array}{l}\text { Standard } \\
\text { error (\%) }\end{array}$ & $\begin{array}{l}\text { Minimum } \\
(\%)\end{array}$ & $\begin{array}{l}\text { Maximum } \\
(\%)\end{array}$ & $\begin{array}{l}\text { t-palue } \\
(\%)\end{array}$ \\
\hline $\mathrm{V}_{1}$ & 97 & $3,648.2$ & 59.72 & 20.82 & 0.20 & 94.76 & - \\
$\mathrm{V}_{2}$ & 97 & $5,420.9$ & 64.00 & 18.09 & 6.73 & 96.56 & 0.48 \\
$\mathrm{~V}_{3}$ & 96 & $6,317.8$ & 63.70 & 15.71 & 11.94 & 90.75 & -0.03 \\
$\mathrm{~V}_{4}$ & 97 & $7,027.4$ & 62.05 & 19.23 & 2.08 & 91.87 & -0.18 \\
$\mathrm{~V}_{5}$ & 97 & $7,707.8$ & 63.52 & 15.62 & 15.73 & 93.61 & 0.16 \\
$\mathrm{~V}_{6}$ & 97 & $8,246.2$ & 63.49 & 15.31 & 12.53 & 86.73 & -0.003 \\
$\mathrm{~V}_{7}$ & 97 & $8,722.7$ & 65.66 & 14.63 & 22.36 & 95.92 & 0.23 \\
$\mathrm{~V}_{8}$ & 96 & $9,165.9$ & 60.20 & 17.20 & 13.62 & 93.32 & -0.60 \\
$\mathrm{~V}_{9}$ & 97 & $9,618.0$ & 64.76 & 17.30 & 9.27 & 91.76 & 0.50 \\
$\mathrm{~V}_{10}$ & 97 & $10,026.7$ & 62.11 & 17.51 & 5.34 & 91.40 & -0.29 \\
\hline
\end{tabular}

(b) Poor households (sample size: 1,096)

\begin{tabular}{lllllllr}
\hline Class no. Sample Total & $\begin{array}{l}\text { Engel's } \\
\text { size } \\
\text { expenditure } \\
\text { (TS) }\end{array}$ & $\begin{array}{l}\text { Soefficient } \\
\text { error (\%) }\end{array}$ & $\begin{array}{l}\text { Minimum } \\
(\%)\end{array}$ & $\begin{array}{l}\text { Maximum } \\
(\%)\end{array}$ & $\begin{array}{l}\text { t-palue } \\
(\%)\end{array}$ \\
\hline $\mathrm{P}_{1}$ & 110 & $10,457.4$ & 61.53 & 14.52 & 10.30 & 89.78 & -0.06 \\
$\mathrm{P}_{2}$ & 109 & $10,868.2$ & 64.59 & 17.35 & 11.15 & 91.80 & 0.35 \\
$\mathrm{P}_{3}$ & 110 & $11,269.5$ & 65.07 & 16.83 & 6.10 & 94.90 & 0.05 \\
$\mathrm{P}_{4}$ & 109 & $11,698.2$ & 64.27 & 14.47 & 12.81 & 89.58 & -0.09 \\
$\mathrm{P}_{5}$ & 110 & $12,108.1$ & 63.62 & 15.73 & 6.62 & 96.47 & -0.07 \\
$\mathrm{P}_{6}$ & 110 & $12,457.0$ & 63.74 & 14.43 & 12.45 & 92.37 & -0.04 \\
$\mathrm{P}_{7}$ & 109 & $12,808.1$ & 64.16 & 14.04 & 20.03 & 89.30 & 0.10 \\
$\mathrm{P}_{8}$ & 110 & $13,171.1$ & 66.11 & 13.65 & 14.81 & 92.15 & 0.27 \\
$\mathrm{P}_{9}$ & 109 & $13,512.3$ & 63.22 & 17.63 & 10.04 & 90.61 & -0.38 \\
$\mathrm{P}_{10}$ & 110 & $13,849.0$ & 66.50 & 14.76 & 9.17 & 90.86 & 0.37 \\
\hline
\end{tabular}

(c) Non-poor households (sample size: 8,342)

\begin{tabular}{llllllll} 
Class no. Sample Total & $\begin{array}{l}\text { Engel's } \\
\text { size } \\
\text { expenditure } \\
\text { (TS) }\end{array}$ & $\begin{array}{l}\text { Standard } \\
\text { coeficnt }\end{array}$ & $\begin{array}{l}\text { Minimum } \\
(\%)\end{array}$ & $\begin{array}{l}\text { Maximum } \\
(\%)\end{array}$ & $\begin{array}{l}\text { t-palue } \\
(\%)\end{array}$ \\
\hline $\mathrm{N}_{1}$ & 834 & $15,248.2$ & 64.08 & 14.37 & 3.59 & 94.58 & -0.37 \\
$\mathrm{~N}_{2}$ & 834 & $17,799.1$ & 64.68 & 14.99 & 2.72 & 93.49 & 0.19 \\
$\mathrm{~N}_{3}$ & 835 & $20,296.4$ & 63.26 & 15.68 & 3.40 & 95.57 & -0.45 \\
$\mathrm{~N}_{4}$ & 834 & $22,972.4$ & 62.05 & 14.97 & 12.33 & 92.24 & -0.39 \\
$\mathrm{~N}_{5}$ & 834 & $25,969.5$ & 61.50 & 15.97 & 7.84 & 95.18 & -0.18 \\
$\mathrm{~N}_{6}$ & 834 & $29,577.4$ & 60.39 & 16.27 & 4.83 & 94.72 & -0.37 \\
$\mathrm{~N}_{7}$ & 834 & $34,070.5$ & 59.16 & 16.15 & 8.34 & 94.19 & -0.42 \\
$\mathrm{~N}_{8}$ & 835 & $40,356.5$ & 59.17 & 16.87 & 4.97 & 95.28 & 0.003 \\
$\mathrm{~N}_{9}^{9}$ & 834 & $50,521.9$ & 56.53 & 17.73 & 4.79 & 97.25 & -0.93 \\
$\mathrm{~N}_{10}$ & 834 & $90,470.3$ & 52.05 & 20.70 & 2.80 & 96.28 & -1.68 \\
\hline
\end{tabular}




\section{Atsushi Maki and Mlemba Abassy Kamwe}

Belgian workers' households in the low total expenditure class was 70.89 percent, 67.37 percent for middle-class households, and 62.42 percent for high total expenditure households (cf. Deaton 1997). Engel's coefficient in the Tanzania HBS ranges between 52.05 percent (tenth deciles of non-poor households [N10] in Table 2.4) and 66.50 percent (eighth deciles of poor households [P8] in the same table).

The change in Engel's coefficient due to the total expenditure level is indicated in Figure 2.1. In the low total expenditure levels of less than TS 20,000, there is no clear downward-sloping trend regarding Engel's coefficient, while there is a downward-sloping tendency after the total expenditure level exceeds TS 20,000 .

Using the values provided in Table 2.2 , it is possible, by applying the $t$-test, to test whether or not two population means of Engel's coefficient are equal between two adjacent total expenditure classes. The hypothesis and alternative hypothesis are

$$
\begin{aligned}
& H_{0}: \mu_{1}-\mu_{2}=0 \\
& H_{A}: \mu_{1}-\mu_{2} \neq 0
\end{aligned}
$$

where $\mu_{1}$ and $\mu_{2}$ are the population means of the $i$-th and $(i+1)$-th total expenditure classes, respectively. The $t$-test statistic is obtained by the following equation:

$$
\begin{aligned}
t= & \bar{x}_{1}-\bar{x}_{2}-\left(\mu_{1}-\mu_{2}\right) / \sqrt{ }\left[\left(n_{1}-1\right) s_{1}^{2}+\left(n_{2}-1\right) s_{2}^{2}\right] \\
& \sqrt{ }\left[n_{1} n_{2}\left(n_{1}+n_{2}-2\right)\right] /\left(n_{1}+n_{2}\right)
\end{aligned}
$$

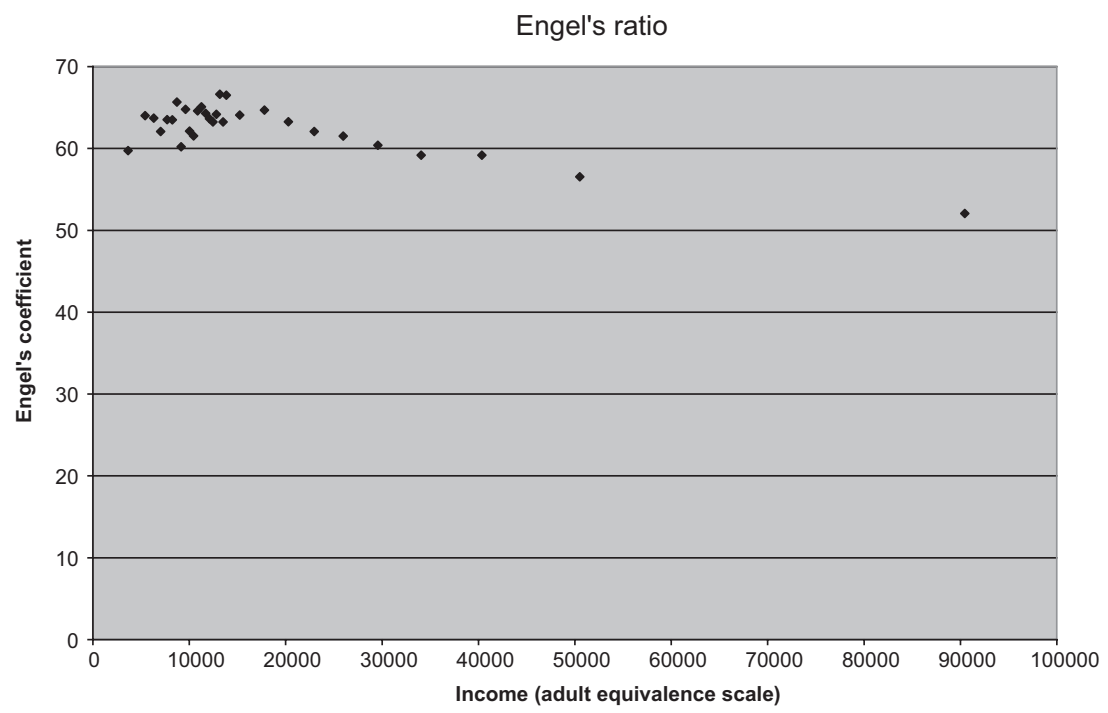

Figure 2.1 Scatter between Engel's coefficient and total expenditure 
where $\bar{x}_{1}$ and $\bar{x}_{2}$ are the means of Engel's coefficient for the $i$-th and $(i+1)$-th total expenditure classes, respectively; $s_{1}^{2}$ and $s_{2}^{2}$ are their standard errors; and $n_{1}$ and $n_{2}$ are their sample size. The $t$-value is indicated in the last column of Table 2.2.

Examining the $t$-values for the hypothesis that $\mu_{1}-\mu_{2}=0$, the hypothesis is not rejected for all total expenditure classes at the significance level of 5 percent (the critical value is 1.960 ). On the other hand, the hypothesis of $\mu_{1}-\mu_{2}=0$ is rejected between the ninth and tenth deciles of the non-poor households at the significance level of 10 percent (the critical value is 1.645 ), indicating that the Engel's Law works. Based on this method, we do not find that the Engel curve is inverse U-shaped. We now use the nonparametric regression method to further examine the tendency of the Engel curve in Tanzania.

According to Greene (2012), nonparametric regression is defined as

$$
y=\mu(x)+\varepsilon
$$

where $y$ is a dependent variable, $x$ is a single independent variable, and $\varepsilon$ is a stochastic disturbance term. A conditional mean estimating function is defined as

$$
\hat{\mu}\left(x^{*}\right)=\sum w_{i}\left(x^{*} \mid x_{1}, \ldots, x_{n}\right) y_{i}
$$

where the weights sum to unity. The kernel weighted regression method is a standard tool in nonparametric analysis

$$
\begin{aligned}
\hat{\mu}\left(x^{*} \mid X, b\right)= & \left\{\sum(1 / n) K\left[\left(x_{i}-x^{*}\right) / h\right] y_{i}\right\} / \\
& \left\{\sum(1 / n) K\left[\left(x_{i}-x^{*}\right) / b\right]\right\}
\end{aligned}
$$

where $K\left[\left(x_{i}-x^{*}\right) / h\right]$ is the kernel density.

Applying nonparametric regression,

$$
w_{i}=\mu\left(\ln x_{i}\right)+\varepsilon_{i}
$$

where $w_{i}$ is Engel's coefficient (food share) at the $i$-th total expenditure household, $x_{i}$ is the corresponding total expenditure, and $\varepsilon_{i}$ is a stochastic disturbance term. The Engel curve is obtained graphically as indicated in Figure 2.2.

Though the movement of the food share obtained by the classified data indicated in Figure 2.1 may be flat as total expenditure increases, the tendency of the Engel curve derived by the nonparametric regression has a hump among the very poor households. As the Engel curve obtained by nonparametric regression has a hump in the low total expenditure class, we have to specify a quadratic form of the Engel curve and test the validity of the model.

The Engel curve was estimated parametrically based on the utility maximizing behavior for households. We specify the quadratic almost ideal demand (QUAID) system in the price-independent generalized logarithmic (PIGLOG)-type utility 


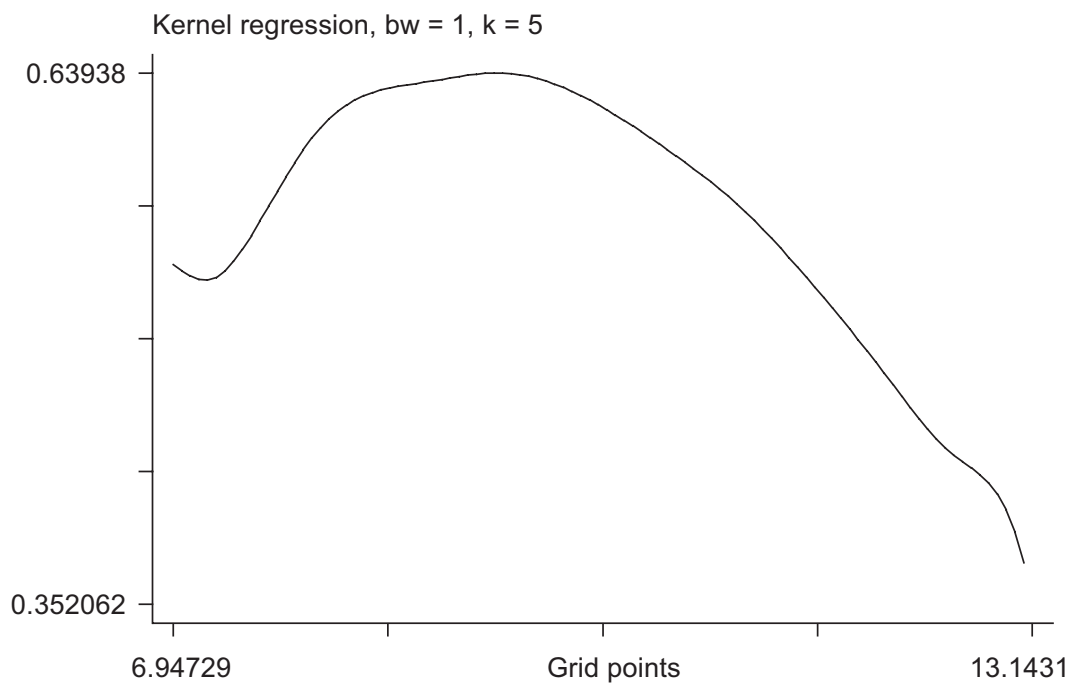

Figure 2.2 Nonparametric regression

class. Banks, Blundell, and Lewbel (1997) proposed the QUAID system. The specification of the QUAID system share equation is:

$$
w_{i j}=a_{j}+b_{j} \ln x_{i}+c_{j}\left(\ln x_{i}\right)^{2}
$$

The total expenditure elasticity of demand, $\eta_{i j}$, for the $j$-th commodity at the $i$-th household in the QUAID system is:

$$
\eta_{i j}=\left[a_{j}+b_{j}+\left(2 c_{j}+b_{j}\right) \ln x_{i}+c_{j}\left(\ln x_{i}\right)^{2}\right] / w_{i j}
$$

When the parameter, $c$, is negative, as indicated in Table 2.3, the quadratic form has the maximum value regarding the food share, $w_{p}$, at the point of the total expenditure level of $\ln x_{i}=-b_{j} /\left(2 c_{j}\right)$, and the maximum share is:

$$
w_{j}^{*}=a_{j}-b_{j}^{2} /\left(4 c_{j}\right)
$$

We also calculate the effective range of the total expenditure for the estimated QUAID system between $x_{\min }=\exp \left[\left(-b_{j}+\sqrt{ }\left(b_{j}^{2-4} a_{j} c_{j}\right)\right] /\left(2 c_{j}\right)\right.$ and $x_{\max }=\exp \left[\left(-b_{j}-\right.\right.$ $\left.\sqrt{ }\left(b_{j}^{2-4} 4 a_{j} c_{j}\right)\right] /\left(2 c_{j}\right)$, respectively. ${ }^{5}$

We divide total expenditure into two clusters of items: food and non-food expenditures. Because of Walras' Law, the number of estimating equations is one in the two-commodity classification. From now on, we drop the suffix $j$ without any loss of generality. 
The specification of the QUAID system share equation is:

$$
w_{i}=a+b \ln \left(x_{i}\right)+c\left[\ln \left(x_{i}\right)\right]^{2}+\varepsilon_{i}
$$

where $w_{i}$ is the food share for the $i$-th household and $x_{i}$ is the total expenditure adjusted by the adult equivalence scale.

The QUAID system food share functions are estimated by the OLS and quantile regression methods. The criterion of the OLS estimation method is:

$$
\min \left[(y-X \beta)^{\prime}(y-X \beta)\right]
$$

where $y$ is the column vector of order $N, X$ is the $N \times K$ matrix, and $\beta$ is the column vector of order $K$. According to Koenker and Bassett (1978), the $\theta$-th quantile regression, $0<\theta<1$, is defined as any solution to the minimization problem:

$$
\min \left[\theta 1_{n}|y-X \beta|+(1-\theta) 1_{n}|y-X \beta|\right]
$$

As the special case for quantile regression, the least absolute error (LAE) estimator is the same as that derived from the median regression - namely, the case of $\theta=0.5$ in the quantile regression.

The quantile regression problem is reformulated as a linear programming technique by introducing slack variables of $u$ and $v$ :

$$
\min \left[\theta 1_{n} u+(1-\theta) 1_{n} p \mid X \beta+u-v=y\right]
$$

The estimates, $\beta$, are obtained by solving the linear programming model (cf. Koenker and Bassett 1982, Koenker 2005, and Cameron and Trivedi 2005).

The estimation results are reported in Table 2.3 for the OLS regression and the quantile regression for the three cases: the first quantile $\left(Q_{1}\right)$, the second quantile (median), and the third quantile $\left(Q_{3}\right){ }^{6}$

The parameter, $c$, is negative, and therefore the quadratic form has the maximum of the food share at the point of $\ln x_{i}=\exp [-b /(2 c)]$. We find that the maximum percentage of total expenditure spent on food is among the very poor households. The maximum point for the OLS estimation is TS 9,850 and that for the median estimation is TS 11,712 , as indicated in Table 2.3.

Table 2.4 reports the total expenditure elasticity of demand at different total expenditure levels from TS 5,000 through TS 1000,000.

The interesting observation here is that total expenditure elasticity is elastic namely, the value of the total expenditure elasticity is greater than unity at the total expenditure level of less than TS 10,000. This means that when total expenditure is increased by 1 percent at the total expenditure level of TS 5,000, the increase in food expenditure is greater than 1 percent. This means that additional total expenditure is disproportionately spent on food rather than non-food expenditures in the very poor households. As a result, the food share as a percentage of total expenditure increases with total expenditure for the very poor 
Table 2.3 Estimation results: the QUAID system

\begin{tabular}{|c|c|c|c|c|}
\hline \multirow{2}{*}{$\frac{\text { Method }}{\text { Estimates }}$} & \multirow[t]{2}{*}{ OLS regression } & \multicolumn{3}{|c|}{ Quantile regression } \\
\hline & & $Q_{1}$ & Median & $Q_{3}$ \\
\hline$a($ intercept $)$ & -1.577 & -2.953 & -2.455 & -0.3714 \\
\hline$t$-value & $(-6.7)$ & $(-8.3)$ & $(-7.7)$ & $(-1.5)$ \\
\hline$b$ & 0.4825 & 0.762 & 0.6656 & 0.2524 \\
\hline$t$-value & $(-10.4)$ & $(-10.9)$ & $(-10.6)$ & $(-5.4)$ \\
\hline$c$ & -0.026 & -0.0413 & -0.0355 & -0.0141 \\
\hline$t$-value & $(-11.5)$ & $(-12.0)$ & $(-11.5)$ & $(-6.1)$ \\
\hline$r^{2}$ & 0.0463 & 0.0457 & 0.0224 & 0.011 \\
\hline $\begin{array}{l}\text { White's test } \\
(P \text {-value })\end{array}$ & $\begin{array}{c}224.5 \\
(0.000)\end{array}$ & & & \\
\hline $\begin{array}{l}H_{0}: b_{Q 1}=b_{\mathrm{MED}} \\
\quad=b_{Q 3}^{2} \text { and } \\
\quad c_{Q 1}=c_{\mathrm{MED}} \\
=c_{O 3}\end{array}$ & & & 38.23 & \\
\hline$(P$-value $)$ & & & $(0.000)$ & \\
\hline $\begin{array}{l}\text { Maximum of } \\
\text { food share } \\
(\%)\end{array}$ & 64.14 & 55.83 & 66.2 & 75.32 \\
\hline $\begin{array}{l}\text { Its total } \\
\text { expenditure } \\
\text { (TS) }\end{array}$ & $9,850.1$ & $10,077.3$ & $11,712.8$ & $7,415.1$ \\
\hline $\begin{array}{l}\text { Minimum total } \\
\text { expenditure } \\
\text { (TS) (food } \\
\text { share }=0)\end{array}$ & 70.1 & 255.3 & 156.2 & 5 \\
\hline $\begin{array}{l}\text { Maximum total } \\
\text { expenditure } \\
\text { (TS) (food } \\
\text { share }=0)\end{array}$ & $1,382,958$ & 397,622 & 878,012 & $10,901,125$ \\
\hline
\end{tabular}

households below the threshold of TS 9,850.1 for the OLS regression, that of TS 10,077.3 for the first-quartile regression, that of TS $11,712.8$ for the median regression, and that of TS 7,415.1 for the third-quartile regression.

The food category is usually classified as necessary goods, and its total expenditure elasticity is inelastic - namely, the value is less than unity. But in the lowest total expenditure levels among the very poor households, food items are necessary goods, though the total expenditure elasticity is elastic. This finding is important in terms of economic and social policy in developing countries.

Contrary to Engel's Law, the Engel curve in Tanzania is U-shaped, meaning that food expenditure as a share of total expenditure increases with total 
Table 2.4 Total expenditure elasticity of demand at different total expenditure levels: the QUAID system

\begin{tabular}{|c|c|c|c|c|c|c|c|c|c|}
\hline $\begin{array}{l}\text { Total } \\
\text { expenditure } \\
\text { levels (TS) }\end{array}$ & & 5,000 & 10,000 & 15,000 & 20,000 & 30,000 & 50,000 & 80,000 & 100,000 \\
\hline $\begin{array}{l}\text { OLS } \\
\text { regression }\end{array}$ & & 1.056 & 0.998 & 0.965 & 0.940 & 0.904 & 0.851 & 0.791 & 0.757 \\
\hline \multicolumn{10}{|l|}{$\begin{array}{l}\text { Quantile } \\
\text { regression }\end{array}$} \\
\hline & Median & 1.095 & 1.016 & 0.973 & 0.941 & 0.894 & 0.824 & 0.742 & 0.694 \\
\hline & $Q$ & 1.107 & 1.001 & 0.940 & 0.894 & 0.822 & 0.707 & 0.550 & 0.443 \\
\hline & $\overrightarrow{Q_{3}}$ & 1.014 & 0.988 & 0.973 & 0.961 & 0.945 & 0.922 & 0.899 & 0.887 \\
\hline
\end{tabular}

expenditure; after reaching the maximum of Engel's coefficient, it monotonically decreases as total expenditure increases. This behavior is well described by the specification of the QUAID system.

\section{Estimating demand functions for nineteen commodities in the food category}

The main objective of demand analysis consists of calculating the elasticity of demand for total expenditure, own prices, and cross prices. The estimating equation is specified as the Working-Leser demand function:

$$
w_{i k}=a_{i}+b_{i} \ln x_{k}+c_{i} \ln p_{i}+\sum_{j \neq i} d_{i j} \ln p_{j}
$$

where $w_{i k}$ is the budget share for the $i$-th commodity of the $k$-th household; $x_{k}$ is the total expenditure adjusted by the adult equivalence scale for the $k$-th household; $p_{i}$ is the price of the $i$-th commodity; $p_{j}$ is the price of the $j$-th commodity $(j \neq i)$; and $a_{i}, b_{i}, c_{i}$, and $d_{i j}(j \neq i)$ are parameters of the $i$-th commodity to be estimated using regression analysis.

In the aforementioned specification, we calculate the elasticity of demand for total expenditure, own prices, and cross prices, respectively, as

Total expenditure elasticity: $1+b_{i} / w_{i}$

Own-price elasticity: $c_{i} / w_{i}-1$

Cross-price elasticity for $j$-th commodity: $d_{i j} / w_{i}$

where $w_{i}$ is the average share of the $i$-th commodity. From the previous equation, we understand that when parameter $b_{i}$ is positive, the commodity is total expenditure elastic and vice versa; when parameter $c_{i}$ is positive, the commodity is price inelastic and vice versa; when parameter $d_{i j}$ is positive, the commodity is 


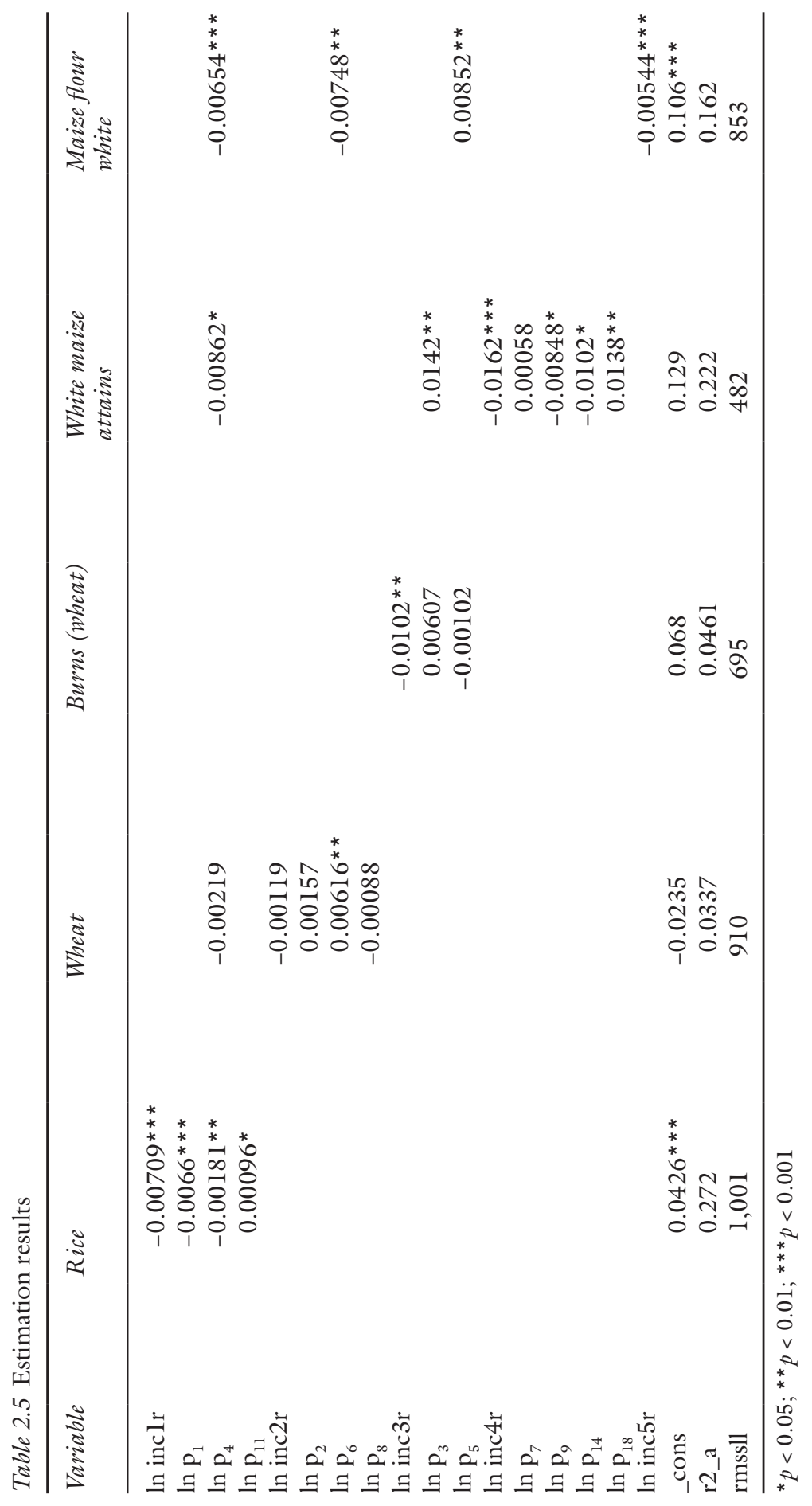




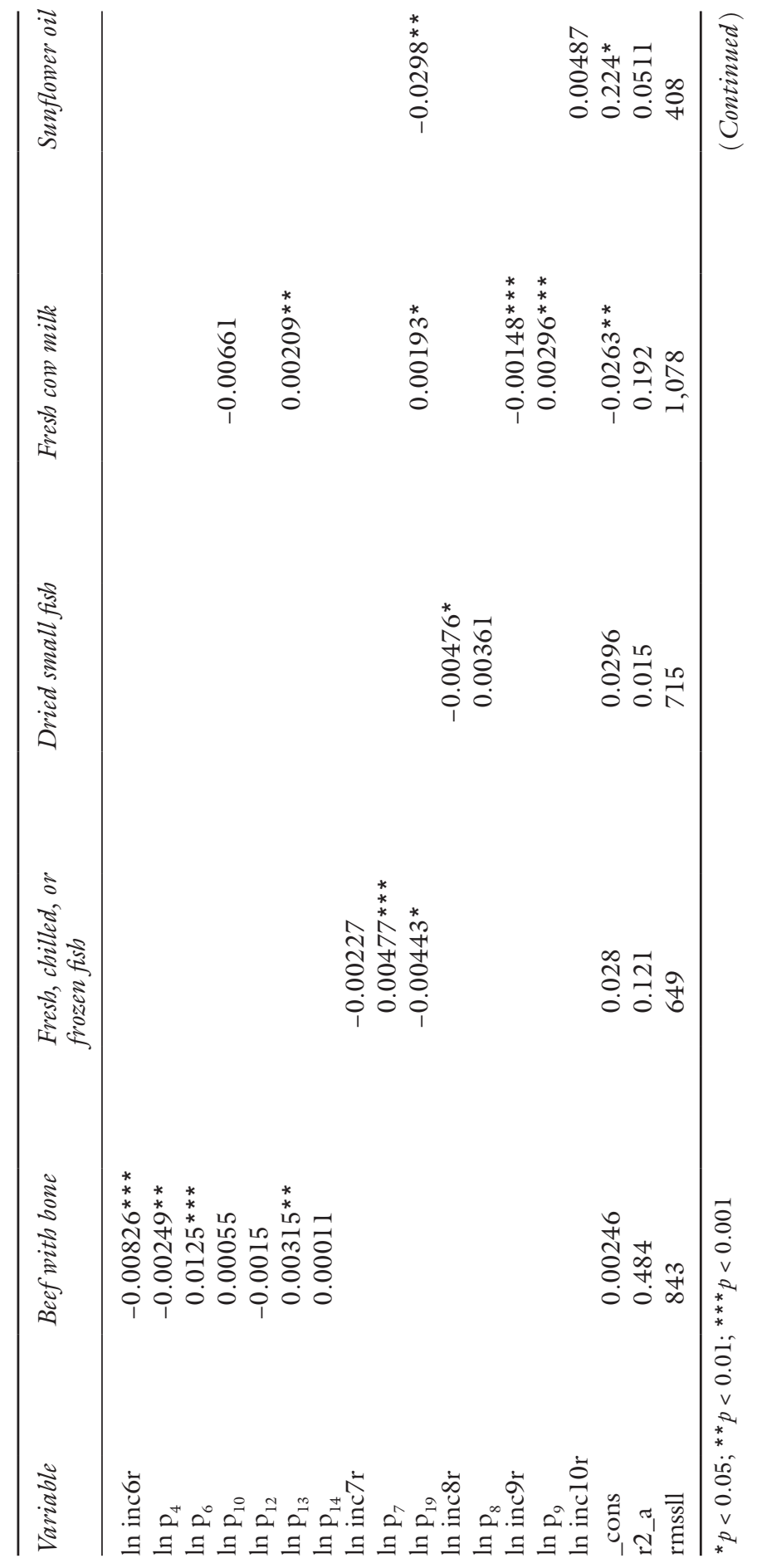




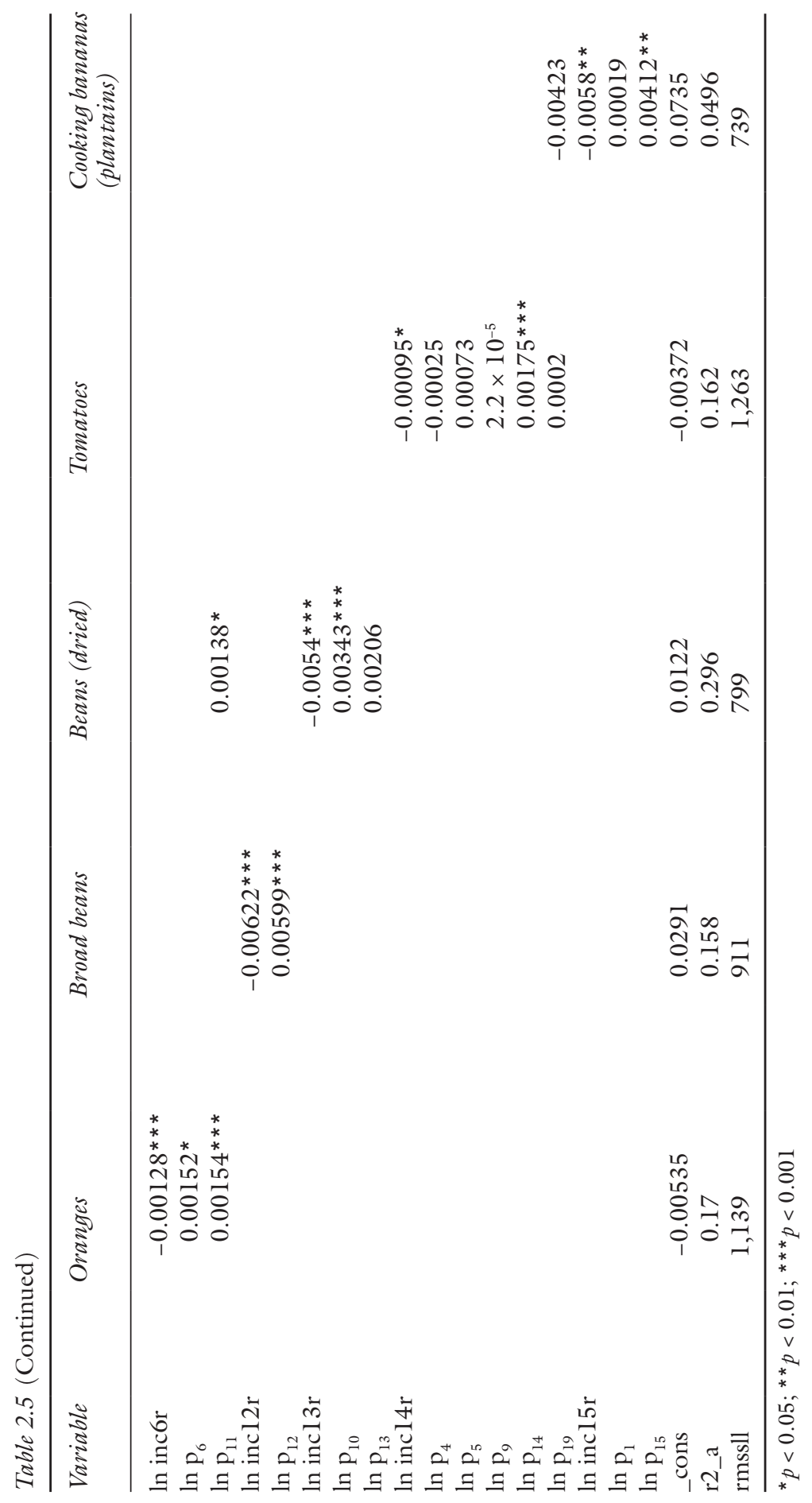




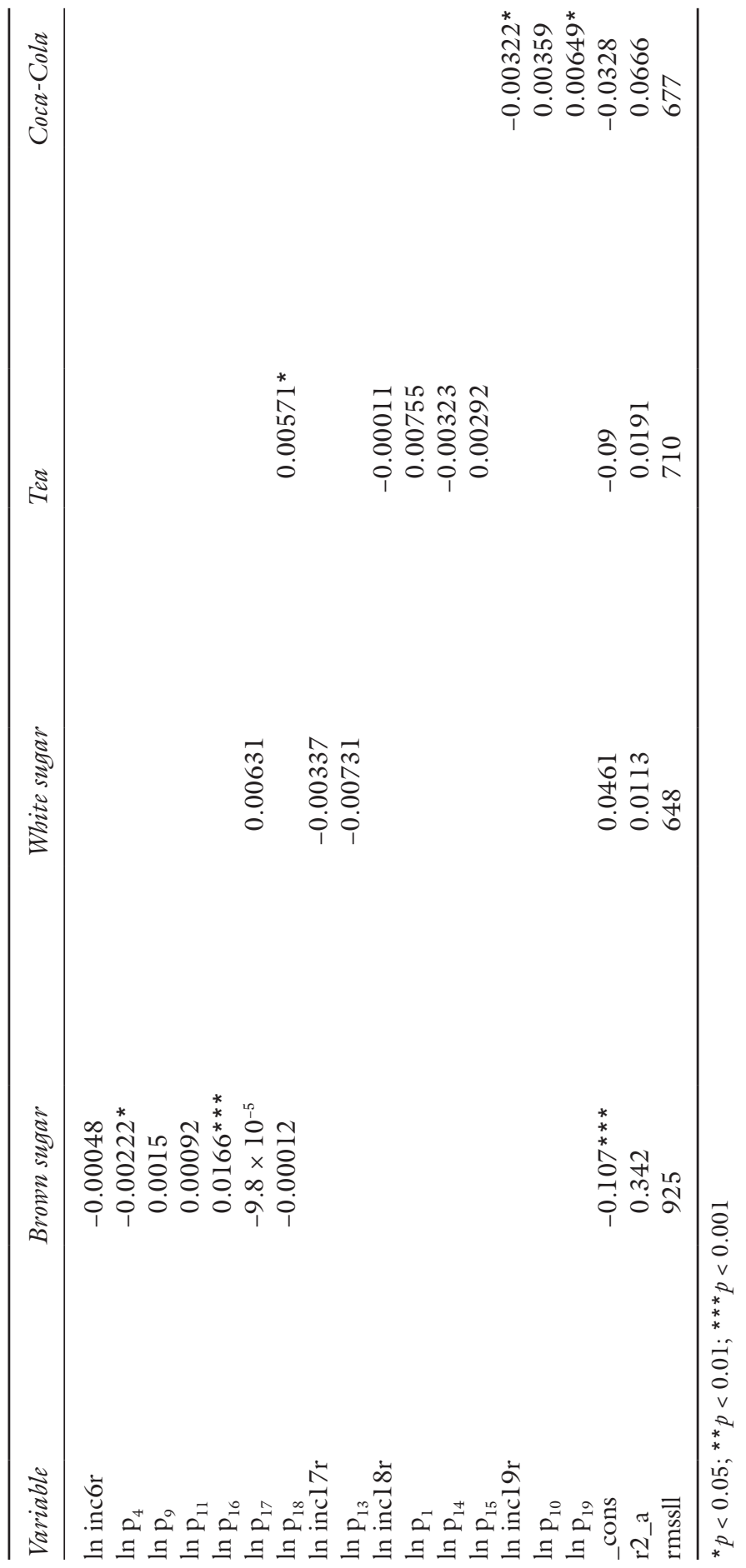


classified as a substitute; and when parameter $d_{i j}$ is negative, the commodity is classified as a complement.

The value of own-price elasticity classifies a commodity as a necessary good or a luxury good. When a commodity is own-price inelastic - namely, the value of its price elasticity is between -1 and $0-$ it is classified as a necessary good, and if the value is less than -1 , it is classified as a luxury good.

The estimating equation includes not only total expenditure and the own price but also the cross prices of commodities. After estimating this specification when the estimate of the other price of the commodity is not significant statistically, we excluded such cross prices from the estimating equation. Table 2.5 provides the estimation results.

The estimated elasticity of demand using the final specification is indicated in Table 2.6. The two right-hand columns classify the commodity as a necessary or luxury good defined by total expenditure elasticity and own-price elasticity, respectively.

Table 2.6 indicates that almost all commodities are necessary goods evaluated by total expenditure elasticity and own-price elasticity. When we evaluate luxury

Table 2.6 Elasticity of demand

\begin{tabular}{|c|c|c|c|c|}
\hline Commodity & $\begin{array}{l}\text { Total } \\
\text { expenditure } \\
\text { elasticity }\end{array}$ & $\begin{array}{l}\text { Price } \\
\text { elasticity }\end{array}$ & $\begin{array}{l}\text { Necessary or } \\
\text { luxury good } \\
\text { (defined by total } \\
\text { expenditure) }\end{array}$ & $\begin{array}{l}\text { Necessary or } \\
\text { luxury good } \\
\text { (defined by } \\
\text { own price) }\end{array}$ \\
\hline (1) Rice & 0.53 & -0.34 & Necessary & Necessary \\
\hline (2) Wheat & 1.05 & -0.61 & Luxury & Necessary \\
\hline (3) Burns (wheat) & 0.39 & -0.45 & Necessary & Necessary \\
\hline (4) White maize attains & 0.59 & -1.47 & Necessary & Luxury \\
\hline (5) Maize flour white & 0.14 & 0.3 & Necessary & Not defined \\
\hline (6) Beef with bones & 0.42 & -0.15 & Necessary & Necessary \\
\hline $\begin{array}{l}\text { (7) Fresh, chilled, or } \\
\text { frozen fish }\end{array}$ & 0.95 & -0.72 & Necessary & Necessary \\
\hline (8) Dried small fish & 0.66 & -0.68 & Necessary & Necessary \\
\hline (9) Fresh cow milk & 0.58 & -0.36 & Necessary & Necessary \\
\hline (10) Sunflower oil & 1.32 & -2.3 & Luxury & Luxury \\
\hline (11) Oranges & 0.66 & -0.53 & Necessary & Necessary \\
\hline (12) Broad beans & 0.18 & -0.36 & Necessary & Necessary \\
\hline (13) Beans (dried) & 0.15 & -1.04 & Necessary & Luxury \\
\hline (14) Tomatoes (round) & 0.82 & -0.58 & Necessary & Necessary \\
\hline $\begin{array}{l}\text { (15) Cooking bananas } \\
\text { (plantains) }\end{array}$ & 0.04 & -0.46 & Necessary & Necessary \\
\hline (16) Brown sugar & 0.58 & -0.31 & Necessary & Necessary \\
\hline (17) White sugar & 0.29 & -2.03 & Necessary & Luxury \\
\hline (18) Tea & 1.95 & -0.3 & Luxury & Necessary \\
\hline (19) Coca-Cola & 0.42 & -0.32 & Necessary & Necessary \\
\hline
\end{tabular}


goods regarding total expenditure elasticity, there are three commodities: wheat (2); sunflower oil (10); and tea (18). Regarding own-price elasticity, there are four commodities that are classified as luxury goods: white maize attains (4); sunflower oil (10); beans (dried) (13); and white sugar (17). Sunflower oil (10) is both a total expenditure elastic and an own-price elastic commodity, while wheat (2), white maize attains (4), beans (dried) (13), white sugar (17), and tea (18) show mixed elasticities. ${ }^{7}$

\section{The linear expenditure system (LES) and the quadratic expenditure system (QES)}

As indicated in Table 2.5 of Section 3, we estimate the demand functions that do not satisfy adding-up, homogeneity, or symmetry conditions. In this section, we estimate two types of complete demand system demand functions to check the magnitude of elasticity of demand derived from the previous analysis. One is the linear expenditure system (LES), and the other is the quadratic expenditure system (QES).

As we are interested in the estimation of committed expenditure for food, we have to specify the complete demand system that relies on the concept of committed expenditure in the model. In order to satisfy the characteristics, we specified the LES proposed by Stone (1954) and the QES proposed by Howe, Pollak, and Wales (1979). The specification of the LES is

$$
p_{i} q_{i}=p_{i} \gamma_{i}+\beta_{i}\left(x-\sum p_{j} \gamma_{j}\right)(i=1,2, \ldots, n)
$$

where total expenditure in the model is defined as total food expenditure, the values of $q_{i}$ are the quantity of the $i$-th food category, the values of $p_{i}$ are the corresponding prices, and the values of $\beta_{i}$ and $\gamma_{i}$ are parameters to be estimated. The specification of the QES is

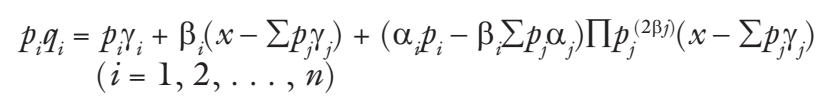

When $\gamma_{i}$ is positive in the LES and the QES, the commodity is classified as a necessary good, and in the LES the sign of $\gamma_{i}$ directly connected with own-price elasticity is either inelastic or elastic. This property is derived as follows:

Own-price elasticity: $-\beta_{i}\left(x-\sum_{j \neq i} p_{j} \gamma_{j}\right) / p_{i} q_{i}<0$

Own-price flexibility: $-p_{i} q_{i} / \beta_{i}\left(x-\sum_{j \neq i} p_{j} \gamma_{j}\right)$

$$
\begin{aligned}
& =-\left[p_{i} \gamma_{i}\left(1-\beta_{i}\right)+\beta_{i}\left(x-\sum_{j \neq i} p_{j} \gamma_{j}\right)\right] / \beta_{i}\left(x-\sum_{j \neq i} p_{j} \gamma_{j}\right) \\
& =-\left[1+p_{i} \gamma_{i}\left(1-\beta_{i}\right) / \beta_{i}\left(x-\sum_{j \neq i} p_{j} \gamma_{j}\right)\right]
\end{aligned}
$$

if $\gamma_{i}>0$, the item is price flexible, indicating an inelastic price;

if $\gamma_{i}<0$, the item is price inflexible, indicating an elastic price.

The estimated results for the LES and the QES are listed in Table 2.7. 
Table 2.7 Estimation results

\begin{tabular}{|c|c|c|c|c|c|}
\hline Parameter & Estimate & Standard error & t-statistic & P-value & $\begin{array}{l}\text { Necessary or } \\
\text { luxury }\end{array}$ \\
\hline$\gamma_{1}$ & 0.282063 & 0.024973 & 11.2948 & {$[0.000]$} & Necessary \\
\hline$\gamma_{2}$ & 0.022184 & 0.024482 & 0.906125 & {$[0.365]$} & Necessary \\
\hline$\gamma_{3}$ & 0.068855 & 0.012776 & 5.38951 & {$[0.000]$} & Necessary \\
\hline$\gamma_{4}$ & -0.249906 & 0.263230 & -0.949382 & {$[0.342]$} & Luxury \\
\hline$\gamma_{5}$ & 0.224813 & 0.171856 & 1.30814 & {$[0.191]$} & Necessary \\
\hline$\gamma_{6}$ & 0.192492 & 0.010520 & 18.2973 & {$[0.000]$} & Necessary \\
\hline$\gamma_{7}$ & 0.093179 & 0.018792 & 4.95853 & {$[0.000]$} & Necessary \\
\hline$\gamma_{8}$ & 0.026159 & 0.019481 & 1.34280 & {$[0.179]$} & Necessary \\
\hline$\gamma_{9}$ & 0.159059 & 0.028660 & 5.54989 & {$[0.000]$} & Necessary \\
\hline$\gamma_{10}$ & -1.36502 & 0.217297 & -6.28185 & {$[0.000]$} & Luxury \\
\hline$\gamma_{11}$ & 0.052135 & $0.944918 \times 10^{-2}$ & 5.51737 & {$[0.000]$} & Necessary \\
\hline$\gamma_{12}$ & 0.130072 & 0.038063 & 3.41724 & {$[0.001]$} & Necessary \\
\hline$\gamma_{13}$ & 0.065806 & 0.027572 & 2.38667 & {$[0.017]$} & Necessary \\
\hline$\gamma_{14}$ & 0.072771 & $0.664539 \times 10^{-2}$ & 10.9505 & {$[0.000]$} & Necessary \\
\hline$\gamma_{15}$ & 0.330486 & 0.047544 & 6.95111 & {$[0.000]$} & Necessary \\
\hline$\gamma_{16}$ & 0.079478 & 0.016515 & 4.81260 & {$[0.000]$} & Necessary \\
\hline$\gamma_{17}$ & -0.123191 & 0.113029 & -1.08991 & {$[0.276]$} & Luxury \\
\hline$\gamma_{18}$ & $-0.119646 \times 10^{-2}$ & 0.015223 & -0.078597 & {$[0.937]$} & Luxury \\
\hline$\gamma_{19}$ & 0.141212 & 0.017959 & 7.86318 & {$[0.000]$} & Necessary \\
\hline$\beta_{1}$ & 0.022605 & $0.284444 \times 10^{-2}$ & 7.94708 & {$[0.000]$} & \\
\hline$\beta_{2}$ & 0.020938 & $0.698323 \times 10^{-2}$ & 2.99826 & {$[0.003]$} & \\
\hline$\beta_{3}$ & $.412326 \times 10^{-2}$ & $.302889 \times 10^{-2}$ & 1.36131 & {$[0.173]$} & \\
\hline$\beta_{4}$ & 0.125852 & 0.011755 & 10.7066 & {$[0.000]$} & \\
\hline$\beta_{5}$ & 0.040505 & 0.011278 & 3.59157 & {$[0.000]$} & \\
\hline$\beta_{6}$ & 0.023736 & $0.343047 \times 10^{-2}$ & 6.91918 & {$[0.000]$} & \\
\hline$\beta_{7}$ & 0.019669 & $0.381055 \times 10^{-2}$ & 5.16168 & {$[0.000]$} & \\
\hline$\beta_{8}$ & 0.030895 & $0.630004 \times 10^{-2}$ & 4.90401 & {$[0.000]$} & \\
\hline$\beta_{9}$ & 0.014019 & $0.262025 \times 10^{-2}$ & 5.35034 & {$[0.000]$} & \\
\hline$\beta_{10}$ & 0.495839 & 0.034905 & 14.2056 & {$[0.000]$} & \\
\hline$\beta_{11}$ & $0.998550 \mathrm{E}-02$ & $0.132607 \times 10^{-2}$ & 7.53012 & {$[0.000]$} & \\
\hline$\beta_{12}$ & 0.015352 & $0.459674 \times 10^{-2}$ & 3.33986 & {$[0.001]$} & \\
\hline$\beta_{13}$ & 0.022263 & $0.327487 \times 10^{-2}$ & 6.79803 & {$[0.000]$} & \\
\hline$\beta_{14}^{15}$ & $0.519011 \times 10^{-2}$ & $0.894363 \times 10^{-3}$ & 5.80313 & {$[0.000]$} & \\
\hline$\beta_{15}$ & 0.026245 & $0.433724 \times 10^{-2}$ & 6.05116 & {$[0.000]$} & \\
\hline$\beta_{16}$ & 0.018053 & $0.301987 \times 10^{-2}$ & 5.97806 & {$[0.000]$} & \\
\hline$\beta_{17}$ & 0.063438 & 0.019128 & 3.31650 & {$[0.001]$} & \\
\hline$\beta_{18}$ & 0.033914 & 0.016429 & 2.06430 & {$[0.039]$} & \\
\hline
\end{tabular}

(b) QES demand functions

\begin{tabular}{llllll}
\hline Parameter & Estimate & Standard error & t-statistic & P-value & $\begin{array}{l}\text { Necessary or } \\
\text { luxury }\end{array}$ \\
\hline$\gamma_{1}$ & 0.070871 & 0.053590 & 1.32245 & {$[0.186]$} & Necessary \\
$\gamma_{2}$ & 0.039669 & 0.024796 & 1.59979 & {$[0.110]$} & Necessary \\
$\gamma_{3}$ & 0.115262 & 0.020551 & 5.60846 & {$[0.000]$} & Necessary \\
$\gamma_{4}$ & 0.480078 & 0.229926 & 2.08796 & {$[0.037]$} & Necessary \\
$\gamma_{5}$ & 0.099774 & 0.127832 & 0.780511 & {$[0.435]$} & Necessary \\
\hline
\end{tabular}




\begin{tabular}{|c|c|c|c|c|c|}
\hline Parameter & Estimate & Standard error & t-statistic & P-palue & $\begin{array}{l}\text { Necessary or } \\
\text { luxury }\end{array}$ \\
\hline$\gamma_{6}$ & 0.391498 & 0.018534 & 21.1237 & {$[0.000]$} & Necessary \\
\hline$\gamma_{7}$ & 0.080583 & 0.020401 & 3.95005 & {$[0.000]$} & Necessary \\
\hline$\gamma_{8}$ & 0.087420 & 0.017896 & 4.88475 & {$[0.000]$} & Necessary \\
\hline$\gamma_{9}$ & 0.317509 & 0.065745 & 4.82941 & {$[0.000]$} & Necessary \\
\hline$\gamma_{10}$ & -0.529502 & 0.096029 & -5.51395 & {$[0.000]$} & Luxury \\
\hline$\gamma_{11}$ & 0.029980 & 0.028051 & 1.06876 & {$[0.285]$} & Necessary \\
\hline$\gamma_{12}$ & 0.160310 & 0.044777 & 3.58018 & {$[0.000]$} & Necessary \\
\hline$\gamma_{13}$ & 0.154329 & 0.050243 & 3.07163 & {$[0.002]$} & Necessary \\
\hline$\gamma_{14}$ & 0.081003 & 0.028083 & 2.88442 & {$[0.004]$} & Necessary \\
\hline$\gamma_{15}$ & 0.345633 & 0.054471 & 6.34522 & {$[0.000]$} & Necessary \\
\hline$\gamma_{16}$ & 0.162922 & 0.034245 & 4.75751 & {$[0.000]$} & Necessary \\
\hline$\gamma_{17}$ & 0.128512 & 0.084565 & 1.51968 & [0.129] & Necessary \\
\hline$\gamma_{18}$ & -0.021229 & 0.011690 & -1.81593 & {$[0.069]$} & Luxury \\
\hline$\gamma_{19}$ & 0.276885 & 0.046016 & 6.01716 & {$[0.000]$} & Necessary \\
\hline$\beta_{1}$ & 0.024773 & $0.345716 \times 10^{-2}$ & 7.16565 & {$[0.000]$} & \\
\hline$\beta_{2}$ & 0.023072 & $0.992866 \times 10^{-2}$ & 2.32381 & {$[0.020]$} & \\
\hline$\beta_{3}$ & $0.517157 \times 10^{-2}$ & $0.419188 \times 10^{-2}$ & 1.23371 & {$[0.217]$} & \\
\hline$\beta_{4}$ & 0.122591 & 0.016061 & 7.63267 & {$[0.000]$} & \\
\hline$\beta_{5}$ & 0.040612 & 0.012962 & 3.13315 & {$[0.002]$} & \\
\hline$\beta_{6}$ & 0.028987 & $0.415064 \times 10^{-2}$ & 6.98377 & {$[0.000]$} & \\
\hline$\beta_{7}$ & 0.027188 & $0.536029 \times 10^{-2}$ & 5.07206 & {$[0.000]$} & \\
\hline$\beta_{8}$ & 0.040054 & $0.858461 \times 10^{-2}$ & 4.66581 & {$[0.000]$} & \\
\hline$\beta_{9}$ & 0.016016 & $0.360116 \times 10^{-2}$ & 4.44746 & {$[0.000]$} & \\
\hline$\beta_{10}$ & 0.484387 & 0.035439 & 13.6682 & {$[0.000]$} & \\
\hline$\beta_{11}$ & 0.012671 & $0.185084 \times 10^{-2}$ & 6.84593 & {$[0.000]$} & \\
\hline$\beta_{12}$ & 0.016399 & $0.555363 \times 10^{-2}$ & 2.95285 & {$[0.003]$} & \\
\hline$\beta_{13}$ & 0.022483 & $0.414603 \times 10^{-2}$ & 5.42275 & {$[0.000]$} & \\
\hline$\beta_{14}$ & $0.658356 \times 10^{-2}$ & $0.122714 \times 10^{-2}$ & 5.36497 & {$[0.000]$} & \\
\hline$\beta_{15}$ & 0.033780 & $0.608252 \times 10^{-2}$ & 5.55364 & {$[0.000]$} & \\
\hline$\beta_{16}$ & 0.019430 & $0.368413 \times 10^{-2}$ & 5.27406 & {$[0.000]$} & \\
\hline$\beta_{17}$ & 0.085785 & 0.020878 & 4.10881 & {$[0.000]$} & \\
\hline$\beta_{18}^{17}$ & 0.090881 & 0.017931 & 5.06842 & {$[0.000]$} & \\
\hline$\alpha_{1}$ & 0.286232 & 0.050323 & 5.68788 & {$[0.000]$} & \\
\hline$\alpha_{2}$ & 0.015001 & 0.014291 & 1.04968 & {$[0.294]$} & \\
\hline$\alpha_{3}$ & -0.040826 & 0.017677 & -2.30954 & {$[0.021]$} & \\
\hline$\alpha_{4}$ & 0.590553 & 0.064234 & 9.19370 & {$[0.000]$} & \\
\hline$\alpha_{5}$ & 0.394066 & 0.051910 & 7.59135 & {$[0.000]$} & \\
\hline$\alpha_{6}$ & -0.176816 & 0.017026 & -10.3850 & {$[0.000]$} & \\
\hline$\alpha_{7}$ & 0.035180 & 0.012390 & 2.83935 & {$[0.005]$} & \\
\hline$\alpha_{8}^{\prime}$ & -0.038346 & $0.777920 \times 10^{-2}$ & -4.92932 & {$[0.000]$} & \\
\hline$\alpha_{9}$ & -0.109939 & 0.060901 & -1.80520 & {$[0.071]$} & \\
\hline$\alpha_{10}$ & -0.022113 & 0.010690 & -2.06863 & {$[0.039]$} & \\
\hline$\alpha_{11}$ & 0.042346 & 0.027991 & 1.51282 & {$[0.130]$} & \\
\hline$\alpha_{12}$ & 0.019435 & 0.033191 & 0.585551 & {$[0.558]$} & \\
\hline$\alpha_{13}$ & -0.012172 & 0.045456 & -0.267773 & {$[0.789]$} & \\
\hline$\alpha_{14}$ & $0.196070 \times 10^{-2}$ & 0.027587 & 0.071074 & {$[0.943]$} & \\
\hline$\alpha_{15}$ & 0.073099 & 0.036168 & 2.02111 & {$[0.043]$} & \\
\hline$\alpha_{16}$ & -0.046567 & 0.031862 & -1.46152 & {$[0.144]$} & \\
\hline$\alpha_{17}$ & -0.086285 & 0.037332 & -2.31126 & {$[0.021]$} & \\
\hline$\alpha_{18}$ & 0.012798 & $0.380874 \times 10^{-2}$ & 3.36023 & {$[0.001]$} & \\
\hline
\end{tabular}


When we check the values for $\gamma_{i}\left(\gamma_{i}\right.$ in the table) in the LES, commodities such as white maize attains (4), sunflower oil (10), white sugar (17), and tea (18) show a minus sign, indicating that the own-price elasticity of demand for the commodity is elastic in the LES demand function. On the other hand, commodities such as sunflower oil (10) and tea (18) are negative for the parameter $\gamma_{i}$ in the QES. This result does not contradict the result obtained by the Working-Leser demand functions that indicate price-elastic commodities such as white maize attains (4), sunflower oil (10), beans (dried) (13), and white sugar (17). Thus, we can conclude that almost all the food categories are classified as necessary goods and own-price inelastic goods.

\section{The Törnqvist-Wold hypothesis regarding necessities and luxuries}

The value of own-price elasticity classifies a commodity as a necessary good or a luxury good. When a commodity of the own price is inelastic - namely, the value of its price elasticity is between -1 and $0-$ it is classified as a necessary good, and if the value is less than -1 , it is classified as a luxury good. We usually define necessary and luxury goods regarding the value of the own-price elasticity of demand. However, we also have another definition for necessities.

We divide commodities and services into two categories. One is necessities, and the other is luxuries. According to Wold and Juréen (1953), when own-price elasticity is between -1 and 0 , the item is classified as a necessity. In their book, the researchers classified necessities and luxuries using the relationship combining own-price and total expenditure elasticities following Törnqvist:

Törnqvist groups the commodities into "necessities" and "luxuries," with price elasticity below and above unity, respectively. This leads to the conclusion that, as a rule, income elasticities of necessities are smaller than their price elasticities, whereas income elasticities of luxuries are greater than their price elasticities.

(Wold and Juréen 1953, p. 115)

This phenomenon is explained in the following manner: regarding elasticities of demand, we have three important characteristics in a complete demand system whose demand functions indicate homogeneity of degree zero:

(1) The sum of total expenditure elasticity, own-price elasticity, and cross-price elasticities for an $i$-th item is equal to zero.

$$
\begin{aligned}
& \left(\partial q_{i} / \partial x\right)\left(x / q_{i}\right)+\left(\partial q_{i} / \partial p_{1}\right)\left(p_{1} / q_{i}\right)+\ldots+\left(\partial q_{i} / \partial p_{i}\right)\left(p_{i} / q_{i}\right)+\ldots \\
& \quad+\left(\partial q_{i} / \partial p_{n}\right)\left(p_{n} / q_{i}\right)=0
\end{aligned}
$$

Or elasticity representation

$$
E q_{i} / E x+E q_{i} / E p_{1}+\ldots+E q_{i} / E p_{i}+\ldots+E q_{i} / E p_{n}=0
$$


where $E q_{i} / E p_{j}=\partial \log q_{i} / \partial \log p_{j}(j=1, \ldots, n)$, and $E q_{i} / E x=\partial \log q_{i} / \partial \log x$.

(2) Taking the expenditures for weight, the weighted average of the total expenditure elasticities is unity.

$$
\left[\Sigma_{i}\left(p_{i} q_{i}\right)\left(\partial q_{i} / \partial x\right)\left(x / q_{i}\right)\right] / \Sigma_{i}\left(p_{i} q_{i}\right)=1
$$

Or elasticity representation

$$
\sum_{i}\left(p_{i} q_{i}\right) E q_{i} / E x / \sum_{i}\left(p_{i} q_{i}\right)=1
$$

(3) Taking the expenditure for weights, the average of demand elasticities with respect to the price of a fixed commodity equals the minus of the proportion between the expenditure for the $i$-th item and total expenditure.

$$
\sum_{j}\left(p_{j} q_{j}\right)\left(\partial q_{j} / \partial p_{i}\right)\left(p_{i} / q_{j}\right) / \Sigma_{j}\left(p_{j} q_{j}\right)=-\left(p_{i} q_{i}\right) / x
$$

Or elasticity representation

$$
\sum_{j}\left(p_{j} q_{j}\right)\left(E q_{j} / E p_{i}\right) / \Sigma_{j}\left(p_{j} q_{j}\right)=-\left(p_{i} q_{i}\right) / x
$$

For the two-commodity (food and non-food) case, we obtain the following equation system from (1)

$$
\begin{aligned}
& E q_{1} / E x+E q_{1} / E p_{1}+E q_{1} / E p_{2}=0, \\
& E q_{2} / E x+E q_{2} / E p_{1}+E q_{2} / E p_{2}=0 .
\end{aligned}
$$

We assume that the own-price elasticity of Commodity 1 is inelastic - namely, that it is classified as a necessity according to the Törnqvist-Wold hypothesis. We focus on the characteristic of Commodity 1 to derive the Törnqvist-Wold hypothesis. We obtain the following equation system from (3):

$$
\begin{aligned}
& \left(p_{1} q_{1}\right)\left(E q_{1} / E p_{1}\right)+\left(p_{2} q_{2}\right)\left(E q_{2} / E p_{1}\right)=-\left(p_{1} q_{1}\right) \\
& \left(p_{1} q_{1}\right)\left(E q_{1} / E p_{2}\right)+\left(p_{2} q_{2}\right)\left(E q_{2} / E p_{2}\right)=-\left(p_{2} q_{2}\right)
\end{aligned}
$$

From the second equation of Equation (23), we obtain:

$$
\begin{aligned}
\left(E q_{1} / E p_{2}\right) & =-\left[\left(p_{2} q_{2}\right) /\left(p_{1} q_{1}\right)\right]\left(E q_{2} / E p_{2}\right)-\left(p_{2} q_{2}\right) /\left(p_{1} q_{1}\right) \\
& =-\left[\left(p_{2} q_{2}\right) /\left(p_{1} q_{1}\right)\right]\left(E q_{2} / E p_{2}+1\right)
\end{aligned}
$$

Let us consider the following two cases: one is that Commodity 2 is own-price elastic, and the other is that it is own-price inelastic. When Commodity 2 is own-price elastic - namely, $E q_{2} / E p_{2}$ is less than -1 - the cross-price elasticity of 
demand, $E q_{1} / E p_{2}$, is positive and therefore $E q_{1} / E x+E q_{1} / E p_{1}<0$ when substituting $E q_{1} / E p_{2}$ into the first equation of Equation (22). When the total expenditure elasticity of demand is less than the absolute value of the own-price elasticity of demand, $E q_{1} / E x<-E q_{1} / E p_{1}$, this leads to the Törnqvist-Wold hypothesis: as a rule, income elasticities of necessities are smaller than their price elasticities.

When Commodity 2 is own-price inelastic - namely, $-1<E q_{2} / E p_{2}<0$ - the cross-price elasticity of demand, $E q_{1} / E p_{2}$, is negative and therefore $E q_{1} / E x+$ $E q_{1} / E p_{1}>0$ after substituting $E q_{1} / E p_{2}$ into the first equation of Equation (22). When the total expenditure elasticity of demand is greater than the absolute value of the own-price elasticity of demand, $E q_{1} / E x>-E q_{1} / E p_{1}$, this leads to the counter-conclusion of the Törnqvist-Wold hypothesis that as a rule, income elasticities of necessities are larger than their price elasticities.

It is not difficult to verify the Törnqvist-Wold hypothesis in the two-commodity case because it is easy to check the movement of two factors, $E q_{1} / E p_{2}$ and $E q_{2} / E p_{2}$, in addition to $E q_{1} / E x$ and $E q_{1} / E p_{1}$. However, if we extend the model to the $n$-commodity case, it becomes much more complex than the two-commodity case to verify the Törnqvist-Wold hypothesis. Let us expand the two-commodity to the $n$-commodity case. From the first characteristics:

$$
\left(\partial q_{i} / \partial x\right)\left(x / q_{i}\right)+\left(\partial q_{i} / \partial p_{1}\right)\left(p_{1} / q_{i}\right)+\ldots+\left(\partial q_{i} / \partial p_{n}\right)\left(p_{n} / q_{i}\right)=0
$$

From this equality of Equation (25), we obtain

$$
\begin{aligned}
& \left(\partial q_{i} / \partial x\right)\left(x / q_{i}\right)+\left(\partial q_{i} / \partial p_{i}\right)\left(p_{i} / q_{i}\right)=-\left(\partial q_{i} / \partial p_{1}\right)\left(p_{1} / q_{i}\right)-\ldots \\
& \quad-\left(\partial q_{i} / \partial p_{n}\right)\left(p_{n} / q_{i}\right)
\end{aligned}
$$

Or elasticity representation

$$
E q_{i} / E x+E q_{i} / E p_{i}=-\left(E q_{i} / E p_{1}+E q_{i} / E p_{2}+\ldots+E q_{i} / E p_{n}\right)
$$

When the sum of the total expenditure elasticity and own-price elasticity is negative namely, the total expenditure elasticity is less than the absolute value of the own-price elasticity, $\left(\partial q_{i} / \partial x\right)\left(y / q_{i}\right)<-\left(\partial q_{i} / \partial p_{1}\right)\left(p_{1} / q_{i}\right)$ - the following inequality is satisfied:

$$
\sum_{j}\left(\partial q_{i} / \partial p_{j}\right)\left(p_{j} / q_{i}\right)>0 . .^{8}
$$

This indicates that the sum of the cross-price elasticities for the $i$-th commodity is positive, and the $i$-th commodity is classified as a necessity according to the results obtained in the two-commodity case. On the other hand, when the total expenditure elasticity is greater than the absolute value of the own-price elasticity, $\left(\partial q_{i} / \partial x\right)\left(x / q_{i}\right)>-\left(\partial q_{i} / \partial p_{1}\right)\left(p_{1} / q_{i}\right)$, the following inequality is satisfied:

$$
\sum_{j}\left(\partial q_{i} / \partial p_{j}\right)\left(p_{j} / q_{i}\right)<0.9
$$

This indicates that the sum of the cross-price elasticities is negative and that the $i$-th commodity is classified as a luxury good. However, we cannot obtain the 
exact relationship between the cross-price elasticities, $E q_{i} / E p_{j}(j \neq i, j=1,2, \ldots$, $n)$, and the own-price elasticity, $E q_{j} / E p_{j}(j \neq i, j=1,2, \ldots, n)$, mathematically. We also have difficulty in estimating the cross-price elasticities, $E q_{i} / E p_{j}(j \neq i$, $j=1,2, \ldots, n)$, stably using the demand function for the $i$-th commodity. For these reasons, we examine the validity of the Törnqvist-Wold hypothesis empirically using the empirical results obtained by the real-world data. The aforementioned condition is indicated in Table 2.8 and Figure 2.3.

Table 2.8 The classification between necessities and luxuries based on the TörnqvistWold hypothesis and the alternative hypothesis

(a) Törnqvist-Wold hypothesis

\begin{tabular}{lll}
\hline (1) & $-1<$ own-price elasticity $<0$ & Necessities \\
(2) & Own-price elasticity $<-1$ & \\
(2.a) & $\begin{array}{c}\text { Total expenditure elasticity }<\text { absolute value of own-price } \\
\text { elasticity }\end{array}$ & Necessities \\
(2.b) & $\begin{array}{c}\text { Total expenditure elasticity }>\text { absolute value of own-price } \\
\text { elasticity }\end{array}$ & Luxuries \\
\hline
\end{tabular}

(b) Alternative hypothesis

\begin{tabular}{lll}
\hline (1) & $-1<$ own-price elasticity $<0$ & Necessities \\
$(2)$ & Own-price elasticity $<-1$ & \\
(2.a) & $\begin{array}{c}\text { Total expenditure elasticity }<\text { absolute value of own-price } \\
\text { elasticity }\end{array}$ & Luxuries \\
(2.b) & $\begin{array}{c}\text { Total expenditure elasticity }>\text { absolute value of own-price } \\
\text { elasticity }\end{array}$ & Necessities \\
\hline
\end{tabular}

(a)

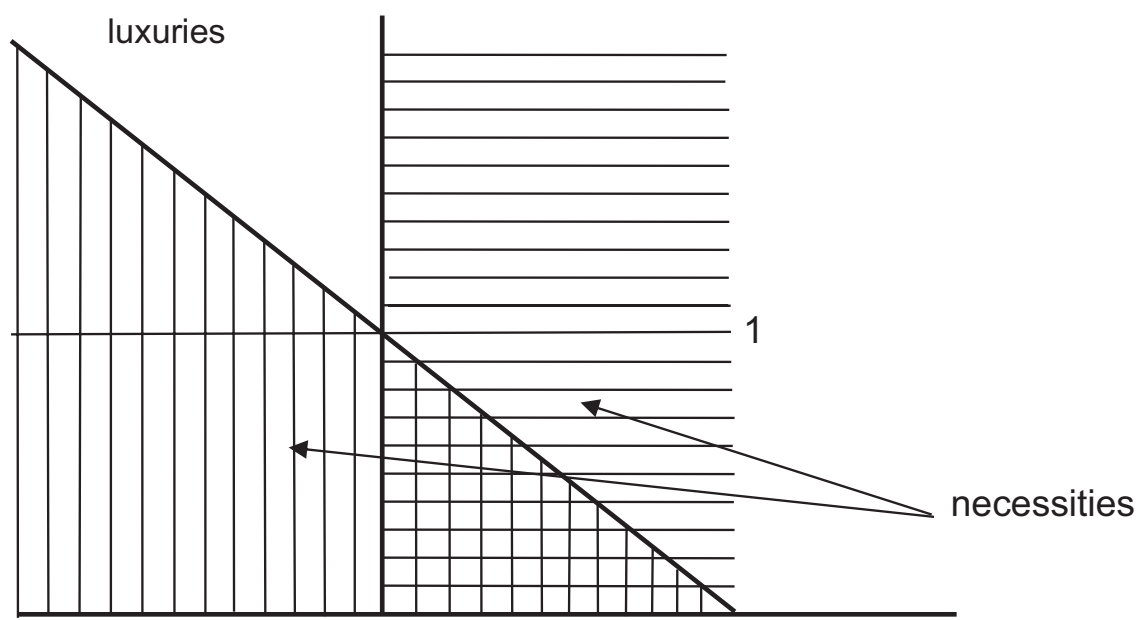

Figure 2.3 Graphic representation of necessities and luxuries 
(b)

total

expenditure elasticity

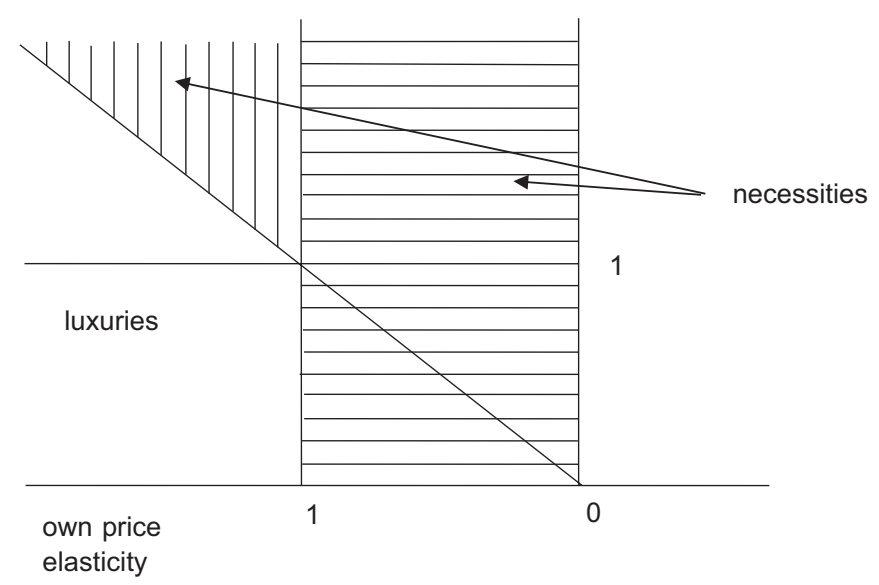

Figure 2.3 (Continued)

From Figure 2.3, we can understand the characteristics of the Törnqvist-Wold hypothesis and the alternative hypothesis; the range of necessities is wider in the Törnqvist-Wold hypothesis compared with the alternative hypothesis. This is because the category of necessities includes not only own-price inelastic goods but also some luxury goods whose total expenditure elasticities are smaller than their own-price elasticities. To the extent that policy makers rely on the Törnqvist-Wold hypothesis in formulating anti-poverty programs, this could have important implications.

\section{Comparisons of empirical findings conducted by Deaton $(1987,1988,1990)$ and Maki $(1998,2002)$ regarding the validity of the Törnqvist-Wold hypothesis}

We checked the magnitude between the total expenditure elasticity and own-price elasticity whose elasticity is elastic in order to classify the commodity as either a necessity or a luxury according to the Törnqvist-Wold hypothesis and the alternative hypothesis in Tanzania. Table 2.9 indicates that almost all commodities are necessities based on the Törnqvist-Wold hypothesis. In contrast, four commodities - white maize attains (4), sunflower oil (10), beans (dried) (13), and white sugar (17) - are classified as luxuries based on the alternative hypothesis.

Deaton $(1987,1988,1990)$ conducted a series of seminal studies estimating the own-price and cross-price elasticities of demand from cross-sectional data for Cote d'Ivoire and Indonesia. In Deaton (1987), the data is derived from five 
Table 2.9 Necessities or luxuries based on elasticity of demand: the Törnqvist-Wold hypothesis versus the alternative hypothesis

\begin{tabular}{lccll}
\hline Commodity & $\begin{array}{l}\text { Total } \\
\text { expenditure } \\
\text { elasticity }\end{array}$ & $\begin{array}{l}\text { Price } \\
\text { elasticity }\end{array}$ & $\begin{array}{l}\text { Törnqvist-Wold } \\
\text { bypothesis }\end{array}$ & $\begin{array}{l}\text { Alternative } \\
\text { hypothesis }\end{array}$ \\
\hline (1) Rice & 0.53 & -0.34 & Necessities & Necessities \\
(2) Wheat & 1.05 & -0.61 & Necessities & Necessities \\
(3) Burns (wheat) & 0.39 & -0.45 & Necessities & Necessities \\
(4) White maize attains & 0.59 & -1.47 & Necessities & Luxuries \\
(5) Maize flour white & 0.14 & 0.3 & Not defined & Not defined \\
(6) Beef with bones & 0.42 & -0.15 & Necessities & Necessities \\
(7) Fresh, chilled, or & 0.95 & -0.72 & Necessities & Necessities \\
frozen fish & 0.66 & -0.68 & Necessities & Necessities \\
(8) Dried small fish & 0.58 & -0.36 & Necessities & Necessities \\
(9) Fresh cow milk & 1.32 & -2.3 & Necessities & Luxuries \\
(10) Sunflower oil & 0.66 & -0.53 & Necessities & Necessities \\
(11) Oranges & 0.18 & -0.36 & Necessities & Necessities \\
(12) Broad beans & 0.15 & -1.04 & Necessities & Luxuries \\
(13) Beans (dried) & 0.82 & -0.58 & Necessities & Necessities \\
(14) Tomatoes (round) & 0.04 & -0.46 & Necessities & Necessities \\
(15) Cooking bananas & & & & \\
(plantains) & 0.58 & -0.31 & Necessities & Necessities \\
(16) Brown sugar & 0.29 & -2.03 & Necessities & Luxuries \\
(17) White sugar & 1.95 & -0.3 & Necessities & Necessities \\
(18) Tea & 0.42 & -0.32 & Necessities & Necessities \\
(19) Coca-Cola & & & &
\end{tabular}

categories of food expenditure: Meat, Fresh Fish, Other Fish, Starches, and Cereals. In Deaton (1988), the total expenditure and own-price elasticity of demand are analyzed for eight categories of food: Beef, Fish, Imported Rice, Domestic Rice, Maize, Yams, Plantain, and Cassava. Deaton (1990), using Indonesian household survey data, estimated total expenditure and own- and cross-price elasticities for eleven clusters of commodities: Rice, Wheat, Maize, Cassava, Roots, Vegetables, Legumes, Fruits, Meat, Fresh Fish, and Dried Fish. Maki (1998, 2002 ) used household data of eight broader items for Japan and that of seven broader items for New Zealand.

We compare the present estimation result with the existing observation reported by Deaton $(1987,1988,1990)$ and Maki $(1998,2002)$ in Table 2.10(a)-(e).

First we evaluate the empirical observation based on the Törnqvist-Wold hypothesis. Looking at the previous table, we can see that almost all commodities and services are classified as necessities. However, some categories are luxuries based on the Törnqvist-Wold hypothesis such as cereals in Cote d'Ivoire (Table 2.10[a]), and meat in Indonesia (Table 2.10[c]). In Japan and New Zealand, all the items are classified as necessities, even though the absolute value of the price elasticity is greater than unity in New Zealand (Table 2.10[e]). 
Table 2.10 Comparison of the present analysis with past findings

(a) Total and price elasticities for particular commodities in Cote d'Ivoire (from Table 3 in Deaton [1988])

\begin{tabular}{lccll}
\hline Commodity & $\begin{array}{l}\text { Total } \\
\text { expenditure } \\
\text { elasticity }\end{array}$ & $\begin{array}{l}\text { Price } \\
\text { elasticity }\end{array}$ & $\begin{array}{l}\text { Törnqvist-Wold } \\
\text { bypothesis }\end{array}$ & $\begin{array}{l}\text { Alternative } \\
\text { bypothesis }\end{array}$ \\
\hline Meat & 1.305 & -0.739 & Necessities & Necessities \\
Cereals & 1.091 & -1.076 & Luxuries & Necessities \\
Starches & 0.84 & -0.847 & Necessities & Necessities \\
Fresh fish & 0.682 & -1.575 & Necessities & Luxuries \\
Other fish & 0.536 & -1.189 & Necessities & Luxuries \\
\hline
\end{tabular}

(b) Total and price elasticities for particular commodities in Cote d'Ivoire (from Table 4 in Deaton [1988])

\begin{tabular}{lccll}
\hline Commodity & $\begin{array}{l}\text { Total } \\
\text { expenditure } \\
\text { elasticity }\end{array}$ & $\begin{array}{l}\text { Price } \\
\text { elasticity }\end{array}$ & $\begin{array}{l}\text { Törnqvist-Wold } \\
\text { bypothesis }\end{array}$ & $\begin{array}{l}\text { Alternative } \\
\text { bypothesis }\end{array}$ \\
\hline Beef & 1.56 & -1.91 & Necessities & Luxuries \\
Fish & 0.74 & -1.31 & Necessities & Luxuries \\
Imported rice & 0.73 & -1.4 & Necessities & Luxuries \\
Domestic rice & 0.73 & -1.02 & Necessities & Luxuries \\
Maize & 0.52 & -1.19 & Necessities & Luxuries \\
Yams & 1 & -1.49 & Necessities & Luxuries \\
Plantain & 0.95 & -1.41 & Necessities & Luxuries \\
Cassava & 0.85 & -0.91 & Necessities & Necessities \\
\hline
\end{tabular}

(c) Own-price elasticities for Java, Indonesia (from Tables 5a and 5b in Deaton [1990])

\begin{tabular}{lclll}
\hline Commodity & $\begin{array}{l}\text { Total } \\
\text { expenditure } \\
\text { elasticity }\end{array}$ & $\begin{array}{l}\text { Price } \\
\text { elasticity }\end{array}$ & $\begin{array}{l}\text { Törnqvist-Wold } \\
\text { bypothesis }\end{array}$ & $\begin{array}{l}\text { Alternative } \\
\text { bypothesis }\end{array}$ \\
\hline Rice & 0.49 & -0.424 & Necessities & Necessities \\
Wheat & 1.567 & -0.692 & Necessities & Necessities \\
Maize & 0.088 & -0.822 & Necessities & Necessities \\
Cassava & 0.139 & -0.325 & Necessities & Necessities \\
Roots & 0.709 & -0.953 & Necessities & Necessities \\
Vegetables & 0.67 & -1.113 & Necessities & Luxuries \\
Legumes & 0.85 & -0.954 & Necessities & Necessities \\
Fruit & 1.385 & -0.953 & Necessities & Necessities \\
Meat & 2.296 & -1.091 & Luxuries & Necessities \\
Fresh fish & 1.082 & -0.762 & Necessities & Necessities \\
Dried fish & 0.566 & -0.239 & Necessities & Necessities \\
\hline
\end{tabular}


Table 2.10 (Continued)

(d) Elasticities of demand for total expenditure and prices in Japan (from Table 5 in Maki [1998])

\begin{tabular}{lccc}
\hline Item & $\begin{array}{l}\text { Total } \\
\text { expenditure } \\
\text { elasticity }\end{array}$ & $\begin{array}{l}\text { Price } \\
\text { elasticity }\end{array}$ & $\begin{array}{l}\text { Necessities } \\
\text { or luxuries }\end{array}$ \\
\hline Food, beverages, and tobacco & 0.56 & -0.51 & Necessities \\
Clothing and footwear & 0.7 & -0.76 & Necessities \\
Gross rent, fuel, and power & 1.35 & -0.4 & Necessities \\
Household equipment and & 1.08 & -0.31 & Necessities \\
$\quad$ operation & 1.38 & -0.78 & Necessities \\
Medical and health care & 1.09 & -0.45 & Necessities \\
Transport and communication & 1.2 & -0.73 & Necessities \\
Education, recreation, and culture & 0.96 & -0.57 & Necessities \\
Miscellaneous goods and services & & & \\
\hline
\end{tabular}

(e) Elasticities of demand for total expenditure and prices in New Zealand (from Table 3 in Maki [2002])

\begin{tabular}{lccll}
\hline Item & $\begin{array}{l}\text { Total } \\
\text { expenditure } \\
\text { elasticity }\end{array}$ & $\begin{array}{l}\text { Price } \\
\text { elasticity }\end{array}$ & $\begin{array}{l}\text { Törnqvist-Wold } \\
\text { bypothesis }\end{array}$ & $\begin{array}{l}\text { Alternative } \\
\text { bypothesis }\end{array}$ \\
\hline Food & 0.74 & -0.48 & Necessities & Necessities \\
Housing & 1.08 & -0.45 & Necessities & Necessities \\
Household operation & 0.71 & -1.96 & Necessities & Luxuries \\
Apparel & 1.14 & -0.68 & Necessities & Necessities \\
Transportation & 1.12 & -1.45 & Necessities & Luxuries \\
Other goods & 1.04 & -0.45 & Necessities & Necessities \\
Other services & 1.27 & -0.14 & Necessities & Necessities \\
\hline
\end{tabular}

Based on the alternative hypothesis, the number of luxuries increases; fresh fish and other fish in Cote d'Ivoire (Table 2.10[a]), beef, fish, imported rice, domestic rice, maize, yams, and plantain in Cote d'Ivoire (Table 2.10[b]); vegetables in Indonesia (Table 2.10[c]); and household operation and transportation (Table 2.10[e]) are classified as luxuries. Particularly in Table 2.10(b), one out of eight commodities is a luxury based on the alternative hypothesis.

Our findings suggest that the Törnqvist-Wold hypothesis is better than the alternative hypothesis in identifying necessities and luxuries in household consumption categories. Necessities are consumed in order to maintain a subsisting living standard, and therefore goods and services are classified as necessities. Focusing on policy implications, it is better to broadly recognize goods and 
services as necessities in order to improve the national living standard, especially among lower total expenditure households.

\section{Conclusion}

In the present analysis, we tested the validity of the downward-sloping Engel curve using cross-sectional data in Tanzania, one of the developing countries in Africa. Since we verified the validity of Engel's Law in various developed countries, we are interested in determining whether the downward-sloping Engel curve is also evident in developing countries. This issue has important policy implications because the absolute poverty problem is serious in developing countries, and it is therefore important to have a detailed understanding of food consumption patterns among households in different total expenditure groups.

Our empirical findings in the present analysis are as follows: first, contrary to Engel's Law, we find that the Engel curve is upward sloping in the very poor households whose caloric intake for the daily food expenditure evaluated by the adult equivalence scale is less than 2,200 calories, meaning that food expenditure as a share of total expenditure increases among the very poor. When the total expenditure adjusted by the adult equivalence scale increases, the very poor households increase their food expenditure more than the increase in total expenditure because the total expenditure elasticity for the very poor households is greater than unity. This behavior is well described by the specification of the QUAID system. In Table 2.4, the total expenditure elasticity has a value greater than unity in the lowest deciles based on the results of both the OLS and quantile regressions.

Second, regarding micro-data analysis, nonparametric regression plays an important role before estimating econometric models based on economic theory conducting parametric analysis. Using the micro-data set, it is difficult to obtain the true relationship because of "noise," so we obtain much more information utilizing not only the OLS regression but also the quantile regressions. By using first-quartile, median, and third-quartile regressions, we clarify the data dispersion in much more detail. As it is difficult to exclude heteroskedasticity in the micro-data set, we obtained extra information using the micro-data set by utilizing a couple of test statistics applied to the quantile regressions.

Third, regarding economic and social policy, the upward-sloping Engel curve suggests that poverty alleviation and economic development programs have not had an impact on the poorest households and that more targeted assistance is crucial.

Based on the aforementioned findings regarding the inverse U-shaped Engel curve, we consider the characteristics of necessities and luxuries utilizing not only total expenditure elasticity but also own-price elasticity in the theory of consumer demand. The objective of the analysis is to estimate the elasticity of demand for total expenditure and prices regarding food categories. This information is important for the government to target subsidies and other transfer payments to maintain the standard of living and support the most vulnerable populations. 
During bad harvests, because of price increases in necessities, the standard of living in the nation decreases. When we have information regarding the price elasticity of demand, it is possible to fine-tune subsidies and the distribution of necessities in order to mitigate the negative impact of inflation and shortages.

In the consumer demand theory, we have two possibilities to define necessities and luxuries: one is the Törnqvist-Wold hypothesis, and the other is the alternative hypothesis. Theoretically, both hypotheses are reasonable. After confirming the existing empirical observations, we found that the Törnqvist-Wold hypothesis is more suitable for explaining the real-world observations.

Regarding the empirical results by Deaton (1987, 1988, 1990) and Maki (1998, 2002), we know that almost all the food commodities and broader items for households indicated in Table 2.10(d) and (e) are necessities, although some particular commodities - such as meat, for example - are classified as luxuries in Indonesia.

This empirical analysis clarifies the utility of measuring household demand and price elasticities for basic necessities in order to improve programs targeting poor households. Such policy is very important to mitigate absolute poverty in developing countries and develop more effective anti-poverty programs.

Turning to the original problem that certain food items are classified as luxury goods in the very poor households while being classified as necessities in the poor and non-poor households in Tanzania, we can see that food expenditure is classified as a necessity according to the Törnqvist-Wold hypothesis because own-price elasticity for the food category as a whole is inelastic, as indicated in Tables 2.6 and 2.9. When economists evaluate a commodity or service as a necessity or luxury only using cross-sectional data, they sometimes misunderstand the data because they overlook the price effects.

\section{Notes}

1 As mentioned in the Introduction chapter of this monograph, we found a U-shaped Engel curve in Indonesia in the 2001 data and also found a U-shaped Engel curve excluding in-kind consumption from total expenditure in several countries such as Indonesia in 2006, the Philippines, Vietnam, and so forth.

2 Generally speaking, the contents of the food category in a given society are nearly similar for all households, even in developed countries.

3 We distinguish necessary goods and necessities and luxury goods and luxuries in the following manner: necessary goods and luxury goods are used to classify the characteristics of demand solely concentrating on the total expenditure elasticity or own-price elasticity. Necessary goods are directly connected with necessities, while luxury goods defined by own-price elasticity are not necessarily luxuries, and luxury goods defined by total expenditure elasticity are not necessarily luxuries. Necessities and luxuries are defined based on the consumer theory of demand in Section 5 of this chapter.

4 When we consider the estimating process for the food poverty line, the adult equivalence scale plays an important role for food expenditure related to caloric intake. However, it is difficult to make a direct link between the adult equivalence scale and non-food expenditures. There are relatively many categories in non-food expenditures that are strongly related to factors other than calories. For example, 
educational expenditures are strongly connected with the number of children and their ages within the household.

5 Banks, Blundell, and Lewbel (1997) reported in their analysis that the almost ideal demand (AID) system is sufficient to explain the expenditure share on food in the Family Expenditure Survey (FES) in the UK for the period between 1980 and 1982. This is mainly due to the shape of the food expenditure share in the observation data. The food expenditure share in the UK data decreases monotonically as total expenditure increases in the observation period.

6 We introduce the estimation results by the QUAID system, applying the OLS and the quantile regression method for the first quartile $\left(Q_{1}\right)$, the second quartile (median), and the third quartile $\left(Q_{3}\right)$, respectively. We usually observe a small value for Engel's coefficient, even in the very poor households. The previous table indicates that the minimum value for Engel's coefficient in the lowest total expenditure deciles (VI in Table 2.2) among the very poor households is 0.20 percent, indicating that very poor households purchased almost nothing for food items during the survey period. There are some reasonable explanations for this finding: (1) members of the household stayed at their friends' houses as guests and consumed food without any charge; (2) a household purchased no food commodities for the survey period of one month for some unexplained reason and reported zero expenditure in the survey; (3) a household reported nothing due to misreporting on in-kind consumption for food; and (4) a household forgot to report its food expenditure, though it purchased food categories during the one-month period (Maki and Nishiyama 1996). However, the weight of very poor households in Tanzania is above 10 percent ( 1,000 households) and thus cannot be ignored.

7 Due to the Törnqvist-Wold hypothesis, sunflower oil (10) is classified as a necessity, as indicated in Table 2.9.

8 This means that $E q_{1} / E p_{2}$ is positive in the two-commodity case.

9 This means that $E q_{1} / E p_{2}$ is negative in the two-commodity case.

\section{References}

Banks, J., R. Blundell and A. Lewbel (1997), "Quadratic Engel curves and consumer demand," Review of Economics and Statistics, 79, 527-539.

Cameron, A. C. and P. K. Trivedi (2005), Microeconometrics: Methods and Applications. Cambridge University Press: Cambridge, UK.

Deaton, A. (1987), "Estimation of own- and cross-price elasticities from household survey data," Journal of Econometrics, 36, 7-30.

Deaton, A. (1988), "Quality, quantity, and special variation of price," American Economic Review, 78, 418-430.

Deaton, A. (1990), "Price elasticities from survey data - Extensions and Indonesian results," Journal of Econometrics, 44, 281-309.

Deaton, A. (1997), The Analysis of Household Surveys: A Microeconometric Approach to Development Policy. Johns Hopkins University Press: Baltimore, MD.

Deaton, A. and J. Muellbauer (1980), "An almost ideal demand system," American Economic Review, 70, 312-336.

Engel, E. (1895), Die Lebenskosten belgischer Arbeiter-familien fruber und jetzt. C. Heinrich: Dresden.

Greene, W. H. (2012), Econometric Analysis. 6th edition, Pearson: New York.

Howe, H., R. A. Pollak and T. J. Wales (1979), "Theory and time series estimation of the quadratic expenditure system," Econometrica, 47, 1231-1247. 
Koenker, R. (2005), Quantile Regression. Cambridge University Press: Cambridge, UK. Koenker, R. and G. Bassett, Jr. (1978), "Regression quantiles," Econometrica, 46, 33-50.

Koenker, R. and G. Bassett, Jr. (1982), "Robust tests for heteroscedasticity based on regression quantiles," Econometrica, 50, 43-61.

Maki, A. (1998), "How high consumer prices are in Japan!" Japan and the World Economy, 10, 173-186.

Maki, A. (2002), "Changes in New Zealand consumer living standards during the period of deregulation 1984-1996," Economic Record, 78, 443-450.

Maki, A. and S. Nishiyama (1996), "An analysis of under-reporting for micro-data sets: The misreporting or double hurdle model," Economics Letters, 52, 211-220.

Stigler, G. J. (1954), “The early history of empirical studies of consumer behavior," Journal of Political Economy, 62, 95-113.

Stone, J.R.N. (1954), "Linear expenditure systems and demand analysis: An application to the pattern of British demand," Economic Journal, 64, 511-527.

Wold, H. and L. Juréen (1953), Demand Analysis: A Study in Econometrics. John Wiley \& Sons: New York. 


\title{
3 Engel's Law in Vietnam and the Philippines
}

\author{
Effects of in-kind consumption \\ on inequality and poverty
}

\section{Atsushi Maki and Satoshi Ohira}

\section{Introduction}

In developing economies, many transactions occur outside of markets and involve the bartering of goods and services. The challenge for economists is to capture the extent and impact of such in-kind transactions; not to do so creates an erroneous impression of living standards and patterns of consumption. This paper focuses on the Philippines and Vietnam, where poverty alleviation programs play a critical role in maintaining minimal living standards, making it essential to understand how impoverished households make ends meet through in-kind transactions.

Economists treat in-kind consumption as non-cash-based consumption as opposed to cash-based consumption. Viewed in terms of the scope of the transaction process, in-kind consumption is treated as a household consumption expenditure without through markets. When the consumer obtains goods outside of markets, the goods obtained through such transactions without money-based exchange are called in-kind goods.

In-kind consumption plays an important role for the poor in developed and developing countries. In the cases of developed countries, the role of in-kind transaction is especially relevant to government subsidy programs. Economists theoretically and empirically question the role of in-kind consumption and whether or not there are any differences between in-kind and cash transfers. The answer, according to standard neoclassical theory, is that there is no difference between the two. Consumers maximize their utility subject to their budget constraints. If the amount of transfer from the government is excessive, households will resell some of the received resources to others; if the amount is inadequate, they will seek to buy additional resources by trading some of their initial endowments. From this standard perspective, the only important aspect of the government subsidy program is the amount of additional resources provided, not the type of resources. For this reason, the difference between in-kind and cash transfers is not considered.

Government subsidy programs tend to provide in-kind transfers rather than cash transfers. Some research empirically examines cases where in-kind and cash transfers have a different impact. ${ }^{1}$ They assume market imperfection as a 
hypothesis and assume that the government's subsidies based on in-kind transfer deviate from the market optimum. Fraker (1990), for example, examines the different policy impacts of in-kind and cash transfers.

In contrast, there are studies that support the standard neoclassical view that the impact of in-kind and cash transfers is similar (Slesnick 1996; Hoynes and Schanzenbach 2009). Slesnick (1996) empirically analyzed the effect of in-kind subsidies for food, housing, and health care provided by the US government using the Consumer Expenditure Survey (CEX) compiled by the Bureau of Labor Statistics. He concluded that multiple goods transfers are essentially equivalent to cash grants and that in-kind transfers by the government have a positive impact regarding the improvement in living standards on poor households. Hoynes and Schanzenbach (2009) analyzed the effect of the Food Stamp Program (FSP) in the US as a case study of in-kind transfer programs using the Panel Survey of Income Dynamics (PSID). They concluded that households respond similarly to US \$1 in cash income and US $\$ 1$ in food stamps and that due to the introduction of the FSP, overall food expenditure increased while out-of-pocket food spending decreased.

Cash (or credit card) transactions dominate in advanced market economies. In developed countries, government subsidies are the main source of in-kind consumption. However, to better understand developing economies, it is essential to understand the dynamics of in-kind transactions because they are a significant factor influencing household consumption and welfare. Generally, in developing countries, sources of in-kind consumption include: (1) subsidies for food, housing, and health care through coupons and other instruments distributed by the government; (2) consumption of food or housing-related goods produced by households as household production, especially by agricultural households; (3) barter of food between households in rural areas; and (4) gifts of food from neighbors or communities.

In our analysis, we examine the validity of Engel's Law in developing countries i.e. does food as a percentage of household spending decline with rising income, and how is this influenced by observed patterns of in-kind consumption? Engel's Law is one of the most important empirical laws for analyzing consumer behavior and has been verified by cross-sectional data from many countries. The downward-sloping Engel curve demonstrates the negative correlation between income (or total expenditure) and the proportion spent on food. However, the negative correlation between the two is not always validated by family expenditure surveys conducted in developing countries. For example, Kedir and Girma (2007) estimated quadratic Engel curves using the 1994 Ethiopian Urban Household Survey. Maki and Kamwe (2012) analyzed consumer behavior in Tanzania using the 2007 Tanzanian Household Budget Survey (HBS). They found a hump-shaped Engel curve where the hump or peak of Engel's coefficient appears in those households classified as very poor.

In the present analysis, using the 2006 Vietnam Housebold Living Standard Survey compiled by the Statistics Bureau in Vietnam and the 2006 Family Income and Expenditure Survey compiled by the National Statistical Office of the Philippines, we again found an inverse U- shaped Engel curve when we excluded 
in-kind consumption from total expenditure in the survey. This indicates that as cash-based total consumption expenditure increases, Engel's coefficient excluding in-kind food consumption (i.e. food purchases as a proportion of cash-based total expenditure) increases in low-income households, and Engel's coefficient excluding in-kind consumption reaches its maximum value among these low-income households. After reaching the peak, Engel's coefficient decreases monotonically as total consumption expenditure increases. The hump-shaped Engel curve leads to two interesting conclusions regarding empirical analysis of consumer behavior. The first is that Engel's Law does not always hold, particularly among poor households in developing countries. The second is that the income elasticity of demand for food is elastic in the left-hand side of the income level where Engel's coefficient peaks. Though we usually observe that income elasticity for food expenditure is inelastic, this is not true among poor households excluding in-kind consumption in Vietnam and in the Philippines and including both cash and in-kind consumption in Ethiopia and Tanzania.

Based on the Vietnam Household Living Standard Survey and the Family Income and Expenditure Survey in the Philippines, we focus on three issues: (1) the shape of the Engel curve, particularly in low-income households whether or not an inverse U-shaped Engel curve exists; (2) the specification of the adult equivalence scale and changes in inequality measures such as the Gini coefficient, depending on the different specifications of the adult equivalence scale; and (3) the role of in-kind consumption of food and non-food expenditures in consumer behavior.

Section 2 explains the characteristics of the 2006 Vietnam Household Living Standard Survey and the 2006 Family Income and Expenditure Survey in the Philippines and reports basic statistics. Several types of the adult equivalence scale are introduced in order to test the changes in the values of the Gini coefficient when the definition of the adult equivalence scale differs. We report the degree of inequality in Vietnam and the Philippines using the Gini coefficient. We also calculate two kinds of inequality measures - namely, the Gini index including and excluding in-kind consumption.

Section 3 considers poverty in Vietnam and the Philippines from the perspective of the Engel curves. We report the shape of the Engel curves utilizing nonparametric and parametric approaches. Section 4 considers the role of in-kind consumption in developing countries, and Section 5 evaluates the results obtained by the analysis of Tanzania (for details, refer to Chapter 2 of this book), Vietnam, and the Philippines. Finally, in Section 6 we summarize the empirical results and evaluate policy implications.

\section{Data used for empirical analysis of consumer behavior in Vietnam and the Philippines}

\subsection{Data source}

In the present analysis, we use the micro-data set of the 2006 Vietnam Household Living Standards Survey compiled by the Statistics Bureau in Vietnam and the 2006 Family Income and Expenditure Survey compiled by the National Statistical 
Office of the Philippines. The surveys reported consumption expenditures for commodities and services; household characteristics such as the number of household members and their ages and occupations; and household income, assets, and liabilities in addition to other social and economic information such as the distance of the household from a medical center. We selected the following categories included in the survey data for the present analysis in Vietnam and the Philippines: number of household members, household characteristics of household members, amount of food expenditure for a household, amount of in-kind food expenditure for a household, amount of non-food expenditure for a household, and amount of in-kind non-food expenditure for a household. Utilizing such data, we calculated Engel's coefficient in two cases: including and excluding in-kind consumption.

\subsection{Basic statistics}

We present some basic statistics drawn from the 2006 Household Living Standards Survey in Vietnam in Tables 3.1a and 3.1b.

In Vietnam, the number of households in the survey is less than 10,000 in a total population of nearly $87,000,000$. The monetary unit in Vietnam is the dong. The average total household expenditure in 2006 was 28,697,000 dong or about US $\$ 1,794$ (the 2006 exchange rate was US $\$ 1=15,994.25$ dong). Regarding food expenditure, the average monthly amount for all households is $11,109,000$ dong, including 2,166,000 dong for in-kind food consumption, indicating that 20 percent of food expenditure is from in-kind food consumption. However, regarding the distribution of in-kind food expenditure by income class, we find that it is concentrated in poor households, as indicated in Table 3.9a. The overall percentage of in-kind non-food consumption is less than 2 percent, indicating that this is relatively small compared to in-kind food expenditure of 20 percent.

Table 3.1a Basic statistics from the 2006 Household Living Standards Survey in Vietnam (per household, number of observations: 9,189; monetary unit: thousand dong)

\begin{tabular}{lll}
\hline Variable Mean & $\begin{array}{l}\text { Standard Minimum Maximum } \\
\text { deviation }\end{array}$ \\
\hline
\end{tabular}

\begin{tabular}{lrrrr}
\hline Amount of consumption expenditure & & & \\
Food & 11,109 & 6,925 & 600 & 114,505 \\
Non-food & 17,588 & 36,848 & 236 & $1,238,492$ \\
Total expenditure & 28,697 & 39,832 & 1,179 & $1,277,234$ \\
In-kind food & 2,166 & 2,276 & 0 & 18,635 \\
In-kind non-food & 328 & 770 & 0 & 49,612 \\
Food (excluding in-kind) & 8,943 & 7,330 & 0 & 109,565 \\
Non-food (excluding in-kind) & 17,259 & 36,823 & 0 & $1,238,492$ \\
Engel's coefficient & & & & \\
Engel's coefficient & 0.488 & 0.159 & 0.017 & 0.944 \\
Engel's coefficient & 0.422 & 0.161 & 0 & 0.943 \\
$\quad$ (excluding in-kind) & & & & \\
\hline
\end{tabular}


Table 3.1b Basic statistics from the 2006 Household Living Standards Survey in Vietnam focusing on very poor households (per household, number of observations: 2,297; monetary unit: thousand dong)

\begin{tabular}{lrrrr}
\hline Variable & Mean & $\begin{array}{c}\text { Standard } \\
\text { deviation }\end{array}$ & Minimum & Maximum \\
\hline Amount of consumption expenditure & & & \\
Food & 7,006 & 2,981 & 600 & 23,633 \\
Non-food & 4,620 & 2,584 & 236 & 19,582 \\
Total expenditure & 11,627 & 4,843 & 1,179 & 39,772 \\
In-kind food & 2,949 & 2,324 & 0 & 14,674 \\
In-kind non-food & 445 & 475 & 0 & 5,760 \\
Food (excluding in-kind) & 4,057 & 2,631 & 0 & 18,758 \\
Non-food (excluding in-kind) & 4,174 & 2,554 & 0 & 18,788 \\
Engel's coefficient & & & & \\
Engel's coefficient & 0.612 & 0.107 & 0.233 & 0.944 \\
Engel's coefficient (excluding & 0.493 & 0.147 & 0 & 0.943 \\
$\quad$ in-kind) & & & & \\
\hline
\end{tabular}

In the following sections, we present some basic statistics for very poor households in Vietnam, as indicated in Table 3.1b. In the present analysis, very poor households refer to the bottom five rungs of the twenty income classes.

The average total household consumption expenditure for the poorest 25 percent of all households in 2006 was 11,627,000 dong or about US \$726. In very poor households in Vietnam, 42 percent of food consumption is obtained by in-kind food consumption. We find that the share of in-kind food consumption is relatively large among the lower-income classes, while as total expenditure increases the share of in-kind food consumption sharply decreases.

Next, we present the basic statistics of the 2006 Family Income and Expenditure Survey in the Philippines in Tables 3.1c and 3.1d. The number of households in the survey is more than 38,000 . The monetary unit in the Philippines is the Philippine peso (PHP). The average of total household expenditure in 2006 was 138,892 PHP, meaning US \$2,707 (the 2006 exchange rate was US $\$ 1=$ 51.314 PHP). Regarding food expenditure, the average monthly amount for all households is 58,216 PHP, including 4,710 PHP for in-kind food consumption, indicating that 8 percent of food expenditure is from in-kind food consumption. However, regarding the distribution of in-kind food expenditure by income level, the amount of in-kind food expenditure is concentrated among poor households. On the other hand, the overall percentage of in-kind non-food consumption is about 25 percent, indicating that it is relatively large compared to the in-kind food expenditure of 8 percent. We speculate that this is due to the different stages of economic development between Vietnam and the Philippines. When the stage of economic development is low, the weight of in-kind consumption for food is larger in order to maintain basic subsistence. 
Table 3.1c Basic statistics of the 2006 Family Income and Expenditure Survey in the Philippines (per household, number of observations: 38,483; monetary unit: Philippine peso)

\begin{tabular}{|c|c|c|c|c|}
\hline Variable & Mean & $\begin{array}{l}\text { Standard } \\
\text { deviation }\end{array}$ & Minimum & Maximum \\
\hline \multicolumn{5}{|c|}{ Amount of consumption expenditure } \\
\hline Food & 58,216 & 38,298 & 0 & 801,142 \\
\hline Non-food & 80,676 & 113,386 & 1,250 & $3,687,796$ \\
\hline Total expenditure & 138,892 & 143,124 & 4,111 & $4,242,148$ \\
\hline In-kind food & 4,710 & 6,521 & 0 & 278,392 \\
\hline In-kind non-food & 20,476 & 34,836 & 0 & $1,263,634$ \\
\hline Food (excluding in-kind) & 53,505 & 39,223 & 0 & 801,042 \\
\hline $\begin{array}{l}\text { Non-food (excluding } \\
\text { in-kind) }\end{array}$ & 60,199 & 91,511 & 0 & $3,387,796$ \\
\hline \multicolumn{5}{|l|}{ Engel's coefficient } \\
\hline Engel's coefficient & 0.504 & 0.144 & 0 & 0.936 \\
\hline $\begin{array}{l}\text { Engel's coefficient } \\
\quad(\text { excluding in-kind) }\end{array}$ & 0.559 & 0.150 & 0 & 1 \\
\hline
\end{tabular}

Table 3.1d Basic statistics of the 2006 Family Income and Expenditure Survey in the Philippines focusing on very poor households (per household, number of observations: 9,633; monetary unit: Philippine peso)

\begin{tabular}{lrrrr}
\hline Variable & Mean & $\begin{array}{r}\text { Standard } \\
\text { deviation }\end{array}$ & Minimum & Maximum \\
\hline Amount of consumption expenditure & & 0 & 174,220 \\
Food & 35,959 & 13,939 & 1,420 & 163,204 \\
Non-food & 21,626 & 10,793 & 0 & 57,223 \\
Total expenditure & 57,585 & 22,273 & 0 & 54,400 \\
In-kind food & 6,575 & 6,338 & 0 & 172,074 \\
In-kind non-food & 6,949 & 4,252 & 0 & 138,779 \\
Food (excluding in-kind) & 29,384 & 13,649 & & \\
Non-food (excluding in-kind) & 14,676 & 8,564 & 0 & 0.891 \\
Engel's coefficient & & & 0 & 0.937 \\
Engel's coefficient & 0.630 & 0.086 & & \\
Engel's coefficient (excluding & 0.669 & 0.098 & & \\
$\quad$ in-kind) & & & & \\
\hline
\end{tabular}

Table 3.Id denotes basic statistics for very poor households in the Philippines. The definition of very poor households is the lowest 25 percent of households in terms of total expenditure.

The average total household expenditure in 2006 was 57,585 PHP or about US $\$ 1,122$. In very poor households in the Philippines, 18 percent of food consumption is obtained by in-kind food consumption. The tendency for the share 
of in-kind food expenditure being larger in poorer households is similar to the situation in Vietnam.

\subsection{Equivalence scale}

Food and non-food consumption for households are evaluated on an individual basis using an adult equivalence scale. Regarding the topic of the adult equivalence scale, Prais and Houthakker noted that:

The method of measuring household size by scales of equivalent-adults, man-values or unit-consumers [which is the terminology adopted herein] consists in regarding a child, say, as equivalent to a fraction of a man. This method was already used by Engel who labelled the unit a quet after the Belgian statistician Quetelet (in piam memorium) who had so much influenced his attitude to quantitative research in his youth. The main problem is, of course, what are the appropriate fractions for each type of person and how they are to be determined.

Very many scales have been proposed, and there is a considerable literature and a variety of opinions on the subject. Some hold that the phenomena are too complicated to be treated by the simple device of a scale of equivalences and conclude that the problem is more or less insoluble, as Allen (1942), or that it requires a much more intensive investigation in which the device of a scale of equivalences is unnecessary and possibly misleading. (1955, p. 126)

The information on household characteristics is used to calculate an adult equivalence scale. Some of the most commonly used scales include: ${ }^{2}$

(1) Per capita scale: All members of a household have the same weight so there is no adjustment for age and gender.

(2) Oxford equivalence scale (Oxford scale in Table 3.2): This assigns a value of 1 to the first household member, 0.7 to each additional adult, and 0.5 to each child.

(3) Organisation for Economic Co-operation and Development (OECD)-modified scale (OECD scale in Table 3.2): In the late 1990s, the Statistical Office for the European Union (EUROSTAT) modified the Oxford equivalence scale that was used widely in the 1980s and early 1990s. This scale assigns a value of 1 to the household head, 0.5 to each additional adult member, and 0.3 to each child.

(4) Square root scale: Recent OECD publications comparing income inequality and poverty across countries use a scale which divides household income by the square root of household size.

Let us show the difference of the adult equivalence scale in a typical household that includes (1) a husband, wife, and two children; and (2) a husband, wife, their aged parent(s), and two children. 
Table 3.2 Differences of the values between adult equivalence scales

(1) Husband, wife, and two children

\begin{tabular}{lcllll}
\hline & Husband & Wife & Child 1 & Child 2 & Total \\
\hline Per capita & 1 & 1 & 1 & 1 & 4 \\
Oxford & 1 & 0.7 & 0.5 & 0.5 & 2.7 \\
OECD & 1 & 0.5 & 0.3 & 0.3 & 2.1 \\
Square root & 1 & 0.414 & 0.317 & 0.267 & 2 \\
\hline
\end{tabular}

(2) Husband, wife, their aged parent(s), and two children

\begin{tabular}{lclllll}
\hline & Husband & Wife & Child 1 & Child 2 & Parent & Total \\
\hline Per capita & 1 & 1 & 1 & 1 & 1 & 5 \\
Oxford & 1 & 0.7 & 0.5 & 0.5 & 0.7 & 3.4 \\
OECD & 1 & 0.5 & 0.3 & 0.3 & 0.5 & 2.6 \\
Square root & 1 & 0.414 & 0.317 & 0.267 & 0.236 & 2.236 \\
\hline
\end{tabular}

It is true that different definitions of the adult equivalence scale produce different figures and interpretations regarding household consumption, sowing confusion about the actual state of affairs. But when the transformation is applied to all the households uniformly according to the same definition to obtain an index measuring the inequality of income distribution in a society, there is little difference between the different definitions. As indicated in Table 3.2(1), the value is different depending on the definition of the adult equivalence scale - namely, 4 for the per capita definition, 2.7 for the Oxford definition, 2.1 for the OECD definition, and 2 for the square root definition. However, when the defined figure is used uniformly for all the households, the inequality index, such as the Gini coefficient, does not fluctuate as a whole.

We explain the difference of income inequality applying different definitions of the adult equivalence scale. The degree of income inequality in a society is often measured by the Gini coefficient. The range of the Gini coefficient is between zero and unity. When the value is zero, the society is egalitarian because household income is equal for every household within a society. The higher the value of the Gini coefficient, the greater the disparities in a society. We calculated a preliminary adult equivalence scale using the aforementioned four definitions and adjusted total expenditure applying the four different types of adult equivalence scales. Table 3.3 indicates the changes in the Gini coefficient including and excluding in-kind consumption in Vietnam.

Including in-kind consumption produces a lower Gini coefficient (about 0.42) than in the case of excluding in-kind consumption (about 0.47). Thus, in-kind consumption has a redistribution effect and demonstrates the value of mutual help within communities that prevails in developing countries.

The difference of the value of the Gini coefficient according to the different definitions of calculating the adult equivalence scale within the same category such as including or excluding in-kind consumption is not large, meaning that 
Table 3.3 Gini coefficient using different definitions of the adult equivalence scale

\begin{tabular}{lcc}
\hline & $\begin{array}{c}\text { Including in-kind } \\
\text { consumption }\end{array}$ & $\begin{array}{c}\text { Excluding in-kind } \\
\text { consumption }\end{array}$ \\
\hline Household base & 0.430 & 0.479 \\
Per capita & 0.433 & 0.484 \\
Oxford scale & 0.420 & 0.472 \\
OECD scale & 0.415 & 0.468 \\
Square root scale & 0.418 & 0.470 \\
\hline
\end{tabular}

the different methods make little difference from the standpoint of economic policy regarding inequality. Therefore, we will use the per capita basis to calculate household food and non-food consumption.

One of the purposes of the present analysis is to find out whether or not the Engel curve is downward sloping monotonically. We compare the consumption behavior among three different stages of economic growth: Tanzania, Vietnam, and the Philippines. In the HBS in Tanzania, we found an inverse U-shaped Engel curve (see Chapter 2). As total expenditure increases in the very poor households, Engel's coefficient increases; the value reaches a peak within the range of income for very poor households and then decreases monotonically. Because of the inverse U-shaped Engel curve, income elasticity for the food category is elastic in the very poor households in Tanzania. ${ }^{3}$

In this section, we check the tendency of Engel's coefficient in Vietnam and the Philippines, particularly that of households in the bottom quartile of households, dividing the households into twenty income classes. In a subsequent section, we analyze the differences in the value of Engel's coefficient in each income class. We divide the whole population into twenty income classes (refer to the appendix in this chapter) and the lowest quartile income class into twenty income classes in order to observe the movement of Engel's coefficient in the very poor households. Engel's coefficients of very poor households are summarized in Tables 3.4a for Vietnam and 3.4b for the Philippines. ${ }^{4}$

Table 3.4a indicates the tendency of Engel's coefficient at the bottom quartile of all the households in Vietnam including and excluding in-kind consumption. The very poor households are divided into twenty income classes. Each cell includes 1.25 percent of total households in the survey. The underlined figures show that Engel's coefficient is larger than that in the previous income class, meaning that the Engel curve of the adjacent two classes is upward sloping. Engel's coefficient including in-kind consumption increases at the income class between 3 and 4, 4 and 5, 6 and 7, 13 and 14, and 15 and 16, while that excluding in-kind consumption increases between 3 and 4, 4 and 5, 6 and 7, 7 and 8, 10 and 11,11 and 12,13 and 14 , and 15 and 16. This indicates that the increasing tendency is observed in six out of twenty income classes including in-kind consumption and eight out of twenty income classes excluding in-kind consumption. Though Engel's coefficient decreases monotonically for all households in 
Table 3.4a Engel's coefficient including and excluding in-kind consumption: very poor households in Vietnam (per capita; monetary unit: thousand dong)

\begin{tabular}{|c|c|c|c|c|c|c|c|}
\hline \multirow{2}{*}{$\begin{array}{l}\text { Income } \\
\text { class }\end{array}$} & \multicolumn{5}{|l|}{ Expenditure } & \multicolumn{2}{|c|}{ Engel's coefficient } \\
\hline & Observation & Mean & $\begin{array}{l}\text { Standard } \\
\text { deviation }\end{array}$ & Minimum & Maximum & $\begin{array}{l}\text { Including } \\
\text { in-kind }\end{array}$ & $\begin{array}{l}\text { Excluding } \\
\text { in-kind }\end{array}$ \\
\hline 1 & 114 & 1,199 & 187 & 611 & 1,429 & 0.693 & 0.534 \\
\hline 2 & 115 & 1,554 & 68 & 1,432 & 1,660 & 0.670 & 0.519 \\
\hline 3 & 115 & 1,737 & 44 & 1,661 & 1,816 & 0.644 & 0.502 \\
\hline 4 & 115 & 1,886 & 32 & 1,819 & 1,942 & $0.646^{*}$ & $0.505^{*}$ \\
\hline 5 & 115 & 2,003 & 36 & 1,943 & 2,059 & $0.649^{*}$ & $0.522^{*}$ \\
\hline 6 & 115 & 2,121 & 34 & 2,059 & 2,173 & 0.636 & 0.483 \\
\hline 7 & 114 & 2,223 & 31 & 2,174 & 2,281 & $0.638^{*}$ & $0.492^{*}$ \\
\hline 8 & 115 & 2,330 & 28 & 2,283 & 2,379 & 0.624 & $0.503^{*}$ \\
\hline 9 & 115 & 2,422 & 25 & 2,379 & 2,465 & 0.619 & 0.500 \\
\hline 10 & 115 & 2,511 & 27 & 2,465 & 2,555 & 0.602 & 0.479 \\
\hline 11 & 115 & 2,602 & 27 & 2,556 & 2,646 & 0.596 & $0.484^{*}$ \\
\hline 12 & 115 & 2,679 & 21 & 2,647 & 2,721 & $0.605^{*}$ & $0.491^{*}$ \\
\hline 13 & 115 & 2,761 & 24 & 2,722 & 2,802 & 0.580 & 0.475 \\
\hline 14 & 114 & 2,839 & 21 & 2,803 & 2,878 & $0.591^{*}$ & $0.495^{*}$ \\
\hline 15 & 115 & 2,916 & 20 & 2,879 & 2,952 & 0.581 & 0.475 \\
\hline 16 & 115 & 2,993 & 22 & 2,952 & 3,031 & $0.593^{*}$ & $0.497^{*}$ \\
\hline 17 & 113 & 3,063 & 19 & 3,031 & 3,097 & 0.589 & 0.488 \\
\hline 18 & 117 & 3,132 & 20 & 3,098 & 3,165 & 0.579 & 0.482 \\
\hline 19 & 115 & 3,208 & 24 & 3,166 & 3,248 & 0.572 & 0.473 \\
\hline 20 & 115 & 3,288 & 22 & 3,248 & 3,326 & 0.556 & 0.463 \\
\hline
\end{tabular}

Note: The two columns on the right-hand side indicate the movement of Engel's coefficient classified into twenty income classes among the lowest 25 percent income class. The ${ }^{*}$ indicates that Engel's coefficient of the current class is larger than that of the previous income class.

Vietnam, we can observe an upward fluctuation of Engel's coefficient when we focus on the very poor households.

The tendency of the movement of Engel's coefficient in the Philippines is the same as in Vietnam. When we focus on the tendency of the lowest 25 percent income class, we observe an upward-sloping Engel's coefficient in three out of twenty income classes in the case of including in-kind consumption and four out of twenty income classes in the case of excluding in-kind consumption, as indicated in Table 3.4b. Though Engel's coefficient decreases monotonically for all the households in the Philippines, as indicated in Table 3A.2 in the appendix, we also observe an upward tendency of Engel's coefficient when we focus on very poor households. ${ }^{5}$

\subsection{Inequality}

To reiterate, the degree of income inequality in a society is often measured by the Gini coefficient. The range of the Gini coefficient is between zero and 


\section{Atsushi Maki and Satoshi Ohira}

Table 3.4b Engel's coefficient including and excluding in-kind consumption: very poor households in the Philippines (per capita; monetary unit: Philippine peso)

\begin{tabular}{|c|c|c|c|c|c|c|c|}
\hline \multirow{2}{*}{$\begin{array}{l}\text { Income } \\
\text { class }\end{array}$} & \multicolumn{5}{|l|}{ Expenditure } & \multicolumn{2}{|c|}{ Engel's coefficient } \\
\hline & Observation & Mean & $\begin{array}{l}\text { Standard } \\
\text { deviation }\end{array}$ & Minimum & Maximum & $\begin{array}{l}\text { Including } \\
\text { in-kind }\end{array}$ & $\begin{array}{l}\text { Excluding } \\
\text { in-kind }\end{array}$ \\
\hline 1 & 481 & 497 & 74 & 205 & 585 & 0.692 & 0.706 \\
\hline 2 & 482 & 629 & 23 & 585 & 667 & 0.673 & 0.706 \\
\hline 3 & 481 & 700 & 17 & 667 & 730 & 0.667 & 0.700 \\
\hline 4 & 482 & 756 & 15 & 730 & 782 & 0.662 & 0.694 \\
\hline 5 & 482 & 805 & 13 & 782 & 828 & 0.650 & 0.683 \\
\hline 6 & 481 & 847 & 11 & 828 & 866 & 0.642 & 0.680 \\
\hline 7 & 482 & 886 & 11 & 866 & 904 & 0.640 & 0.675 \\
\hline 8 & 482 & 922 & 9 & 904 & 938 & 0.635 & $0.678^{*}$ \\
\hline 9 & 481 & 955 & 9 & 938 & 972 & $0.636^{*}$ & $0.680^{*}$ \\
\hline 10 & 482 & 990 & 9 & 972 & 1,006 & 0.626 & 0.669 \\
\hline 11 & 482 & 1,023 & 9 & 1,006 & 1,040 & 0.622 & 0.662 \\
\hline 12 & 481 & 1,056 & 9 & 1,040 & 1,073 & 0.619 & $0.663^{*}$ \\
\hline 13 & 482 & 1,089 & 9 & 1,073 & 1,107 & $0.621^{*}$ & 0.660 \\
\hline 14 & 482 & 1,123 & 9 & 1,107 & 1,141 & 0.609 & 0.651 \\
\hline 15 & 481 & 1,156 & 8 & 1,141 & 1,171 & 0.606 & $0.653^{*}$ \\
\hline 16 & 482 & 1,188 & 10 & 1,171 & 1,205 & 0.594 & 0.639 \\
\hline 17 & 482 & 1,220 & 8 & 1,205 & 1,235 & $0.614^{*}$ & $0.659^{*}$ \\
\hline 18 & 481 & 1,253 & 10 & 1,235 & 1,271 & 0.607 & 0.653 \\
\hline 19 & 482 & 1,287 & 9 & 1,271 & 1,302 & 0.595 & 0.642 \\
\hline 20 & 482 & 1,319 & 9 & 1,302 & 1,334 & 0.598 & 0.642 \\
\hline
\end{tabular}

unity. The higher the value of the Gini coefficient, the greater the disparities in a society.

Particularly regarding inequality, the role of in-kind consumption is important in policy evaluation. This is because in-kind consumption has a redistribution effect in developing countries. Table 3.5 indicates the changes in the Gini coefficient including and excluding in-kind consumption.

Usually the Gini coefficient is applied to verify the degree of income inequality in a society. In addition to the usual method regarding income inequality among households, we calculated the degree of inequality for the distribution of food and non-food items among the households. The Gini coefficient including in-kind consumption is 0.433 in Vietnam and that excluding in-kind consumption is 0.484 . The Gini coefficient including in-kind consumption is 0.456 in the Philippines and that excluding in-kind consumption is 0.471 , indicating that the value of the Gini coefficient including in-kind consumption is lower than that excluding in-kind consumption. Including in-kind consumption produces a lower Gini coefficient in both Vietnam and the Philippines. Thus, in-kind consumption has a redistribution effect in developing countries. 
Table 3.5 Gini coefficient including and excluding in-kind consumption (per capita)

\begin{tabular}{llcc}
\hline Country & Item & $\begin{array}{c}\text { Including in-kind } \\
\text { consumption }\end{array}$ & $\begin{array}{c}\text { Excluding in-kind } \\
\text { consumption }\end{array}$ \\
\hline Vietnam (2006) & Total expenditure & 0.433 & 0.484 \\
& Food & 0.287 & 0.395 \\
Philippines (2006) & Non-food & 0.561 & 0.572 \\
& Total expenditure & 0.456 & 0.471 \\
& Food & 0.322 & 0.363 \\
& Non-food & 0.566 & 0.589 \\
\hline
\end{tabular}

In order to check the characteristics of the food category, we applied the Gini coefficient to the distribution of food expenditure for all households. According to the increase in the amount of income, dietary consumption patterns shift from cereals and vegetables to cereals, vegetables, and meats. We also checked for inequality in consumption by measuring the variety of food in the diet according to the Gini coefficient. When the value is zero, all the households consume the same kind of food regardless of income level. As the value of the Gini coefficient rises, the share of subsidiary food increases, and so the number of dishes increases. The Gini coefficient for food in Vietnam including in-kind consumption is 0.287 and that for food excluding in-kind consumption is 0.395 . The Gini coefficient for food in the Philippines including in-kind consumption is 0.322 and that for food excluding in-kind consumption is 0.363 . Observing the value for the Gini coefficient of food, the variety of dishes is small compared with other categories, indicating that people consume similar meals (food category) across income classes.

We checked the Gini coefficient for the non-food category. As the non-food category includes not only necessities but also luxury goods and services, the value of the Gini coefficient is large compared with food consumption. The value of the Gini coefficient for non-food items in Vietnam including in-kind consumption is 0.561 and that excluding in-kind consumption is 0.572 , whereas the value of the Gini coefficient for non-food items in the Philippines including in-kind consumption is 0.566 and that excluding in-kind consumption is 0.589 . In comparing the values for Vietnam and the Philippines, we found that the degree of inequality is larger for non-food than for food categories in both countries. This is due to the effect of increasing the weight for purchasing luxury goods according to increases in income.

\section{Engel curves in Vietnam and the Philippines}

\subsection{Nonparametric regression}

One of the enduring truths in economics is Engel's Law; i.e. the ratio between food expenditure and income (or total expenditure) decreases as income (or total 


\section{Atsushi Maki and Satoshi Ohira}

expenditure) increases. We tested whether or not the downward-sloping tendency of Engel's coefficient is evident in Vietnam and the Philippines. First, we conducted nonparametric regression estimation.

According to Greene (2012), nonparametric regression is defined as

$$
y=\mu(x)+\varepsilon
$$

where $y$ is a dependent variable and $x$ is a single independent variable. A conditional mean estimating function is defined as

$$
\mu\left(x^{*}\right)=\sum w_{i}\left(x^{*} \mid x_{1}, \ldots, x_{n}\right) y_{i}
$$

where the weights sum to unity. The kernel weighted regression method is a standard tool in nonparametric analysis

$$
\mu\left(x^{*} \mid X, b\right)=\left\{\sum(1 / n) K\left[\left(x_{i}-x^{*}\right) / h\right] y_{i}\right\} /\left\{\sum(1 / n) K\left[\left(x_{i}-x^{*}\right) / b\right]\right\}
$$

where $K\left[\left(x_{i}-x^{*}\right) / h\right]$ is the kernel density.
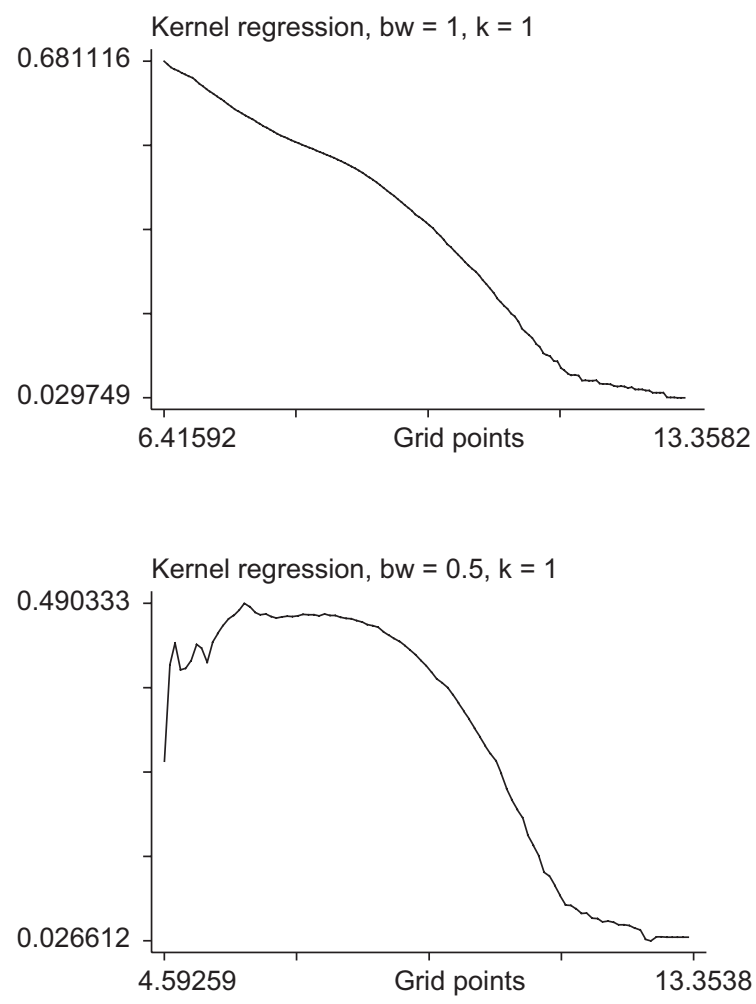

Figure 3.1a All households in Vietnam 
The Engel curves including and excluding in-kind consumption are obtained graphically as indicated in Figures 3.1a through 3.1d.

We observe the figures derived by nonparametric regression for the cases of Vietnam and the Philippines. As shown in Figures 3.1a and 3.1c, the Engel curves do not have a hump in the cases that include in-kind consumption. In Figures $3.1 \mathrm{~b}$ and 3.1d excluding in-kind consumption, Engel's coefficient increases as income increases, indicating that cash-based food consumption is something of a luxury good in poor households.

\subsection{Quadratic almost ideal demand (QUAID) system including in-kind consumption}

We specify quadratic almost ideal demand (QUAID)-type Engel curves and test the validity of the model. ${ }^{6}$ We estimate the Engel curves parametrically based on
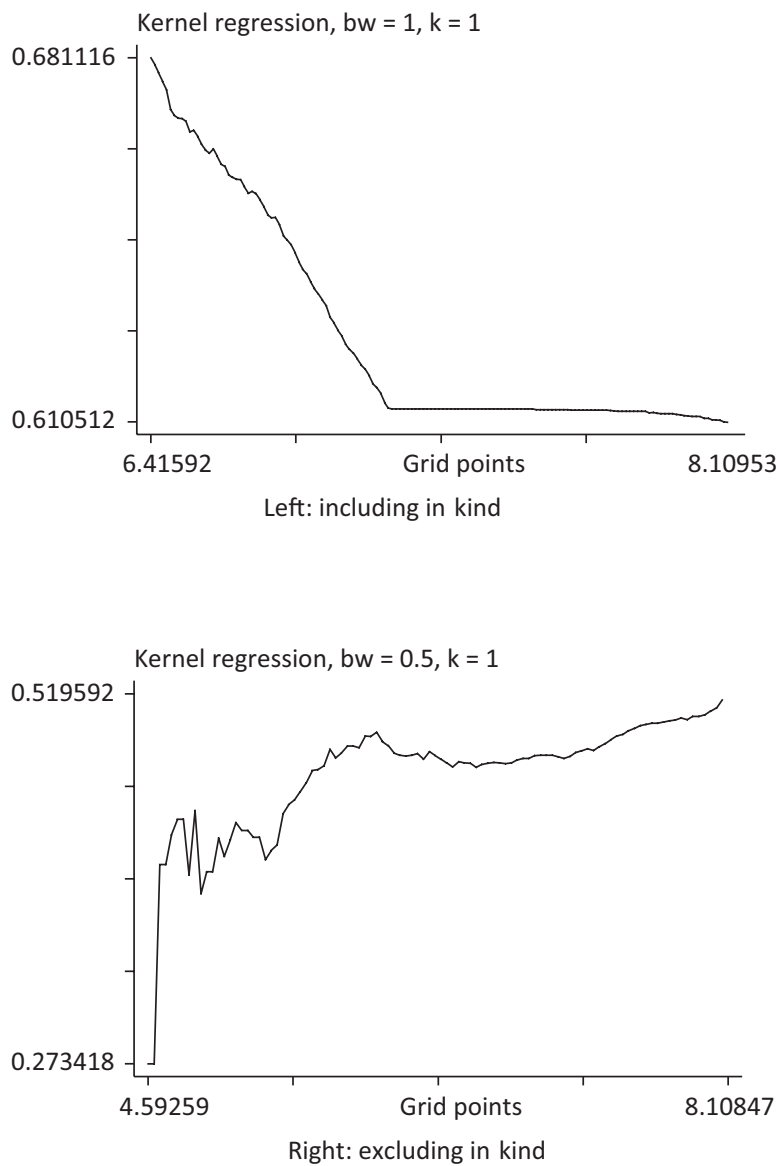

Figure 3.1b Very poor households in Vietnam (the lowest 25\%) 

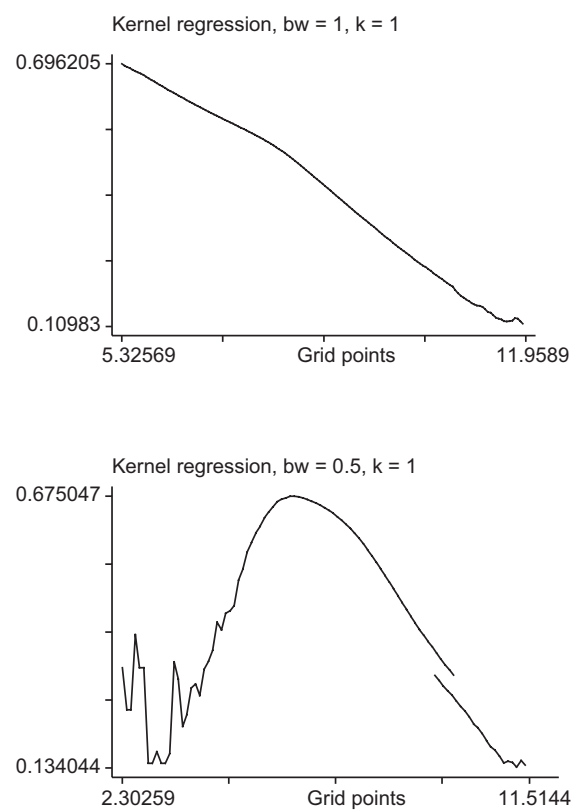

Figure 3.1c All households in the Philippines

the utility maximizing behavior for households. We specify the QUAID system in the price-independent generalized logarithmic (PIGLOG)-type utility class.

Banks, Blundell, and Lewbel (1997) proposed the QUAID system. The specification of the QUAID system food share equation is:

$$
w_{i}=a+b \ln x_{i}+c\left(\ln x_{i}\right)^{2}
$$

where $w_{i}$ is the food share for the $i$-th household, and $a, b$, and $c$ are parameters to be estimated. The income elasticity of demand for food, $\eta$, in the QUAID system is:

$$
\eta=\left[(a+b)+(b+2 c) \ln x_{i}+c\left(\ln x_{i}\right)^{2}\right] / w_{i}
$$

When the parameter $c$ is negative, the quadratic form has a maximum value regarding the food share, $w^{*}$, at the point of the income level of $\ln x_{i}=-b /(2 c)$, and the maximum share is:

$$
w^{*}=a-b^{2} /(4 c)
$$

We also calculate the effective range of income for the estimated QUAID system between $x_{\text {min }}=\exp \left[\left(-b+\sqrt{ }\left(b^{2}-4 a c\right)\right] /(2 c)\right.$ and $x_{\max }=\exp \left[\left(-b-\sqrt{ }\left(b^{2}-4 a c\right)\right] /\right.$ $(2 c)$, respectively. 

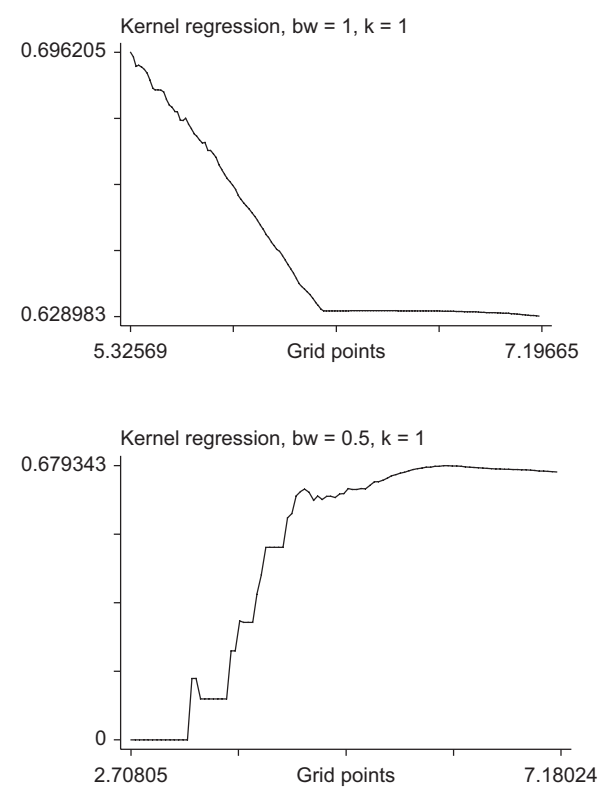

Figure 3.1d Very poor households in the Philippines (the lowest 25\%)

When the regression coefficient of the quadratic term on income - namely, $c$ in the model - is zero, the QUAID system is ascribed to the almost ideal demand (AID) system proposed by Deaton and Muellbauer (1980).

In the present analysis, we divide total expenditure into two clusters of items: food and non-food expenditures. Because of Walras' Law, there is only one estimating equation in the two-commodity classification.

The estimating food share equation for the specification of the QUAID system is:

$$
w_{i}=a+b \ln x_{i}+c\left(\ln x_{i}\right)^{2}+\varepsilon_{i}
$$

where $w_{i}$ is the food share for the $i$-th household, $x_{i}$ is the income adjusted by the adult equivalence scale, and $\varepsilon_{i}$ is the stochastic disturbance with the characteristics of independent identically distributed (i.i.d.) normal distribution.

The QUAID system food share functions are estimated by the ordinary least-squares (OLS) and quantile regression methods. The criterion of the OLS estimation method is:

$$
\min \left[(y-X \beta)^{\prime}(y-X \beta)\right]
$$

where $y$ is the column vector of order $N, X$ is the $N \times K$ matrix, and $\beta$ is the column vector of order $K$. According to Koenker and Bassett (1978), the $\theta$-th 
quantile regression, $0<\theta<1$, is defined as any solution to the minimization problem:

$$
\min \left[\theta\left|1_{N}(y-X \beta)\right|+(1-\theta)\left|1_{N}(y-X \beta)\right|\right]
$$

where $l_{N}$ is the $N$-th-order raw vector whose elements are unity. As the special case for quantile regression, the least absolute error estimator is the same as that derived from the median regression - namely, the case of $\theta=0.5$ in the quantile regression.

The quantile regression problem is reformulated as a linear programming technique by introducing the slack vectors of $u$ and $v$ :

$$
\min \left[\theta 1_{N} u+(1-\theta) 1_{N} v \mid X \beta+u-v=y\right]
$$

The estimates, $\beta$, are obtained by solving the linear programming model.

We estimated the QUAID system. The estimation results of the QUAID system food share function including in-kind consumption are reported in Table 3.6a for the OLS regression and the quantile regression for the three cases - namely, the first quantile $\left(Q_{1}\right)$, the second quantile (median), and the third quantile $\left(Q_{3}\right)$.

The parameter $c$ of the OLS and the first-quantile $\left(Q_{1}\right)$ regressions are positive, meaning that the Engel curves are not inverse U-shaped, while those of the median and third-quantile $\left(Q_{3}\right)$ regressions are not statistically significant at the significance level of 0.05 . Table $3.6 \mathrm{~b}$ provides the estimation results in the Philippines.

Regarding the parameter of the quadratic term, $c$, the $t$-value is low and does not differ from zero statistically, indicating that the Engel curve is not a quadratic form but rather a linear form. Though the coefficient of the quadratic term is statistically significant in the case of the first-quantile $\left(Q_{1}\right)$ regression in Table $3.6 \mathrm{~b}$, the sign of the quadratic term is positive, indicating that the Engel

Table 3.6a Estimation results: the QUAID system food share function in Vietnam (including in-kind consumption)

\begin{tabular}{lcccc}
\hline Method & OLS regression & \multicolumn{2}{c}{ Quantile regression } \\
\cline { 3 - 5 } Estimate & & $Q_{1}$ & Median & $Q_{3}$ \\
\hline \multirow{2}{*}{$a$ (intercept) } & 1.899 & 2.46 & 1.881 & 1.577 \\
& $(17.2)$ & $(15.9)$ & $(13.1)$ & $(11.0)$ \\
$b$ & -0.173 & -0.308 & -0.160 & -0.086 \\
& $(-6.9)$ & $(-8.8)$ & $(-4.9)$ & $(-2.7)$ \\
$c$ & $0.001^{*}$ & $0.007^{*}$ & $-0.000^{*}$ & $-0.003^{*}$ \\
$R^{2}$ & $(0.7)$ & $(4.0)$ & $(-0.1)$ & $(-1.9)$ \\
& 0.460 & 0.303 & 0.267 & 0.228 \\
\hline
\end{tabular}

Note: the $t$-value is indicated in parentheses; ${ }^{*}$ indicates that the parameter is not statistically different from zero and/or that it does not satisfy theoretical restrictions in economic theory. 
Table 3.66 Estimation results: the QUAID system food share function in the Philippines (including in-kind consumption)

\begin{tabular}{lcccc}
\hline Method & OLS regression & \multicolumn{2}{c}{ Quantile regression } \\
\cline { 3 - 5 } Estimate & & $Q_{1}$ & Median & $Q_{3}$ \\
\hline$a$ (intercept) & 1.529 & 1.853 & 1.558 & 1.263 \\
$b$ & $(41.8)$ & $(40.1)$ & $(30.8)$ & $(23.0)$ \\
& -0.122 & -0.215 & -0.126 & -0.040 \\
$c$ & $(-13.3)$ & $(-18.7)$ & $(-9.9)$ & $(-2.9)$ \\
& -0.001 & $0.004^{*}$ & $-0.001^{*}$ & -0.006 \\
$R^{2}$ & $(-2.0)$ & $(6.1)$ & $(-1.4)$ & $(-7.1)$ \\
\hline
\end{tabular}

Note: the $t$-value is indicated in parentheses; ${ }^{*}$ indicates that the parameter is not statistically different from zero and/or that it does not satisfy theoretical restrictions in economic theory.

Table 3.7a Estimation results: the QUAID system food share function in Vietnam (excluding in-kind consumption)

\begin{tabular}{|c|c|c|c|c|}
\hline \multirow{2}{*}{$\frac{\text { Method }}{\text { Estimate }}$} & \multirow[t]{2}{*}{ OLS regression } & \multicolumn{3}{|c|}{ Quantile regression } \\
\hline & & $Q_{1}$ & Median & $Q_{3}$ \\
\hline$a($ intercept $)$ & $\begin{array}{l}-0.641 \\
(-7.3)\end{array}$ & $\begin{array}{c}-0.653 \\
(-4.7)\end{array}$ & $\begin{array}{c}-0.764 \\
(-5.8)\end{array}$ & $\begin{array}{c}-0.821 \\
(-6.2)\end{array}$ \\
\hline$b$ & $\begin{array}{l}0.322 \\
(15.7)\end{array}$ & $\begin{array}{c}0.303 \\
(9.3)\end{array}$ & $\begin{array}{l}0.356 \\
(10.9)\end{array}$ & $\begin{array}{l}0.394 \\
(12.5)\end{array}$ \\
\hline$c$ & $\begin{array}{c}-0.023 \\
(-7.3)\end{array}$ & $\begin{array}{l}-0.022 \\
(-11.6)\end{array}$ & $\begin{array}{l}-0.025 \\
(-12.6)\end{array}$ & $\begin{array}{l}-0.027 \\
(-14.5)\end{array}$ \\
\hline$R^{2}$ & 0.165 & 0.101 & 0.083 & 0.073 \\
\hline
\end{tabular}

Note: the $t$-value is indicated in parentheses; $w_{j}$ has a maximum value of 0.485 at the point where income is 4,515,000 dong. Minimum income is $11,000 \mathrm{dong}$, and maximum income is 105,386 dong.

curve is $\mathrm{U}$-shaped but not inverse $\mathrm{U}$-shaped. This result is meaningless as an empirical result because Engel's coefficient becomes larger when the income level increases, even in non-poor households, contradicting the theoretical expectations of a downward-sloping Engel curve.

\subsection{QUAID system excluding in-kind consumption}

Tables 3.7 a and 3.7b provide the estimation results of the QUAID system food share function excluding in-kind consumption in Vietnam and the Philippines.

The results from including and excluding in-kind food are very different. The regression coefficient of the quadratic term is negative in the case of excluding 
Table 3.7b Estimation results: the QUAID system food share function in the Philippines (excluding in-kind consumption)

\begin{tabular}{|c|c|c|c|c|}
\hline \multirow{2}{*}{$\frac{\text { Method }}{\text { Estimate }}$} & \multirow[t]{2}{*}{ OLS regression } & \multicolumn{3}{|c|}{ Quantile regression } \\
\hline & & $Q_{1}$ & Median & $Q_{3}$ \\
\hline$a($ intercept $)$ & $\begin{array}{c}-0.025 \\
(-0.8)\end{array}$ & $\begin{array}{c}0.103 \\
(2.3)\end{array}$ & $\begin{array}{c}0.212 \\
(5.6)\end{array}$ & $\begin{array}{c}0.233 \\
(6.0)\end{array}$ \\
\hline$b$ & $\begin{array}{l}0.270 \\
(32.3)\end{array}$ & $\begin{array}{l}0.227 \\
(19.4)\end{array}$ & $\begin{array}{l}0.217 \\
(21.8)\end{array}$ & $\begin{array}{l}0.224 \\
(22.2)\end{array}$ \\
\hline$c$ & $\begin{array}{l}-0.025 \\
(-46.4)\end{array}$ & $\begin{array}{l}-0.023 \\
(-30.2)\end{array}$ & $\begin{array}{l}-0.022 \\
(-34.4)\end{array}$ & $\begin{array}{l}-0.022 \\
(-34.1)\end{array}$ \\
\hline$R^{2}$ & 0.448 & 0.295 & 0.284 & 0.244 \\
\hline
\end{tabular}

Note: the $t$-value is indicated in parentheses; $w_{j}$ has a maximum value of 0.696 at the point where income is $5 \mathrm{PHP}$. Minimum income is $1 \mathrm{PHP}$, and maximum income is 39,536 PHP.

Table 3.8a Income elasticity of demand at different income levels in Vietnam (including in-kind consumption): the QUAID system

Income levels (thousand dong)

\begin{tabular}{lcccccccc}
\hline Income & 500 & 1,000 & 1,500 & 2,000 & 3,000 & 5,000 & 8,000 & 10,000 \\
\hline OLS & 0.813 & 0.788 & 0.769 & 0.754 & 0.728 & 0.687 & 0.636 & 0.605 \\
$Q_{1}$ & 0.754 & 0.721 & 0.696 & 0.675 & 0.639 & 0.580 & 0.502 & 0.452 \\
Median & 0.814 & 0.786 & 0.765 & 0.748 & 0.719 & 0.672 & 0.612 & 0.576 \\
$Q_{3}$ & 0.854 & 0.831 & 0.815 & 0.802 & 0.780 & 0.746 & 0.705 & 0.680 \\
\hline
\end{tabular}

Table 3.8b Income elasticity of demand at different income levels in the Philippines (including in-kind consumption): the QUAID system

Income levels (PHP)

\begin{tabular}{lcccccccc}
\hline Income & 500 & 1,000 & 1,500 & 2,000 & 3,000 & 5,000 & 8,000 & 10,000 \\
\hline OLS & 0.809 & 0.778 & 0.754 & 0.734 & 0.699 & 0.642 & 0.566 & 0.517 \\
$Q_{1}$ & 0.762 & 0.727 & 0.700 & 0.678 & 0.639 & 0.572 & 0.482 & 0.423 \\
Median & 0.806 & 0.773 & 0.749 & 0.728 & 0.692 & 0.632 & 0.551 & 0.499 \\
$Q_{3}$ & 0.846 & 0.814 & 0.791 & 0.771 & 0.738 & 0.683 & 0.611 & 0.567 \\
\hline
\end{tabular}

in-kind consumption and is statistically significant from zero, indicating that the Engel curve is inverse U-shaped. This observation satisfies Engel's Law on the right-hand side of the income level that indicates the highest Engel's coefficient.

Table 3.8 a reports the income elasticity of demand in Vietnam at different income levels from 500,000 dong up to 10,000,000 dong including in-kind consumption. Table $3.8 \mathrm{~b}$ indicates the income elasticity of demand in the Philippines. When we calculated income elasticity for the downward-sloping Engel curve, 
income elasticity of demand was inelastic, and the value was less than unity. When we calculated income elasticity excluding in-kind consumption, we observed income elasticity that is elastic on the left-hand side of the income level that indicates the highest Engel's coefficient. This means that cash-based and in-kind food consumption have different characteristics for very poor households. ${ }^{7}$

\section{The role of in-kind transactions}

Tables 3.9a and 3.9b indicate: (1) the ratio between total expenditure excluding in-kind consumption and total expenditure including in-kind consumption; (2) the ratio between in-kind food expenditure and total expenditure; and (3) the ratio between in-kind food expenditure and in-kind total expenditure (i.e. total expenditure minus cash-based total expenditure) classified by income classes. The first indicates the weight of in-kind consumption out of total consumption. When the value is large, the weight of in-kind consumption is small, and vice versa. The second indicates the weight of in-kind food expenditure. When the value is large, households consume more in-kind food, and vice versa. The third indicates the weight of in-kind food expenditure in terms of the in-kind total expenditure. When the value is large, most in-kind consumption is for food.

In Vietnam, the role of in-kind consumption monotonically decreases as total expenditure increases, as indicated in the fourth column of Table 3.9a. For the lowest income class (first income class) the rate is 60 percent, meaning that the weight of in-kind consumption out of total expenditure is 40 percent and that the value monotonically decreases as the income level increases. At the highest income class, the share is only 2 percent for in-kind consumption. The tendency for food expenditure is the same as in the previous case. At the lowest income class, about one third of total expenditure is in-kind food. As total expenditure increases, the ratio monotonically decreases; finally, at the highest income class, the weight for in-kind food consumption is only 1 percent. Out of in-kind total expenditure, about 80 percent was accounted for by the in-kind food category, as indicated in the sixth column of Table 3.9a.

In the Philippines, the role of in-kind consumption is relatively stable compared with the case of Vietnam, as indicated in the fourth column of Table 3.9b. For the lowest income class, in-kind consumption accounts for 30 percent of total expenditure. As total expenditure increases, the weight of in-kind consumption decreases by only 10 percent, dropping to 20 percent at the highest income class. This tendency for in-kind food expenditure is different from that in Vietnam. At the lowest income class, about 16 percent out of total expenditure is in-kind food. As total expenditure increases, the ratio monotonically decreases; finally, at the highest income class, there is no in-kind food consumption. In terms of in-kind total expenditure, the weight for food is relatively large in the lowest income class, constituting about 50 percent, again differing from the case in Vietnam. In the Philippines, as income increases, the ratio of in-kind food expenditure to total in-kind expenditure decreases monotonically, reaching 5 percent for the highest income class. 


\section{Atsushi Maki and Satoshi Ohira}

We summarize the different tendencies of in-kind consumption in Vietnam and the Philippines in Table 3.9c. We attribute the difference in (1) to the different weight of in-kind food consumption in Vietnam and the Philippines. Though the weight of in-kind food consumption is large in lower-income classes in Vietnam, it decreases sharply by 40 percent with increases in total expenditure. We attribute the difference in (3) to the different weight of non-food in-kind consumption in the two countries. As the weight of food in-kind consumption is small in the Philippines, the fluctuation of the ratio is relatively large compared to that in Vietnam.

Table $3.9 a$ The role of in-kind consumption in Vietnam (mean, per capita)

\begin{tabular}{lccccc}
\hline $\begin{array}{l}\text { Income } \\
\text { class }\end{array}$ & Observation & $\begin{array}{l}\text { Total } \\
\text { expenditure } \\
\text { (thousand } \\
\text { dong) }\end{array}$ & $\begin{array}{l}\text { Total } \\
\text { expenditure } \\
\text { excluding } \\
\text { in-kind/total } \\
\text { expenditure (1) }\end{array}$ & $\begin{array}{l}\text { Food in-kind/ } \\
\text { total } \\
\text { expenditure (2) }\end{array}$ & $\begin{array}{l}\text { Food in-kind/ } \\
\text { expenditure } \\
\text { in-kind (3) }\end{array}$ \\
\hline 1 & 459 & 1,595 & 0.60 & 0.34 & 0.81 \\
5 & 460 & 3,173 & 0.77 & 0.20 & 0.83 \\
10 & 460 & 4,816 & 0.86 & 0.12 & 0.84 \\
15 & 459 & 7,620 & 0.93 & 0.06 & 0.83 \\
20 & 460 & 37,501 & 0.98 & 0.01 & 0.73 \\
\hline
\end{tabular}

Table $3.9 b$ The role of in-kind consumption in the Philippines (mean, per capita)

\begin{tabular}{lccccc}
\hline $\begin{array}{l}\text { Income } \\
\text { class }\end{array}$ & Observation & $\begin{array}{l}\text { Total } \\
\text { expenditure } \\
\text { (thousand } \\
\text { dong) }\end{array}$ & $\begin{array}{l}\text { Total } \\
\text { expenditure } \\
\text { excluding } \\
\text { in-kind/total } \\
\text { expenditure (1) }\end{array}$ & $\begin{array}{l}\text { Food in-kind/ } \\
\text { total } \\
\text { expenditure (2) }\end{array}$ & $\begin{array}{l}\text { Food in-kind/ } \\
\text { expenditure } \\
\text { in-kind (3) }\end{array}$ \\
\hline 1 & 1,924 & 645 & 0.71 & 0.16 & 0.50 \\
5 & 1,924 & 1,269 & 0.76 & 0.10 & 0.37 \\
10 & 1,924 & 2,063 & 0.79 & 0.06 & 0.26 \\
15 & 1,924 & 3,636 & 0.82 & 0.02 & 0.12 \\
20 & 1,924 & 15,798 & 0.79 & 0.00 & 0.05 \\
\hline
\end{tabular}

Table 3.9c Summary table on the role of in-kind consumption

\begin{tabular}{lcc}
\hline Ratio & Vietnam & Philippines \\
\hline (1) Total expenditure excluding in-kind/total expenditure & $(\nearrow)$ & $(\rightarrow)$ \\
(2) Food in-kind/total expenditure & $(\searrow)$ & $(\searrow)$ \\
(3) Food in-kind/total expenditure in-kind & $(\rightarrow)$ & $(\searrow)$ \\
\hline
\end{tabular}




\section{Implications}

We find that there is a link between the poverty line and the degree of in-kind consumption, especially in-kind food consumption. To clarify this, we considered two poverty lines in our analysis of Tanzanian households; one is the food poverty line, and the other is the basic needs poverty line. We explain the two kinds of poverty lines applied to the Tanzanian Statistics Bureau as an example.

The food poverty line is derived under the condition that the sum of calories obtained by food consumption expenditures per adult equivalence scale is 2,200 calories per day. The level of 2,200 calories per day is defined by the Food and Agriculture Organization (FAO) of the United Nations as the minimum necessary for survival. The food poverty line is defined as the minimum cost of consuming 2,200 calories per day using diary-based data from the Tanzanian HBS for food consumption expenditure.

To estimate the basic needs poverty line, the Tanzanian Statistics Bureau uses the diary-based data for food consumption expenditures and the recall-based data for non-food consumption expenditures. According to the HBS report in $2000 / 01$ (HBS 2000/01), the basic needs poverty line is obtained in the following manner: after calculating the share - say, $\alpha-$ of the food expenditure to total food and non-food expenditures in the poorest 25 percent of all households, the basic needs poverty line is obtained as the value of the food poverty line multiplied by the reciprocal of $\alpha$. As an example, let us assume that the food poverty line is Tanzanian Shilling (TS) 10,000 and that the share of food expenditure in the poorest 25 percent is 80 percent. Thus, the basic needs poverty line is calculated as TS 12,500 - namely, $10,000 \times(1 / 0.8) .{ }^{8}$

There are important differences between the food and basic needs poverty lines. A presumption of the food poverty line is that without sufficient food consumption, human beings cannot survive. Thus, the food poverty line mainly focuses on the problem of surviving and what the minimum subsistence amount of money is (including cash and in-kind transactions) to do so. On the other hand, the basic needs poverty line considers not only just surviving but also the standard of living in a society beyond basic food consumption. Basic needs include accommodation; educational expenses; commuting expenses; and social overhead costs such as seasonal festivals and ceremonies associated with marriages, births, and funerals. Covering such costs requires payment by cash or labor services to the community.

In considering social life in developing countries, we make the following observations: (1) for food consumption, the role of in-kind transfer within a society is important, and when a household is poor, it will obtain food through in-kind transactions. Therefore, the weight of in-kind food consumption is large at lower income levels in Vietnam and the Philippines; (2) for non-food consumption, even the poorest households need to pay for some amount of non-food expenditure for social obligations and basic needs depending on the ability to pay; and (3) therefore, the non-food category features two different characteristics - namely, some expenditures are basic needs, while others are discretionary luxury items. 
Our findings suggest that for poor households, food purchased with cash is something of a luxury item compared with food in-kind. To summarize the discussion, we classify goods in four categories:

Food 1: Everybody has to consume a minimum amount of food. In developing societies, people often obtain food through in-kind transactions.

Food 2: Food classified in this category is not necessarily a necessity. People obtain food through cash transactions when their income becomes large enough.

Non-food 1: Even in a developing society, people have to consume non-food items that are basic necessities. In order to do so, they obtain such goods through in-kind transactions.

Non-food 2: Non-food classified in this category includes both luxuries and necessities. People obtain non-food items through cash transactions when their income becomes large enough.

In this setting, we can classify the development into at least three stages:

\begin{tabular}{ll}
\hline Stage & Consumption \\
\hline Stage 1 & (Most basic) Food 1+ Non-food 1 \\
Stage 2 & Food 1 + Food 2 + Non-food 1 + Non-food 2 \\
Stage 3 & Food 2 + Non-food 2 \\
\hline
\end{tabular}

In the first stage, households with very low incomes still have basic non-food needs, so they rely on in-kind transactions for food, while non-food expenditure is paid for by community service and in-kind transactions. In the second stage, income is enough for subsistence food requirements through in-kind transactions, while additional food is bought at markets using cash. In the second stage, the income elasticity of food can be elastic. Because income increases, households tend to purchase some luxury foods with cash. In the third stage, as income increases, cash transactions prevail for both food and non-food consumption. Due to income increases, the weight of the non-food category out of total expenditure, especially luxury goods, increases, while income elasticity for food decreases monotonically as income increases.

Table 3.10 indicates the development process based on the cases of Tanzania, Vietnam, and the Philippines, and we consider the possibility of the existence of inverse U-shaped Engel curves using numerical examples. We divided the period into four phases: I, II, III, and IV. The amount of food, non-food, and total expenditure in the table is considered depending on the level of economic development.

In the Tanzanian case, we observed an inverse U-shaped Engel curve including in-kind consumption. Looking at the development process, Tanzania stays in the interval between Phases I and III, meaning that Engel's coefficient reaches a maximum value at Phase II; the Engel curve is upward sloping in the left-hand 
Table 3.10 Numerical example of inverse U-shaped Engel curves

(a) Numerical example

\begin{tabular}{|c|c|c|c|c|c|}
\hline Phase & $I$ & $I I$ & $I I I$ & $I V$ & Trend \\
\hline & $(\leftarrow$ & $\begin{array}{l}\text { Tanzania } \\
(\leftarrow \text { Vietnan }\end{array}$ & $\begin{array}{c}\rightarrow) \\
m \text { and th }\end{array}$ & hilippines $\rightarrow$ ) & \\
\hline Food total & 50 & 70 & 107.5 & 120 & $(\pi)$ \\
\hline Food cash & & 30 & 67.5 & 100 & $(\pi)$ \\
\hline Food in-kind & & 40 & 30 & 20 & $(\Delta)$ \\
\hline Non-food total & 30 & 30 & 52.5 & 80 & $(\pi)$ \\
\hline Non-food cash & & 20 & 42.5 & 70 & $(\pi)$ \\
\hline Non-food in-kind & & 10 & 10 & 10 & $(\rightarrow)$ \\
\hline Total expenditure & 80 & 100 & 150 & 200 & \\
\hline Engel's coefficient (\%) & 67.5 & 70 & 65 & 60 & \\
\hline $\begin{array}{l}\text { Total expenditure } \\
\text { excluding in-kind }\end{array}$ & 50 & 110 & 170 & & \\
\hline $\begin{array}{l}\text { Engel's coefficient } \\
\text { excluding in-kind (\%) }\end{array}$ & & 60 & 61 & 58 & \\
\hline
\end{tabular}

Note: Tanzania covers Phases I, II, and III, while Vietnam and the Philippines cover Phases II, III, and IV.

(b) Movement of Engel's coefficient indicating inverse U-shaped Engel curves

\begin{tabular}{lccccc}
\hline & $I$ & $I I$ & III & IV & Trend \\
\hline Engel's coefficient & 67.5 & 70 & 65 & 60 & $(\curvearrowright)$ \\
Engel's coefficient excluding in-kind & & 60 & 61 & 58 & $(\curvearrowright)$ \\
\hline
\end{tabular}

side, and it is downward sloping in the right-hand side of the peak. In Vietnam and the Philippines, we cannot observe an upward-sloping Engel curve including in-kind consumption, meaning that the two countries are in Phases II, III, and IV. In these phases (II, III, and IV), the Engel curve is downward sloping monotonically. On the other hand, the Engel curve excluding in-kind consumption in the two countries is inverse U-shaped. This is shown in Table 3.10b, indicating changes in Engel's coefficient excluding in-kind consumption.

The results of the accumulated empirical analysis on consumer demand behavior draw on cross-sectional data and/or micro-data sets in developed countries, but not micro-data sets in developing countries. Because of this, we observed downward-sloping Engel curves as a stable empirical law. Based on Engel's Law, we note the following characteristics: the food category is classified as a necessary good, and thus income and price elasticity are inelastic. But in the lowest income levels among very poor households in Tanzania and the low income levels among very poor households excluding in-kind consumption in Vietnam and the Philippines, the income elasticity of food expenditure is elastic. This finding is interesting in terms of considering the policy implications of the upward-sloping Engel curve among very poor households in developing countries. Therefore, 
in theoretical terms, we have to reconsider the different characteristics between in-kind and cash consumption in the development process.

\section{Conclusion}

In the present analysis, we considered the role of in-kind consumption in terms of the total consumption expenditure of households. Using Engel curves including and excluding in-kind consumption, we found that when we include in-kind consumption in consumption expenditure, the Engel curve is monotonic downward sloping in Vietnam and the Philippines. On the other hand, when we exclude in-kind consumption from consumption categories, the Engel curve is hump shaped. This finding is obtained by using micro-data sets in developing countries.

Contrary to Engel's Law, we find that the Engel curve is upward sloping in very poor households, meaning that food expenditure as a percentage of income increases with income. Considering the income adjusted by the adult equivalence scale, very poor households increase their food expenditure more than the increase in income. This is because the income elasticity for very poor households is greater than unity.

We also find that there is no significant difference between the various methods for calculating the adult equivalence scale in terms of Engel curves.

Consumer behavior is well described by the specification of the QUAID system. In developing countries, it is possible to have upward-sloping Engel curves when excluding in-kind consumption. In addition to the empirical findings of an inverse U-shaped Engel curve in Tanzania, Vietnam, and the Philippines, we raise some questions about the validity of Engel's Law that require further empirical research in developing nations. Our findings are also suggestive about the different effects of in-kind consumption depending on the stages of economic development that may be relevant in terms of economic and social policies in developing countries, especially those targeting improvement in the standard of living for poor households. 


\section{Appendix}

Table 3A.1 All households in Vietnam (per capita; monetary unit: thousand dong)

\begin{tabular}{|c|c|c|c|c|c|c|c|}
\hline \multirow{2}{*}{$\begin{array}{l}\text { Income } \\
\text { class }\end{array}$} & \multicolumn{5}{|l|}{ Expenditure } & \multicolumn{2}{|c|}{ Engel's coefficient } \\
\hline & Observation & Mean & $\begin{array}{l}\text { Standard } \\
\text { deviation }\end{array}$ & Minimum & Maximum & $\begin{array}{l}\text { Including } \\
\text { in-kind }\end{array}$ & $\begin{array}{l}\text { Excluding } \\
\text { in-kind }\end{array}$ \\
\hline 1 & 459 & 1,595 & 276 & 611 & 1,942 & 0.663 & 0.515 \\
\hline 2 & 459 & 2,169 & 125 & 1,943 & 2,379 & 0.637 & 0.5 \\
\hline 3 & 460 & 2,554 & 99 & 2,379 & 2,721 & 0.605 & 0.488 \\
\hline 4 & 459 & 2,877 & 89 & 2,722 & 3,031 & 0.586 & 0.486 \\
\hline 5 & 460 & 3,173 & 86 & 3,031 & 3,326 & 0.574 & 0.476 \\
\hline 6 & 459 & 3,480 & 87 & 3,327 & 3,629 & 0.563 & 0.471 \\
\hline 7 & 460 & 3,779 & 87 & 3,630 & 3,935 & 0.538 & 0.452 \\
\hline 8 & 459 & 4,091 & 90 & 3,936 & 4,245 & 0.533 & 0.454 \\
\hline 9 & 459 & 4,430 & 108 & 4,245 & 4,627 & 0.521 & 0.447 \\
\hline 10 & 460 & 4,816 & 108 & 4,628 & 5,017 & 0.515 & 0.448 \\
\hline 11 & 459 & 5,238 & 130 & 5,017 & 5,470 & 0.493 & 0.44 \\
\hline 12 & 460 & 5,699 & 136 & 5,471 & 5,942 & 0.476 & 0.427 \\
\hline 13 & 459 & 6,224 & 181 & 5,942 & 6,539 & 0.457 & 0.41 \\
\hline 14 & 460 & 6,874 & 199 & 6,542 & 7,225 & 0.442 & 0.403 \\
\hline 15 & 459 & 7,620 & 231 & 7,227 & 8,022 & 0.437 & 0.402 \\
\hline 16 & 460 & 8,521 & 284 & 8,024 & 9,034 & 0.415 & 0.387 \\
\hline 17 & 459 & 9,678 & 400 & 9,035 & 10,441 & 0.396 & 0.372 \\
\hline 18 & 460 & 11,516 & 668 & 10,447 & 12,789 & 0.362 & 0.343 \\
\hline 19 & 459 & 14,984 & 1,502 & 12,791 & 18,227 & 0.334 & 0.319 \\
\hline 20 & 460 & 37,501 & 48,146 & 18,233 & 633,002 & 0.217 & 0.208 \\
\hline
\end{tabular}




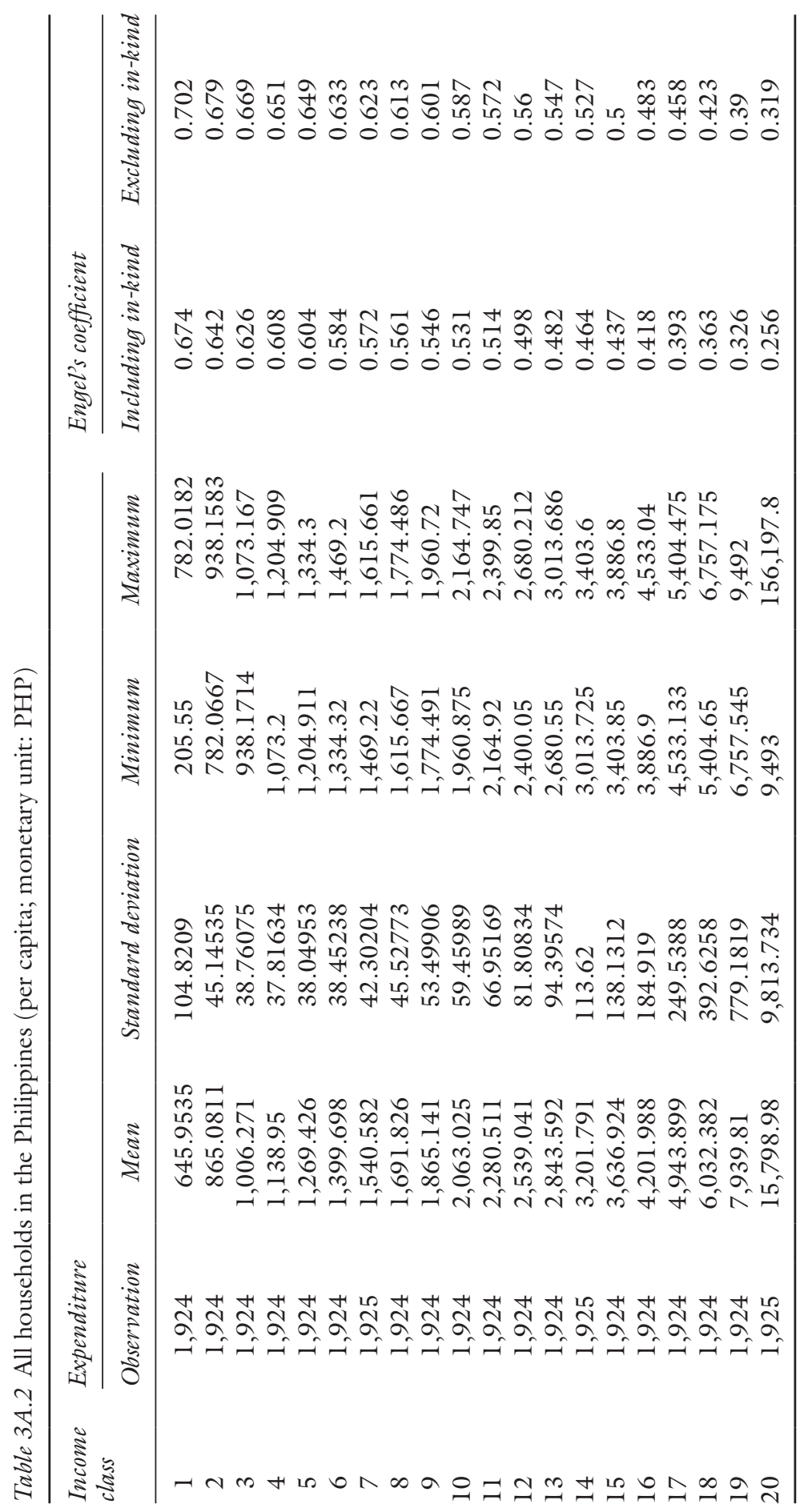




\section{Notes}

1 Currie and Gahvari (2008) surveys the literature.

2 In Tanzania, the Statistics Bureau made its own adult equivalence scale, which is provided in Chapter 2 of this book.

3 In the present analysis, we compare the characteristics of the Engel curve in Tanzania, the Philippines, and Vietnam. According to the World Development Indicators database compiled by the World Bank, the per capita gross domestic product (GDP) of Tanzania in 2007 was US \$419.50, that of Vietnam in 2006 was US \$730, and that of the Philippines in 2006 was US \$1,349.40, enabling us to observe the changes in expenditure patterns and compare them among the countries at different stages of economic development; Vietnam's per capita GDP is nearly double Tanzania's, while the Philippines' per capita GDP is nearly double that of Vietnam's.

4 As indicated in Appendix 3A.1, the Engel curves in Vietnam and the Philippines are downward sloping for all the households including in-kind consumption.

5 In the appendix, we report the movement of the Engel's coefficient for all the households in Vietnam (Table 3A.1) and the Philippines (Table 3A.2).

6 The specification of QUAID was strongly influenced by the analysis of Tanzanian consumer behavior in Chapter 2. In Tanzania, we observed the inverse U-shaped Engel curve including in-kind consumption, and the specification of QUAID is reasonable.

7 Kedir and Girma (2007) analyzed consumer behavior in Ethiopia using quadratic Engel curves. However, their sophisticated empirical analysis may be wrong regarding income elasticity of food expenditure; in their paper, the food category is classified as inferior goods, meaning that income elasticity is negative.

8 For details about estimating the two poverty lines, refer to Chapter 2 in this monograph.

\section{References}

Allen, R.G.D. (1942), "Expenditure patterns of families of different size," in O. Lange, F. McIntyre and T. Yntema (Eds.), Studies in Mathematical Economics, Cambridge University Press: Cambridge, UK.

Banks, J., R. Blundell and A. Lewbel (1997), "Quadratic Engel curves and consumer demand," Review of Economics and Statistics, 79, 527-539.

Currie, J. and F. Gahvari (2008), "Transfers in cash and in-kind: Theory meets the data," Journal of Economic Literature, 46(2), 333-383.

Deaton, A. and J. Muellbauer (1980), "An almost ideal demand system," American Economic Review, 70, 312-326.

Fraker, T. M. (1990), Effects of Food Stamps on Food Consumption: A Review of the Literature. Mathematica Policy Research Inc.: Washington, DC.

Greene, W. H. (2012), Econometric Analysis. 6th edition, Pearson: New York.

Hoynes, H. W. and D. W. Schanzenbach (2009), "Consumption responses to in-kind transfers: Evidence from the introduction of the Food Stamp Program," American Economic Journal: Applied Economics, 1, 109-139.

Kedir, A. M. and S. Girma (2007), "Quadratic Engel curves with measurement error: Evidence from a budgetary survey," Oxford Bulletin of Economics and Statistics, 69, $123-138$.

Koenker, R. and G. Bassett, Jr. (1978), “Regression quantiles,” Econometrica, 46, 33-50. 
Maki, A. and M. A. Kamwe (2012), “Does Engel's Law apply to households in a developing country?” Discussion Paper Series No. 11, Tokyo International University: Kawagoe, Japan.

Prais, S. J. and H. S. Houthakker (1955), The Analysis of Family Budgets. Cambridge University Press: Cambridge, UK.

Slesnick, D. T. (1996), “Consumption and poverty: How effective are in-kind transfers?" Economic Journal, 106, 1527-1545. 


\title{
4 Informal agriculture sector in Indonesia
}

\author{
Big in size, small in contribution, \\ and full of the working poor
}

\author{
Kadarmanto*
}

\section{What is the informal economy?}

While the economies of developing member countries (DMCs) continue to grow at high rates, recent research indicates that there are widening inequalities in the standard of living and that the poor are being bypassed by growth. Based on the household income and expenditure survey data of DMCs, the special chapter of the 2008 Key Indicators (Asian Development Bank [ADB] 2008) provides evidence that absolute inequalities have increased in many countries in Asia and that the rich have grown richer faster than the poor. How can this problem be addressed? One way is to improve labor market opportunities for workers since employment is the major vehicle for the poor to rise out of poverty. The primary channel through which economic growth reduces poverty is employment. When employment opportunities improve as economic activity expands, the benefits of growth will be broadly shared. However, access to employment is not sufficient. Kapsos (2004) shows that over 500 million employed individuals worldwide live in households that fall below the dollar-a-day poverty line.

To cope with poverty, the poor take on informal employment like subsistence informal jobs, secondary jobs, and occasional jobs. This type of labor arrangement has grown in many DMCs, making the informal sector a major component of the economy. Such situations also occur in Indonesia, as it is a DMC. Informal employment in the country represents a large share of total employment. Moreover, informal employment is, on average, precarious, low paid, and risky. Therefore, the informal sector contributes significantly to Indonesia's economy, particularly in terms of employment by providing economic opportunities to those who have been displaced from or cannot be absorbed by the formal sector. Hence, understanding the link between informal employment and poverty is critical for formulating policy. Understanding the connection between employment and poverty requires analysis of the full employment structure of the country.

\section{Informal workers}

Street vendors, three-wheel-vehicle drivers, roadside barbers, or those who work on the streets or in the open air are more visible examples of workers in the

*The author thanks Asian Development Bank (ADB) for funding this research and providing technical assistance. 


\section{Kadarmanto}

informal economy. Less visible activities and workers who work in small shops such as those that repair bicycles and motorcycles, make furniture and metal parts, and sort and sell cloth, for example, are also included in the informal economy. In extreme cases, the least visible informal workers, such as those selling or producing goods or services from their homes, may also be included in the informal economy. In other words, all home-based workers who work on their own account are examples of informal workers.

Informal workers may also be found in restaurants, hotels, construction, and agriculture as casual or day laborers. Such workers may also be employed as temporary office helpers. Without secure contracts, worker benefits, or social protection, such workers are informally employed. Though they are highly segmented in terms of workplace, sector, employment status, and gender, they do have some issues in common: unsecure working conditions and a lack of social protection.

\section{Informal sector}

The 1993 International Conference of Labor Statisticians (ICLS) adopted an international statistical definition of the "informal sector" that was included in the revised International System of National Accounts (1993 SNA). The definition was based on the production unit or enterprise rather than on employment relations. With such a definition, a separate accounting of gross domestic production (GDP) in the informal sector can be performed. ${ }^{1}$

\section{Informal economy}

"Informal economy" is a broader concept that incorporates certain types of informal employment that were not included in the 1993 international statistical definitions of the "informal sector." Both the enterprise and employment relations are incorporated in the definition of the informal economy.

In the expanded conceptual framework, the informal economy is viewed as comprising informal employment (without a secure contract, worker benefits, or social protection) both inside and outside informal enterprises (see Table 4.1), such as:

- Informal employment in informal enterprises (small unregistered or unincorporated enterprises), including employers, employees, own-account workers, and unpaid family workers in informal enterprises.

- Informal employment outside informal enterprises (for formal enterprises, for households, or with no fixed employer), including domestic workers, casual or day laborers, temporary or part-time workers, industrial outworkers (including those who work at home), and unregistered or undeclared workers.

Thus, the informal economy consists of a wide range of informal enterprises and informal jobs. This informal economy is a place for the poor to survive since 


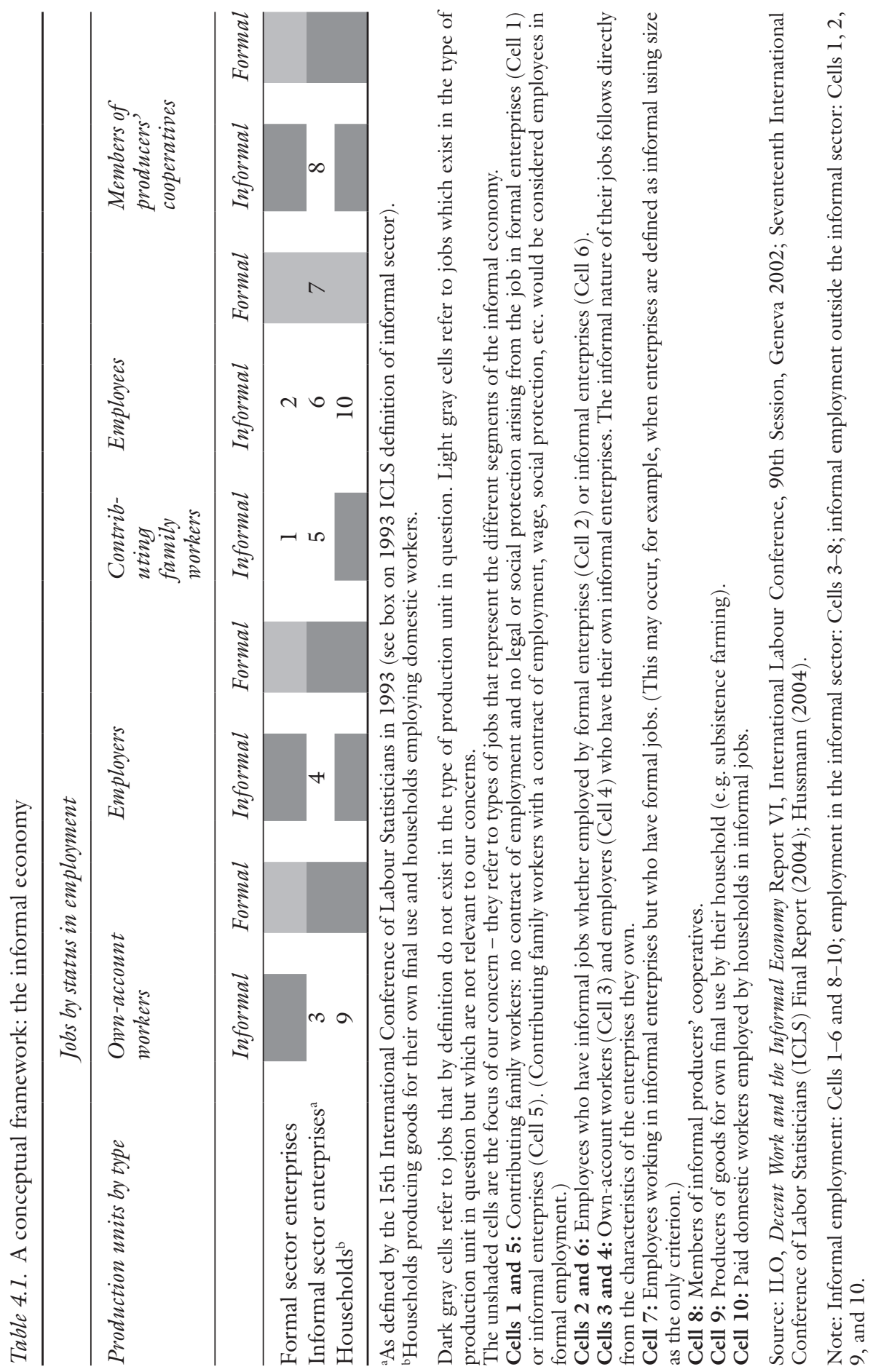


they mostly have less skills and less education, which are requirements for engaging in the formal economy. Thus, there is a link between working in the informal economy and being poor. This is because those who work in the informal economy are generally not covered by labor legislation or social protection and earn less, on average, than workers in the formal economy.

To summarize, according to the recommendations and guidelines of the 15th and the 17th ICLS, the "informal sector" and "informal employment" refer to distinct concepts. The "informal sector" is an enterprise-based concept of informal economic activities which includes both informal own-account enterprises and enterprises of informal employers. "Informal employment," on the other hand, refers to a broader, job-based concept of informal activities.

\section{ICLS definition of the informal sector}

The resolution concerning statistics of employment in the informal sector adopted by the 15th International Conference of Labour Statisticians in 1993 defined the informal sector as follows:

The informal sector is regarded as a group of household enterprises or unincorporated enterprises owned by households that includes:

- informal own-account enterprises, which may employ contributing family workers and employees on an occasional basis

- enterprises of informal employers which employ one or more employees on a continuous basis.

The enterprise of informal employers must fulfill one or both of the following criteria: the size of the unit must be below a specified level of employment and the enterprise or its employees must not be registered.

This framework proposed by the ICLS resolution allows countries to adapt the basic operational definition and criteria to their specific circumstances. In particular, flexibility is allowed with respect to the upper limit on the size of employment; the introduction of additional criteria such as non-registration of either the enterprise or its employees; the inclusion or exclusion of professionals or domestic employees; and the inclusion or exclusion of agriculture.

Source: International Labor Organization (ILO) Report of the 15th International Conference of Labour Statisticians, Geneva 1993.

\section{The gap between the formal and informal sectors}

\section{Industry}

The two provinces are fast-growing economies in Indonesia. As of 2009, DI Yogyakarta had a population of 3,501,900, while Banten's population stood at $9,782,800$. While the country's total output is growing at 4.93 percent on 
average, Yogyakarta and Banten posted growth of 4.39 percent and 4.69 percent, respectively. Estimates for 2009 show that the per capita (total) gross valued added (GVA) in Yogyakarta amounted to rupiah (Rp) 11.83 million, while in Banten this is estimated at Rp 13.60 million. In particular, more than half of Yogyakarta's economy is driven by its four largest sectors: agriculture, hunting, forestry, and fishery (15 percent); public administration and defense (14 percent); manufacturing ( 13 percent); and hotels and restaurants ( 12 percent).

DI Yogyakarta is also known as the "city of education" because of the volume of educational institutions in the province. As the cultural center of Java, the province also draws 45,883 tourists who arrive at Adi Sucipto Airport, Yogyakarta, every year. In addition, its economy is also supported by strong agricultural development and export-oriented production. On the other hand, Banten, formerly a part of West Java, has been considered a separate province since 2000 by virtue of Act No. 23. Banten is strategically located near Jakarta, which has helped manufacturing and wholesale and retail trade to flourish in the province. The Port of Merak, also in Banten, is one of the ports on the island of Java with the highest export volume in Indonesia. In 2009, the manufacturing industry accounted for as much as 43 percent of its total GVA, followed by wholesale and retail trade (17 percent). In general, Banten's factories and industrial sectors, accompanied by infrastructure, have continuously contributed to accelerating the economic growth of the province. Recently, Banten has started promoting eco-tourism spots, such as natural reserves, water tourism, and stone tourism. Overall, preliminary survey estimates suggest that the informal sector accounts for 37.3 percent and 26.6 percent of the total gross regional domestic product (GRDP) of Yogyakarta and Banten, respectively. Figure 4.1 depicts the respective contribution of the informal sector, by industry, for the two provinces.

At a glance, Yogyakarta's informal enterprises are major players in the sectors of agriculture, forestry, and fishery; manufacturing; and wholesale and retail trade, accounting for more than half of its respective GVA. In particular, these sectors already account for $\mathrm{Rp} 11.30$ trillion or 73.10 percent of the total informal sector's GVA of Yogyakarta. Noted to be relatively more industrialized than Yogyakarta, the bulk of GVA among informal enterprises in Banten comes from wholesale and retail trade; agriculture, forestry, and fishery; and hotels and restaurants, contributing Rp 27.21 trillion or 76.87 percent of the total informal sector's GVA of Banten. In both provinces, service-oriented sectors, such as electricity, gas, and water; public administration; defense and social security; and transport, communications, and storage, are mostly comprised of formal enterprises. Other capital-intensive sectors, ${ }^{2}$ such as finance, provide limited opportunities for entrepreneurial activity among informal enterprises, as these sectors require a larger pool of human and financial capital.

\section{Agriculture and nonagriculture sectors}

In Yogyakarta, the informal sector in agriculture contributed Rp 5.65 trillion or 88.95 percent of its total GVA, while the informal sector in nonagriculture 


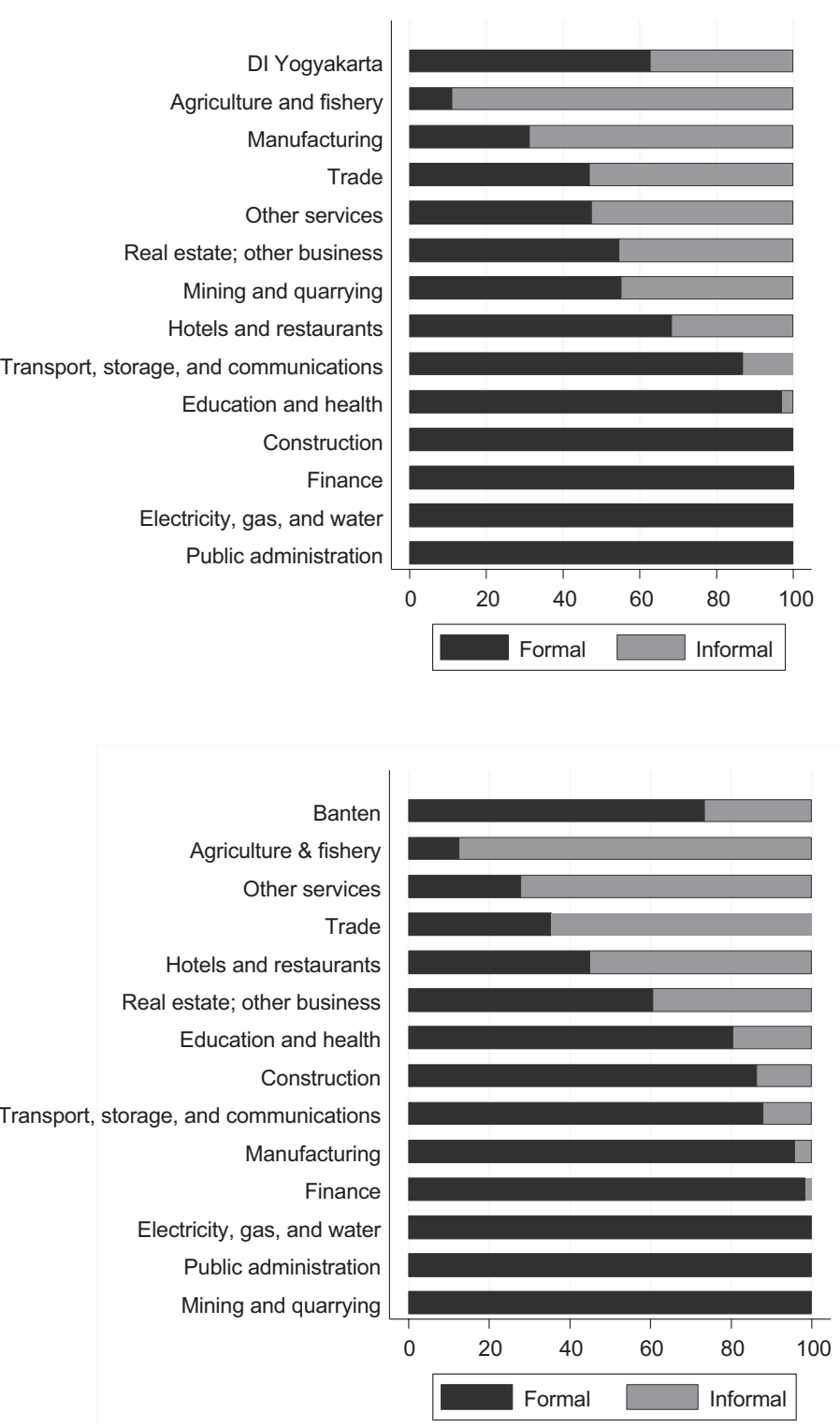

Figure 4.1 Contribution to GDP by sector and industry (\%) 


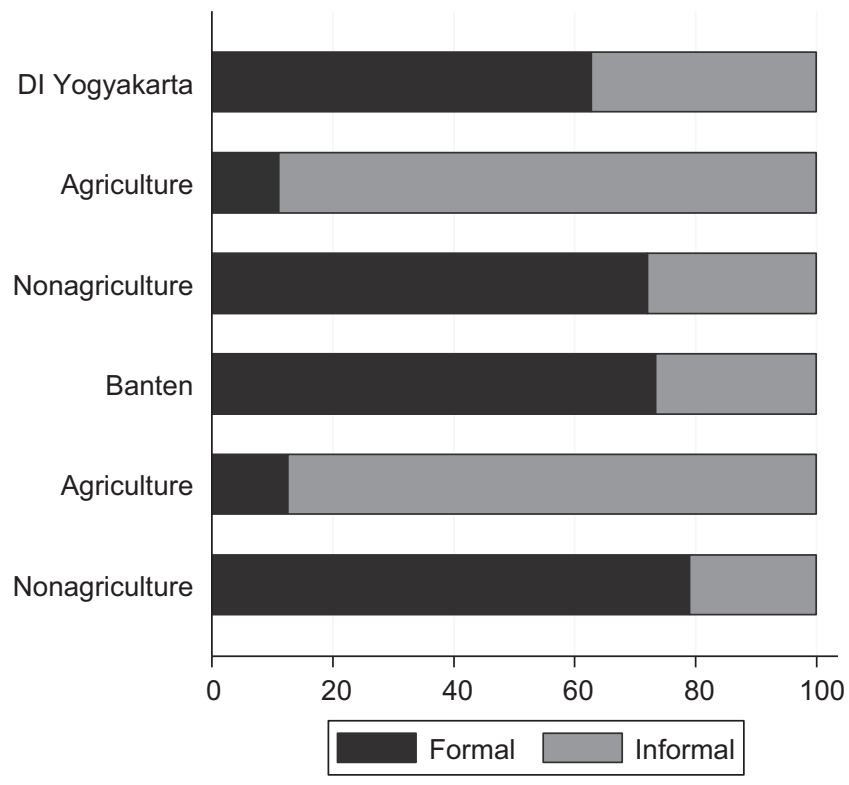

Figure 4.2 Informal sector production in the agriculture and nonagriculture sectors $(\%)$

generated Rp 9.80 trillion or 27.95 percent of gross domestic product GDP of nonagriculture. The fact that Yogyakarta's economy is based on agriculture is one of the reasons for the high contribution of the informal sector in agriculture. Yogyakarta's landscape, climate condition, and its reputation as one of the major food suppliers to the country are key factors that have allowed agriculture to flourish as the dominant sector in this province.

In Banten, the informal sector in agriculture contributed Rp 9.8 trillion or 87.43 percent of its total GVA, while nonagriculture contributed Rp 25.59 trillion or 21 percent of GDP of nonagriculture. It seems that, in Banten, the informal sector engaged in nonagriculture production contributed more than that engaged in agriculture. Banten's economy is well known as a buffer zone for the metropolitan area of Jakarta. In particular, although a number of large multinational companies' headquarters are in the capital city of Jakarta, most of its factories are situated in Banten. Hence, it is not surprising that the contribution of manufacturing industries exceeds that of the agriculture sector in the province.

\section{Labor productivity}

This section investigates how productively labor is used to generate economic output among informal enterprises in Yogyakarta and Banten. Productivity measures reflect the joint influence of changes in capital, intermediate inputs, technical 
efficiency, economies of scale, and capacity utilization of enterprises (Organisation for Economic Co-operation and Development [OECD] 2001).

A variety of productivity measures can be used. For example, gross outputbased labor productivity measures labor requirements per unit of output, while value added-based labor productivity serves as an alternative measure that can be directly linked with existing income-based measures of living standards. For a detailed comparison of these statistical measures, readers are referred to the OECD Manual on Measuring Productivity (OECD 2001). This section uses the value added-based measure of labor productivity.

Whereas total labor productivity is usually computed per worker, it is more straightforward to compute labor productivity in the informal sector by job. This is because a person may have multiple jobs: his or her first job may be in the formal sector, while the second may be in the informal sector. Consequently, it is operationally difficult to determine whether to classify this person in the formal or the informal sector. For comparability, all labor productivities provided in this section are expressed on a per-job basis.

Based on the 2009 survey results, total labor productivity, measured by the ratio of GRDP to total employment (i.e. the total number of jobs), is estimated at Rp 16.26 million in Yogyakarta. In Banten, it is estimated at Rp 33.90 million, more than twice that in Yogyakarta.

Although the concept of the formal sector ${ }^{3}$ in this section also accounts for subsistence household production, it is not surprising to note that labor productivity in the formal sector exceeds that of the informal sector by severalfold. On average, a job in Yogyakarta's formal sector contributed $\mathrm{Rp} 76.55$ million value added, while its informal sector counterpart contributed Rp 7.00 million. On the other hand, labor productivity in Banten's informal economy is estimated at Rp 12.74 million per job, about six times less than the Rp 85.12 million contribution of an average job in the formal sector in 2009.

Labor productivity for the informal sector in real estate, renting, and business activities in Yogyakarta showed the highest figure of $\mathrm{Rp} 68.46$ million, indicating the flourishing opportunities for informal players to tap the market created by the city's famous landmark: educational institutions. In Yogyakarta, the lowest labor productivity is in finance, which recorded a figure of Rp 0.07 million, probably because of the steep competition posted by the existing players in this capitalintensive industry.

The informal sector industry, such as real estate and other business activities, had the highest labor productivity in Banten. Labor productivity in real estate recorded Rp 23.7 million, indicating that, in Banten, informal sector workers engaged in this industry are more productive compared with informal workers in other industries. The lowest labor productivity, at $\mathrm{Rp} 1.7$ million, occurred in finance.

Overall, the estimates provided in this section support the notion that the informal sector accounts for a significant portion of the economy. After estimating the contribution of the informal sector to its respective regional economy, the next section examines the productivity and wage/earnings gap. 

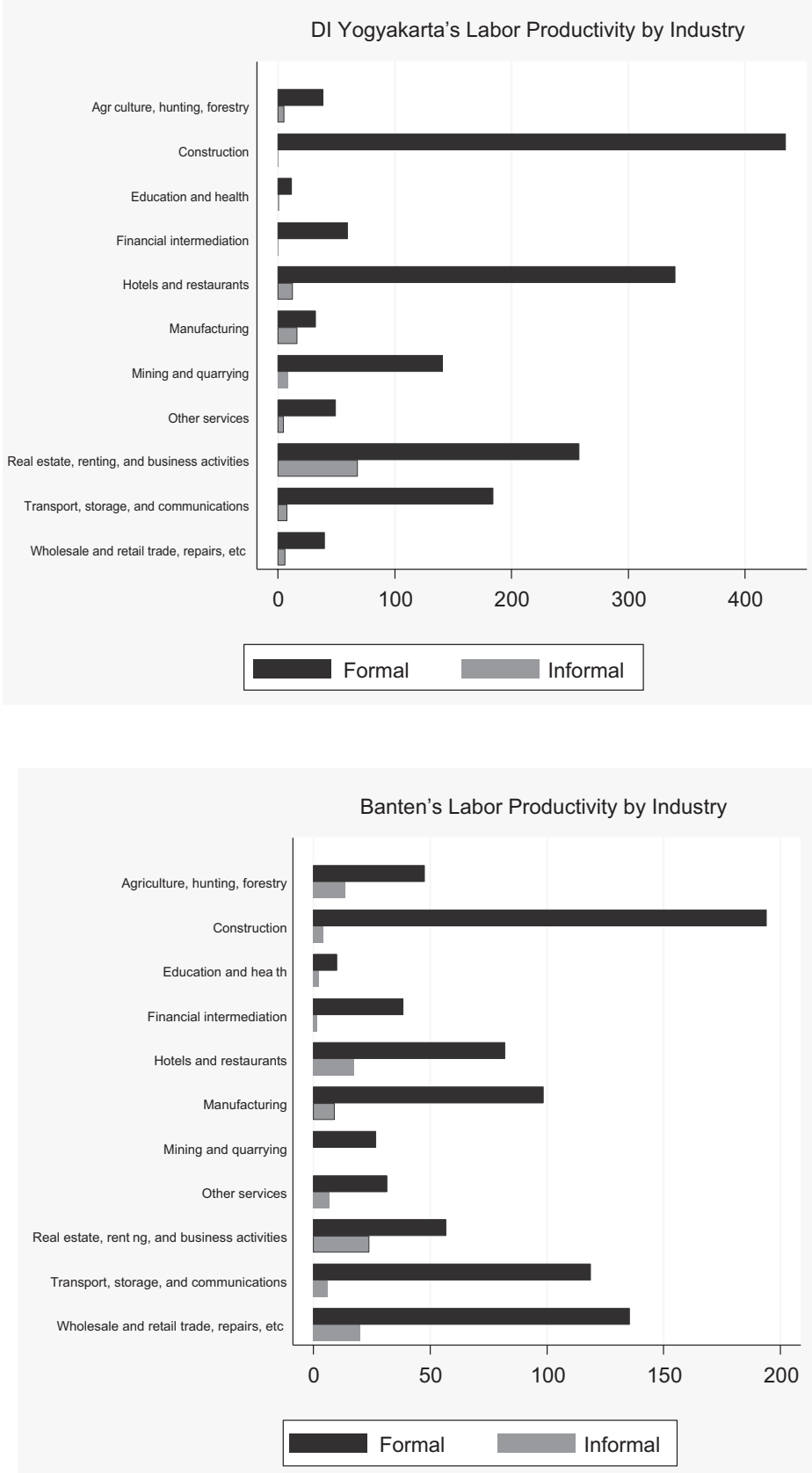

Figure 4.3 Labor productivity by industry in the formal and informal sectors (Rp million) 


\section{Kadarmanto}

\section{Wage/earnings}

On the whole, the average wage/earnings for informal employment are much lower than for formal employment, as shown in Table 4.2. Across provinces, the table shows that workers in formal employment receive significantly higher earnings - more than twice as much on average - than those in informal employment. Specifically in Yogyakarta, formal employees' wages are three times what informal employees earn. Thus, there is a big gap between formal and informal employment. The situation of informal employment workers in Banten is a little bit better than their counterparts in Yogyakarta in the sense that the gap between the formal and informal average wage becomes smaller. Formal employees, for example, received only less than twice (1.48) as much money as that of informal employees. A similar situation can also be observed among the self-employed. The informal self-employed in Banten earn only 0.65 times what the formal selfemployed acquire.

\section{Productivity and wage/earnings}

As shown in Table 4.3, higher compensation given to formal jobs than to informal jobs both in Yogyakarta and Banten has increased productivity in formal jobs. With average earnings of Rp 1,893,031 (\$205), formal jobs in Yogyakarta could provide productivity of Rp 76.55 million. On the other hand, with a smaller average wage of Rp 811,806 (\$88), informal jobs could only provide productivity of Rp 7 million.

Similar figures are also shown in Banten. Formal jobs could provide productivity of $\mathrm{Rp} 85.12$ million with an average wage of $\mathrm{Rp} 1,704,493$ (\$185), which is

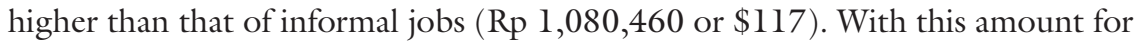
the average wage, informal jobs in Banten provided productivity of less than one seventh of formal jobs.

Table 4.2 Average wage and earnings by employment status and nature of employment (monetary unit: Rp)

\begin{tabular}{lcccr}
\hline Class of workers & Formal & Informal & Ratio & \multicolumn{1}{c}{ All } \\
\hline Yogyakarta & & & & \\
Employees & $1,893,031$ & 775,247 & 0.41 & $1,220,291$ \\
Self-employed & - & 853,233 & - & 853,233 \\
Average earnings & $1,893,031$ & 811,806 & 0.43 & $1,092,962$ \\
Banten & & & & \\
Employees & $1,710,182$ & $1,158,954$ & 0.68 & $1,426,725$ \\
Self-employed & $1,491,483$ & 970,822 & 0.65 & 975,953 \\
Average earnings & $1,704,493$ & $1,080,460$ & 0.63 & $1,304,547$ \\
\hline
\end{tabular}


Table 4.3 Productivity and wage/earnings

\begin{tabular}{lrr}
\hline Job & Productivity (million Rp) & Wage/earnings $(R p)$ \\
\hline Yogyakarta & & \\
Formal & 76.55 & $1,893,031$ \\
Informal & 7.00 & 811,806 \\
All & 16.26 & $1,092,962$ \\
Banten & & \\
Formal & 85.12 & $1,704,493$ \\
Informal & 12.74 & $1,080,460$ \\
All & 33.90 & $1,304,547$ \\
\hline
\end{tabular}

\section{Poverty: households engaged in informal employment in agriculture or nonagriculture sectors}

\section{Working poor}

The analysis so far suggests that a higher risk of income poverty is characterized by working people engaged in informal employment. This higher risk is mainly caused by those engaged in informal employment, which provides low earnings. It is well known that most households (particularly poor households) rely on jobs as their income source. As a consequence, low-income households will likely be in the low-income class and will raise the incidence of poverty.

In order to create a link between employment, which is at the individual level, and poverty, which is at the household level, two techniques are used to clearly show the connection - namely, defining poverty at the household level using the concept of the "working poor" and examining how household income derived from different kinds of employment influences the household's risk of poverty.

Individuals will be classified as part of the working poor if they are taking part in a certain type of employment and living in a poor household. Combining the specific labor market characteristics with poverty data, we can see a clearer picture of the relationship between poverty and employment through the working poverty estimate compared with that of traditional poverty. The working poverty rate is then calculated as the ratio between the number of working poor individuals and total employment. ${ }^{4}$ As shown in Table 4.5, working poor ${ }^{5}$ individuals are mostly those who are engaged in informal employment. The working poverty rate is at 16.13 percent in Yogyakarta and at 5.88 percent in Banten.

It must be noted that those working in formal employment are not free from poverty, particularly those who are engaged as casual workers in the agriculture sector. All formal casual workers in the agriculture sector in Yogyakarta but not in Banten are categorized as the working poor; they represent only 0.02 percent of total employment (Table 4.6). 


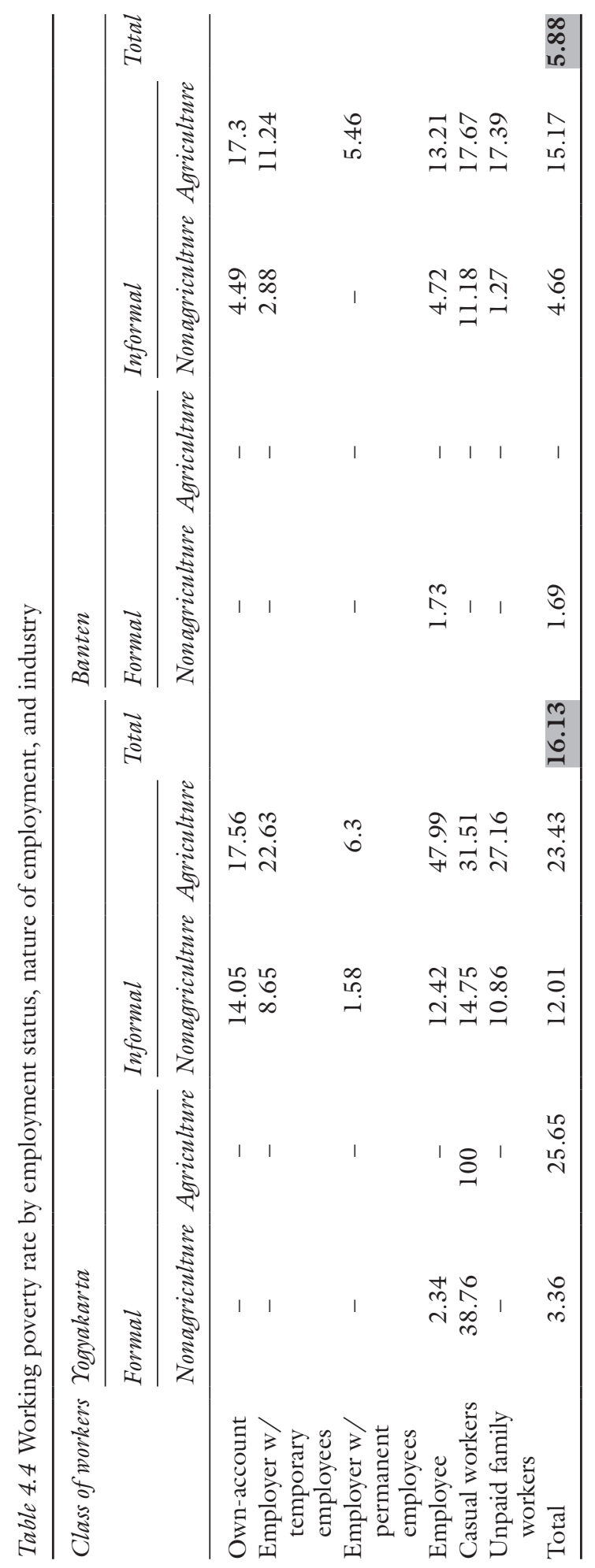




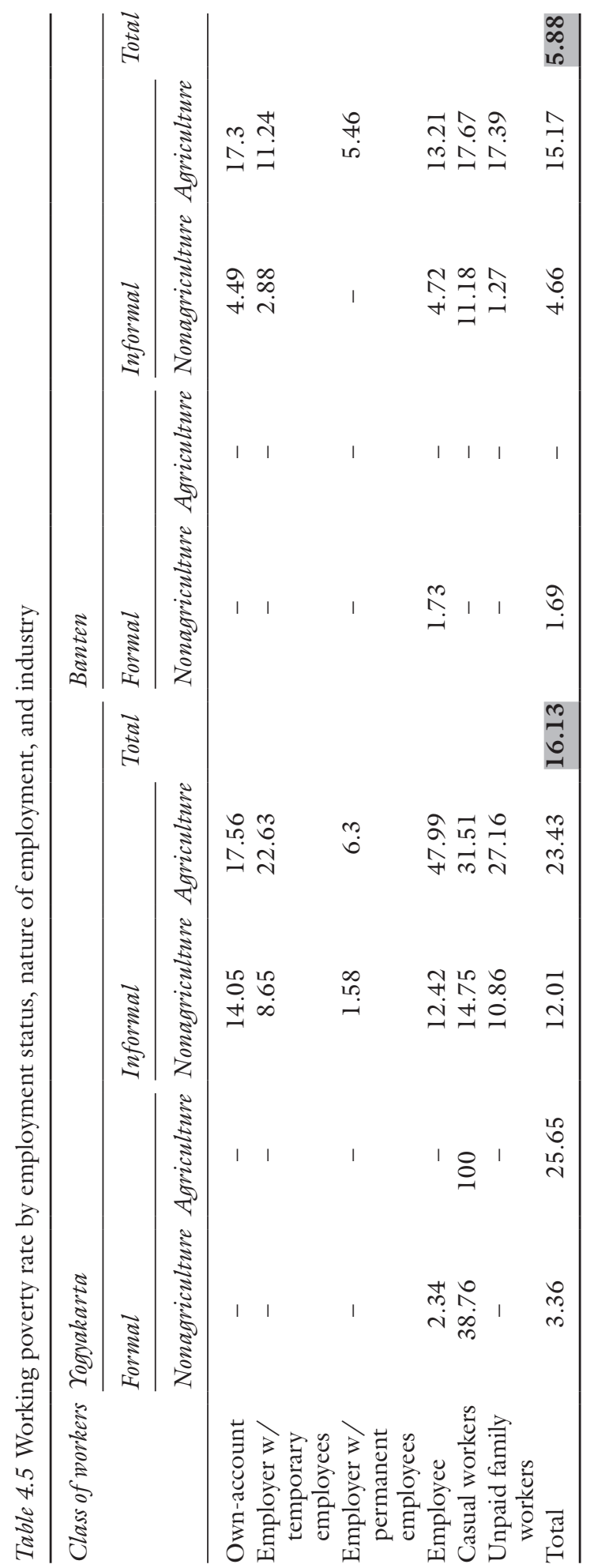




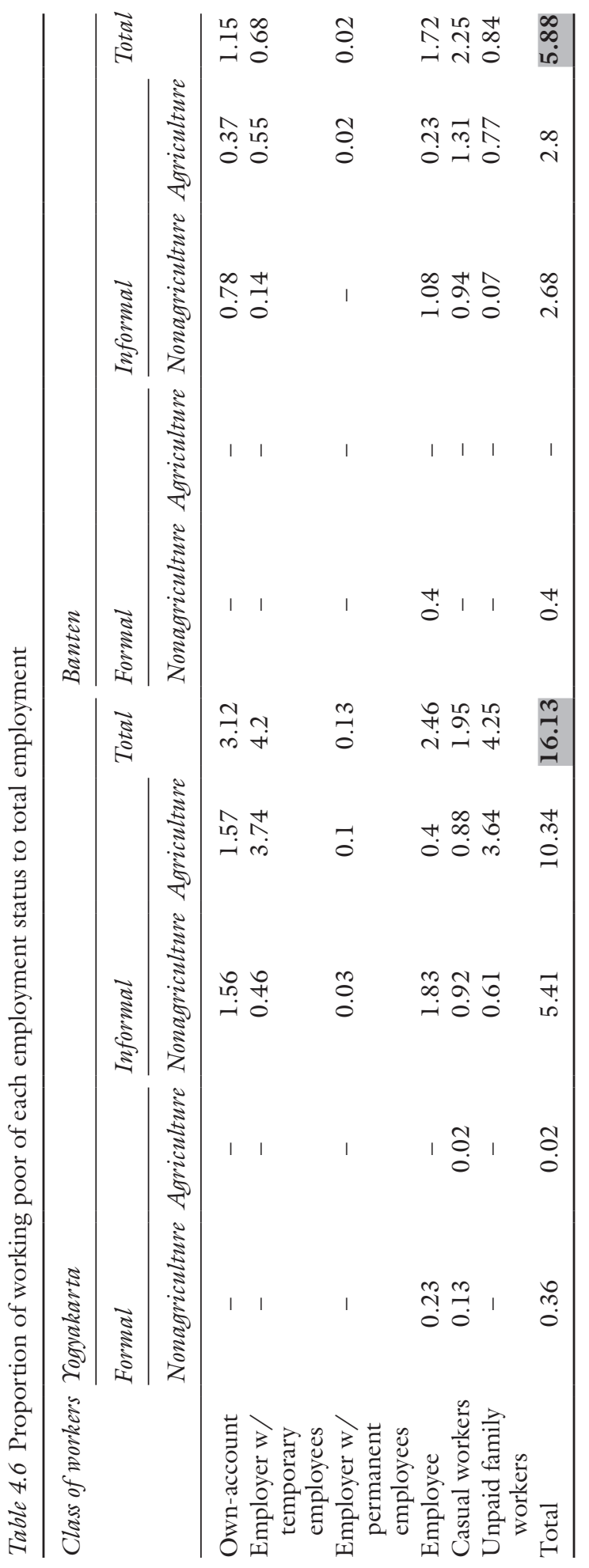


Formal employees and formal casual workers are two classes of workers that contribute to working poverty in Yogyakarta, whereas employees are the only class of workers in formal employment in the nonagriculture sector which can be categorized as poor in Banten. Thus, this confirms that the number of the working poor in informal employment is higher than that in formal employment. Informal agricultural workers account for the highest numbers of the working poor in Yogyakarta and in Banten (Table 4.6). Employers with temporary workers have the highest risk of poverty if they are engaged in agricultural informal employment in Yogyakarta, whereas those classified as casual workers working in agricultural informal employment are the most vulnerable class in terms of poverty in Banten. Unpaid family workers have the second-highest risk of poverty in both provinces.

\section{Poverty rate for households that sustain themselves on informal employment}

The second approach to linking poverty and employment is to show the poverty rates for households that sustain themselves on informal employment income by industry and type of household. If a household with at least one person employed as an informal worker and no other household member employed outside of the informal economy, such a household is then defined as a household that sustains itself on informal employment income. Unlike the first approach, this approach defines poverty at the household level like the official poverty figures. It has already been determined that the proportion of the population below the specified poverty line is officially called the "poverty estimate." As previously mentioned, the calculation of the poverty line in Indonesia is based on the consumption expenditure data. Thus, individuals with consumption below the poverty line are defined as "poor." In the discussion using the second approach, very simple definitions of the groups of household/individuals are adopted. The poor are further classified into two classes: those with consumption of less than 80 percent of the poverty line are classified as "very poor," while the remaining poor are classified as "moderately poor."

Table 4.7 presents the (poor) poverty ratios among individuals in households sustaining themselves on informal employment. No informal employers with permanent workers but that are in the nonagriculture sector belong to the poor group. Households that depend mostly on informal employment in agriculture have the highest poverty rates compared to other types of households in Yogyakarta. Nearly three fourths of households belonging to this group are poor; this type of household still dominates the very poor ( 63.15 percent), as shown in Table 4.8 .

On the other hand, households that depend mostly on informal nonagriculture employers with temporary workers are the household types that are the most vulnerable to poverty in Banten. This type of household, however, is not the poorest household. As a matter of fact, the poorest households are mostly those with casual workers in the agriculture sector rather than nonagriculture employers 
Table 4.7 Poverty ratios among individuals in households sustaining themselves on informal employment by household employment income type and industrial sector (poor)

\begin{tabular}{lcccccc}
\hline $\begin{array}{l}\text { Household } \\
\text { industrial sector }\end{array}$ & \multicolumn{1}{l}{ Household income type } \\
\cline { 2 - 7 } & $\begin{array}{l}\text { Own- } \\
\text { account }\end{array}$ & $\begin{array}{l}\text { Employer w/ } \\
\text { temporary } \\
\text { employees }\end{array}$ & $\begin{array}{l}\text { Employer w/ } \\
\text { permanent } \\
\text { employees }\end{array}$ & Employee & $\begin{array}{l}\text { Casual } \\
\text { workers }\end{array}$ & $\begin{array}{l}\text { Unpaid } \\
\text { family } \\
\text { workers }\end{array}$ \\
\hline Yogyakarta & & & & & & \\
Agriculture & 19.28 & 16.27 & - & 72.51 & 43.48 & 46.37 \\
Nonagriculture & 22.62 & 14.06 & 7.48 & 8.78 & 14.8 & 19.36 \\
All & 21.33 & 16.04 & 5.19 & 14.62 & 27.51 & 37.33 \\
Banten & & & & & & \\
Agriculture & 31.99 & 4.41 & - & 12.93 & 30.42 & 14.87 \\
Nonagriculture & 5.3 & 32.31 & - & 6.08 & 11.42 & - \\
All & 10.5 & 10.6 & - & 6.98 & 22.48 & 8.13 \\
\hline
\end{tabular}

Table 4.8 Poverty ratios among individuals in households sustaining themselves on informal employment by household employment income type and industrial sector (very poor)

\begin{tabular}{|c|c|c|c|c|c|c|}
\hline \multirow{2}{*}{$\begin{array}{l}\text { Household } \\
\text { industrial sector }\end{array}$} & \multicolumn{6}{|c|}{ Household income type } \\
\hline & $\begin{array}{l}\text { Own- } \\
\text { account }\end{array}$ & $\begin{array}{l}\text { Employer w/ } \\
\text { temporary } \\
\text { employees }\end{array}$ & $\begin{array}{l}\text { Employer w/ } \\
\text { permanent } \\
\text { employees }\end{array}$ & Employee & $\begin{array}{l}\text { Casual } \\
\text { workers }\end{array}$ & $\begin{array}{l}\text { Unpaid } \\
\text { family } \\
\text { workers }\end{array}$ \\
\hline \multicolumn{7}{|l|}{ rogyakarta } \\
\hline Agriculture & 3.62 & 8.69 & - & 63.15 & 6.2 & 21.03 \\
\hline Nonagriculture & 8.19 & - & - & 5.92 & 4.11 & 12.27 \\
\hline All & 6.42 & 7.81 & - & 11.16 & 5.04 & 18.1 \\
\hline \multicolumn{7}{|l|}{ Banten } \\
\hline Agriculture & 16.41 & - & - & - & 17.23 & - \\
\hline Nonagriculture & 1.36 & - & - & 3.85 & 3.53 & - \\
\hline All & 4.29 & - & - & 3.35 & 11.51 & - \\
\hline
\end{tabular}

with temporary workers in Banten. This indicates that informal employers with temporary workers belong to "moderately poor" households.

What we can infer from Tables 4.7 and 4.8 is that two classes of workers in the informal sector that should be paid special attention are informal casual workers and unpaid family workers. These two types of workers are mostly characterized by a lack of social protection and irregular wages/earnings. Particular attention should be paid to informal employers in agriculture, especially in Yogyakarta, as 
it is a province that relies mostly on the agriculture sector for economic growth. Informal employers in agriculture are dominant in the poor and very poor classifications.

There is a wage discrepancy between urban and rural workers within the same class of workers. Therefore, it is also critical to differentiate between urban and rural informal employment. As a result of rural development, rural areas are characterized by growing non-farm employment. Thus, jobs in rural areas are not only in agriculture. Therefore, the urban and rural groups and the agriculture and nonagriculture sectors should be analyzed separately.

As shown in Table 4.9, in less industrialized provinces like Yogyakarta, the poverty rate of urban households that sustain themselves on informal employment mostly depending on nonagriculture activities is higher than that of similar households in rural areas. On the other hand, in more industrialized provinces such as Banten, the poverty rate between the two is the other way round. In other words, the poverty rate of urban households that sustain themselves on informal employment depending mostly on nonagriculture activities ( 5.80 percent) is lower than that of similar households in rural areas, which is registered at 8.67 percent. However, the two provinces consistently show that urban households that sustain themselves on informal employment depending mostly on agricultural jobs are at the highest risk of poverty. In Banten, for example, almost half of such households are poor. It seems that nonagriculture informal employment in rural areas is a way for the rural poor to escape from poverty. As shown in Table 4.10 supplementing the previous discussion on wage and earnings (Tables 4.2 and 4.3), the average wage/earnings of nonagriculture informal employment are higher those of rural employment in Banten. In Yogyakarta, despite the wage/earnings of nonagriculture rural informal employment being lower than those of urban employment, it seems that informal nonagriculture jobs are the best choice for rural workers if they wish to escape from poverty without migrating to the city and with no opportunity to be engaged in a formal job.

None of the nonagriculture households that sustain themselves on informal employment is categorized as very poor in Yogyakarta, but this is not the case

Table 4.9 Poverty ratios among individuals in households sustaining themselves on informal employment by urbanity

\begin{tabular}{|c|c|c|c|c|c|c|c|c|}
\hline \multirow{3}{*}{$\begin{array}{l}\text { Housebold } \\
\text { industrial sector }\end{array}$} & \multicolumn{4}{|c|}{ Yogyakarta } & \multicolumn{4}{|l|}{ Banten } \\
\hline & \multicolumn{2}{|c|}{ Very poor } & \multicolumn{2}{|l|}{ Poor } & \multicolumn{2}{|c|}{ Very poor } & \multicolumn{2}{|l|}{ Poor } \\
\hline & Urban & Rural & Urban & Rural & Urban & Rural & Urban & Rural \\
\hline Agriculture & 19.19 & 10.34 & 36.54 & 29.2 & 22.36 & 5.78 & 48.5 & 15.77 \\
\hline Nonagriculture & 8.23 & - & 16.82 & 4.62 & 3.36 & 1.98 & 5.8 & 8.67 \\
\hline All & 11.14 & 7.78 & 22.04 & 23.12 & 5.46 & 3.95 & 10.52 & 12.33 \\
\hline
\end{tabular}




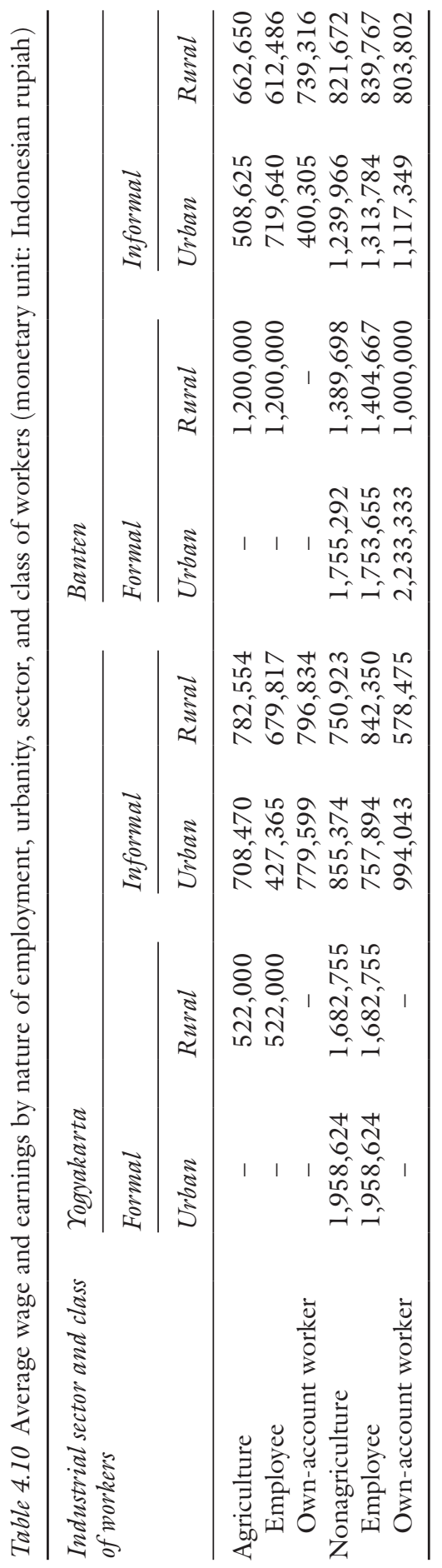


in the industrialized province of Banten. In general, more "moderately poor" households sustaining themselves on informal employment live in rural areas, as the poverty rate in terms of the "very poor" is higher in urban areas than in rural areas.

\section{Case study of regional differences between the two provinces}

The two provinces in this case study are Yogyakarta and Banten. These two provinces are fast-growing economies in Indonesia. As of 2009, Yogyakarta had a population of 3,501,900, while Banten's population stood at 9,782,800. While the country's total output is growing at 4.93 percent on average, Yogyakarta and Banten posted growth of 4.39 percent and 4.69 percent, respectively. Yogyakarta is also known as the "city of education" because of the number of educational institutions in the province. As the cultural center of Java, the province also draws 45,883 tourists who arrive at Adi Sucipto Airport in Yogyakarta every year. In addition, the province's economy is also supported by strong agricultural development and export-oriented production. Yogyakarta is more dependent on agriculture than Banten, which is near the capital city of Jakarta. This strategic location has helped manufacturing and wholesale and retail trade to flourish in the province. In general, Banten's factories and industrial sectors, accompanied by infrastructure, have continuously contributed to the acceleration of the economic growth of the province. This province is supported by the existence of the main sea port of Merak, which is one of the ports on the island of Java with the highest export volume in Indonesia. The Jakarta International Airport of Soekarno-Hatta is also located in Banten.

\section{Nature of employment}

In analyzing this section, it is important to note that the discussions are based on estimates of the labor force. The estimation of formal and informal employment is chiefly based on the number of jobs and not the number of persons. This is an important distinction since a person may have more than one job, which is a typical situation in Asian countries, including Indonesia. An employed person may be a formal employee working as a regular bus driver at a company for his main job. But he may also be working as a three-wheeledbicycle driver for his second job using a vehicle he owns and can be considered an own-account worker. Hence, the total employment in terms of the nature of a job will be larger than the total number of workers. The tables presented in this section use the relevant set of criteria to characterize employment as either formal or informal across different employment status categories. Contracts and records of accounts can be used as variables to distinguish between formal and informal employment. Bookkeeping and paychecks were used to determine 
Table 4.11 Number of informal jobs/employment by province and production unit

\begin{tabular}{|c|c|c|c|c|c|}
\hline \multirow{2}{*}{$\begin{array}{l}\text { Province and } \\
\text { production } \\
\text { unit }\end{array}$} & \multicolumn{3}{|c|}{$\begin{array}{l}\text { Nature of employment } \\
\text { (number of jobs) }\end{array}$} & \multicolumn{2}{|c|}{$\begin{array}{l}\text { Nature of } \\
\text { employment (\%) }\end{array}$} \\
\hline & Informal & Formal & Total & Informal & Formal \\
\hline \multicolumn{6}{|l|}{ rogyakarta } \\
\hline Formal & 103,642 & 233,553 & 337,196 & 30.74 & 69.26 \\
\hline Informal & $2,164,886$ & 43,120 & $2,208,006$ & 98.05 & 1.95 \\
\hline Household & 2,119 & - & 2,119 & 100 & - \\
\hline Total & $2,270,647$ & 276,673 & $2,547,320$ & 89.14 & 10.86 \\
\hline \multicolumn{6}{|l|}{ Banten } \\
\hline Formal & 372,874 & 769,087 & $1,141,961$ & 32.65 & 67.35 \\
\hline Informal & $2,600,403$ & 176,845 & $2,777,248$ & 93.63 & 6.37 \\
\hline Household & 5,455 & - & 5,455 & 100 & - \\
\hline Total & $2,978,732$ & 945,931 & $3,924,663$ & 75.9 & 24.1 \\
\hline
\end{tabular}
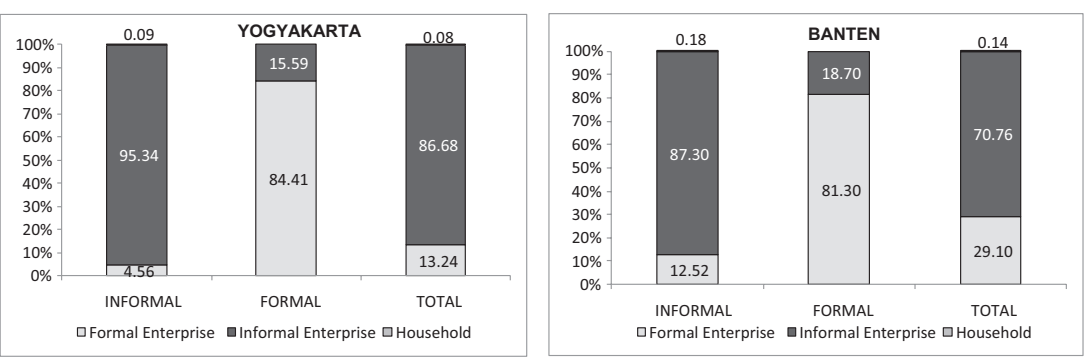

Figure 4.4 Nature of employment by production unit

formal and informal enterprises. The detailed sampling design is presented in the appendix.

Table 4.11 illustrates the significance of informal employment in the two provinces. In fact, 89.14 percent of the 2,547,320 total jobs in Yogyakarta were informal, whereas informal jobs accounted for 75.90 percent out of 3,924,663 jobs observed in Banten. While informal employment is expected to prevail in informal enterprises, the data showed that formal enterprises also supply a substantial amount of informal jobs. The estimates showed that 30.74 percent of jobs in formal enterprises in Yogyakarta were informal; in Banten, this rate was at 32.65 percent (of the 1,141,961 jobs in formal enterprises).

Figure 4.4 shows the relevance of the informal sector in providing employment. Informal enterprises engaged 86.68 percent of total employment in Yogyakarta; in Banten, the jobs supplied by informal enterprises were relatively less at 
70.76 percent of the total. Informal enterprises generally employed their workers informally, though there were instances in which they also provided formal employment. In the same manner, formal enterprises mostly provided more formal than informal jobs.

As shown in Figure 4.4, 95.34 percent of informal jobs were supplied by informal enterprises in Yogyakarta; this rate was 87.30 percent in Banten, whereas formal jobs in formal enterprises in Yogyakarta and Banten accounted for 84.41 percent and 81.30 percent, respectively, of the total formal jobs available in the respective province.

\section{Labor force characteristics}

In analyzing this section, it is important to note that the discussions are based on estimates of the labor force with persons as a unit of measure.

Yogyakarta is more dependent on agriculture than Banten. In Yogyakarta, the proportion of employed persons engaged in agriculture was 33.98 percent, while the rest ( 66.02 percent) was in the nonagriculture sector. In Banten, the percentage of employed persons engaged in agricultural activities was much less than that in Yogyakarta at 18.77 percent.

Whereas Figure 4.5 characterizes the labor force in terms of gender and sector, Figure 4.6 provides a picture of the composition of the labor force by further dividing the composition into formal-informal employment and enterprises. Thus, Figure 4.6 divides the total labor force by gender in each province into five components. Further, Figure 4.5 does not show the composition of formal employment in agriculture in each category because of the insignificant

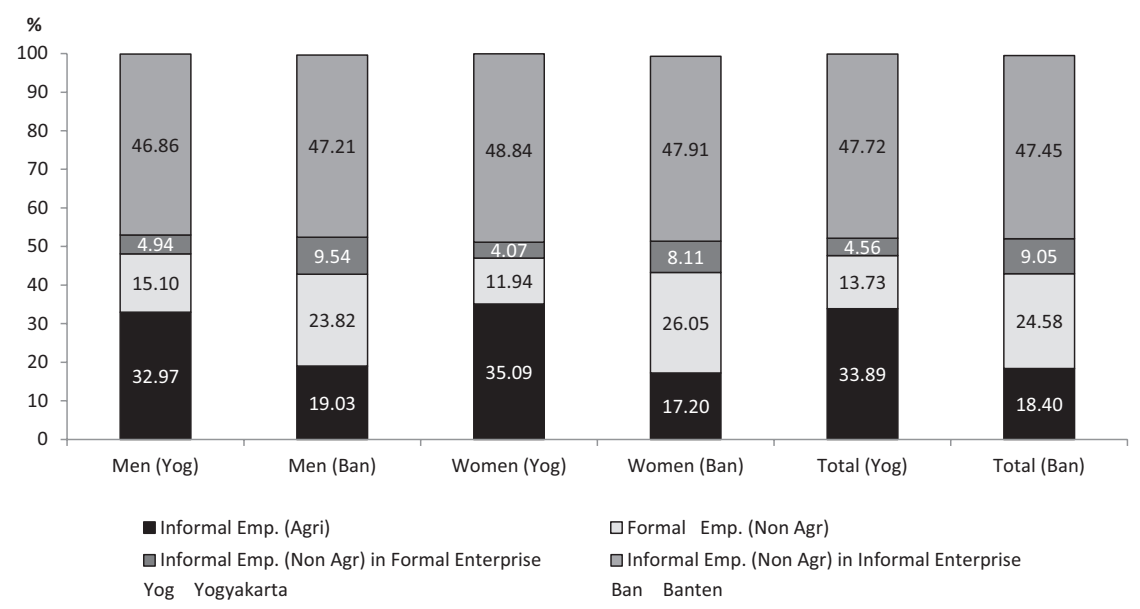

Figure 4.5 Labor force characteristics by gender, nature of employment, and sector 


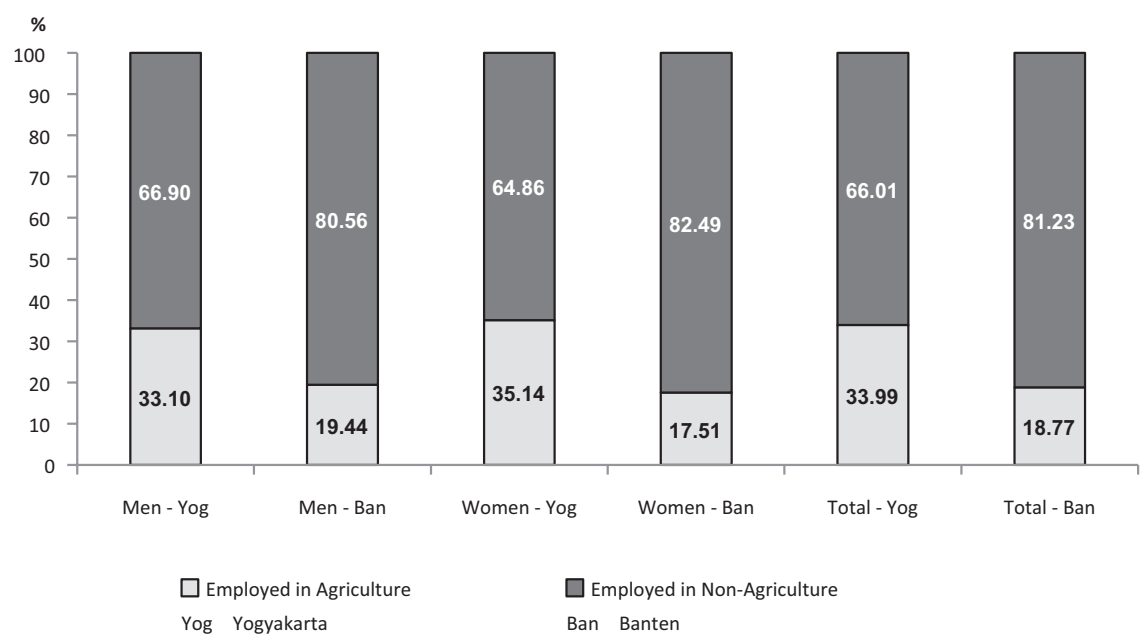

Figure 4.6 Labor force characteristics by gender: agriculture and nonagriculture

figures: 0.13 percent, 0.05 percent, and 0.09 percent, respectively, for men, women, and the total figure in Yogyakarta. The corresponding figures for Banten are 0.41 percent, 0.31 percent, and 0.38 percent. Similar reasoning was used for not recording the nonagriculture informal employment in the households in Yogyakarta. In Banten, however, this employment rate was at a very low percentage of 0.42 for the female workforce, which was 0.14 percent of the total.

Hence, for both Yogyakarta and Banten, almost all employed persons in the agriculture sector are working under informal arrangements. The percentage of men working informally in the agriculture sector was almost the same as the percentage of informal employment among women in both provinces.

Meanwhile, the percentage of informal employment in the nonagriculture sector was quite different from that in the agriculture sector. From almost 100 percent in the agriculture sector, informal employment in the nonagriculture sector in Yogyakarta dropped to 79.2 percent. The same trend was noted in the nonagriculture sector in Banten, where informal employment was posted at 69.73 percent. Hence, for both provinces, formal employment was more likely to exist in the nonagriculture sector, at 20.80 percent in Yogyakarta and 30.27 percent in Banten, rather than in the agriculture sector.

It is interesting that in Yogyakarta, the percentage of men engaged in nonagriculture informal employment is lower than the percentage of women in the same case, at 77.83 percent and 81.59 percent, respectively. However, the opposite is observed in Banten: 70.44 percent of the men in the nonagriculture sector 


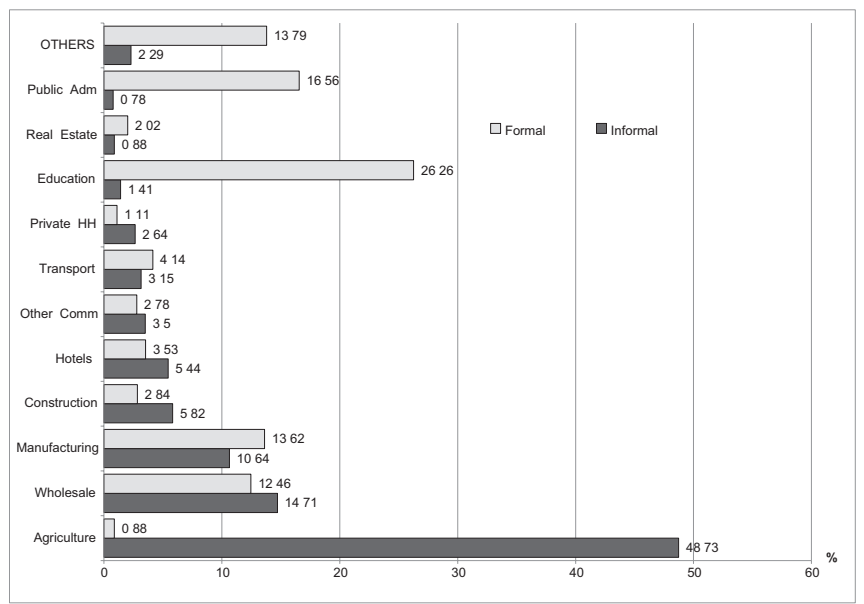

Figure 4.7 Structure of informal employment in Yogyakarta

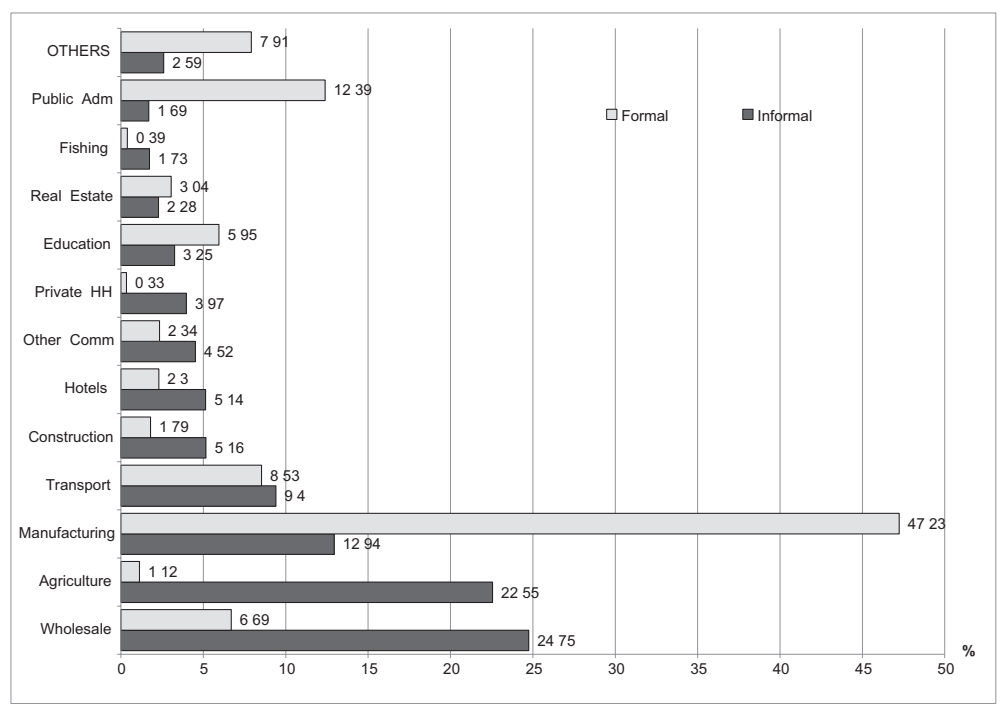

Figure 4.8 Structure of informal employment in Banten

were informally employed, which is higher than the 68.42 percent of women in informal employment.

It is also noteworthy to mention that the share of nonagriculture formal enterprises in providing informal employment in the sector is significantly larger in Banten than in Yogyakarta at 15.97 percent and 8.73 percent, respectively. This 


\section{Kadarmanto}

implies that formal enterprises in Banten hire one out of every five informal workers in the nonagriculture sector of the province, while formal establishments in Yogyakarta only engage one in every ten.

\section{Industry of economic activity}

A significant portion of informal employment in Yogyakarta was engaged in the agriculture sector, with as much as 48.7 percent of the total number of jobs having informal arrangements $(2,270,647)$. This is followed by wholesale and retail trade (14.7 percent) and manufacturing (10.6 percent). Unlike in Yogyakarta, informal employment in Banten is predominantly driven by the wholesale and retail trade sector, followed by the agriculture and manufacturing sectors, as shown in Figure 4.8.

\section{Occupation}

Figure 4.9 illustrates the skill discrepancy between informal and formal workers. The types of skills, however, differed between the two provinces, whereas jobs for skilled agricultural workers were most prevalent in formal employment in Yogyakarta. Banten employs more unskilled workers in informal jobs.

Skilled agricultural and fishery workers already comprise two fifths of the total number of jobs in Yogyakarta. Since this province shows a higher incidence of informal than formal employment, it is not surprising to note that 46.2 percent of informal jobs are those of skilled agricultural and fishery workers (Code 6);

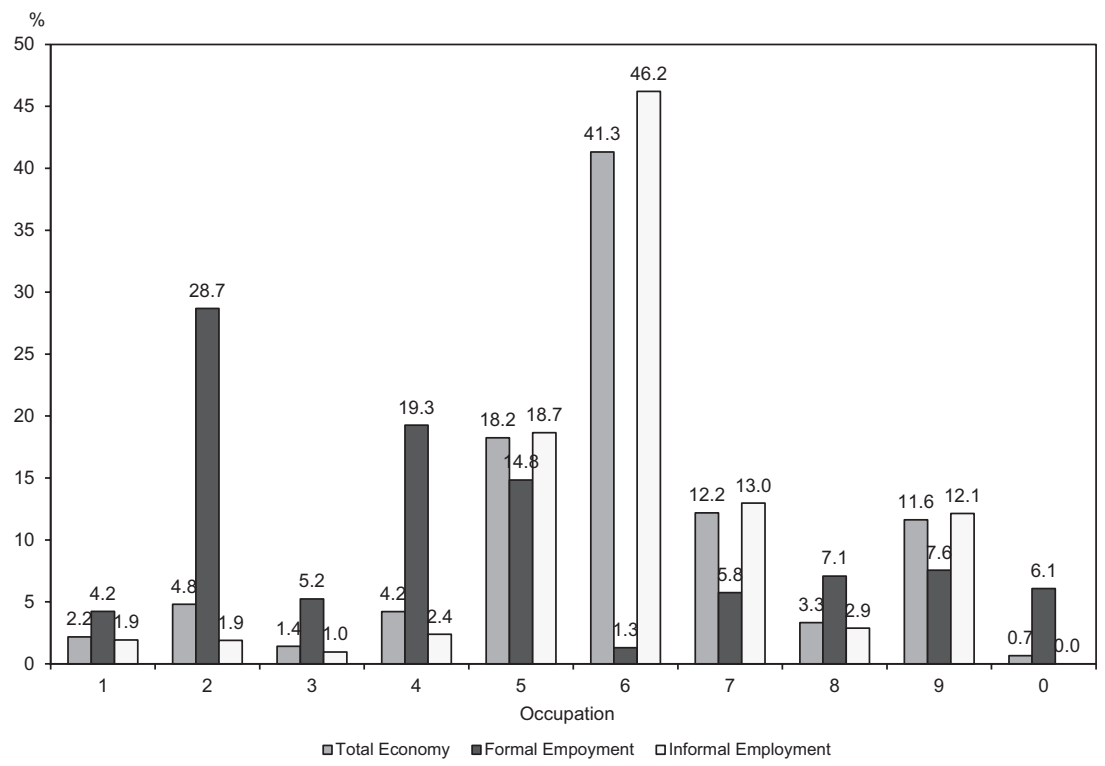

Figure 4.9 Employment by occupation and nature of employment in Yogyakarta 


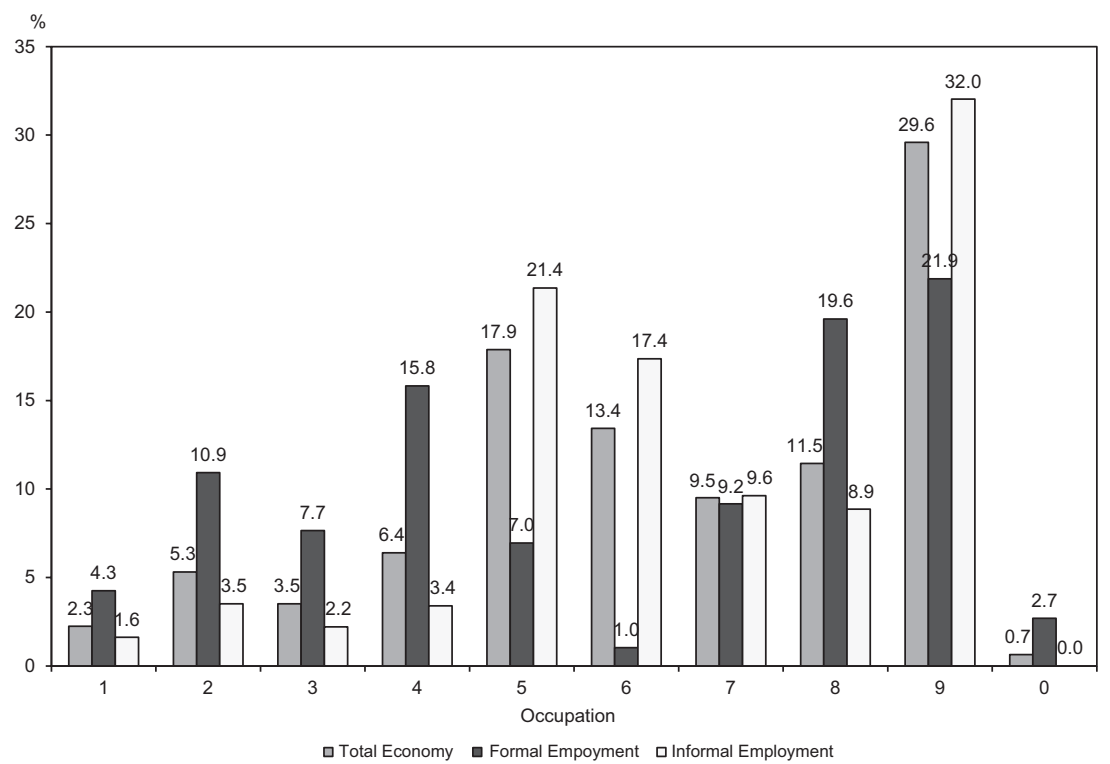

Figure 4.10 Employment by occupation and nature of employment in Banten

18.7 percent are service workers and shop and market sales workers (Code 5); 13 percent are craftspeople and those in related workers (Code 7); and 12.1 percent are jobs assumed by elementary (unskilled) workers (Code 9). Occupations requiring more technical skills account only for less than one tenth of the total number of informal jobs in the province. Expectedly, the skilled agricultural and fishery worker classification is the smallest source of formal employment in Yogyakarta, at only 1.3 percent. Most of these workers are either professionals (28.7 percent of total formal jobs) or clerks (19.3 percent) (Figure 4.9).

On the other hand, Figure 4.10 also shows that almost 40 percent of the total number of jobs in Banten is either elementary occupations or plant and machine operation and assembly. This is because Banten is relatively more industrialized such that its economy depends more on the nonagriculture sector, particularly manufacturing, unlike Yogyakarta, whose main source of jobs is agriculture.

Informal jobs in Banten are generally divided into the following occupational classifications: service workers, skilled agricultural and fishery workers, and unskilled workers. Unlike Yogyakarta, where agriculture employment comprises the bulk of informal employment, informal jobs in Banten are distributed between the agriculture and nonagriculture sectors.

\section{Type of enterprise}

Overall, Banten posted a higher proportion (29.1 percent of the total number of jobs) of jobs associated with formal enterprises compared to Yogyakarta 
Table 4.12 Percentage of type of enterprise and nature of employment

\begin{tabular}{lccccccc}
\hline \multirow{2}{*}{ Type of enterprise } & \multicolumn{2}{l}{ Yogyakarta } & & & \multicolumn{2}{l}{ Banten } \\
\cline { 3 - 4 } \cline { 7 - 8 } & Formal & $\begin{array}{c}\text { Informal } \\
\text { enterprise }\end{array}$ & Household & $\begin{array}{l}\text { Formal } \\
\text { enterprise }\end{array}$ & $\begin{array}{l}\text { Informal } \\
\text { enterprise }\end{array}$ & Household \\
\hline Factory & 23.29 & 76.71 & - & & 68.17 & 31.83 & - \\
Bank/insurance & 97.21 & 2.79 & - & & 96.57 & 3.43 & - \\
Restaurant & 22.22 & 77.78 & - & & 41.45 & 58.55 & - \\
Construction & 7.62 & 92.38 & - & & 35.53 & 64.47 & - \\
Hospital/school & 72.5 & 27.5 & - & & 55.09 & 44.91 & - \\
Engineering firm & 28.81 & 71.19 & - & & 26.57 & 73.43 & - \\
Farm & 3.35 & 96.46 & 0.19 & & 1.88 & 97.61 & 0.52 \\
Other & 11.8 & 88.2 & - & & 16.67 & 83.33 & - \\
Total & 13.24 & 86.68 & 0.08 & & 29.1 & 70.76 & 0.14 \\
\hline
\end{tabular}

(13.2 percent), as shown in Table 4.11. This implies that, in relative terms, Banten's formal enterprises generated more jobs than the formal enterprises in Yogyakarta. This may stem from the fact that Banten is within driving distance (three hours) of Jakarta, the country's capital. The limited space in Jakarta has forced many establishments to build new buildings/offices/factories in nearby locations. Moreover, Yogyakarta, which is less urbanized than Banten, relies on the informal enterprises that are mostly carried out on farms.

\section{Summary and policy implications}

\section{Summary}

The results show that informal employment for Yogyakarta and Banten is 81.9 percent and 75.9 percent, respectively. Yogyakarta, which is the lesser industrialized province of the two, is more dependent on informal employment than Banten. This implies that jobs in less developed areas are more informal. Still, the dominance of informal employment, as measured by the number of jobs, despite the difference in the provinces' levels of economic development, is apparent and supports the conclusion that the labor markets in these two provinces are dominated by informal employment. These are also indications that, considering the similarity of Banten and Yogyakarta to other provinces in Indonesia, informal employment is prevalent in most of Indonesia.

In terms of the GRDP, the share of the informal sector in the economic output of Yogyakarta is estimated to be 37.03 percent. On the other hand, the contribution of the informal sector to the production in Banten is smaller, at 26.60 percent. As mentioned previously, Banten is more industrialized and is the seat of many large-scale enterprises both domestic and foreign. Hence, the larger extent of manufacturing production and service providers are from formal enterprises. 
The informal sector posted a share of 88.95 percent in the agricultural production of Yogyakarta, greater than its contribution in the nonagriculture sector. In Banten, while the nonagriculture informal sector contributes 21 percent of production, 87.4 percent of agricultural production is from the informal sector.

These results show that in terms of economic production, as measured by the GRDP, the share of the informal sector is much lower than that of the formal sector. However, with regard to jobs, informal employment is a vital source of income to the employed population.

Informal workers are more likely to be poor than those who are formally employed. Of those who depend on informal employment in Yogyakarta and Banten, the poverty rate is at least 17.99 percent and 8.9 percent; these percentages account for 47.36 percent and 23.42 percent of the total poverty rate, respectively.

In terms of the working poverty rate - namely, the number of working poor individuals expressed as a percent of total employment - the rate is higher in Yogyakarta ( 16.13 percent) than in Banten (5.88 percent). In this case, employers with temporary workers have the highest risk of poverty if they are engaged in agricultural informal employment in Yogyakarta, while the most vulnerable class to poverty in Banten is casual workers working in agricultural informal employment. The households most vulnerable to poverty are those that sustain themselves on informal employment, especially members who solely depend on agricultural jobs as employees in Yogyakarta and as casual workers in Banten.

\section{Policy implications}

Even though Yogyakarta and Banten exhibit different levels of economic development, informal employment is still prevalent in both of the provinces' labor markets. Meanwhile, the informal sector is vital in the agriculture sector of Yogyakarta and in the trade industry of Banten. If these results are representative of the Indonesian economy, Indonesia, as a developing country, may also be characterized by sizable informal employment and the industry-specific high economic contribution of the informal sector.

Competition among the labor force to engage in formal employment is very high. Thus, only those who are highly skilled are expected to be able to engage in formal employment and reap the benefits of this type of employment. However, while formal employment presents better opportunities to the employed population, informal employment provides the needed income to most people. Therefore, the informal sector plays an important role in running the Indonesian economy, and its existence increases opportunities for the poor in the labor market. It creates alternative employment for production and income generation. Due to the high rate of population growth and urbanization in Indonesia, the huge labor force, especially in urban areas, can be absorbed in the labor market through informal employment. On the other hand, in order to survive, the poor tend to be involved in any kind of activity, even if a job is characterized by a very low wage, irregular working hours, uncertain job security, and similar conditions. 


\section{Kadarmanto}

With the linkages between informal employment and poverty, it can be observed that those engaged in agricultural activities are faced with a high poverty rate. Thus, agricultural informal employment accounts for a large share of the labor market, provides only a small contribution to GDP, and has a high poverty rate.

Given these factors, policy makers should take informal employment and informal sector conditions into account, especially with regard to regulations and policies that aim to improve the working conditions and the legal and social protection of persons employed in the informal economy and to increase the productivity of informal economic activities. With a high poverty rate, the government of Indonesia, especially those members who formulate pro-poor policies, should also support the informal sector by providing the informal enterprises with muchneeded access to credit, labor skill development, and so forth. 


\section{Appendix}

The mixed household-enterprise survey approach utilizes a household survey in the first phase to identify the household unincorporated enterprises with at least some market production (HUEMs), some of which will be sampled for the second-phase survey or the HUEM survey. Phase 1 or the expanded Labour Force Survey (LFS) contains additional questions that can be classified into three categories: (1) the informal employment module; (2) the informal sector enterprise module; and ( 3 ) the HUEM identification module.

The data to be collected will be used to analyze the characteristics of informal workers, available social protection mechanisms, and working conditions. This module, when combined with the informal enterprise module, will further enrich the examination by determining informal employment in the informal sector. The informal sector enterprise module will determine if the enterprise/establishment of a respondent worker is informal or not. This is significant since the concept of informal employment also includes people who are informally employed in the formal sector. The HUEM identification module determines the existence of a probable HUEM in the household and identifies the respondent in Phase 2 of the survey. The HUEMs that are identified will be used as the sampling frame for the Phase 2 survey. In this case, all identified HUEMs are surveyed using the Form 2 Questionnaire (please see ADB (2011)). Meanwhile, Phase 2 focuses on the enterprise and its production, providing relevant information about the informal sector's contribution to the country's economic output or GDP.

In order to obtain a more representative sector in the sample HUEMs, good auxiliary data are needed for subsampling primary sampling units (PSUs). Moreover, since the primary purpose of Phase 2 is to estimate the contribution of the informal sector to GDP, the sectors of the national accounts must be well represented in the Phase 2 sample. Hence, the PSUs must be stratified according to the sectors of the national accounts based on the number of potential HUEMs from the 2008 Sakernas. This will be straightforward if the HUEMs in the PSUs are homogeneous. Oftentimes, HUEMs in a PSU can come from different sectors of the industry - some are quite prevalent or widespread in many PSUs (e.g. agriculture; wholesale and retail trade; transport, communications, and storage), while others are hard to find (these we will term as sparse sectors). Thus, if a PSU contains any sparse sector, it should be classified under the sector that has 
Table 4A.I Primary sampling unit (PSU) distribution for LFS and Phase 2 of the informal sector survey: Indonesia

\begin{tabular}{|c|c|c|c|c|}
\hline \multirow{2}{*}{ Sector strata } & \multicolumn{2}{|l|}{ Banten } & \multicolumn{2}{|c|}{ Yogyakarta } \\
\hline & $\begin{array}{c}\text { Sakernas } \\
\text { (LFS) }\end{array}$ & $\begin{array}{l}\text { Subsample } \\
\text { for Phase } 2\end{array}$ & $\begin{array}{c}\text { Sakernas } \\
\text { (LFS) }\end{array}$ & $\begin{array}{l}\text { Subsample } \\
\text { for Phase } 2\end{array}$ \\
\hline Agriculture & 29 & 10 & 51 & 17 \\
\hline Construction & 17 & 17 & 15 & 15 \\
\hline Electricity, gas, and water & 2 & 2 & & \\
\hline Education & 2 & 2 & 2 & 2 \\
\hline Finance & 1 & 1 & 1 & 1 \\
\hline Health & 3 & 3 & 5 & 5 \\
\hline Hotels & 8 & 8 & 6 & 6 \\
\hline Manufacturing & 6 & 6 & 12 & 12 \\
\hline Mining and quarrying & 5 & 5 & 9 & 9 \\
\hline Other & 4 & 4 & 10 & 10 \\
\hline $\begin{array}{l}\text { Transport, communication, } \\
\text { and storage }\end{array}$ & 10 & 10 & & \\
\hline Wholesale and retail trade & 36 & 12 & 31 & 10 \\
\hline Total & 123 & 80 & 142 & 87 \\
\hline
\end{tabular}

the lowest HUEM count. Otherwise, classify it under the sector with the highest HUEM count. The first part of the rule is to ensure that sparse sectors will be represented in Phase 2. The second part of the rule, which identifies the dominant sector, allows us to develop a subsampling strategy for the PSUs that contain the dominant sector. Only PSUs in the dominant sectors will be subsampled, and all those in the sparse sectors will be included in the Phase 2 survey. Table 4A.1 shows the results of the stratification.

\section{Notes}

1 See box on "1993 ICLS Definition of the Informal Sector."

2 The construction industry in Yogyakarta has noted a relatively low contribution of the informal sector ( 0.83 percent of its total GVA). This may be due to the confusion over the HUEM-screening question "Do you sell goods or services?" where a number of survey respondents engaged in the construction sector did not consider themselves to be selling their services.

3 Formal sector and households.

4 A person can simultaneously have two or more formal and/or informal jobs. In view of such multiple job holding, JOBS - rather than employed persons - were used as the observation units for employment.

5 Assuming that (1) the poverty rate of working-age people is equal to that of the population as a whole; (2) the labor force participation rate of the poor is equal to that of the population as a whole; and (3) all poor individuals in the labor force are counted as poor, Madjid (2001) defines the working poor as:

WP $=$ Poverty Rate $\times$ Labor Force 
which provides a "lower bound" on working poor estimates. On the other hand, Berger and Harasty (2002) provide an "upper bound" of the working poor estimates as follows:

WP $=$ Poverty Rate $\times$ Working Age Population

\section{References}

Asian Development Bank (ADB) (2008), Key indicators 2008: Comparing poverty across countries: The role of purchasing power parities. Author: Manila.

Asian Development Bank (ADB) (2011), The Informal Sector and Informal Employment in Indonesia. Author: Manila.

Berger, S. and C. Harasty (2002), "World and regional employment prospect: Halving the world's working poor by 2010," Employment Paper 2002/38, International Labor Organization (ILO): Geneva.

Hussmann, R. (2004), “Defining and measuring informal employment," paper presented at Economic Statistics: Statistics on the Informal Sector and the Non-Observed Economy, First Session, ESCAP Subcommittee on Statistics Meeting, 18-20 February, Bangkok, Thailand.

Kapsos, S. (2004), "Estimating growth requirement for reducing working poverty: Can the world halve working poverty by 2015?" Employment Strategy Paper No. 2004/14, Employment Strategy Department, International Labor Organization (ILO): Geneva. Available from: http://www.ilo.org/wcmsp5/groups/ public/---ed_emp/---emp_elm/documents/publication/wcms_114248.pdf

Madjid, N. (2001), "The size of the working poor population in developing countries," Employment Paper 2001/16, Employment Strategy Department, International Labor Organization (ILO): Geneva. Available from: http://ilo.org/ wcmsp5/groups/public/---ed_emp/---emp_strat/documents/publication/ wcms_079076.pdf

Organisation for Economic Co-operation and Development (OECD) (2001), Measuring Productivity - OECD Manual: Measurement of Aggregate and Industry-Level Productivity Growth. Author: Paris. Available from: http://www.oecd.org/std/ productivity-stats/2352458.pdf

Seventeenth International Conference of Labor Statisticians (ICLS) Final Report (2004), International Labor Organization (ILO). Available from: http://www. ilo.org/global/What_we_do/Statistics/events/icls/lang-en/docNameWCMS_087568/index.htm 


\title{
5 Effects of remittances on income inequality and poverty in the Philippines
}

\author{
Satoshi Ohira and Karen Villaquer Firshan
}

\section{Introduction}

Remittances from overseas are one of the most important sources of income in the Philippines. The Survey of Overseas Filipinos conducted by the National Statistics Office defines remittances as the amount of cash and in-kind transfers received by families from overseas Filipino workers (OFWs). Remittances during the period from April to September 2013 sent by OFWs amounted to 163.2 billion Philippine pesos (PHP), ${ }^{1}$ with OFWs from Asia remitting the largest proportion (81.2 percent). Altogether, 2.3 million OFWs worked abroad during that period, with Saudi Arabia the preferred destination (22.1 percent of OFWs), followed by 15.4 percent in the United Arab Emirates, 7.3 percent in Singapore, 5.8 percent in Qatar, 5.1 percent in Hong Kong, and 5.0 percent in other countries in western Asia. Just over half of OFWs ( 50.3 percent) were men, with male OFWs generally older than female OFWs (22.0 percent of male OFWs belong to the 45-years-and-older age group compared with 10.8 percent of female OFWs). However, only 42.1 percent of male OFWs were aged between 25 and 34 years compared with 53.8 percent of female OFWs. Almost one third (30.8 percent) were laborers or unskilled workers, followed by workers in the retail/service sector (16.7 percent), tradespeople (12.9 percent), plant and machine operators and assemblers (11.7 percent), and professionals (11.6 percent). The majority of OFWs (18.4 percent) came from Calabarzon compared with 13.9 percent from Central Luzon and 12.8 percent from the National Capital Region (NCR).

Research on migration and remittances is important for analyzing the policies of the Philippines government because the role of remittances in the country is crucial for tackling the poverty problem. Bayangos (2012), Ratha (2013), and Goce-Dakila and Dakila (2006), for example, examine the effects of remittances on the macroeconomy, with research in general showing that they have a positive impact on economic development in the Philippines.

Some research has used micro-data. Ratha (2013) and Yang (2008), for example, examine the effects of remittances on poverty reduction. Ratha (2013) states that "the merit of remittances flows might lie more on increasing the level of income of the poor rather than the growth of the economy as a whole" (p. 7). Even though the Philippines has extensive micro-data on poverty, research using 
panel data at the micro level has not yet explained poverty and inequality in the country. According to Fuwa (2011), the scarcity of microeconomic research is because of the attrition problem. Based on the aforementioned factors, in this study we examine the effect of remittances by using cross-sectional micro-data in order to investigate how remittances affect inequality.

New Economics of Labor Migration (NELM) theory (Stark and Bloom 1985) claims that income inequality is likely to cause more relative deprivation and that a more relatively deprived person is expected to have a higher tendency to migrate. Migration decisions are often decided jointly by the family members left behind and the migrating person. Remittances from a migrating family member form an important component of direct returns to non-migrating family members. Based on NELM theory, therefore, it is assumed that remittances increase family income and decrease inequality and poverty.

This study investigates the following three claims of NELM theory by using micro-data derived from the Family Income and Expenditure Survey (FIES) of the Philippines and presents empirical findings on their validity:

(1) Poorer families are more likely to send members to a foreign country

(2) Remittances decrease poverty

(3) Remittances decrease inequality.

These three claims are all true if NELM theory holds. In relation to the second claim, we analyze the effect of remittances on poverty indices, which take inequality among the poor into account. The reason for choosing this approach is that remittances should be correlated with inequality if NELM theory holds.

The motivation of our analysis is the observation that very poor families cannot afford to send their members to foreign countries or other regions. Although remittances are a convenient way for families to raise their income, they must have sufficient income to afford to send their members overseas. The educational attainment of family members is also an important factor. Because very poor families do not have high educational attainment, sending their members to foreign countries or urban areas is not a choice for them. Pernia (2008) states that educational attainment is necessary for migration to be successful. Hence, the very poor cannot raise their income through remittances. Only families with enough income can raise their income through remittances. Even so, if the family income necessary for migration is below the poverty line, poor families can raise their income and escape from poverty. Poverty indices may thus decrease if remittances increase. The effect of remittances on inequality is less clear, however. Some poor families can raise their income through remittances, while the very poor cannot.

We conclude that the claims of NELM theory do not hold. The richer the family is, the more remittances it receives. As a result, the effect of remittances on inequality is negative, while the effect on poverty is positive. These results concur with those of Rodriguez (1998) and Pernia (2008), who analyze the effects of remittances on mean income in each income quintile and find that richer families benefit more than poorer families. Our study also confirms that poorer families 
are less likely to send their members to foreign countries. Therefore, the first claim of NELM theory does not hold. Because the effects of remittances are always positive, whereas the size of the effects changes by income level, the second claim holds, while the third claim does not hold. We thus show in this study that remittances have a negative impact on inequality.

The remainder of this paper is organized as follows: Section 2 presents the country profile in terms of income, inequality, and poverty. First, it describes the micro-data used for the analysis and then examines the proportions of different income sources to total family income. By using micro-data from the FIES from 2000 to 2009 , we estimate the proportion of income from wages/salaries, entrepreneurial activities, assistance from abroad (remittances), pensions and retirement benefits, and other income to total family income. The empirical findings show that the proportion of income from assistance from abroad (remittances) to total income increased between 2000 and 2009 and was the third-largest contributor to family income, suggesting that inequality in the Philippines decreased in this period. They also show that poverty, as measured by the poverty index, varies significantly among regions in the Philippines, ranging from 1.2 in the NCR to 40.9 in Caraga.

In Section 3, we analyze the regional data and show that the first claim asserted by NELM theory does not hold in the Philippines. Section 3.1 shows that the richer the region is, the higher its probability of migration. Section 3.2 identifies the socio-demographic characteristics of families as determinants of poverty by using logistic regression analysis. Based on cross-sectional data for 2009 , we identify factors that are statistically significant predictors of families sending their members to foreign countries. The model indicates that the gender, age, educational attainment, and business of the family head; family size; remittance recipient; urbanity; and region where the family lives are all statistically significant predictors of a family sending its members to a foreign country. These results show that very poor families gain little from remittances. The richer families are, the more they benefit from remittances.

Section 4 evaluates the effects of remittances on inequality and poverty and tests the validity of the second and third claims of NELM theory. We first regress poverty status on some basic variables to determine the characteristics of families. One of these variables is whether the family receives remittances. The regression results show that remittances have a negative effect on poverty status. Receiving remittances decreases the probability of being poor. The second claim thus holds. We then regress per capita income on the same variables and use the regression result to calculate two theoretical values of per capita income based on (1) the actual family characteristics and (2) the assumption that no families receive remittances. For these two cases, we calculate Gini coefficients and compare the different states of inequality. The results show that remittances have a negative impact on inequality. Contrary to the proposition in NELM theory, remittances increase inequality.

Finally, Section 5 concludes that remittances are a powerful tool for poverty reduction. However, the effect is limited, especially for the very poor. In order 
to tackle the problems of the very poor, the government must implement other policies instead of only remittance policies.

\section{Income, inequality, and poverty profile}

\subsection{Data}

This study uses micro-data from the FIES for the period from 2000 to 2009. The FIES (National Statistics Office Philippines 2006) is a national survey of families that is carried out every three years. It obtains information on family income and expenditure; levels of consumption; sources of income (cash and in-kind); and the socio-demographic characteristics of the family head such as gender, age, marital status, education, and occupation. The FIES is designed to provide income and expenditure data that are representative of the country and its seventeen regions. It uses a three-stage stratified random sampling design with primary sampling units (PSUs) for the first stage, sample enumeration areas (EAs) for the second stage, and sampling units for the third stage. The domains are the seventeen geographical regions classified into provinces, highly urbanized cities, independent component cities, and other. The seventeen administrative regions are the NCR, the Cordillera Administrative Region (CAR), Ilocos, Cagayan Valley, Central Luzon, Calabarzon, Mimaropa, Bicol, Western Visayas, Central Visayas, Eastern Visayas, Zamboanga Peninsula, Northern Mindanao, Davao, Soccsksargen, Caraga, and the Autonomous Region in Muslim Mindanao (ARMM).

PSUs are defined as a barangay or a combination of barangays with at least 500 families. Stratification involves the division of the entire population into non-overlapping subgroups called strata. Prior to sample selection, the PSUs in each domain are stratified as follows: first, all large PSUs are treated as separate strata and referred to as certainty selections (self-representing PSUs). A PSU is considered to be large if it has a large probability of selection. Second, all other PSUs are then stratified by province, highly urbanized city, and independent component city. Finally, within each province and city, PSUs are further stratified with respect to three socio-economic variables related to poverty incidence: (1) the proportion of strongly built houses (PSTRONG); (2) an indication of the proportion of families engaged in agriculture (AGRI); and (3) per capita income (PERCAPITA). PSUs are selected with a probability proportional to an estimated measure of size based on the total number of families from the 2000 Census of Population and Housing. Because of the wide variation in PSU sizes, PSUs with selection probabilities greater than one are included in the sample as certainty selections.

In the second stage, EAs are selected within the sampled PSUs, while in the third stage, housing units are selected within the sampled EAs. Generally, all families in sampled housing units are enumerated, except for the few cases when the number of families in a housing unit exceeds three. In this case, a sample of three families in a sampled housing unit is selected at random with an equal 


\section{Satoshi Ohira et al.}

probability. The sampling unit is the family, and the sample sizes for the whole country are as follows: 39,615 families in 2000, 42,094 families in 2003, 38,483 families in 2006, and 38,400 families in 2009 .

\subsection{Country profile}

We estimate the proportion of different income sources to total family income. The main sources of income are classified into five major groups:

- Wage/salaries (e.g. wage/salary from agricultural and nonagricultural activities);

- Entrepreneurial activities (e.g. crop farming and gardening, livestock and poultry raising, fishing, forestry and hunting, wholesale and retail, manufacturing, community and other services, transport and communication, mining, and construction);

- Assistance from abroad (remittances);

- Pensions and retirement benefits; and

- Other sources of income (e.g. net share of crops, assistance from domestic sources, rental of lands and other properties, interest from banks/loans, dividends from investments, rental value of owner-occupied dwellings, income from family sustenance activities, gifts received, and other income).

As shown in Figure 5.1, family income is mainly composed of wages and salaries, although the proportion of salaries and wages to total income decreased between 2000 and 2009. Income from entrepreneurial activities is the next major contributor to total family income, but its proportion also decreased in this period. Assistance from abroad is the third-largest contributor (15.3 percent of total family income in 2009), higher by 4.2 percent compared with 2000 , and this continuously increased between 2000 and 2009.

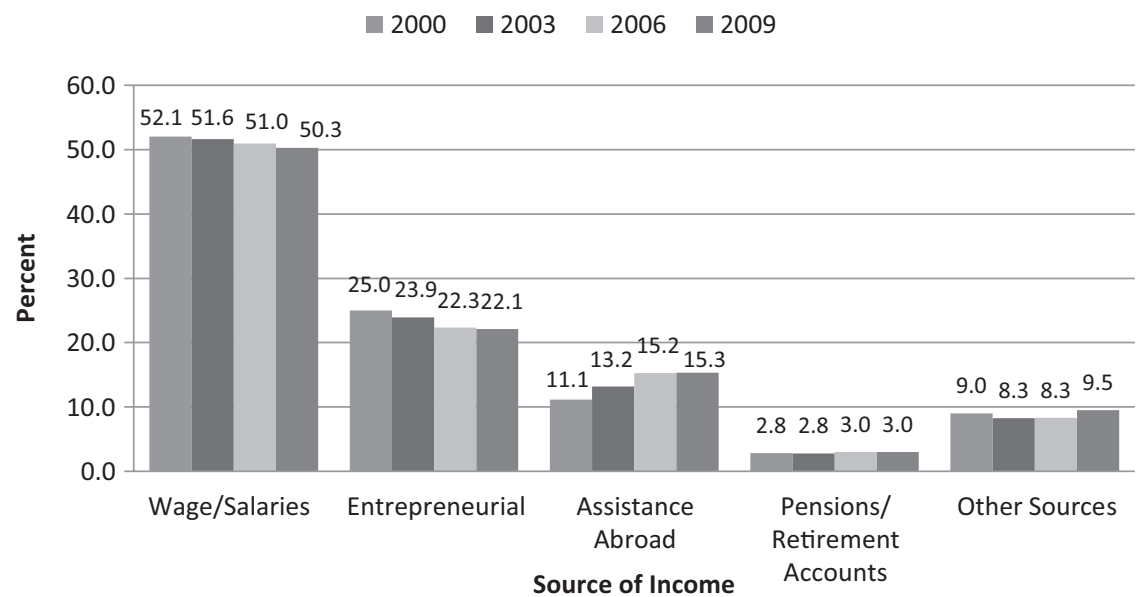

Figure 5.1 Family income composition, 2000-2009 
Table 5.1 shows that the Gini coefficient of income for the Philippines decreased slightly from 0.496 in 2000 to 0.461 in 2009. In particular, income inequality remained high in Eastern Visayas, Zamboanga, and Northern Mindanao.

Table 5.2 summarizes the current state of inequality and poverty in the Philippines in 2009. The column "Gini" is the inequality index for the total population in each region. ${ }^{2}$ Gini (poor) calculates the same index for the poor segment only, where families are defined as poor if their per capita annual income is less than 16,841 PHP. By using the same definition of the poor, four poverty indices are calculated: $P$ (sen) indicates the level of poverty in each region taking Gini (poor) into account, while the headcount ratio $P_{0}$, poverty gap $P_{1}$, and poverty severity $P_{2}$ are examples of the Foster, Greer, and Thorbecke (1984) poverty measure. ${ }^{3}$ Although the headcount ratio is the simplest index to measure poverty, it does not take the severity of the poverty into account. By calculating the poverty gap, we can determine the severity of the poverty. Poverty severity $P_{2}$ considers the severity of poorer families. $P(\operatorname{sen})$ is also considered to be an improvement in the headcount ratio in the sense that the index takes the heterogeneity among the poor into account. Basically, in what follows, we use $P(\operatorname{sen})$ and $P_{2}$ as the poverty indices because we are interested in the heterogeneity among the poor.

Table 5.2 shows that the poorest regions are Zamboanga, Caraga, ARMM, and Eastern Visayas. However, while the headcount ratios are relatively high in all

Table 5.1 Change in the distribution of inequality, 2000-2009

\begin{tabular}{|c|c|c|c|c|}
\hline \multirow[t]{2}{*}{ Region } & \multicolumn{4}{|c|}{ Gini index } \\
\hline & 2000 & 2003 & 2006 & 2009 \\
\hline Philippines & 0.496 & 0.474 & 0.472 & 0.461 \\
\hline NCR & 0.463 & 0.417 & 0.410 & 0.406 \\
\hline CAR & 0.457 & 0.438 & 0.489 & 0.467 \\
\hline Ilocos & 0.416 & 0.404 & 0.404 & 0.421 \\
\hline Cagayan Valley & 0.432 & 0.455 & 0.433 & 0.457 \\
\hline Central Luzon & 0.365 & 0.360 & 0.410 & 0.382 \\
\hline Calabarzon & 0.434 & 0.413 & 0.419 & 0.418 \\
\hline Mimaropa & 0.408 & 0.451 & 0.421 & 0.410 \\
\hline Bicol & 0.459 & 0.481 & 0.457 & 0.429 \\
\hline Western Visayas & 0.474 & 0.449 & 0.444 & 0.430 \\
\hline Central Visayas & 0.483 & 0.483 & 0.477 & 0.472 \\
\hline Eastern Visayas & 0.497 & 0.472 & 0.497 & 0.501 \\
\hline Zamboanga & 0.472 & 0.536 & 0.520 & 0.489 \\
\hline Northern Mindanao & 0.484 & 0.494 & 0.494 & 0.486 \\
\hline Davao & 0.471 & 0.473 & 0.430 & 0.439 \\
\hline Soccsksargen & 0.452 & 0.501 & 0.412 & 0.455 \\
\hline Caraga & 0.423 & 0.440 & 0.461 & 0.475 \\
\hline ARMM & 0.332 & 0.368 & 0.320 & 0.303 \\
\hline
\end{tabular}

Source: Author's calculation based on the FIES. 
Table 5.2 Distribution of inequality and poverty, 2009

\begin{tabular}{lcccccc}
\hline Region & Gini & Gini (poor) & P(sen) & $\begin{array}{c}\text { Headcount } \\
\text { ratio } P_{0}\end{array}$ & $\begin{array}{c}\text { Poverty } \\
\text { gap } P_{1}\end{array}$ & $\begin{array}{l}\text { Poverty } \\
\text { severity } P_{2}\end{array}$ \\
\hline NCR & 0.450 & 0.075 & 0.003 & 0.012 & 0.002 & 0.000 \\
CAR & 0.478 & 0.139 & 0.076 & 0.199 & 0.056 & 0.022 \\
Ilocos & 0.437 & 0.114 & 0.046 & 0.147 & 0.033 & 0.011 \\
Cagayan Valley & 0.476 & 0.116 & 0.060 & 0.190 & 0.043 & 0.015 \\
Central Luzon & 0.398 & 0.102 & 0.026 & 0.090 & 0.019 & 0.006 \\
Calabarzon & 0.443 & 0.103 & 0.026 & 0.092 & 0.018 & 0.006 \\
Mimaropa & 0.454 & 0.138 & 0.119 & 0.323 & 0.087 & 0.034 \\
Bicol & 0.468 & 0.125 & 0.119 & 0.344 & 0.087 & 0.031 \\
Western Visayas & 0.462 & 0.124 & 0.091 & 0.264 & 0.066 & 0.024 \\
Central Visayas & 0.486 & 0.144 & 0.106 & 0.272 & 0.078 & 0.031 \\
Eastern Visayas & 0.519 & 0.141 & 0.143 & 0.370 & 0.105 & 0.041 \\
Zamboanga & 0.518 & 0.166 & 0.184 & 0.410 & 0.139 & 0.062 \\
Northern Mindanao & 0.485 & 0.155 & 0.139 & 0.338 & 0.103 & 0.043 \\
Davao & 0.451 & 0.146 & 0.099 & 0.259 & 0.072 & 0.029 \\
Soccskargen & 0.481 & 0.140 & 0.127 & 0.330 & 0.093 & 0.037 \\
Caraga & 0.506 & 0.150 & 0.167 & 0.409 & 0.125 & 0.052 \\
ARMM & 0.316 & 0.105 & 0.121 & 0.408 & 0.088 & 0.028 \\
\hline
\end{tabular}

Source: Author's calculation based on the FIES.

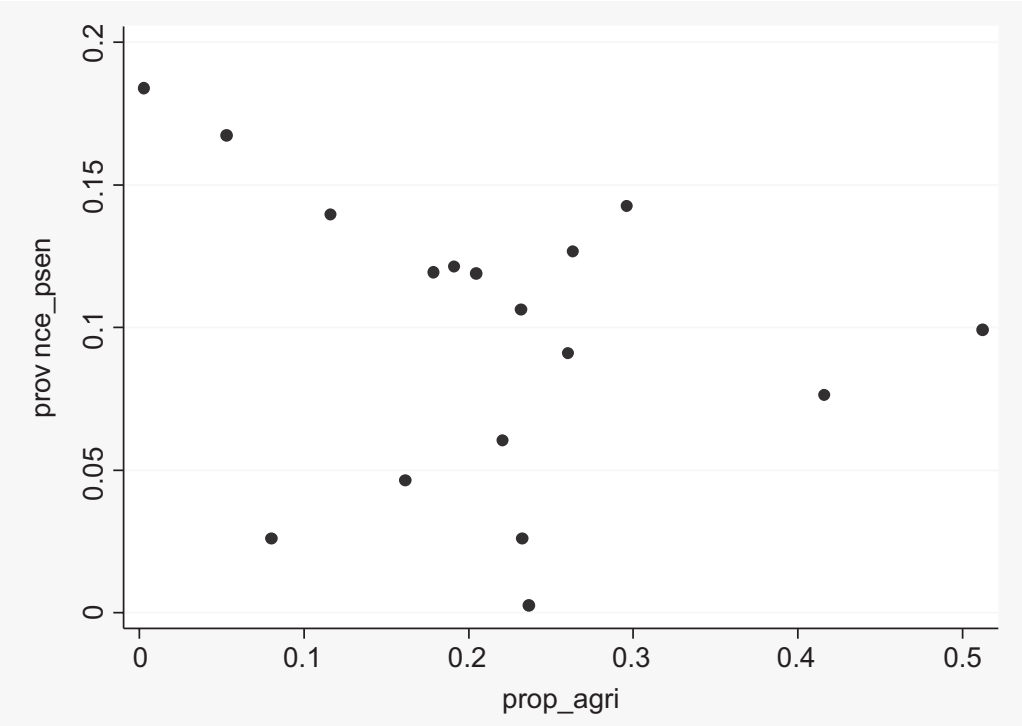

Figure 5.2 Proportion of agricultural GDP and regional poverty $P($ sen $)$

Source: Author's calculation based on the FIES. 
four regions, the seriousness of the poverty state is different. The headcount ratio is higher in ARMM than in Eastern Visayas, whereas the poverty gap is higher in Eastern Visayas than in ARMM. In addition, the proportion of the poor is larger in ARMM, while the seriousness of poverty is greater in Eastern Visayas.

The different states of poverty and inequality found regionally are less easy to understand. Poverty and inequality might be considered to be a problem of rural society whose economy depends heavily on the agricultural sector. From Figure 5.2 , however, we see that the regional diversity of inequality and poverty does not correlate with the proportion of agricultural gross domestic product (GDP) in total GDP. This may suggest that there are different types of poverty such as urban-based or rural-based poverty.

\section{Determinants of the migration decision}

In this section, we analyze the relationship between per capita income and the migration decision. In Section 3.1, we explain this relationship based on income data at the regional level. In Section 3.2, we describe the same relationship based on family-level data.

\subsection{Regional analysis}

In this study, remittances include cash receipts, gifts, support, relief, and other forms of assistance from abroad. Specifically, this source of income includes cash received from family members who are contract workers abroad; cash received from family members who are working abroad; pensions, retirement funds, compensation, and other benefits; cash gifts, support, and relief from abroad; and dividends from investment abroad. ${ }^{4}$

The first two columns in Table 5.3 present the proportion of families receiving remittances and the proportion of remittances to income. The former varies significantly by region. In total, 13.7 percent of families receiving remittances are in Calabarzon, while very few (1.3 percent) are in ARMM. Meanwhile, the proportion of remittance income to total income is high (18.0 percent) in Ilocos but low (3.8 percent) in ARMM.

The third column in Table 5.3 reports the percentage of families with remittances in each region, while the fourth column reports the average proportion of the remittances of families in each region. ${ }^{5}$ By using 2009 data from the FIES, we can calculate both the percentage of families that send members to foreign countries in each region and average per capita income. Figure 5.3 shows the relationship between this percentage and average per capita income. The graph shows an increasing trend, which does not seem to be consistent with NELM theory.

More precisely, we must assess the relationship between the percentage of relocated families and regional inequality. If NELM theory holds, the percentage of families with remittances increases when the Gini coefficient increases. Figure 5.4 shows that this statement is not true. We can observe the negative relationship between this percentage and the regional Gini value. 


\section{Satoshi Obira et al.}

Table 5.3 Distribution of families receiving remittances and proportion of remittances to income by region, 2009

\begin{tabular}{lcccc}
\hline Region & $\begin{array}{l}\text { Proportion of } \\
\text { families receiving } \\
\text { remittances in } \\
\text { total population }\end{array}$ & $\begin{array}{l}\text { Proportion of } \\
\text { remittances to } \\
\text { income }\end{array}$ & $\begin{array}{l}\text { Proportion of } \\
\text { families with } \\
\text { remittances in } \\
\text { each region }\end{array}$ & $\begin{array}{l}\text { Proportion of } \\
\text { remittances }\end{array}$ \\
\hline Philippines & 100.0 & 11.6 & 26.0 & 7.2 \\
NCR & 13.0 & 10.4 & 34.8 & 9.2 \\
CAR & 4.4 & 10.7 & 27.1 & 7.5 \\
Ilocos & 12.3 & 18.0 & 43.4 & 13.9 \\
Cagayan Valley & 5.6 & 9.9 & 31.4 & 8.1 \\
Central Luzon & 11.7 & 14.6 & 35.4 & 10.9 \\
Calabarzon & 13.7 & 13.7 & 32.1 & 10.4 \\
Mimaropa & 2.8 & 7.6 & 18.8 & 4.3 \\
Bicol & 4.0 & 9.3 & 18.8 & 4.6 \\
Western Visayas & 7.9 & 14.2 & 26.7 & 7.4 \\
Central Visayas & 5.7 & 12.6 & 25.1 & 6.6 \\
Eastern Visayas & 4.1 & 9.9 & 20.0 & 5.1 \\
Zamboanga & 2.2 & 8.2 & 17.5 & 4.0 \\
Northern Mindanao & 3.3 & 9.6 & 18.6 & 5.2 \\
Davao & 2.5 & 6.6 & 14.9 & 3.4 \\
Soccskargen & 3.2 & 9.4 & 17.9 & 4.7 \\
Caraga & 2.4 & 8.2 & 17.7 & 4.4 \\
ARMM & 1.3 & 3.8 & 13.6 & 3.2 \\
\hline Samce: Authors can & & & &
\end{tabular}

Source: Author's calculation based on the FIES.

The higher the inequality, the lower the probability of migration. The tendency is even clearer in Figure 5.5. When the poverty index (which takes inequality among the poor into account) increases, the probability of migration decreases. This is true for $P(\operatorname{sen})$ and $P_{2}$.

In summary, we observe that the percentage of families with remittances increases (1) when income increases; (2) when inequality decreases; and (3) when poverty decreases. If we apply the implication of NELM theory, the percentage of families with remittances thus increases when income decreases and when inequality increases. The previous observations are therefore inconsistent with this theory.

\subsection{Micro-data: logistic regression model of migration}

In this section, we analyze the relationship between remittances and inequality/poverty based on micro-data from the FIES. The top graph in Figure 5.6 shows the relationship between per capita income and the proportion of remittances to family income. It is clear that families in the highest income class are outliers. We thus exclude the top 10 percent richest families from our analysis. The bottom graph in Figure 5.6 shows the same relationship after excluding the 


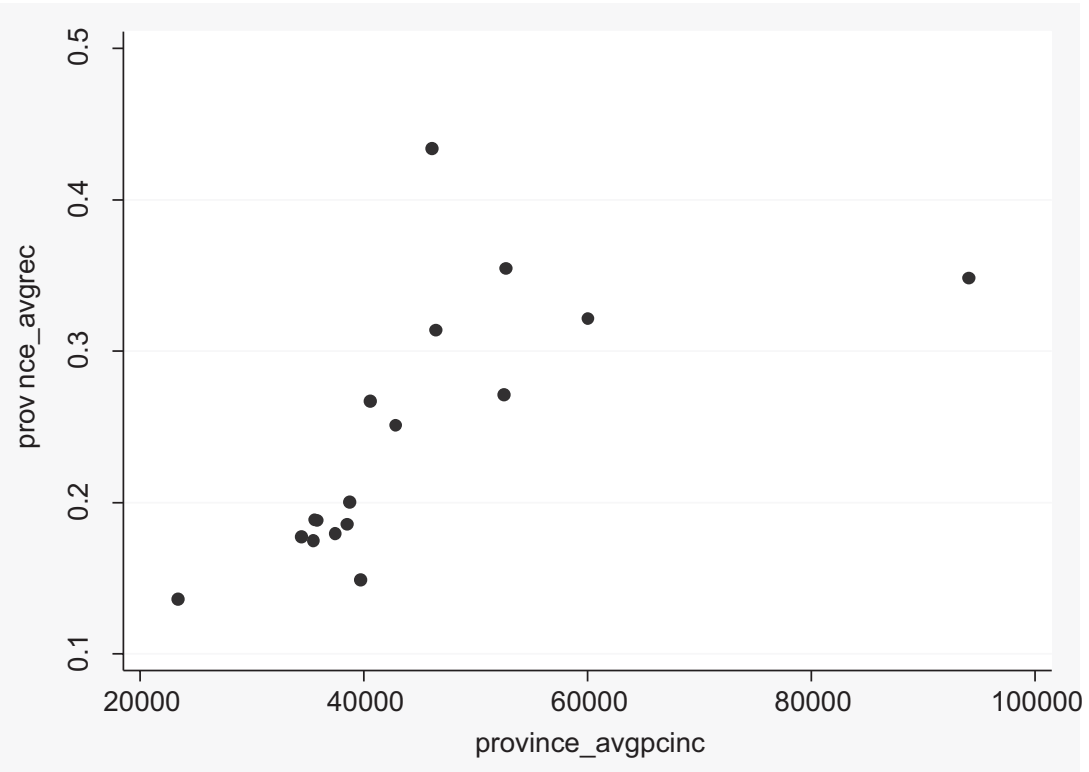

Figure 5.3 Percentage of families that send members to foreign countries and per capita income (by region)

Source: Author's calculation based on the FIES.

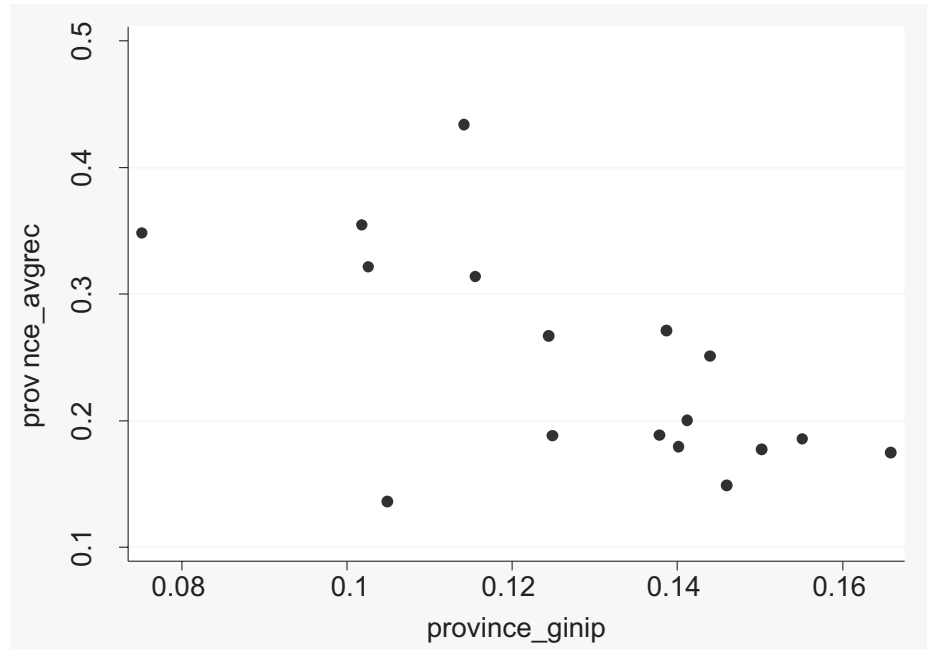

Figure 5.4 Probability of migration and Gini coefficient (poor)

Source: Author's calculation based on the FIES. 

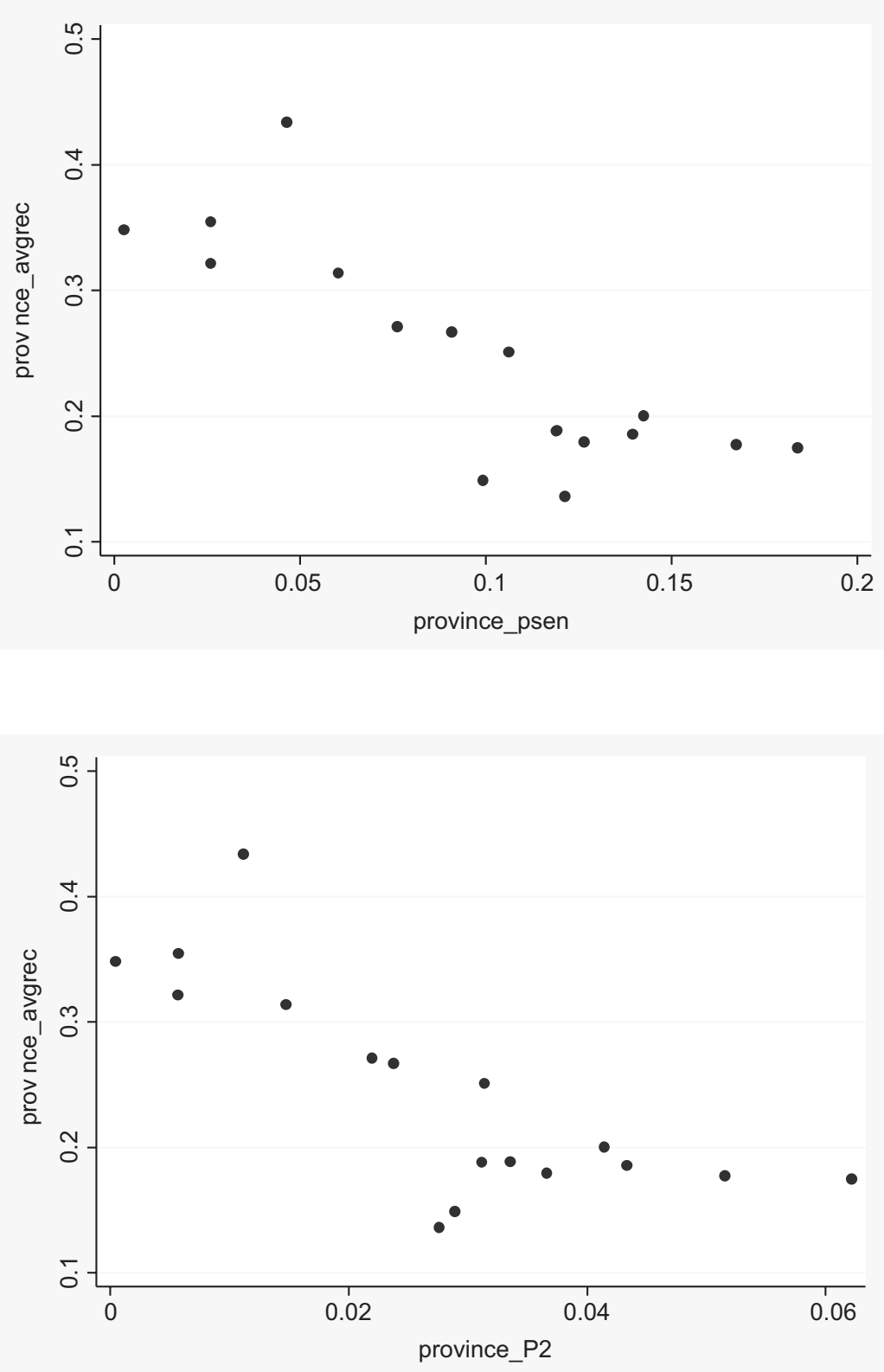

Figure 5.5 Poverty index and probability of migration [top: $P(\operatorname{sen})$; bottom: $P_{2}$ ] Source: Author's calculation based on the FIES. 

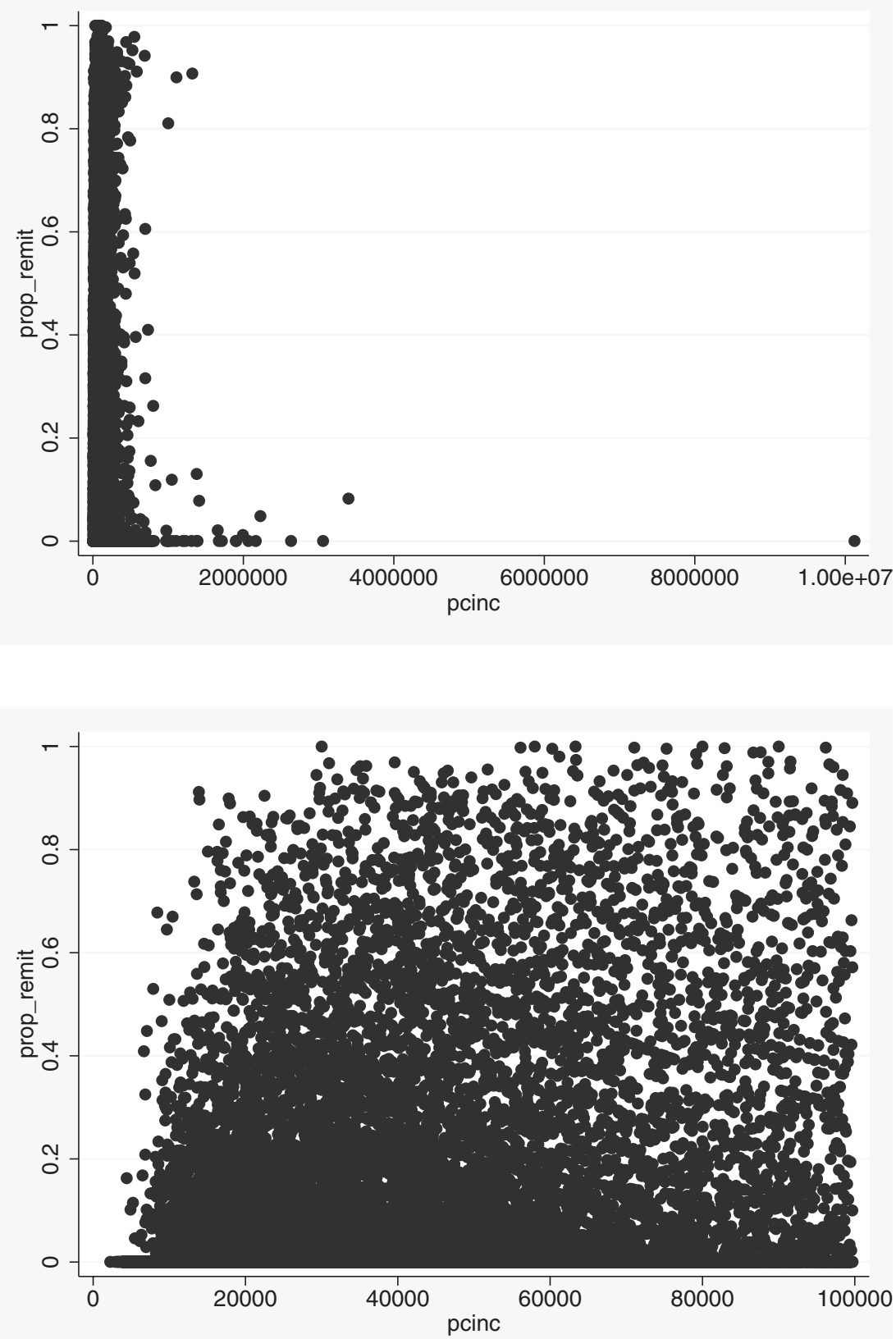

Figure 5.6 Per capita income and the proportion of remittances to household income (left: total data; right: excluding top 10\%)

Source: Author's calculation based on the FIES. 


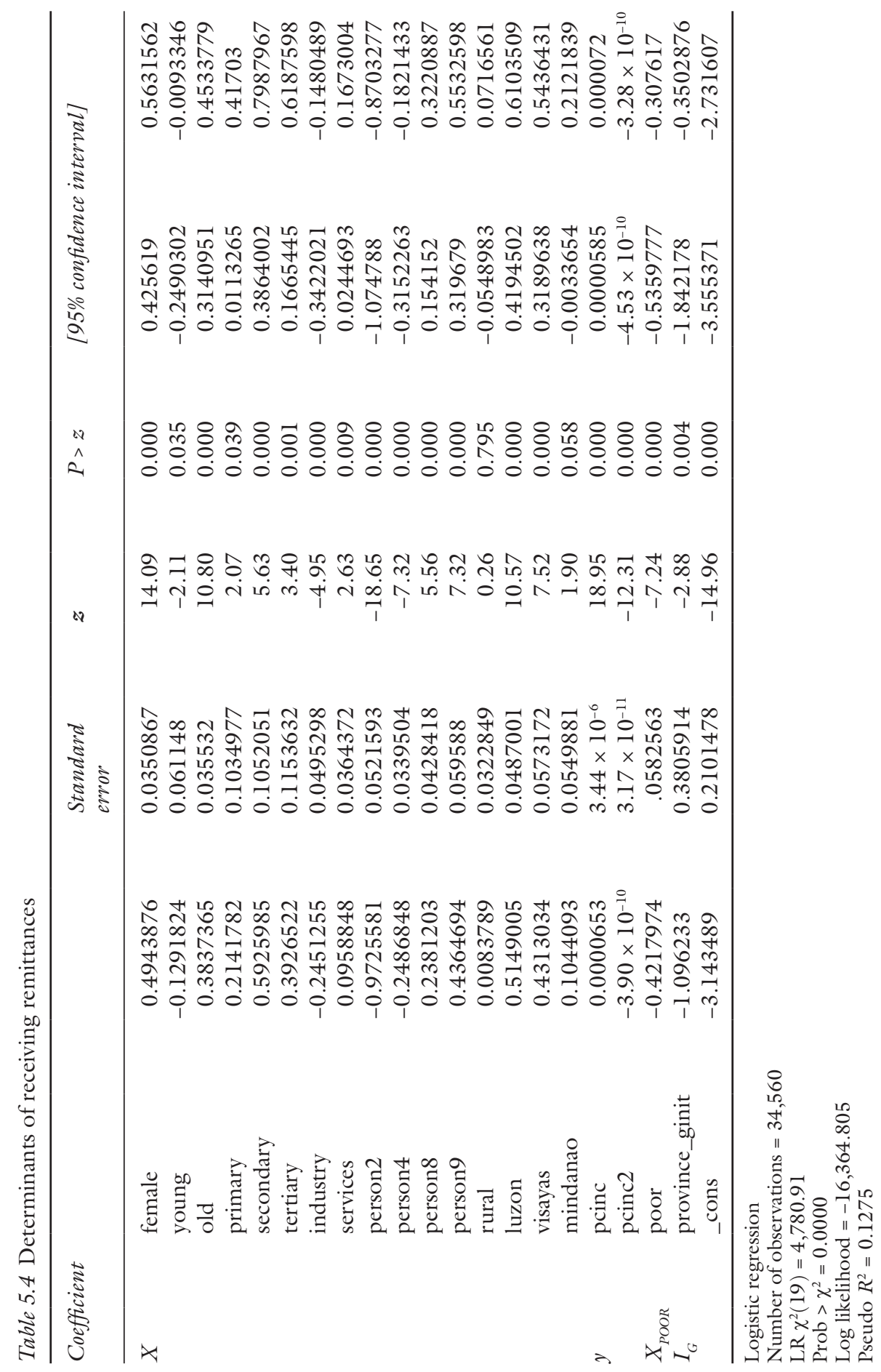


richest families. Since it is difficult to draw firm implications from these graphs, in what follows we regress the remittance status of each family on the families' characteristics.

We will denote $X$ as family attributes such as the gender, age, educational attainment, and business of the family head; family size; urbanity; and region where the family lives. Further, $y$ represents the vector of per capita income and its square, $I_{G}$ is the Gini coefficient for the region where the family lives, and $X_{\text {poor }}$ is the poverty status of each family ( 1 if the family is poor and 0 otherwise). Finally, let us denote $\mathrm{Rem}$ as remittance status ( $\mathrm{l}$ if the family receives remittances and 0 otherwise):

$$
R e m=X \beta+y \beta_{y}+\beta_{\text {Gini }} I_{G}+\beta_{p o o r} X_{p o o r}+\varepsilon
$$

where $R e m=\left\{\begin{array}{lc}1 & \text { if the family receives remittances } \\ 0 & \text { if the family does not receive remittances }\end{array}\right.$

For the analysis, logit analysis or logistic regression is used. This is a regression with categorical binary $\{0,1\}$ dependent (or outcome) variables and with independent (or explanatory) variables that can be either continuous or categorical. The results of estimating Equation (1) are summarized in Table 5.4.

The results of the logistic regression model in Table 5.4 show a number of statistically significant predictors of a family being a recipient of remittances, with very small $p$-values. These predictors include the gender, education attainment, and business of the family head; family size; region where the family lives; per capita income; poverty status; and Gini coefficient of the region. Similarly, the test of the overall model is statistically significant, with a likelihood ratio chi-squared statistic of $4,780.91$ and a corresponding negligible $p$-value of 0.0000 . Note, however, that urbanity is not a significant predictor. Poverty and inequality in the Philippines are thus unrelated to urbanity and/or the importance of the agricultural sector in the region. From these results, we can calculate the theoretical value of the decision to receive remittances:

$$
\widehat{\operatorname{Rem}} X \hat{\beta}+y \widehat{\beta}_{y}+\beta_{\text {Gini }} I_{G}+\beta_{\text {poor }} \widehat{X}_{\text {poor }}
$$

By substituting the theoretical value into the equation

$$
\varphi=\text { Probability }(\text { remittances })=\frac{\exp (\widehat{\operatorname{Rem}})}{1+\exp (\widehat{\operatorname{Rem}})}
$$

we obtain the theoretical value of the probability of receiving remittances. Figure 5.7 shows the relationship between this theoretical value and per capita income. The top graph shows that families send members overseas to work when they are relatively poor. Hence, by removing the top 10 percent of richest families as before, we obtain the bottom graph. This figure shows that the richer the 

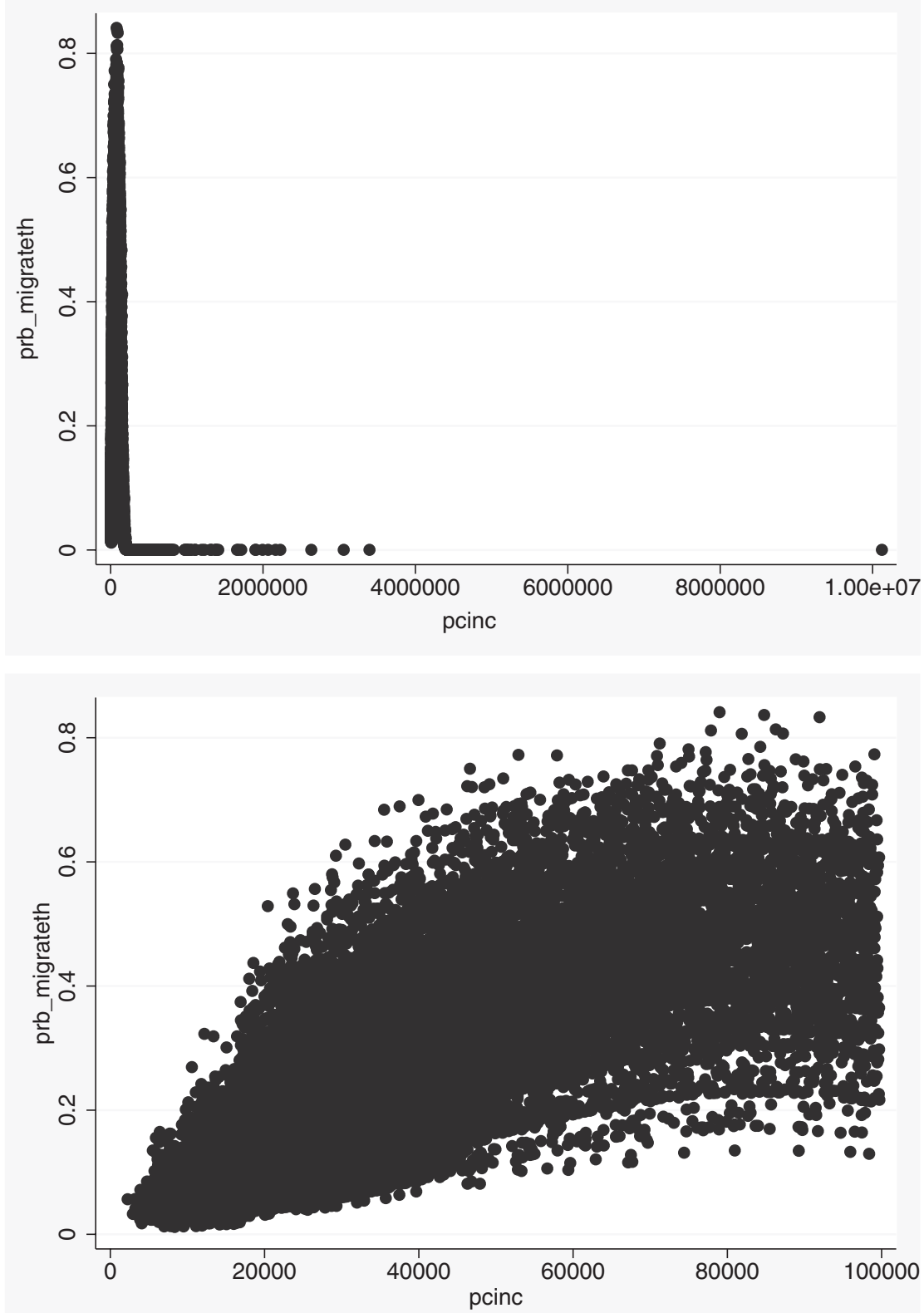

Figure 5.7 Theoretical value of the probability of migration and per capita income (top: total data; bottom: excluding the top 10\%)

Source: Author's calculation based on the FIES. 


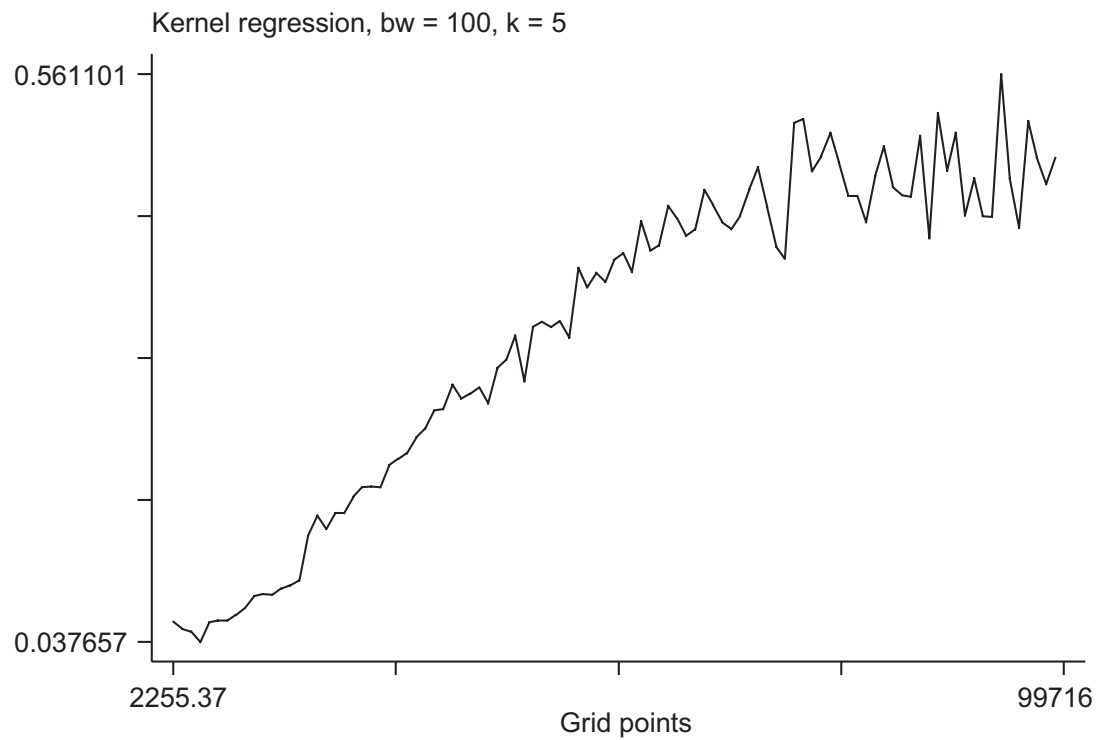

Figure 5.8 Kernel regression result

Source: Author's calculation based on the FIES.

family is, the more likely it is to send its members to foreign countries (if we exclude the richest 10 percent).

The result suggests that the very poor do not migrate and that poor families gradually send members to foreign countries as their income increases to a certain per capita threshold, after which point families gradually decrease migration. Hence, NELM theory does not hold in our analysis. The very poor receive relatively few remittances: they are so poor that they cannot afford to send their family members to foreign countries or even urban areas. Figure 5.8, which shows the kernel regression result for the graph in Figure 5.7, confirms that the richer the family, the higher its probability of receiving remittances.

This result raises the question of whether remittances have a negative impact on poverty and inequality. If remittances are not available for the very poor, then the bottom of the pyramid cannot escape from their current state, and therefore the poverty and/or inequality indices do not decrease when remittances increase. We will consider this question in the next section.

\section{Effects of remittances on inequality and poverty}

\subsection{Effects on poverty}

In this study, we define the outcome variable by categorizing families as poor if their income per capita is below the poverty line and non-poor otherwise. To identify the socio-demographic characteristics of families that are determinants of 


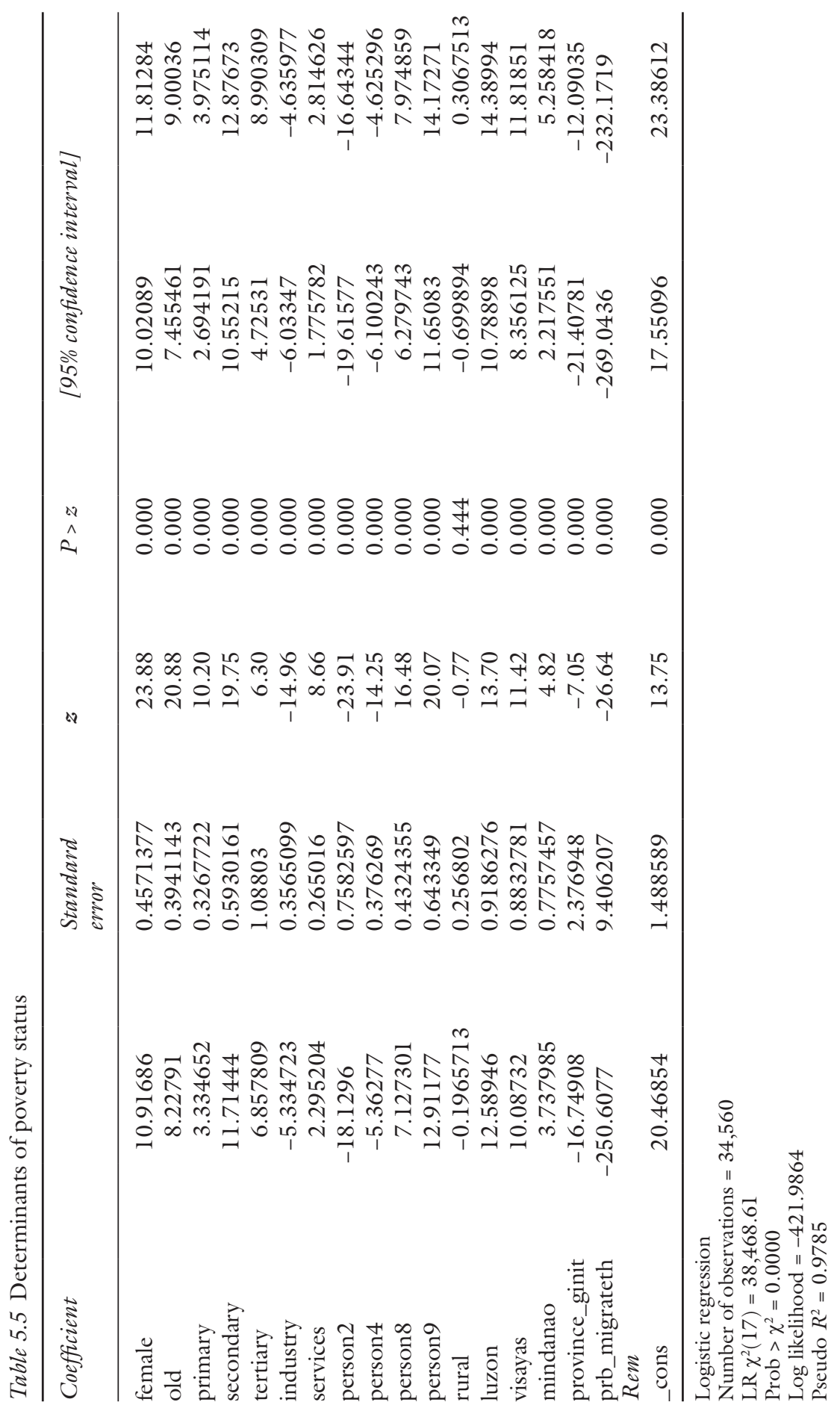


poverty by using the theoretical value of the probability of migration, we estimate the following logistic regression model:

$$
\text { poor }=\mathrm{X} \beta+\beta_{\text {Gini }} I_{G}+\widehat{\operatorname{Rem}} \beta_{\text {Rem }}+\varepsilon
$$

where poor denotes the poverty status of the family, which takes 1 if the per capita income of the family is below the poverty line and 0 otherwise. We exclude the top 10 percent richest families from our analysis (see Figures 5.6 and 5.7).

The results of this logistic regression model in Table 5.5 indicate that the gender, age, educational attainment, and business of the family head; family size; region where the family lives; provincial Gini index; and theoretical value of probability of migration (prb_migrateth) are all statistically significant predictors of a family being poor, with a very small $p$-value. Likewise, the test of the overall model is statistically significant, with a likelihood ratio chi-squared statistic of $38,468.61$ and a corresponding negligible $p$-value of 0.0000 . In addition, the coefficient of $\widehat{R e m}$ is negative at a statistically significant level, suggesting that remittances determine whether a family is poor.

This result is as expected - that is, household income with remittances should be higher than that without remittances. Our analysis in this section thus suggests that families that have the potential to receive remittances are highly likely to have sufficient capacity to escape from poverty.

Table 5.6 Changes in inequality with and without remittances, 2009

\begin{tabular}{lccc}
\hline Region & $\begin{array}{c}\text { (a) Gini (without } \\
\text { remittances) }\end{array}$ & $\begin{array}{l}\text { (b) Gini (with } \\
\text { remittances) }\end{array}$ & (c) (a)/(b) \\
\hline Philippines & 0.518 & 0.460 & 1.126 \\
NCR & 0.479 & 0.405 & 1.183 \\
CAR & 0.524 & 0.466 & 1.124 \\
Ilocos & 0.542 & 0.420 & 1.290 \\
Cagayan Valley & 0.528 & 0.456 & 1.158 \\
Central Luzon & 0.475 & 0.381 & 1.247 \\
Calabarzon & 0.507 & 0.418 & 1.213 \\
Mimaropa & 0.438 & 0.410 & 1.068 \\
Bicol & 0.452 & 0.428 & 1.056 \\
Western Visayas & 0.473 & 0.430 & 1.100 \\
Central Visayas & 0.504 & 0.471 & 1.070 \\
Eastern Visayas & 0.527 & 0.500 & 1.054 \\
Zamboanga & 0.503 & 0.488 & 1.031 \\
Northern Mindanao & 0.519 & 0.486 & 1.068 \\
Davao & 0.463 & 0.438 & 1.057 \\
Soccsksargen & 0.476 & 0.455 & 1.046 \\
Caraga & 0.501 & 0.475 & 1.055 \\
ARMM & 0.327 & 0.303 & 1.079 \\
\hline Source: Authors & & &
\end{tabular}

Source: Author's calculation based on the FIES. 


\section{Satoshi Ohira et al.}

\subsection{Effects on inequality}

The effect of remittances on inequality is more complicated, however. In order to receive remittances, families must earn above a certain income threshold. Only families with a certain amount of income can increase their income through remittances. To analyze the effect of remittances on inequality, Gustafsson and Makonnen (1993) propose calculating inequality indices with and without remittances. For poverty and inequality with remittances, income includes remittances, whereas for poverty and inequality without remittances, remittances are subtracted from income. If we follow this methodology, we obtain the results for the Philippines presented in Table 5.6.

Table 5.6 shows that remittances reduce income inequality in the Philippines. This result seems to be consistent with the claim of NELM theory. However, we must also analyze the factors that determine the per capita income of each family, which might also be those that determine the amount of remittances in each family by controlling for such factors and deriving the effect of remittances on per capita income. In this vein, Pernia (2008) divides the population into five groups and calculates the percentage change in per capita income caused by remittances for each group by using data on 2000 and 2003. Table 5.7 reports the results of a similar calculation based on 2009 data derived from the FIES.

As shown by Pernia (2008), we know that remittances have a positive impact on per capita income and therefore decrease poverty, with the size of the increase being larger for richer families. Hence, remittances are more beneficial for richer families compared with the very poor. In the previous analysis, Gini coefficients with remittances are calculated by subtracting the amount of remittances from income, which means that we do not control for the effect of remittances completely. To model family per capita income, we must estimate the impact of remittances on inequality. Using panel data is the best way in which to avoid endogeneity in the analysis. We use the cross-sectional data from 2009 in the FIES and construct a model to explain the level of per capita income. We assume that per capita income $(p c i n c)$ is determined by the following equation:

$$
\log (p \operatorname{cinc})=X \beta+\varphi^{\prime} \beta_{\varphi}+\varepsilon
$$

where $\varphi$ is the vector of the theoretical value of receiving remittances $\operatorname{Rem}$ and its square. Since Rem is a dummy variable that takes only two values ( 1 and 0 ), we

Table 5.7 Per capita income with and without remittances

\begin{tabular}{lccc}
\hline Income quintile & $\begin{array}{l}\text { (a) Per capita } \\
\text { income }\end{array}$ & $\begin{array}{l}\text { (b) Per capita income } \\
\text { without remittances }\end{array}$ & $\begin{array}{l}\text { (c) (a)/(b) } \\
\text { percentage increase }\end{array}$ \\
\hline 1 & $11,702.67$ & $11,564.87$ & 1.19 \\
2 & $19,587.91$ & $18,983.06$ & 3.18 \\
3 & $29,543.51$ & $27,886.13$ & 5.94 \\
4 & $48,038.2$ & $43,030.78$ & 11.63 \\
5 & $132,608.2$ & $110,997.6$ & 19.46 \\
\hline
\end{tabular}

Source: Author's calculation based on the FIES. 


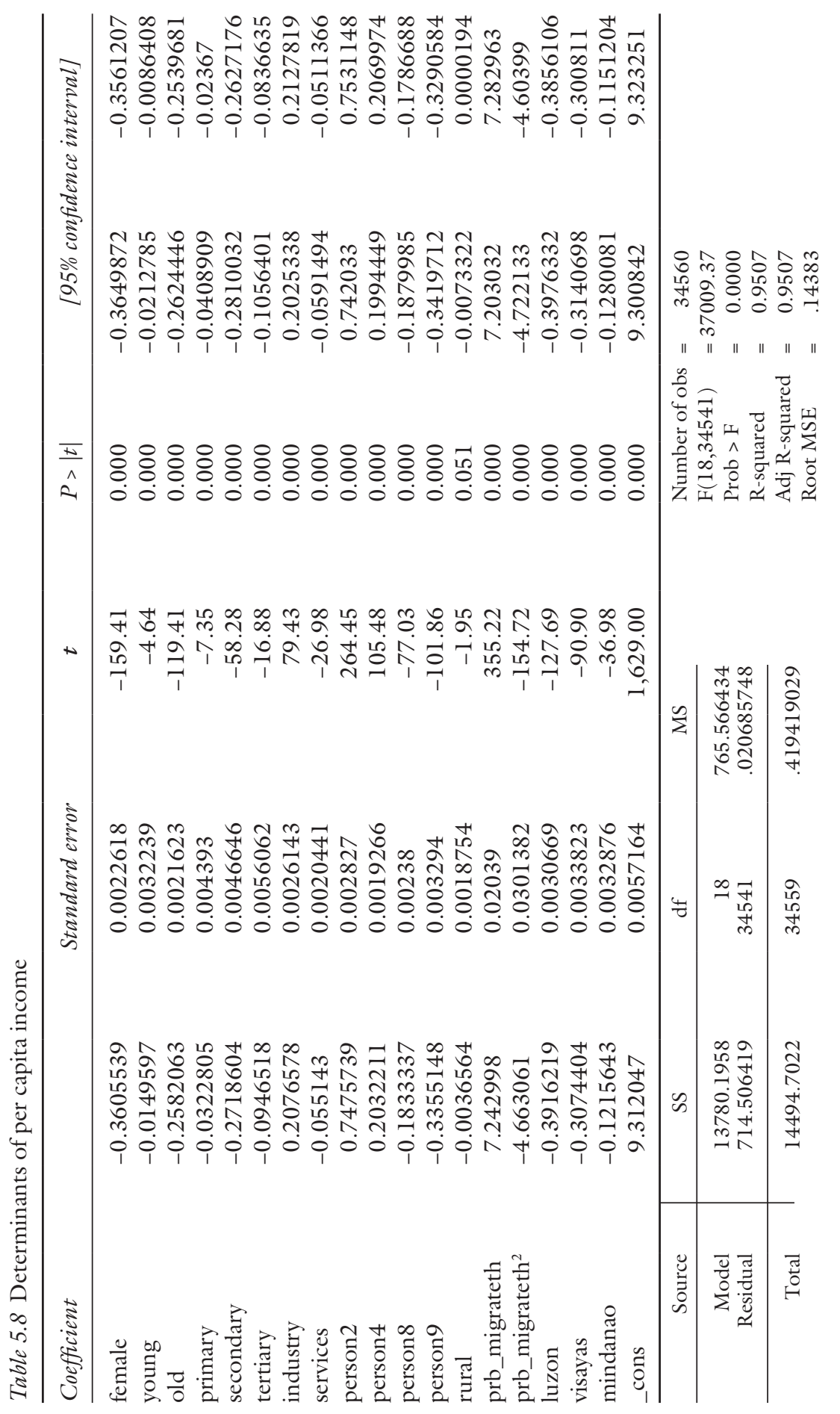


Table 5.9 Theoretical Gini coefficients

\begin{tabular}{lccc}
\hline Region & $\begin{array}{l}\text { (a) Theoretical value } \\
\text { of per capita income } \\
\text { (without remittances) }\end{array}$ & $\begin{array}{l}\text { (b) Theoretical value } \\
\text { of per capita income } \\
\text { (actual remittance } \\
\text { status) }\end{array}$ & $\begin{array}{l}\text { (c) Proportion of } \\
\text { (a)/(b) }\end{array}$ \\
\hline Philippines & 0.175 & 0.600 & 0.292 \\
NCR & 0.192 & 0.600 & 0.319 \\
CAR & 0.191 & 0.606 & 0.316 \\
Ilocos & 0.179 & 0.561 & 0.320 \\
Cagayan Valley & 0.174 & 0.602 & 0.290 \\
Central Luzon & 0.189 & 0.589 & 0.321 \\
Calabarzon & 0.187 & 0.602 & 0.311 \\
Mimaropa & 0.191 & 0.601 & 0.317 \\
Bicol & 0.185 & 0.601 & 0.308 \\
Western Visayas & 0.185 & 0.613 & 0.301 \\
Central Visayas & 0.192 & 0.607 & 0.316 \\
Eastern Visayas & 0.185 & 0.606 & 0.305 \\
Zamboanga & 0.174 & 0.590 & 0.295 \\
Northern Mindanao & 0.182 & 0.591 & 0.309 \\
Davao & 0.184 & 0.582 & 0.317 \\
Soccsksargen & 0.175 & 0.600 & 0.292 \\
Caraga & 0.178 & 0.594 & 0.300 \\
ARMM & 0.154 & 0.585 & 0.264 \\
\hline
\end{tabular}

substitute the theoretical probability (3) instead of regressing Equations (1) and (5) and then regress Equation (6):

$$
\log (\text { pinc })=X \beta+\widehat{\varphi^{\prime}} \beta_{\varphi}+\varepsilon
$$

Per capita income pcinc is assumed to be explained by the family attributes $X$ and the theoretical value of remittance status. Because we know that pcinc has a quadratic effect on remittance status, we assume here that $R \mathrm{em}$ ' is a vector of pcinc and its square. In the previous equation, we use the theoretical value of the probability of sending family members $\varphi^{\prime}$. The linear regression results of estimating Equation (6) are reported in Table 5.8.

By using the results in Table 5.8, the theoretical value of per capita income can be calculated as follows:

$$
\text { pcinc }=X \hat{\beta}+\widehat{\varphi^{\prime}} \widehat{\beta_{\text {rem }}}
$$

Next, by substituting $R e m=0$ into $\varphi^{\prime}$ in the equation, we can calculate the theoretical value of per capita income assuming that there are no remittances at all. Further, by substituting $\varphi^{\prime}=\operatorname{observed}\left(\operatorname{Rem}, \operatorname{Rem}^{2}\right)$, we obtain the theoretical value of per capita income assuming that the remittance status is as in the actual situation. The latter is different from actual per capita income because the value 
is calculated by using Equation (7). Table 5.9 reports the Gini coefficient values calculated by using the theoretical value.

All the Gini coefficients reported in Table 5.9 are theoretical rather than actual values. The Gini coefficient could thus be explained by other factors that are not in Equation (7). For our analysis, however, comparing the state of inequality with and without remittances by calculating the theoretical values in Columns (a) and (b) in Table 5.9 is sufficient. Column (c) in Table 5.9 shows the smaller size of the theoretical values without remittances compared with the size with remittances. Indeed, for all the regions and the Philippines as a whole, the Gini coefficients are larger in the case with remittances than in the case without remittances.

Therefore, the implication of NELM theory does not hold, confirming that remittances have a negative impact on inequality since the poorest families cannot afford to send their members to foreign countries. Only families with a certain level of income can receive remittances and thereby increase their income. As a result, remittances have a negative impact on inequality.

\section{Conclusion}

In the present study, we showed that remittances contributed to the growth in family income and reduction in poverty in the Philippines in the studied period. Remittances are the third-largest source of income for families in the Philippines, and their proportion to total income continuously increased between 2000 and 2009. Undoubtedly, remittances are thus one of the most powerful tools to reduce poverty in the Philippines. At the regional level, the effect of remittances on poverty is high in Ilocos but low in ARMM. Meanwhile, the effect of remittances on inequality is also high in Ilocos but low in Zamboanga.

The effect of remittances on inequality is relatively unclear because of the nonlinearity in the distribution of the benefit of remittances. Very poor families rarely receive remittances compared with richer families. Our simulation shows that income inequality is larger in the case with remittances compared with the case without remittances. Remittances thus have a negative impact on inequality. Although migration policy is one of the most important policies for the Philippines government, it cannot assist the very poor. The government should therefore consider other policies to tackle the poverty problem for very poor families.

It is better to use panel data to avoid the endogeneity problem related to families' responses. In this study, we attempted to derive the implication of remittances for NELM theory as much as possible by using 2009 data from the FIES as the first step in understanding the effect of remittances on inequality.

\section{Notes}

1 International Financial Statistics reports that US \$1 was equal to $42.446 \mathrm{PHP}$ in 2013. Therefore, 163.2 billion PHP is about US $\$ 3.84$ billion.

2

$$
\text { Gini }=1-\sum_{i=1}^{N}\left(x_{i}-x_{i_{1}}\right)\left(y_{i}-y_{i_{1}}\right)
$$


where:

$y_{i}=$ cumulative percentage of the income of family $i$

$x_{i}=$ cumulative percentage of family $i$ (from poor to rich)

$N=$ total number of intervals on the $\mathrm{x}$-axis

3 The Foster, Greer, and Thorbecke (1984) poverty measure takes the following form:

$$
P_{\alpha}=\frac{1}{N}\left(\frac{z-y_{i}}{z}\right)^{\alpha}
$$

$y_{i}=$ per capita income below the poverty line and zero for that above

$N=$ total population

$m=$ number of the poor population

$z=$ poverty line

The National Statistics Office defines the poverty line in terms of a least-cost consumption basket of food and non-food items consumed by families in the lowest quintile, and this was equal to 16,841 PHP in 2009.

If $\alpha=0, P_{\alpha}$ measures the poverty headcount ratio $P_{0}$ as follows:

$P_{0}=\frac{m}{N}$

This ratio measures the magnitude of poverty, referring to the proportion of families who live below the poverty line.

If $\alpha=1, P_{\alpha}$ measures the poverty gap $P_{1}$ as follows:

$P_{1}=\frac{1}{N} \sum_{i}^{m}\left(\frac{z-y_{i}}{z}\right)^{1}$

This measures the relative magnitude of poverty (percentage of poor people) and the depth of poverty (how poor the poor are).

If $\alpha=2, P_{\alpha}$ measures poverty severity $P_{2}$ as follows:

$P_{2}=\frac{1}{N} \sum_{i}^{m}\left(\frac{z-y_{i}}{z}\right)^{2}$

This measures the average value of the square of the depth of poverty (i.e. it is a squared poverty gap index).

4 National Statistics Office Philippines (2006).

5 The second column is calculated as the proportion of total remittances to total income in each region. The third column is a proportion of the number of families with remittances to the total population in each region. The fourth column is an average of the proportion of remittances of each family to the total income of each family.

\section{References}

Bayangos, V. B. (2012), "Going with remittances: The case of the Philippines," Bangko Sentral ng Pilipinas (The Central Bank of the Philippines), BSP Working Paper Series, Center for Monetary and Financial Policy Monetary Policy Sub-Sector: Manila, Philippines. 
Foster, J., J. Greer and E. Thorbecke (1984), “A class of decomposable poverty measures," Econometrica, 52(3), 761-766.

Fuwa, N. (2011), "Should we track migrant households when collecting household panel data? Family relocation, economic mobility, and attrition biases in the rural Philippines," American Journal of Agricultural Economics, 93(1), 56-82.

Goce-Dakila, C. and F. G. Dakila, Jr. (2006), "Modeling the impact of overseas Filipino workers remittances on the Philippine economy: An inter-regional and economy-wide approach," Bangko Sentral ng Pilipinas (The Central Bank of the Philippines), BSP Working Paper Series, Center for Monetary and Financial Policy Monetary Policy Sub-Sector: Manila, Philippines.

Gustafsson, B. and N. Makonnen (1993), "Poverty and remittances in Lesotho," Journal of African Economy, 2(1), 49-73.

National Statistics Office Philippines (2006), Family Income and Expenditure Survey 2006. Enumerator's Manual.

Pernia, E. M. (2008), "Migration remittances, poverty and inequality: The Philippines," Discussion Paper No. 2008-01, School of Economics, University of the Philippines: Quezon City, Philippines.

Ratha, D. (2013), "The impact of remittances on economic growth and poverty reduction," Migration Policy Institute Policy Brief, Migration Policy Institute: Washington, DC.

Rodriguez, E. (1998), "International migration and income distribution in the Philippines," Economic Development and Cultural Change, 48(2), 329-350.

Stark, O. and D. E. Bloom (1985), "The new economics of labor migration," Frontiers in Demographic Economics, 75(2), 173-178.

Yang, D. (2008), "International migration, remittances, and family investment: Evidence from Philippine migrants' exchange rate shocks," The Economic Journal, $118(528), 591-630$. 


\title{
6 Area disparity of income and expenditure in Sri Lanka
}

\author{
Based on micro-data sets of \\ the Household Income and \\ Expenditure Survey of 2006-2007
}

\author{
Yasumasa Baba, Yuko Arai, Hiroko Yasui, and \\ Kaori Yonezawa
}

\section{Introduction}

The Democratic Socialist Republic of Sri Lanka is an island country located in the northern Indian Ocean. Formerly known as Ceylon, this one-time colony of the British Empire became a dominion of the British Commonwealth in 1948 before gaining full independence in 1972. The capital, Sri Jayewardenepura Kotte, is a suburb of the largest city, Colombo. At the first census in 1871, the population of Sri Lanka was 3 million, and after 140 years, the 2011 census recorded a population of 20 million. Sri Lanka has a wide range of ethnicities, religions, and languages due to its diverse population of Sinhalese, Sri Lankan Tamils, Moors, Indian Tamils, Burghers, Malays, Kaffirs, and the aboriginal Vedda. Sinhalese make up 74.9 percent of the population, and they are concentrated in the densely populated southwest and central parts of the island. The largest minority is the Sri Lanka Tamils, who mainly live in the northeast part of the island, forming 11.2 percent of the population. The Moors form the third-largest ethnic group at 9.2 percent of the population, and Indian Tamils make up 4.2 percent of the population. According to the 2011 census, the population of Sri Lanka by religion is as follows: Buddhist: 70.19 percent, Hindu: 12.61 percent, Muslim: 9.71 percent, Christian: 7.46 percent, and other: 0.05 percent. Most Sinhalese are Buddhist, most Tamils are Hindu, and the Moors and Malays are mostly Muslim. Some Sinhalese and Tamils are Christians, and the Veddas have Animist and Buddhist practices. In Sri Lanka, the official languages are Sinhala and Tamil. Middle- and upper-class people speak English. Sri Lanka has been a major tea-producing area since the tea plantations were established during colonial times. Most plantation workers are Indian Tamils who are descendants of the workers brought over from the southern part of India when it was also a colony of the British Empire.

In Sri Lanka, the civil war and tsunamis have had a major influence on the country's economy and people's lives. The Sri Lankan Civil War was an intermittent insurgency against the government by the Liberation Tigers of Tamil Eelam from 1983 through 2009, and about 280,000 Tamils were internally displaced. 
After the civil war in Sri Lanka, infrastructure projects boosted the country's gross domestic product (GDP) per capita, reaching twice the level of that of India. The economy has traditionally depended on agriculture, mainly on rice and the three major plantation crops (tea, rubber, and coconuts), but now the manufacturing industry and wholesale and retail trades have spread with economic development, and recently clothing has become the biggest export item. In addition, there are eight United Nations Educational, Scientific and Cultural Organization (UNESCO)-designated World Heritage Sites, and with the improvements in peace and public order, the number of foreign tourists reached 650,000 people in $2010,850,000$ people in 2011 , and exceeded 1 million people in 2012, continuously reaching record highs. According to the Japan External Trade Organization (JETRO), the Sri Lankan GDP was US \$24.4 billion in 2005 , US $\$ 49.5$ billion in 2010, and US \$59.4 billion in 2012 (Ministry of Finance and Planning 2013). The International Monetary Fund (IMF) estimated that GDP reached US $\$ 71.6$ billion by 2014. The Sri Lankan GDP was US $\$ 59.2$ billion in 2011 , which is smaller than the US $\$ 1,880.1$ billion of India, the US \$213.6 billion of Pakistan, and the US \$2,135.1 billion of the Association of Southeast Asian Nations (ASEAN) countries other than Sri Lanka (International Monetary Fund 2010). However, the real GDP growth rate of 2011 at 8.2 percent reveals that the Sri Lankan growth rate is higher than the 6.6 percent growth rate of India and the 3.6 percent growth rate of Pakistan. It is higher than the 6.5 percent growth rate of Indonesia to join ASEAN.

Various economic development indexes have changed. Unemployment rates in 2006 and 2010 were 6.5 and 4.9, respectively (Department of Census and Statistics - Sri Lanka 2013). The Gini coefficient of household income was 0.46 in 2008-2009, down from 0.49 in 2006-2007. The 2012 annual report by the Ministry of Finance and Planning reported indexes in 2010: access to electricity increased to 84.3 percent from 62.3 percent in 2007 ; access to safe drinking water increased to 65.1 percent from 46.2 percent in 2007 ; and access to education increased from 91.8 percent to 97.4 percent (Ministry of Finance and Planning 2013). The poverty headcount index decreased from 15.2 percent to 8.9 percent between 2006 and 2010 and further decreased to 6.5 percent in 2012 (preliminary results of the Household Expenditure and Income Survey [HIES] 2012/13 report).

Although Sri Lanka has accomplished remarkable development, it faces various problems, including its economic infrastructure, such as transportation, electricity, and social services in the districts, and natural disasters. As the increase of tax revenues is slow despite the growth of its economy, financial resources to compensate for the shortfall in tax revenues and public works spending is reliant on overseas borrowing (Nippon Export and Investment 2014).

As of 2010, Sri Lanka is the twenty-second poorest country in the world, according to the income Gini index based on the 2010 World Bank World Development Indicators. The lowest 20 percent of the population accounted for a small share ( 5 percent) of the total income, and the highest 20 percent of the population accounted for nearly half ( 55 percent) of the total income (World 
Bank 2010). Sri Lanka's inequality cannot be disregarded. There are various kinds of inequalities and disparities related to income, depending on the region. Many papers have examined poverty, inequality, and disparity in Sri Lanka from various perspectives. Kumara (2012) reported on well-being gaps between urban (richer regions) and rural (poorer regions) areas using the HIES 2006/07 and 2002 reports. The report states:

The analysis suggests that the existence of barriers such as remoteness and poor access to markets are a greater factor in preventing lagging regions from being absorbed into the modern sector or growing regions from playing a larger role in perpetuating spatial inequality, especially for the poor, than are disparities in household endowments between regions and sectors.

(Kumara 2012, p. 1)

Himaz and Aturupane (2011) reviewed the impact of education on household economic welfare in Sri Lanka over twenty years from 1985 to 2006 and showed a relationship between education and high returns. De Silva (2013) divided factors of inequality by population subgroups (such as gender, race, employment, education level, etc.) and income sources in Sri Lanka and indicated that inequality in Sri Lanka was driven by the relatively higher levels of expenditure inequalities of those at the top of the expenditure distribution. Factors that exerted the greatest influence on the inequality of income distribution were the within-group component of gender and the between-group component of education. Reduction of total expenditure inequalities should focus more on within areas and within-group disparities than on between areas and between-group disparities. Thus, this study claims that policy targeted at reducing inequality within each of the aforementioned household groups or sectors is needed. Arun and Borooah (2004) and Arun, Borooah, and Arun (2013) classified earners by ethnicity, gender, sectors of employment, place of residence, education, and occupation. They showed that there is no "ethnic effect" in income complaints and made it clear that gender is a factor of income inequity. Gunatilaka, Mayer, and Vodopivec (2010) discussed the problems of the working poor concerned with gender, occupation categories, regional dependencies, and so forth caused by economic development based on income analysis of the years from 1980 to 2002. The paper reported that the government needs to start infrastructure maintenance and education of the poor immediately. Amarasinghe, Samad, and Anputhas (2005) mapped poverty, with reference to a nutrition-based poverty line, to analyze its spatial clustering in Sri Lanka and represented the characteristics of small areas by clustering.

Sri Lanka receives Official Development Assistance (ODA) from the following donor countries and international organizations: Japan, the Asian Development Bank (ADB), and the World Bank, with shares of assistance of approximately 28 percent (approximately US \$301 million), 19 percent (approximately US \$214 million), and 14 percent (approximately US \$156 million), respectively. Subsequent donor countries are Germany, with 9.7 percent (approximately US \$107 million); South Korea, with 1.8 percent (approximately US \$19 million); 
the United States, with 1.7 percent (approximately US \$19 million). The following countries also provide assistance: India (approximately US \$11 million); Sweden (approximately US \$10 million); and China (approximately US \$9 million), each with less than 1 percent (the aforementioned figures are calculated on a disbursement basis for 2006 (Department of External Resources [DER] 2006). The main assistance areas and activities are discussed in the following sections.

Japan focuses on support for the consolidation of peace and reconstruction and assistance in line with the country's mid- and long-term vision for development. The following six factors are examples of the latter: a macropolicy framework, employment labor and human resources development, financial services, infrastructure development, improving productivity, and public sector reforms. The ADB contributes to six items as priority assistance: agriculture and natural resources, energy, private sector development, social sector development, transportation, and governance. The World Bank conducts improvement of infrastructure in the north and east in the areas of health care; education and irrigation; improvement of legislation on labor and land markets; and improvement of access to public services for education, health care, and water supply under three themes: (1) the consolidation of peace; (2) growth; and (3) the promotion of equality. Germany's areas of focus are Deutsche Gesellschaft fur Technische Zusammenarbeit (GTZ) and Kreditanstalt fur Wiederaufbau (KfW), which are implementing organs that offer support for Sri Lanka before fully fledged peace negotiations. Priority areas are achieving lasting economic development, reducing poverty, reducing conflicts, educational reform, and tsunami rehabilitation. The US' areas of focus are Sri Lanka's assistance strategy, for which the United States Agency for International Development (USAID) in 2002-2005 receives support for humanitarian assistance, democracy and governance, and economic growth/ competitiveness. In addition, transition initiatives support the reconstruction of conflict-torn regions, and from 2005 onward, a total of five programs of tsunami reconstruction assistance were carried out. Sweden's areas of focus are the promotion of economic growth for peace building, democratization, human rights, and reduction of poverty.

In this paper, we describe the differences in household income and expenditure of Sri Lanka. In Section 2 of this paper, we illustrate the Household Income and Expenditure Survey of Sri Lanka conducted by the Department of Census and Statistics of Sri Lanka. In Section 3, we review the Income and Expenditure Survey. In Section 4, we present the income and expenditure of specific households such as nuclear families and aged families. Section 5 is devoted to concluding remarks.

\section{Overview of Household Income and Expenditure Survey of Sri Lanka}

The Democratic Socialist Republic of Sri Lanka is an island country located in the northern Indian Ocean with a population of about 20 million. Table 6.1 shows the Sri Lankan population based on the 2001 census and the 2011 census (2012). 
Table 6.1 Population of Sri Lanka and districts

\begin{tabular}{|c|c|c|}
\hline Region & 2001 census & 2011 census (2012) \\
\hline Sri Lanka ${ }^{(a)}$ & $18,797,257$ & $20,277,597$ \\
\hline \multicolumn{3}{|l|}{ Sector $^{(b)}$} \\
\hline -Urban & $2,467,301$ & - \\
\hline -Rural & $13,547,710$ & - \\
\hline -Estate & 914,678 & - \\
\hline \multicolumn{3}{|l|}{ District } \\
\hline -Colombo & $2,251,274$ & $2,323,826$ \\
\hline -Gampaha & $2,063,684$ & $2,298,588$ \\
\hline -Kalutara & $1,066,239$ & $1,214,880$ \\
\hline -Kandy & $1,279,028$ & $1,368,216$ \\
\hline -Matale & 441,328 & 482,348 \\
\hline -Nuwara Eliya & 703,610 & 706,210 \\
\hline -Galle & 990,487 & $1,059,046$ \\
\hline -Matara & 761,370 & 810,703 \\
\hline -Hambantota & 526,414 & 595,877 \\
\hline Jaffna $^{(\mathrm{a})}$ & 490,621 & 583,071 \\
\hline Mannar ${ }^{(a)}$ & 151,577 & 99,063 \\
\hline Vavuniya $^{(a)}$ & 149,835 & 172,789 \\
\hline Mullaitivu $^{(a)}$ & 121,667 & 92,228 \\
\hline Kilinochchi(a) $^{(a)}$ & 127,263 & 112,872 \\
\hline Batticaloa $^{(\mathrm{a})}$ & 486,447 & 525,186 \\
\hline Ampara & 592,997 & 645,825 \\
\hline Trincomalee ${ }^{(a)}$ & 340,158 & 376,366 \\
\hline -Kurunegala & $1,460,215$ & $1,611,407$ \\
\hline -Puttalam & 709,677 & 760,778 \\
\hline -Anuradhapura & 745,693 & 855,562 \\
\hline -Polonnaruwa & 358,984 & 403,859 \\
\hline -Badulla & 779,983 & 811,225 \\
\hline -Moneragala & 397,375 & 448,194 \\
\hline -Ratnapura & $1,015,807$ & $1,082,299$ \\
\hline -Kegalle & 785,524 & 837,179 \\
\hline
\end{tabular}

(a)2001 data are estimates.

(b)2001 data included eighteen districts.

Note: In the 2001 census, out of the five districts in the Northern Province, Jaffna, Kilinochchi, and Mullaitivu were not covered during the preliminary and final census. Vavuniya and Mannar were covered partially. In the Eastern Province, Ampara was covered completely, and Trincomalee and Batticaloa were covered partially. As such, estimates for the districts that were not covered or partially covered are based on the information collected during the listing and numbering operations of the 2001 census, wherever possible, and in the case that the listing and numbering operations were not complete, the Registrar General's Estimates based on the registration of births and deaths have been used.

Source: Census of Population and Housing in Sri Lanka (Department of Census and Statistics 2014). 
For administration, Sri Lanka is divided into nine provinces and twenty-five districts. The population of each district is listed in Table 6.1. Seven cells are blank in the 2001 census. According to the report of the 2001 census, final enumeration was carried out in only eighteen out of twenty-five districts because of the disturbances in the northern and eastern parts of the country.

The Household Income and Expenditure Survey began as the Labor Force and Socio Economic Survey (LFSES) in 1980-1981. In 1990, the LFSES was separated into the Labor Force Survey (LFS) and the HIES. The HIES 2006/07 report that we use in this paper is the sixth survey conducted as the HIES. As the tsunami on December 26, 2004, destroyed most of the houses in the coastal areas, mostly in the Eastern and Southern Provinces, the 2005 survey was postponed to 2006-2007.

In this section, we review the survey according to the final report of HIES 2006/07. This survey provides information on household income and expenditure to measure the levels and changes in the living conditions of people. The questionnaire consists of the following nine sections: "demographic characteristics," "school education," "health information," "expenditure," "income," "inventory of durable goods and household debts," "access to facilities in the area," "housing information," and "agricultural holdings and livestock." Among these, the four items of "demographic characteristics," "school education," "health information," and "income" are obtained for individuals, and the others are obtained for households. As Sri Lanka is a disaster-prone country that is affected by heavy rains with a monsoon almost every year, the questionnaire in the section of "housing information" included a special question about disasters, such as "Was this housing unit affected by any natural disaster during the last year?" - the answer to which consisted of six items: flooding, droughts, earth slips, civil disturbances, damage by wild animals, and other. In addition, it had a column for the names of members of the household who do not live together (but there is no information on such incomes), ${ }^{1}$ service expenses, and non-durable and durable consumer goods that lodgers and servants purchased.

The data were composed of household data and personal data collected through personal interviews. This report provides estimated values based on the twelve-month period from July 2006 to June 2007 (this excludes the Northern Province and the Trincomalee District in the Eastern Province). A two-stage stratified random sample design was used in the survey. Each district is classified into three types of areas: the Urban, Rural, and Estate sectors of the district. Here, an area governed by either a Municipal Council or an Urban Council is considered an Urban sector. Plantation areas that are larger than 20 acres and do not have less than ten residential laborers are considered Estate sectors. Other residential areas that are not Urban or Estate sectors are considered Rural sectors. Figure 6.1 shows the distributions of the households of each area. Statistical analysis related to area disparity will be performed based on such sectors. This sample design is characteristic compared to those conducted in other countries.

In HIES 2006/07, stratified two-stage sampling was used. Primary sampling units (PSUs) are the census blocks prepared for the 2001 Census of Population 
Sri Lanka

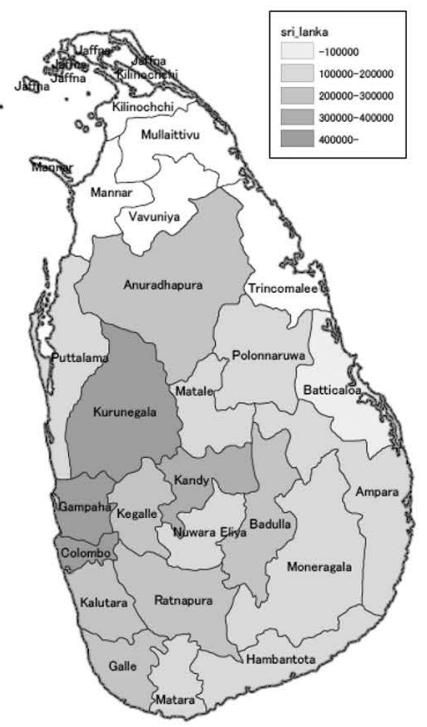

Rural

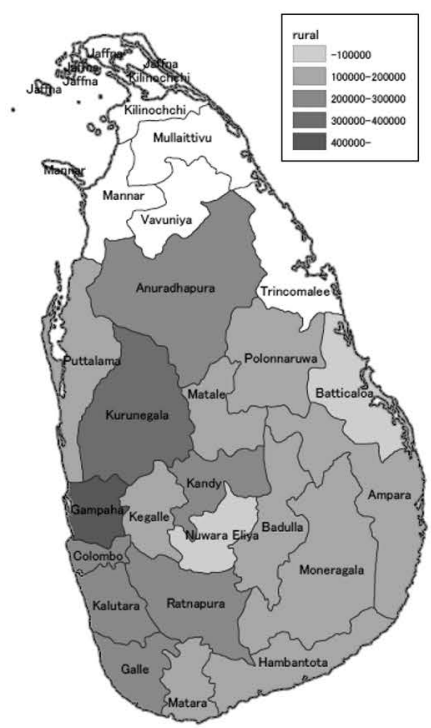

Urban

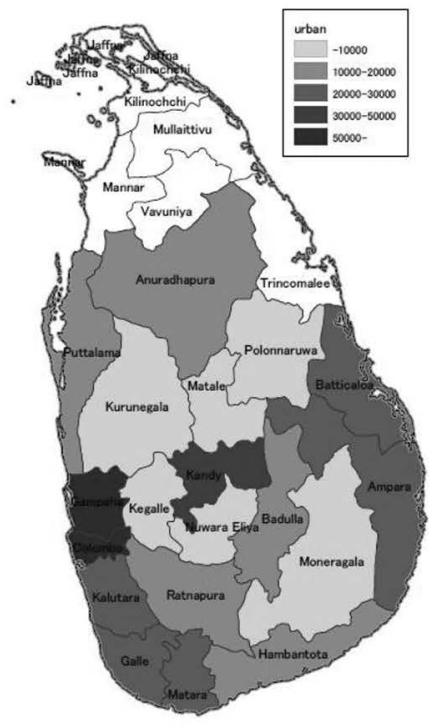

Estate

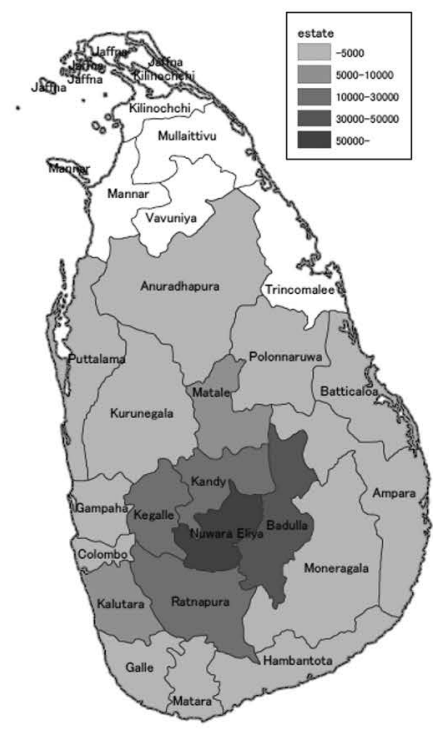

Figure 6.1 Household map 
and Housing. The sample frame is a collection of all census blocks in the domain. It was used for the selection of the PSUs. A sample of 2,200 PSUs was selected from the sampling frame for the survey. Each selected block was updated to include newly built housing units and exclude demolished housing units. This updating operation was also carried out over a period of twelve months, starting from June 2006 to May 2007. For each PSU, updating was performed about one month prior to the scheduled interviews.

Secondary sampling units (SSUs) are the housing units in the selected 2,200 PSUs (census blocks). From each PSU, ten housing units (SSUs) were selected for the survey. Therefore, a total sample size of 22,000 housing units was selected and distributed among the districts in Sri Lanka.

Neyman allocation was applied by using the number of housing units and the standard deviation of the expenditure values reported in the respective domains in the Household Income and Expenditure Survey 2002. The numbers of PSUs for the districts and sectors were allocated proportionately to the number of housing units and the standard deviations according to the survey. District samples were equally distributed among the twelve monthly rounds. Table 6.2 and Table 6.3 give the sample distributions by district and by sector, respectively.

Data was separated into files according to the sections of the questionnaire. Therefore, we needed to connect files to analyze variables belonging to different sections. Some household variables were calculated from individual information. Then, the household and individual information was connected.

Table 6.2 Sample allocation (for twelve months) for districts

\begin{tabular}{lrlr}
\hline District & Housing units & District & Housing units \\
\hline Sri Lanka & 21,790 & Batticaloa & 870 \\
Colombo & 3,000 & Ampara & 900 \\
Gampaha & 2,030 & Kurunegala & 1,220 \\
Kalutara & 1,670 & Puttlam & 870 \\
Kandy & 1,220 & Anuradhapura & 840 \\
Matale & 630 & Polonnaruwa & 600 \\
Nuwara Eliya & 810 & Badulla & 810 \\
Galle & 1,630 & Moneragala & 600 \\
Matara & 1,370 & Ratnapura & 950 \\
Hambantota & 930 & Kegalle & 840 \\
\hline
\end{tabular}

Table 6.3 Sample allocation (for twelve months) for sectors

\begin{tabular}{lr}
\hline Sector & Housing units \\
\hline Sri Lanka & 21,790 \\
Urban & 5,800 \\
Rural & 13,930 \\
Estate & 2,060 \\
\hline
\end{tabular}




\section{Income and expenditure}

In this section, we will present an outline of the Household Income and Expenditure Survey. The HIES 2006/07 report stated that there were 630,891 households in the Urban sector, 3,656,754 in the Rural sector, and 236,120 in the Estate sector. More than 80 percent of Sri Lankans live in the Rural sector.

\subsection{Income}

Figure 6.2 and Figure 6.3 show households by monthly income group. Here, the class interval was determined, excluding the upper 0.3 percent of households because the range of distribution is very large, and most data belong in the first class if the class interval is determined by dividing the range.

Table 6.4 shows average income, and Table 6.5 shows the Gini coefficients of the Urban, Rural, and Estate sectors. The average income of the Estate sector is lower than that of other sectors, and the Gini coefficient is large because the income of a few managers is high and the income of the majority of workers is low as a result of plantations being privatized after independence. Compared with other countries that have plantations, the Gini coefficient of Sri Lanka is higher than the Indonesian Gini coefficient 0.368 (2009) and the Malaysian Gini coefficient 0.462 (2009) (Central Intelligence Agency 2013).

The Gini coefficient of the household income from 1980 to 1981 is included in the report of the HIES 2006/07. According to the list, it was 0.43 in 1980-1981, 0.46 in 1985-1986, 0.43 in 1990-1991, 0.46 in 1995-1996, 0.47 in 2002, and 0.47 in 2005. The Gini coefficient gradually grows (JETRO 2014).

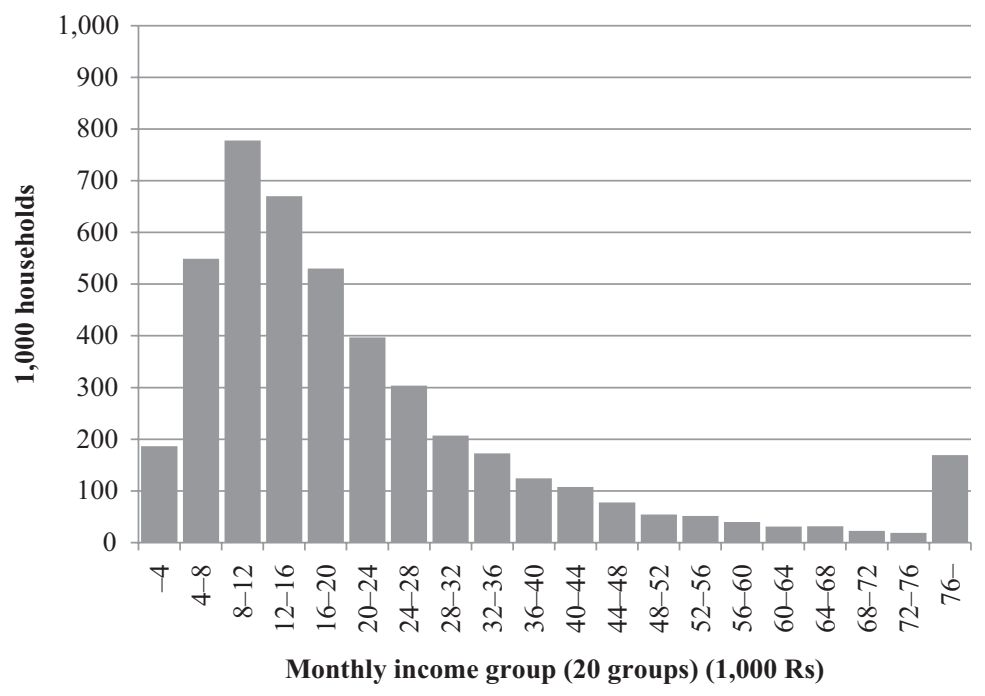

Figure 6.2 Distribution of monthly income of Sri Lanka 


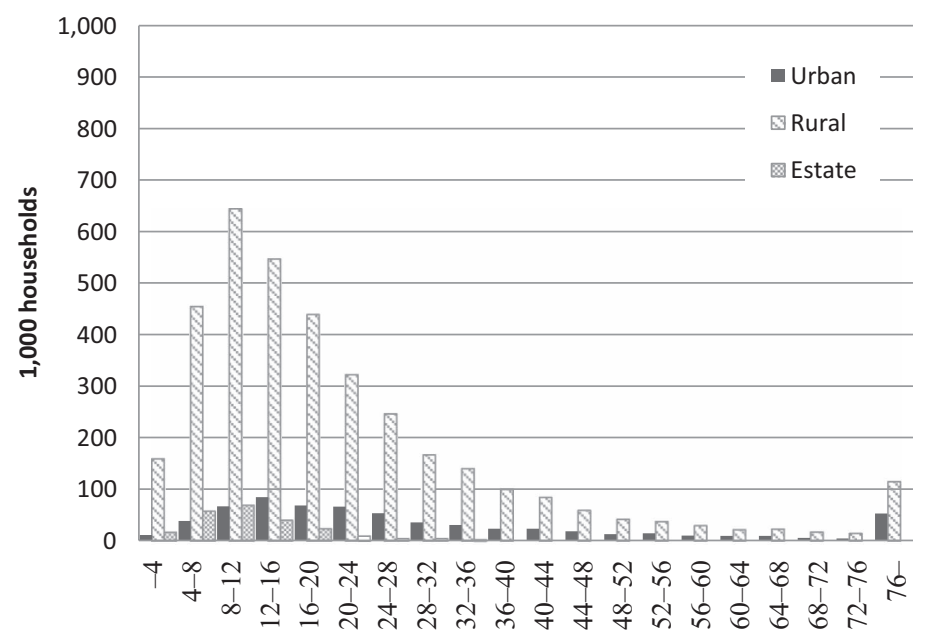

Monthly income group (20 groups) (1,000 Rs)

Figure 6.3 Distribution of monthly income by area

Table 6.4 Average income and expenditure (Rs.)

\begin{tabular}{llll}
\hline Sector (area) & Urban & Rural & Estate \\
\hline Average income & 41,141 & 23,830 & 19,129 \\
Average expenditure & 35,377 & 21,544 & 13,548 \\
\hline
\end{tabular}

Table 6.5 Income Gini coefficients

\begin{tabular}{lcccl}
\hline Sector (area) & Sri Lanka & Urban & Rural & Estate \\
\hline Gini coefficient & 0.495 & 0.550 & 0.462 & 0.570 \\
Proportion & $100.0 \%$ & $13.9 \%$ & $80.8 \%$ & $5.2 \%$ \\
\hline
\end{tabular}

This shows that the income gap of Sri Lanka increases with economic development. Most of the poor are engaged in agriculture and live in sectors with a low maintenance rate of the infrastructure that links markets to farms and villages. In addition, many poor citizens do not have access to basic services such as clean water and sanitation. Working electricity is scarce, and education levels are low. These produce inequities and local differences.

\subsection{Expenditure}

Figure 6.4 and Figure 6.5 show the distributions of monthly expenditure of the households of Sri Lanka and the surrounding areas, respectively. The Gini 


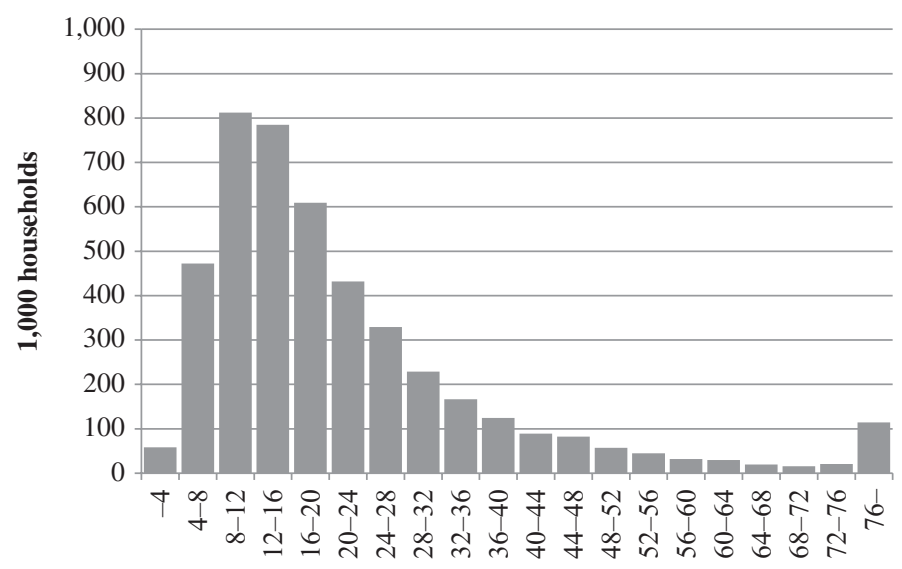

Monthly expenditure group (20 groups) (1,000 Rs)

Figure 6.4 Distribution of monthly expenditure of Sri Lanka

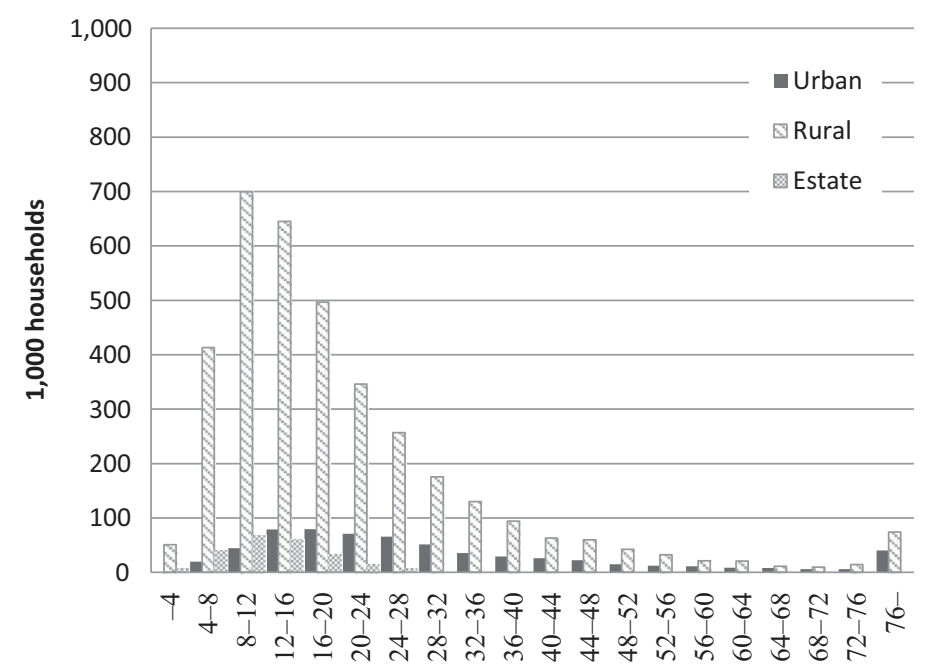

Monthly expenditure group (20 groups) (1,000 Rs)

Figure 6.5 Distribution of monthly expenditure by area

coefficients are given in Table 6.6, and Engel's coefficients are provided in Table 6.7 and Figure 6.6. Engel's coefficient of Sri Lanka becomes higher than Engel's coefficient of Indonesia at 43.0 percent (2009) and Engel's coefficient of Malaysia at 14.0 percent (2009) (Euromonitor International 2014). Table 6.7 
Table 6.6 Expenditure Gini coefficients

\begin{tabular}{lcccl}
\hline Sector (area) & Sri Lanka & Urban & Rural & Estate \\
\hline Gini coefficient & 0.408 & 0.417 & 0.393 & 0.280 \\
Proportion & $100.0 \%$ & $13.9 \%$ & $80.8 \%$ & $5.2 \%$ \\
\hline
\end{tabular}

Table 6.7 Engel's coefficients

\begin{tabular}{lcccc}
\hline Sector (area) & Sri Lanka & Urban & Rural & Estate \\
\hline Engel's coefficient & 46.1 & 39.9 & 43.3 & 51.7 \\
\hline
\end{tabular}

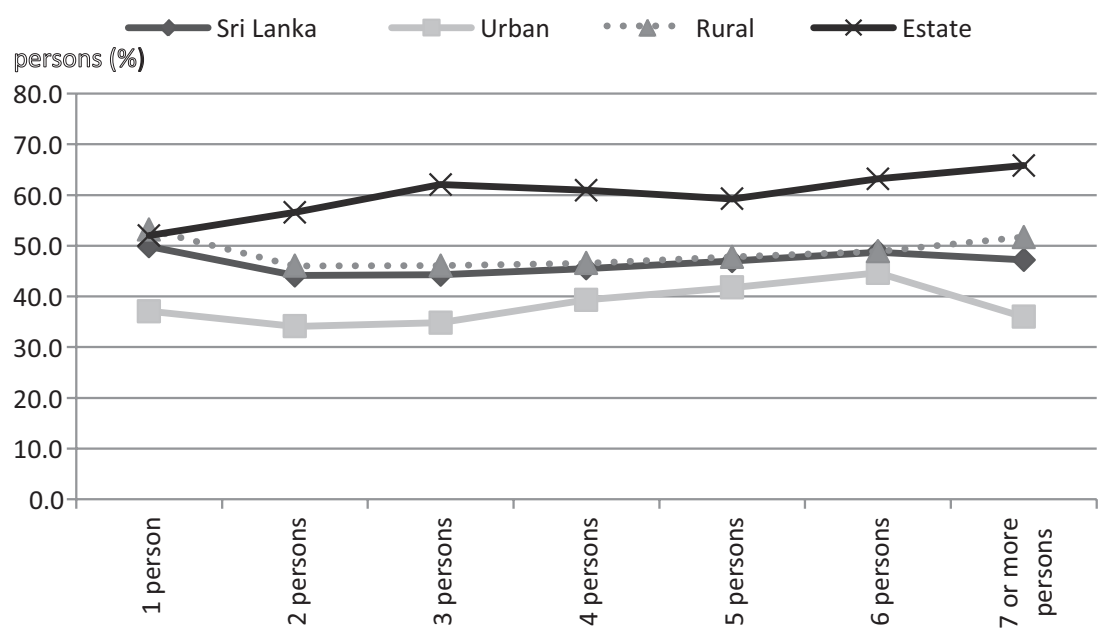

Figure 6.6 Engel's coefficient by number of household members and area

shows that the Gini coefficient of the Estate sector is the smallest and that Engel's coefficient of the Estate sector is the largest.

As shown in Figure 6.6, even if the household members of the Urban and Rural sectors increase, Engel's coefficient does not change significantly, but it does grow little by little when the number of household members increases in the Estate sector. The increase in the number of household members is accompanied by an increase in income in the Urban and Rural sectors, but an increase of the household members affects the family budget expenditure without household incomes increasing even if the number of household members increases in the Estate sector. The labor force of the Estate sector is 70.5 percent of the resident population, which is smaller than the Urban ( 75.7 percent) and Rural (76.5 percent) sectors. This is because the Estate sector has many children who are younger than ten years old as members of the non-working population compared with the Urban and Rural sectors. 
A high Engel's coefficient shows a lower standard of living because saving food expenses makes it difficult to live. In other words, it is thought that the standard of living of Estate is lower than that of other areas with a lower Engel's coefficient. Therefore, it is thought that the standard of living of the Estate sector is lower than that of other areas.

The expenditure terms of the HIES in Sri Lanka are classified as follows: food; housing; fuel and light; personal care expenses (toothpaste, haircuts, perfume, etc.); health expenses; transport; communication; recreation, entertainment, and cultural activities; non-durable household goods; household services; clothing and textiles; footwear; durable household goods; other expenses (insurance, pension, etc.); and other ad hoc expenses. Durable household goods are divided into small household goods, including glassware and pottery (durable household goods A); large household goods, including tables and settees; and electrical appliances such as refrigerators (durable household goods B).

In detail, toothbrushes, haircuts, cosmetics, etc., are included in personal care expenses. Moreover, soap and detergents are included in non-durable household goods. Umbrellas, hats, etc., are included in footwear and other personal effects. Tableware, pillows, and carpets are included in durable household goods A; large furniture and electric appliances are included in durable household goods B; insurance, the Widows'/Widowers' \& Orphans' Pension (W \& O.P.) fund, etc. are included in other expenses and cultural activity expenses; and purchased property such as houses is included in ad hoc expenses.

As mentioned previously, Engel's coefficient calculated from food costs is an important indicator to represent the standard of living. We are also interested in spending on other items other than food. Similar to Engel's coefficient, we examined the proportion of spending on each item to total consumption expenditure. Here, other expenses (insurance, pension, etc.) and other ad hoc expenses are excluded from the analysis because the consumption expenditure referred to here does not include such items.

The highest ratio among the consumption expenses in Sri Lanka as a whole is food costs (46.1 percent). Next is housing (13.9 percent). Housing includes the estimated rent of owner-occupied houses, but about half of it is food costs. It is approximately 70 percent of food costs even if it is calculated by adding fuel and light ( 5.5 percent). This shows the expense for a house, and the expenses for lighting and fuel are not very large in Sri Lanka.

The next-highest item is transportation (9.8 percent). More than 90 percent of land transport depends on roads in Sri Lanka where economic development is progressing. Buses are active all over the country: this is the most important form of public transport in Sri Lanka. However, spending for buses still accounts for about 4 percent of the Estate sector. This suggests that the Estate sector seems to be a closed area.

In addition, other important terms are as follows: health expenses ( 3.7 percent) ${ }^{2}$ personal care expenses ( 1.5 percent); communication (2.8 percent); recreation, entertainment, and cultural activities ( 1.4 percent); non-durable household goods ( 1.0 percent); household services ( 0.6 percent); clothing and 
textiles (2.8 percent); footwear and other personal effects ( 0.6 percent); durable household goods (1) (0.3 percent); and durable household goods (2) (3.9 percent). In particular, the scales of expenditure for transportation; communication; recreation, entertainment, and cultural activities; household services; and durable household goods (2) do not even reach 20 percent compared with Urban areas. Since these items raise the standard of living, it is inferred that households belonging to the Estate sector have limited budgets so that items of expenditure other than food expenses may also be noticeable.

\subsection{Consumption expenditure and Engel's coefficient}

A high Engel's coefficient implies a low standard of living. The values shown in the previous section are Engel's coefficients of the whole of Sri Lanka. We need to calculate Engel's coefficients of various population groups in order to clarify the social or economic structures of households in Sri Lanka. Figure 6.7 shows the movement of Engel's coefficient for consumption in order to compare the Sri Lankan standard of living of households.

The points in the figure are concentrated at less than Rs.100,000 in Sri Lanka as a whole. Most of the data points show movement in a straight line gathered near the $\mathrm{y}$-axis; the small data points are over Rs.100,000 and become roughly flat. By fitting these to a logarithmic trend curve, we find that the relation between consumption and Engel's coefficient changes at approximately Rs.100,000 of consumption. The difference in values of Engel's coefficients in households with consumption of more than Rs.100,000 is around 10 percent. On the other hand, the difference for households with consumption of less than Rs.100,000 is over 70 percent, and there are certain households where Engel's coefficient reaches 95 percent. In such households, most of the consumption expenses are used for food. What are the attributes of these households?

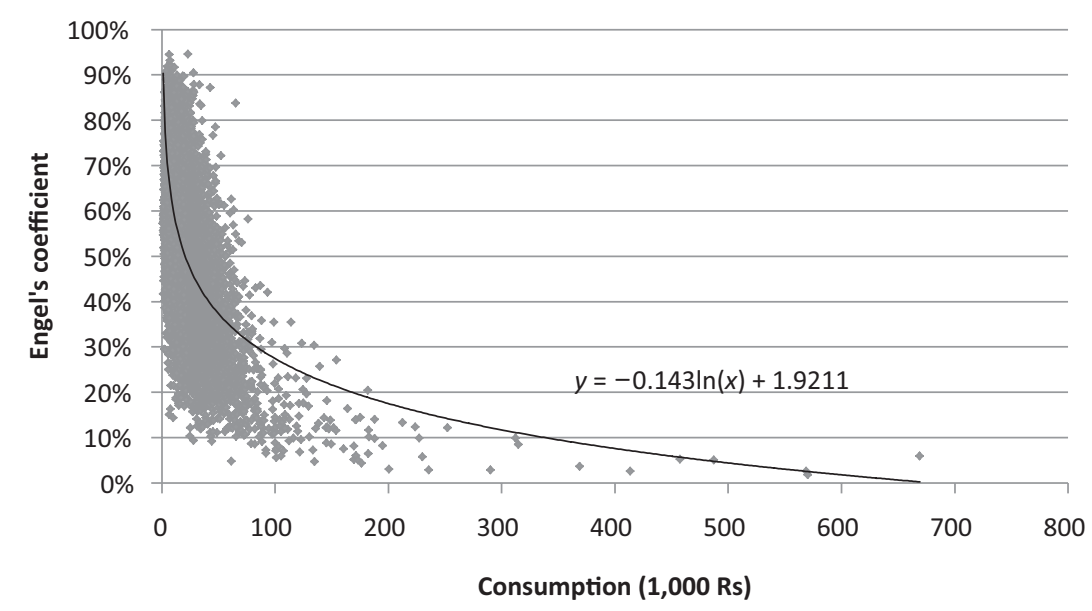

Figure 6.7 Engel's coefficient and consumption 
When observing the top 10 percent (Engel's coefficient is 72 percent or more) of the households of Engel's coefficient, the average number of household members is 4.0 persons, the average age is 49.8 years old, and there is almost no difference compared with the average of the whole of Sri Lanka. However, the value of Engel's coefficient depends on the number of household members: one-person households and households with six or more people have a high value. If the number of household members increases, Engel's coefficient will become high, but Engel's coefficient of one-person households is high. Households with a member who is more than 60 years old account for 60 percent of one-person households. This suggests that it is necessary to improve the standard of living of elderly people in Sri Lanka, where it is predicted that the aging population will increase.

Engel's coefficient is lower in high-income households by Engel's Law. The interregional difference of income will be a factor of disparity of income in Sri Lanka. From this point of view, we compared Engel's coefficient between areas. The household ratios of the top 10 percent in each area are as follows: 5.4 percent in the Urban sector, 10.1 percent in the Rural sector, and 27.3 percent in the Estate sector. One out of twenty households in the Urban sector, one out of ten households in the Rural sector, and three out of ten households in the Estate sector had Engel's coefficients of 72 percent or more. For this reason, improvements in disparities and the development of infrastructure and sanitation are necessary.

\subsection{Poverty line}

In Sri Lanka, the Official Poverty Line (OPL) was introduced in June 2004. The OPL established in 2002 adopts the absolute poverty line, which is fixed at the welfare level of a person who has a certain minimal nutritional intake (2030 kilocalories) (Department of Census and Statistics 2004). The OPL is updated by the Colombo Consumer Price Index (CCPI), reflecting price fluctuations. It adds up the quantity of personal nourishment, calculates the sum total of the whole country of the quantity of daily calories, divides it by the total population, and calculates the quantity of mean calories consumed. Next, to set a poverty line corresponding to this nourishment standard, the Cost of Basic Needs (CBN) is used. The local daily necessities price is calculated by the Laspeyres price index, and the poverty line is calculated from the result of the HIES. According to the Poverty Indicators 2006/07 report, the price index reported by the CCPI was 4,983 in 2006-2007 and the value of the OPL was Rs.2,233 of the expense per capita for one month in 2006-07. ${ }^{3}$ The poverty headcount index is estimated to be 15.2 percent, and 2,805,000 persons are categorized as poor. The poverty ratio by area is 6.7 percent in the Urban sector, 15.7 percent in the Rural sector, and 32.0 percent in the Estate sector. The contribution to total poverty is 6.6 percent in the Urban sector, 82.1 percent in the Rural sector, and 11.3 percent in the Estate sector, with the majority of the poor categorized as living in the Rural sector (Department of Census and Statistics 2008).

For poverty reduction, the Sri Lankan government planned to improve social security policies, maintain infrastructure, and establish secondary schools. The 
most important plan is the Samurdhi program. It was introduced in place of the "Janasabha" program, which was a previous poverty reduction policy in 1994. The government set aside about 1 percent of GDP for the program, and this program covered around 1.6 million households. The Samurdhi program is comprised of the Village Development Program, the Livelihood Development Program, and spiritual and social development programs. The infrastructure development program imposes labor mainly related to the infrastructure development of rural farms to the recipient households in order to qualify for living assistance. Vocational training of the recipient is included as a purpose of the program. The budget allocated to infrastructure development projects in the Samurdhi program in 2010 was Rs. 1,667.80 million (51 percent). The purpose of the program is to help low-income households achieve sustainable growth, and the budget was Rs.810 million in 2010 (25 percent of the total Samurdhi budget). The purposes of these spiritual and social development programs are to combat drugs, provide child welfare services, and provide anti-suicide initiatives. The budget was Rs.437 million in 2010 (13 percent of the total Samurdhi budget). The other budget was Rs.352.2 million in 2010 ( 11 percent of the total Samurdhi budget) (Ministry of Economic Development).

In addition, the Samurdhi finance society program (Samurdhi Banking Societies Program) supports people living in villages in the Rural sector by contributing to microfinance. Its purpose is to provide financing and increase savings. There are 2,588,059 members in total, with $1,691,112$ (65.34 percent of the total) females and 896,947 (35.66 percent of the total) males. Households in which the monthly income is less than Rs.1,500 are able to receive support from this program. Furthermore, there are four lower-level categories classified by monthly income: households that have earnings of less than Rs.500 and more than five members can receive Rs. 1,000; households with only one person or two persons and others can receive Rs.100, Rs.200, and Rs.500, respectively. Support is withdrawn when the income of the household exceeds Rs.2,000 continuously for six months or at least one person in the family finds a job (International Labour Office 2008; Japan Bank for International Cooperation 2001).

According to the announcement of the Samurdhi station, 1,573,207 households were recipients of the Samurdhi subsidy program as of 2010 (Ministry of Economic Development).

\section{Income and expenditure of specific households}

Approximately 60 percent of all households in Sri Lanka are nuclear families. This is similar to the situation in Japan. The number of people 60 years old or older in terms of the overall population of Sri Lanka increased from 5.5 percent to 10.0 percent from 1946 through 2001. Sri Lanka is one of the countries in which the aging of society is progressing. Economic development and migration of family members have resulted in an aging population.

In Japan, the income of elderly households is low, and households consisting of only a mother and child(ren) are in a similar situation in terms of income. 


\section{Yasumasa Baba et al.}

Therefore, we tried to identify two types of families: families living with children under the age of seventeen who attend school and elderly households consisting of a person who is 60 years old or older.

Figures $6.7,6.8$, and 6.9 and Table 6.8 show the monthly income and expenditure offamilies. Household expenditure is the total of consumption expenditure and non-consumption expenditure. Consumption expenditure is the expenditure necessary for daily living needs, such as food, housing, lighting and fuel, clothing, education, cultural and entertainment costs, and transport and communication costs. A family comprised of a mother with children in the Estate sector has the lowest income on average. On the other hand, the average expenditure of couples only in the Estate sector is the lowest. The standard of living is lower in the Estate sector, where income and expenditure are lower than in other sectors. Furthermore, we examined households with child(ren) in a nuclear family who attend school. Table 6.9 shows the income and consumption expenditure by area of families living with children under the age of seventeen who attend school. In Table 6.10, CO-U means Couple Only in the Urban sector, CC-R means Couple with Children in the Rural sector, and so forth. That is, CC and so on represents the family type and $\mathrm{U}, \mathrm{R}$, and $\mathrm{E}$ represent the area.

The income and expenditure of the Estate sector are lower than those of other sectors. In particular, the average balances of income and expenditure are in the

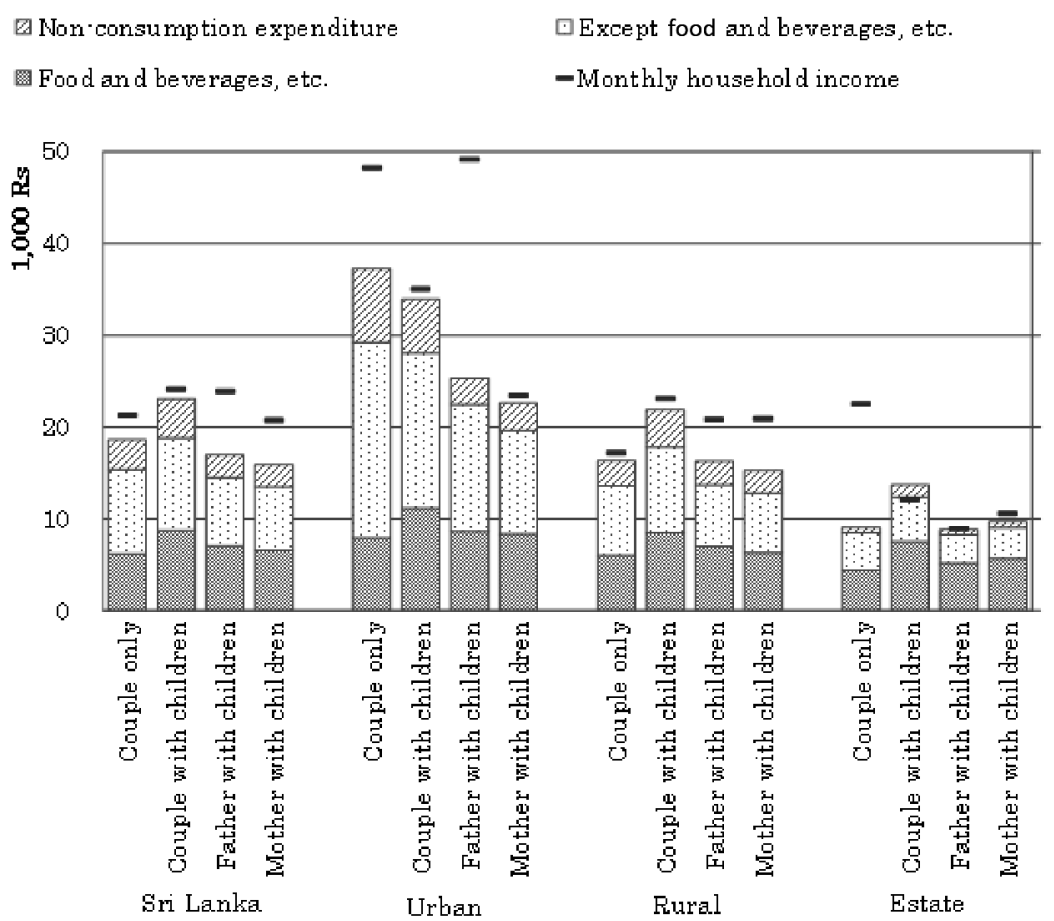

Figure 6.8 Monthly income and expenditure per household by family nuclei 
๑Non-consumption expenditure

$\square$ Food and beverages, etc. $\square$ Except food and beverages, etc.

-Monthly household income

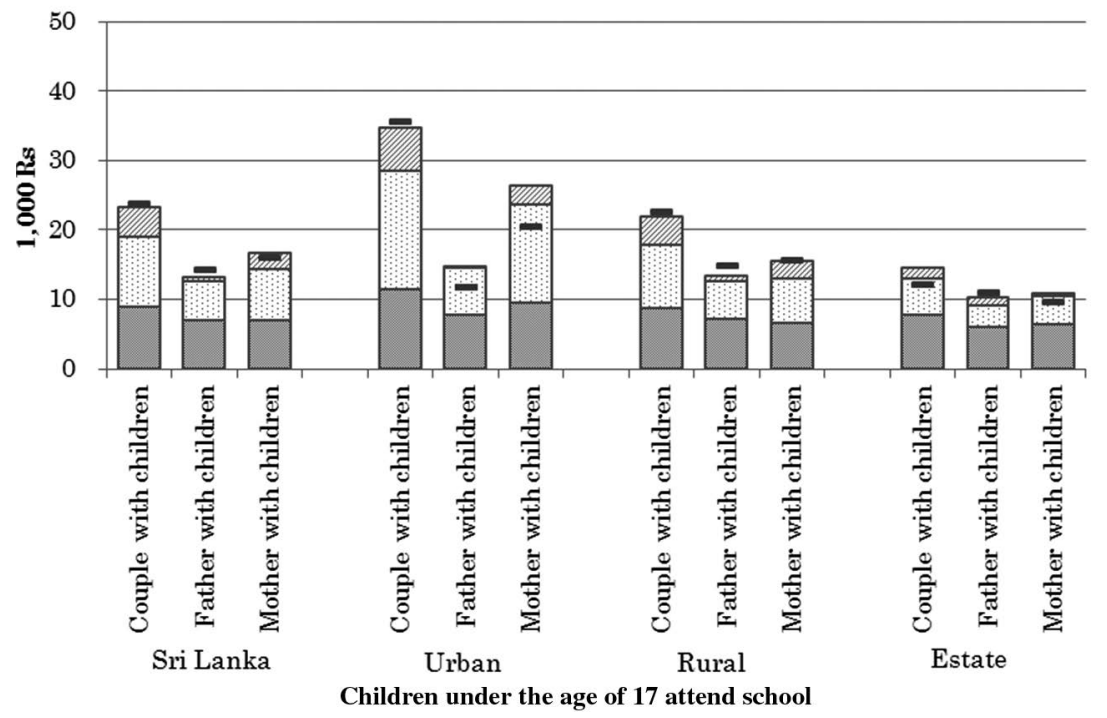

Figure 6.9 Monthly income and expenditure per household by family nuclei and area with children under the age of seventeen who attend school

Table 6.8 Income and expenditure of family nuclei with children under the age of seventeen who attend school

\begin{tabular}{lll}
\hline Household type & $\begin{array}{l}\text { Monthly household } \\
\text { income per household }\end{array}$ & $\begin{array}{l}\text { Consumption } \\
\text { expenditure (Rs.) }\end{array}$ \\
\hline Couple only & 21,264 & 15,290 \\
Couple with children & 23,844 & 18,898 \\
Father with children & 14,169 & 12,523 \\
Mother with children & 16,082 & 14,254 \\
\hline
\end{tabular}

Table 6.9 Income and expenditure of family nuclei by area with children under the age of seventeen who attend school

\begin{tabular}{|c|c|c|c|c|c|c|}
\hline \multirow[t]{2}{*}{ Household type } & \multicolumn{3}{|c|}{$\begin{array}{l}\text { Monthly household income } \\
\text { per housebold }\end{array}$} & \multicolumn{3}{|c|}{$\begin{array}{l}\text { Consumption expenditure } \\
\text { (Rs.) }\end{array}$} \\
\hline & $\begin{array}{l}\text { Urban } \\
(U)\end{array}$ & $\begin{array}{l}\text { Rural } \\
(R)\end{array}$ & $\begin{array}{l}\text { Estate } \\
(E)\end{array}$ & $\begin{array}{l}\text { Urban } \\
(U)\end{array}$ & $\begin{array}{l}\text { Rural } \\
(R)\end{array}$ & $\begin{array}{l}\text { Estate } \\
(E)\end{array}$ \\
\hline Couple & 48,267 & 17,179 & 22,535 & 29,226 & 13,574 & 8,415 \\
\hline Couple with children (CC) & 35,654 & 22,637 & 12,125 & 28,424 & 17,745 & 13,012 \\
\hline Father with children (FC) & 11,700 & 14,839 & 10,918 & 14,542 & 12,690 & 9,129 \\
\hline Mother with children (MC) & 20,537 & 15,687 & 9,525 & 23,729 & 13,022 & 10,400 \\
\hline
\end{tabular}


Table 6.10 Rearrangement of Table 6.9

\begin{tabular}{lccr}
\hline Household type & Income & Expenditure & Difference \\
\hline CO-U & 48,267 & 29,226 & 19,041 \\
CC-U & 35,654 & 28,424 & 7,230 \\
FC-U & 11,700 & 14,542 & $-2,843$ \\
MC-U & 20,537 & 23,729 & $-3,192$ \\
CO-R & 17,179 & 13,574 & 3,605 \\
CC-R & 22,637 & 17,745 & 4,892 \\
FC-R & 14,839 & 12,690 & 2,149 \\
MC-R & 15,687 & 13,022 & 2,665 \\
CO-E & 22,535 & 8,415 & 14,120 \\
CC-E & 12,125 & 13,012 & -887 \\
FC-E & 10,918 & 9,129 & 1,789 \\
MC-E & 9,525 & 10,400 & -875 \\
\hline
\end{tabular}

red for a father with children and a mother with children in the Urban sector and for a couple only and a mother with children in the Estate sector.

The level of education in Sri Lanka is higher than that of other developing countries. For example, the literacy rate is said to be higher than 90 percent. Sri Lanka children start school when they are five years old. Primary school (Grades 1-5) and junior secondary school (Grades 6-9) are compulsory. After graduating from junior secondary school, education is divided into senior secondary school (Grades 10-11), college (Grades 12-13), and university. Up to 70 to 80 percent of students go to cram school after school because it is even possible to fail compulsory education. The graduation ratio is 80 percent. To enter university, students need to qualify by passing the Ordinary Level (O-level) and the Advanced Level (A-level) of the national general examination for the General Certificate of Education (GCE). A senior secondary school where students try to pass the O-level examination is for qualification to enter a college. Those who wish to go to university need to qualify by passing the A-level examination at a college.

Tuition in public schools from primary school to university is free, and teaching materials and uniforms are paid for by the government. However, entrance into a higher-grade school is very difficult, and only $2-3$ percent of all students enter university. Therefore, many students go to cram schools, and the education difference between wealthy households and poor households becomes larger. While some students also go to cram schools, others are from poor families and have to go to work instead. In other words, some children of poor households may not receive sufficient education.

Figure 6.10 and Figure 6.11 show Engel's coefficients by nuclear family and by area. The Estate sector has a higher Engel's coefficient with all family types, and Engel's coefficient is about 50-60 percent for all household types. In other words, because in the Estate sector half or more of consumption expenses are spent on food, it is difficult to spend income on the education of children. In addition, 


\section{(\%)}

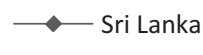

U Urban

$\triangle$ Rural $\longrightarrow$ Estate

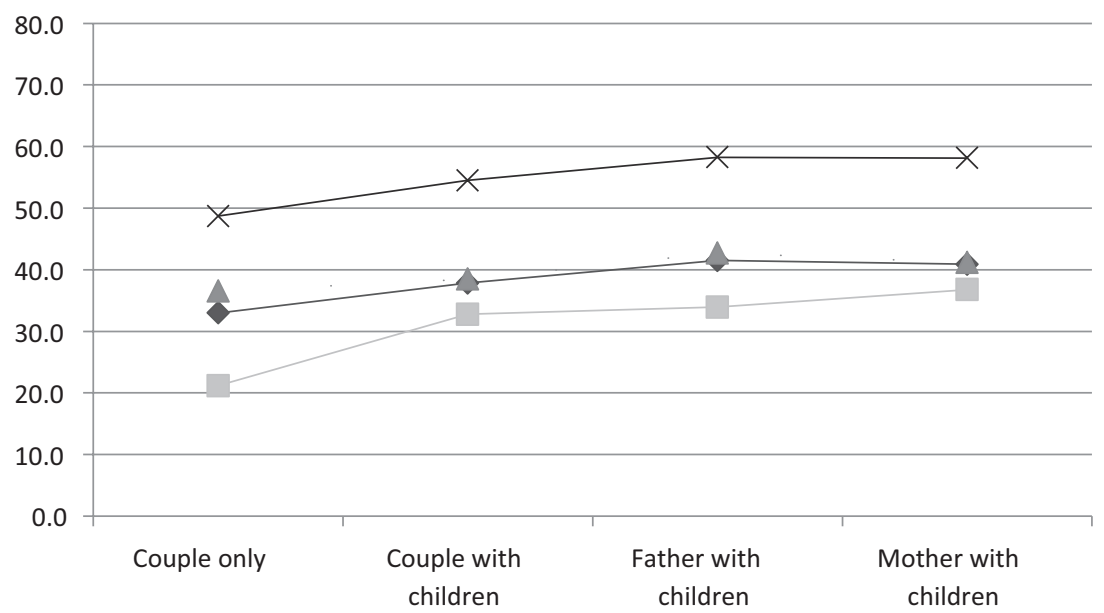

Figure 6.10 Engel's coefficient by family nuclei and area

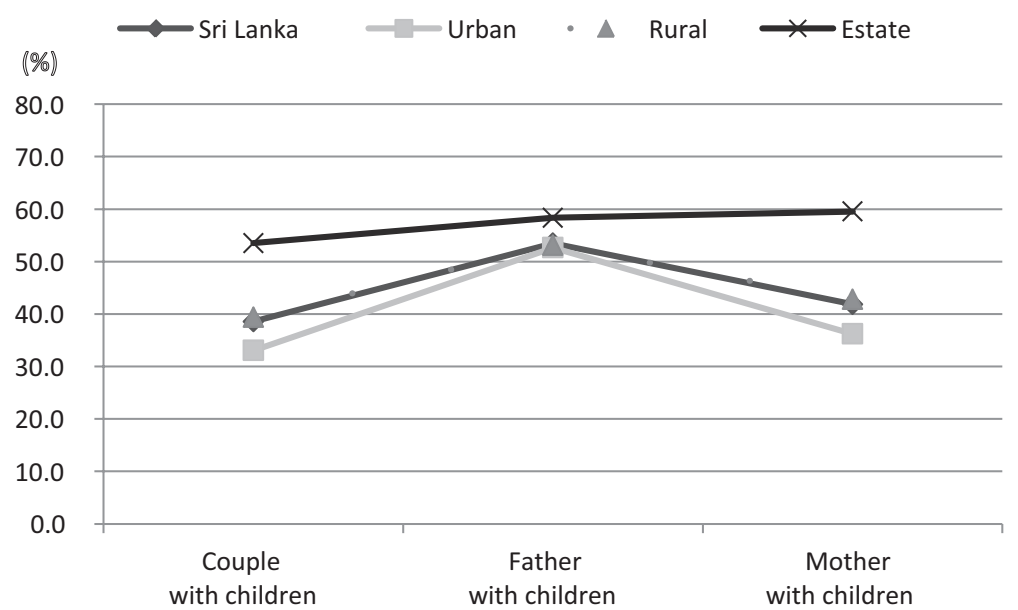

with children under the age of 17

Figure 6.11 Engel's coefficient of family nuclei by area with children under the age of seventeen who attend school

Engel's coefficients of households of fathers with children under 17 years of age in the Urban and Rural sectors are close to the values of Engel's coefficients of such households in the Estate sector. This suggests that in households of fathers with children, it is difficult to pay educational expenses for children. 


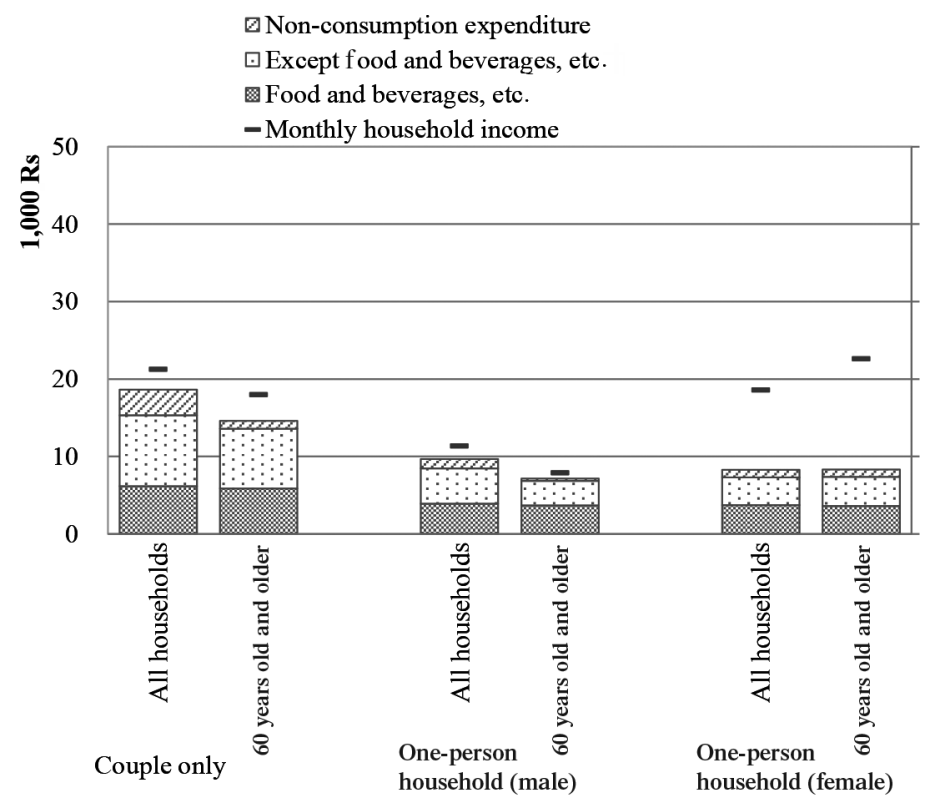

Figure 6.12 Monthly income and expenditure per household by elderly household

Table 6.11 Monthly income and expenditure per household by elderly household (Rs.1,000)

\begin{tabular}{lccc}
\hline Household type & $\begin{array}{c}\text { Monthly household } \\
\text { income per household }\end{array}$ & $\begin{array}{l}\text { Monthly household } \\
\text { expenditure per household }\end{array}$ & $\begin{array}{c}\text { Consumption } \\
\text { expenditure }\end{array}$ \\
\hline $\begin{array}{l}\text { Couple only } \\
\begin{array}{c}\text { Single-person } \\
\text { household (male) }\end{array}\end{array}$ & 17,970 & 14,556 & 13,538 \\
$\begin{array}{c}\text { Single-person } \\
\text { household } \\
\text { (female) }\end{array}$ & 7,900 & 7,106 & 6,801 \\
\hline
\end{tabular}

Next, we consider elderly households. Figure 6.12, Table 6.11, and Figure 6.13 show monthly income and expenditure per household for elderly households. Families with single males have the lowest values. Compared with the average of all family incomes, this is about 40 percent. Figure 6.13 shows Engel's coefficient by elderly household and area. We can see that Engel's coefficients in the Estate area are higher than in other areas.

The results of nuclear family and elderly household inequalities seem to derive from area dispersion. 


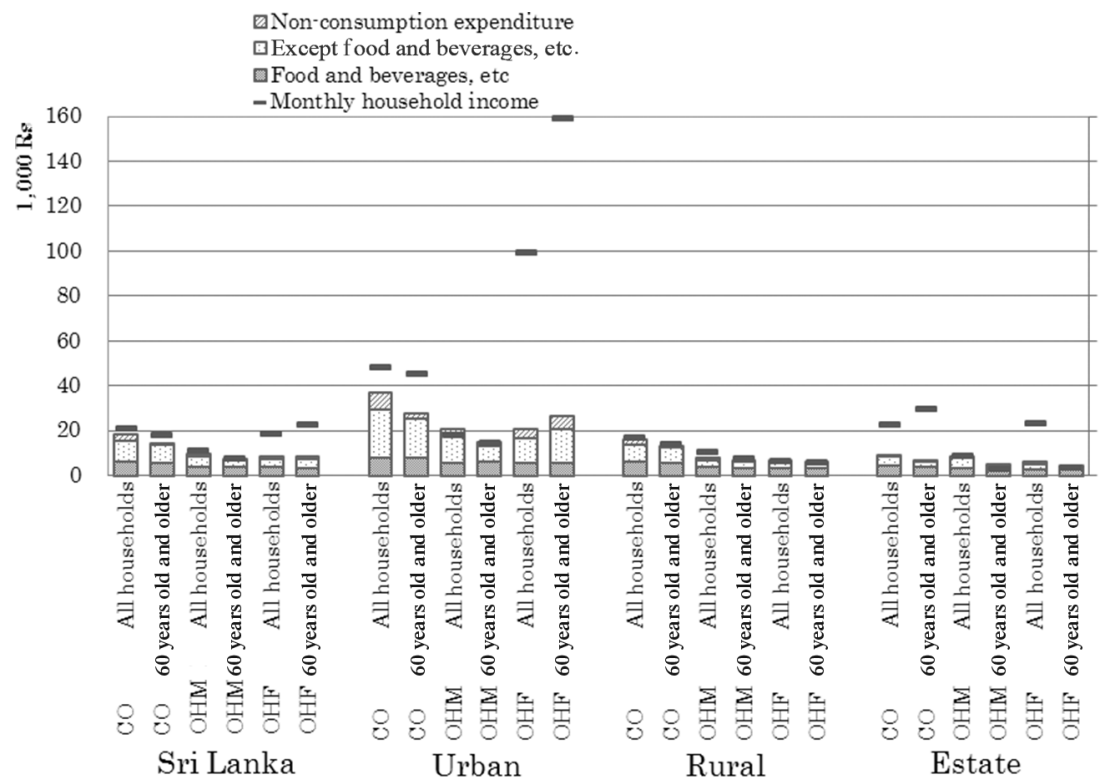

CO: Couple only OHM: One-person household (male) OHF: One-person household (female)

Figure 6.13 Monthly income and expenditure per household by elderly household and area

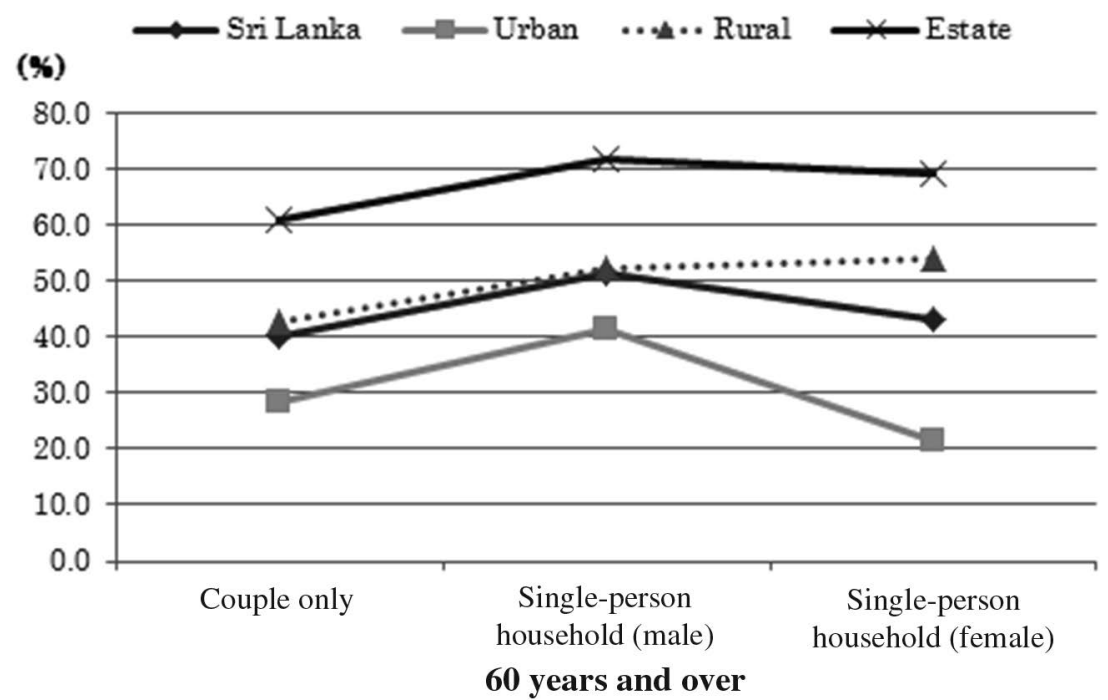

Figure 6.14 Engel's coefficient by elderly household and area 


\section{Conclusion}

In this paper, we show typical cases of disparity. There are disparities of income and expenditure between the Urban, Rural, and Estate areas. The income of a family consisting of a father and children is lower. This seems to affect the education of children. Elderly households have disparities. Here, we omitted illustrating households with deficit and debt. Indeed, about 56 percent of households are deficit households in which income is less than expenditure. Area and family type apparently affect disparity. More detailed analysis is required.

The original micro-data were separated into complex files that needed to be combined for analysis. As our calculated results differed from those of the HIES 2006/07 report, we also presented the original results obtained from the micro-data.

Eighty percent of the resampling data will be provided after carefully checking the individual information. Outliers should be removed to preserve the confidentiality of personal information. We have to develop simple, accurate, and unbiased techniques.

\section{Notes}

1 As a result of having pushed forward an overseas employment policy for openness from the late 1970s, approximately 1,800,000 Sri Lankans are estimated to work abroad. The own country remittance from migrant workers has steadily increased to reach 10 percent of GDP in 2012, which is the country's main source of foreign currency income.

2 The medical services in national hospitals are free in Sri Lanka. Therefore, the health expenses there are for private hospitals, spectacles, and the purchase of medical and pharmaceutical products.

3 The CCPI was 3,176 in 2002, and the value of the OPL was Rs.1,423 of the expense per capita for one month of 2006-2007.

\section{References}

Amarasinghe, U., M. Samad and M. Anputhas (2005), "Spatial clustering of rural poverty and food insecurity in Sri Lanka," Food Policy, 30(5-6), 493-509, Special Issue: Poverty and Food Security Mapping. Available from: ftp://gisweb.ciat. cgiar.org/DAPA/projects/PovertyMapping/download/SriLanka.pdf [accessed March 28, 2014]

Arun, T. and V. Borooah (2004), "Earnings inequality in Sri Lanka," Development Economics and Public Policy Series, Paper No. 10, 1-19. Available from: http:// www.sed.manchester.ac.uk/idpm/research/publications/wp/depp/documents/ depp_wp 10.pdf [accessed March 28, 2014]

Arun, T., V. Borooah and S. Arun (2013), "Earnings inequality in Sri Lanka," The Journal of Developing Areas, 47(1), 335-371.

Central Intelligence Agency (2013), "The World Factbook." Available from: https://www.cia.gov/library/publications/the-world-factbook/fields/2172. html [accessed June 10, 2014] 
Department of Census and Statistics (June 2004), "The Department of Census and Statistics announces the official poverty line for Sri Lanka." Available from: http://www.statistics.gov.lk/poverty/OfficialPovertyLineBuletin.pdf [accessed May 16, 2014]

Department of Census and Statistics (March 2008), "Poverty Indicators 2006/07." Available from: http://www.statistics.gov.lk/poverty/PovertyIndicators.pdf [accessed May 16, 2014]

Department of Census and Statistics Ministry of Finance and Planning Sri Lanka (August 2008), "Household Income and Expenditure Survey - 2006/07 Final Report." Available from: http://www.statistics.gov.lk/HIES/HIES2006_07Web site/Publications/HIES200607Final\%20ReportWeb\%20.pdf [accessed May 16, 2014]

Department of Census and Statistics - Sri Lanka (2013), "National Accounts of Sri Lanka 2012." Available from: http://www.statistics.gov.lk/national_accounts/ National\%20Accounts\%20of\%20Sri\%20Lanka.pdf [accessed March 28, 2014]

Department of Census and Statistics (2014), "Census of Population and Housing 2001 (CPH2001)." and "Census of Population and Housing 2011 (CpH2011)." Available from: http://www.statistics.gov.lk/page.asp?page=Population and Housing [accessed June 10, 2014]

Department of External Resources (DER) (2006), “Annual Report 2006.”

De Silva, I. (2013), "Inequality decomposition by population subgroups and income sources in Sri Lanka," Journal of Economic Studies, 40(1), 4-21.

Euromonitor International (2014), "World Consumer Income and Expenditure Patterns 2014."

Gunatilaka, R., M. Mayer and M. Vodopivec (2010), "The challenge of youth employment in Sri Lanka." Available from: https://openknowledge.worldbank. org/handle/10986/2451 [accessed March 28, 2014]

Himaz, R. and H. Aturupane (2011), "Education and household welfare in Sri Lanka from 1985 to 2006," Economics Series Working Paper No. 527. Available from: http://ideas.repec.org/p/oxf/wpaper/527.html [accessed March 28, 2014]

International Labour Office (November 2008), "Social security in Sri Lanka," A Review of the Social Security System for the Ministry of Labour Relations and Manpower, 15-17. Available from: http://www.ilo.org/gimi/gess/ShowRessource. action? ressource.ressourceId $=7055$ [accessed June 10, 2014]

International Monetary Fund (2010), World Economic Outlook Database. Available from: http://www.imf.org/external/pubs/ft/weo/2014/02/weodata/index. aspx [accessed June 10, 2014]

Japan Bank for International Cooperation (2001), Poverty Profile Executive Summary Democratic Socialist Republic of Sri Lanka. Available from: http://www.jica.go.jp/ activities/issues/poverty/profile/pdf/srilanka_e.pdf [accessed March 28, 2014]

Japan External Trade Organization (JETRO) (2014), "Basic economic indicators." Available from: http://www.jetro.go.jp/world/asia/lk/stat_01/ [accessed March 28, 2014]

Kumara, T. (13-15 June 2012), "Decomposing spatial inequality in Sri Lanka: A quantile regression approach," Inequalities and Development: New Challenges, New Measurements? University of Bordeaux: Bordeaux, France, 1-26. Available from: http://jourdev.gretha.u-bordeaux4.fr/sites/jourdev.gretha/IMG/pdf/lc_ kumara.pdf [accessed March 28, 2014] 


\section{Yasumasa Baba et al.}

Ministry of Economic Development, "Samurdhi." Available from: http://med.gov. $\mathrm{lk} /$ english/?page_id=21 [accessed June 10, 2014]

MinistryofFinance andPlanning(2013), “AnnualReport2013.”Available from:http:// www.treasury.gov.lk/publications/under-fiscal-management-responsibility-act/ annual-reports/26-national-planning/fiscal-policy/580-annual-report-2013-chap ters.html [accessed June 10, 2014]

Nippon Export and Investment (2014), “Country review." Available from: http:// nexi.go.jp/webmagazine/country/005230.html [accessed June 10, 2014]

World Bank (April 2010), "World Development Indicators," 94-97. Available from: http://data.worldbank.org/sites/default/files/wdi-final.pdf [accessed June 10, 2014] 


\title{
7 The agricultural sector in Thailand's middle-income stage
}

\author{
Satoshi Ohira and Atsushi Maki
}

\section{Introduction}

The role of agriculture has long been one of the most important topics in economic development. Country-level economic development can be interpreted as the change from an agriculture-based sectoral structure to an industry-based sectoral structure. The role of agriculture usually decreases in the economic development process. On the other hand, agriculture is the most important sector in the sense that it provides food for subsistence and, at least in the first stage of economic development, provides the largest proportion of employment.

The agricultural sector in Thailand is not an exception. The country saw rapid economic growth in the 1990s. Before that time, it was an agriculture-based country. Particularly during the period of economic growth in the 1990s, many people moved from the agricultural sector to the nonagricultural sector. The percentage of agricultural employment decreased from 70.8 percent in 1980 to 39.6 percent in 2012 .

Lewis (1954) constructed a theoretical model that explains the dynamic path of the change in the relationship between the agricultural and nonagricultural sectors. In the model, the path of economic development is divided into two phases. The first is the developing phase, in which the wage difference between the agricultural and nonagricultural sectors is the key driving force behind the change in the role of agriculture. After the first phase, the development path moves to the second phase, in which there is no longer a wage difference between the sectors. The driving force of the economy in the second phase is the change in consumer preferences. Since consumers prefer nonagricultural goods more and more as they accumulate more wealth in the economic development process, the demand for agricultural goods decreases, and therefore the role of the agricultural sector decreases in importance. Harris and Todaro (1970) described a mechanism explaining migration between sectors in the first phase of the Lewis model. Other researchers, including Gollin, Parente, and Rogerson (2002), Echevarria (1995, 1997), and Matsuyama (1992), have attempted to construct models for the second phase in the Lewis model. These are basically of the standard neoclassical growth model type. 


\section{Satoshi Ohira and Atsushi Maki}

In this paper, we examine which type of model explains the data from Thailand. We show that neither a Harris-Todaro model nor a neoclassical-type model explain the actual data in Thailand. A hybrid of two models is necessary. This conclusion is consistent with the observation that the country is now facing the middle-income problem. Many countries that are in the transitional period from the developing to the developed stage face political and social instability. Following the Asian crisis in 1997, Thailand has experienced such problems.

Thailand enjoyed high economic growth in the 1990s, and the country has now passed the turning point from the first phase to the second phase of economic development. However, in Thailand, the problem of wage difference between the agricultural and nonagricultural sectors commonly found in the developing stage remains even after having passed the turning point. Thailand is a kind of developing country in the sense that wage difference is high, while it is a developed country in the sense that the neoclassical model, in which the wages in rural and urban areas are assumed to have equalized, can be applied. As a result, the neoclassical model with wage differences is valid for the recent data for Thailand.

To arrive at this conclusion, in Section 1 we briefly review the economy of Thailand. We show that gross domestic product (GDP) in the country grew at high rates in 1990s, reducing poverty and inequality. In light of the change in the relative share of the agricultural sector in GDP, we know that sometime around 1993 was the turning point from the developing to the developed stage for Thailand. We then summarize the literature of the two-sector dynamic model and construct a general framework to understand the models in Section 3. The framework contains both a wage-difference model and a neoclassical model; therefore, the hybrid of the two models is also a specification. Using the general framework, in Section 4 we estimate the model by applying the data of Thailand in the period between 2001 and 2009 and conclude that the hybrid model is the best choice for explaining the actual change in the role of the agricultural sector in Thailand. Section 5 summarizes our results and provides concluding remarks.

\section{Economic development in Thailand}

\subsection{Growth, inequality, and poverty in Thailand}

Thailand, one of the four dragons, enjoyed high economic growth in the 1980s and 1990s. GDP per capita in constant 2005 USD, which was 881.7 in 1980, increased to 1,571.5 in 1990 and 2,390.8 in 1996. ${ }^{1}$ This growth was halted by the Asian financial crisis. GDP per capita decreased to 2,332.7 in 1997 and $2,063.7$ in $1998 .^{2}$ However, Thailand returned to rapid economic growth immediately after the crisis. Figure 7.1 shows that the country is now on a long-term growth path, even though the rate of growth is not as high as that of the 1990s.

The World Bank (1993) states that economic growth in Thailand is not only a miracle in terms of speed but is also remarkable because it has been accompanied by greater equity. Figures $7.1,7.2$, and 7.3 show that Thailand is a miracle 


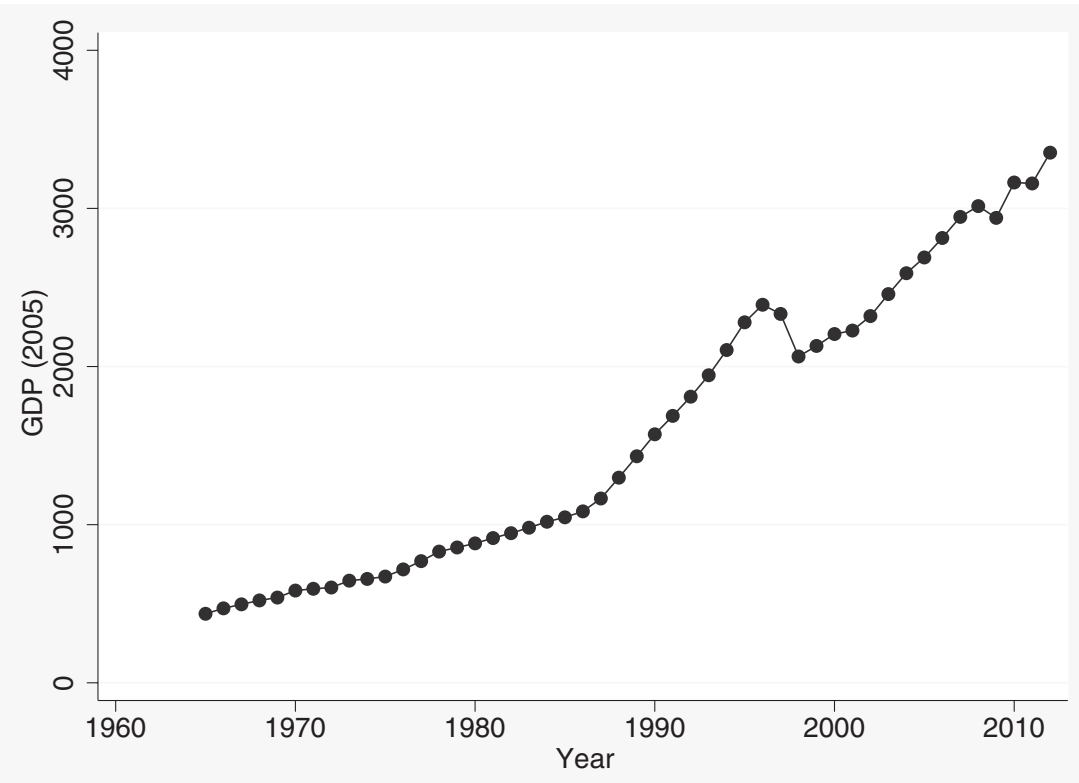

Figure 7.1 Economic growth in Thailand

country in terms of promoting high economic growth while decreasing inequality and poverty.

Inequality increased in the first half of the 1990s, which is clear from Figure 7.2. Figure 7.2 also shows that inequality declined steadily on average between 1980 and 2010. Roughly speaking, Thailand has achieved high growth with equity.

Poverty in the country has also declined steadily. The poverty headcount ratio, the poverty gap, and the squared poverty gap all decreased during this period, and all of the indices were almost at zero for 2010.

It is clear from the data that Thailand has achieved high economic growth with a steady decline in inequality and poverty. Therefore, political instability in Thailand seems quite strange. The country has experienced frequent government changes due to military intervention. There have been more than twenty coups d'état since the establishment of the constitutional monarchy in 1932. Even if we concentrate on the period since the year 2000 , the military proclaimed martial law in both 2006 and 2014. It is surprising to see so many government changes given such high economic growth alongside decreasing inequality and poverty.

Political and social instability in Thailand is due to increasing inequality between the urban sector and the rural sector. While inequality as a whole has declined over the past thirty years, regional inequality has increased over the period. The conflict between the urban sector and rural sector has increased proportionally. 


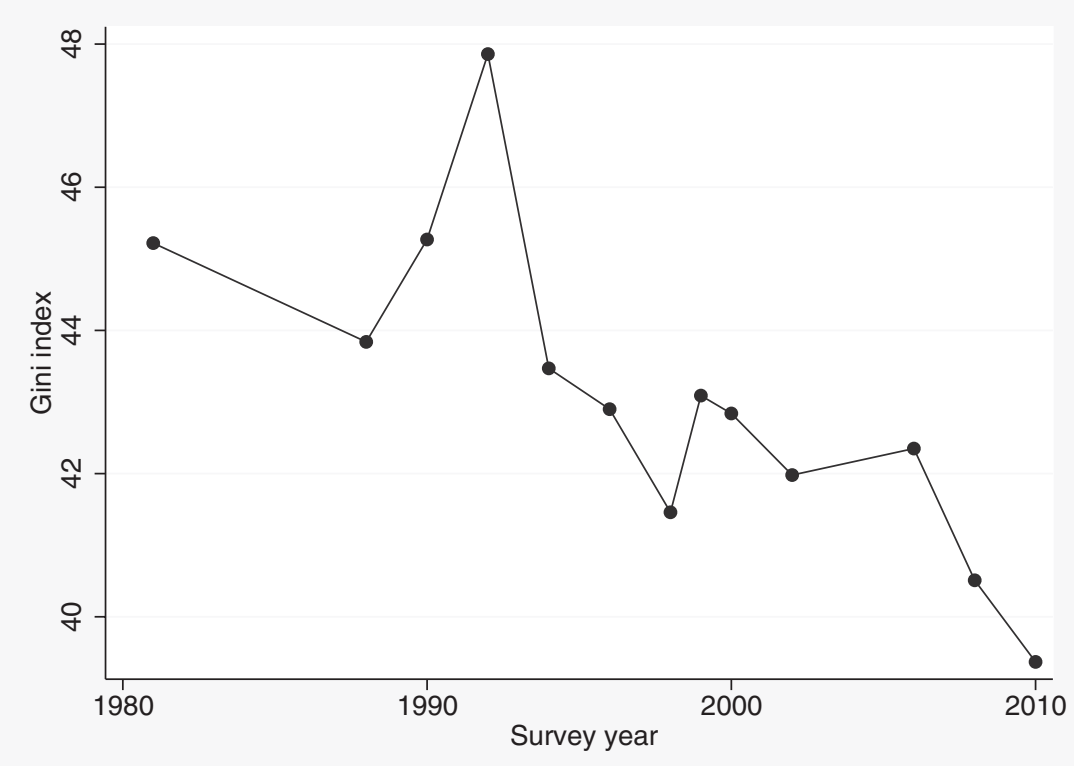

Figure 7.2 Trend of Gini index in Thailand

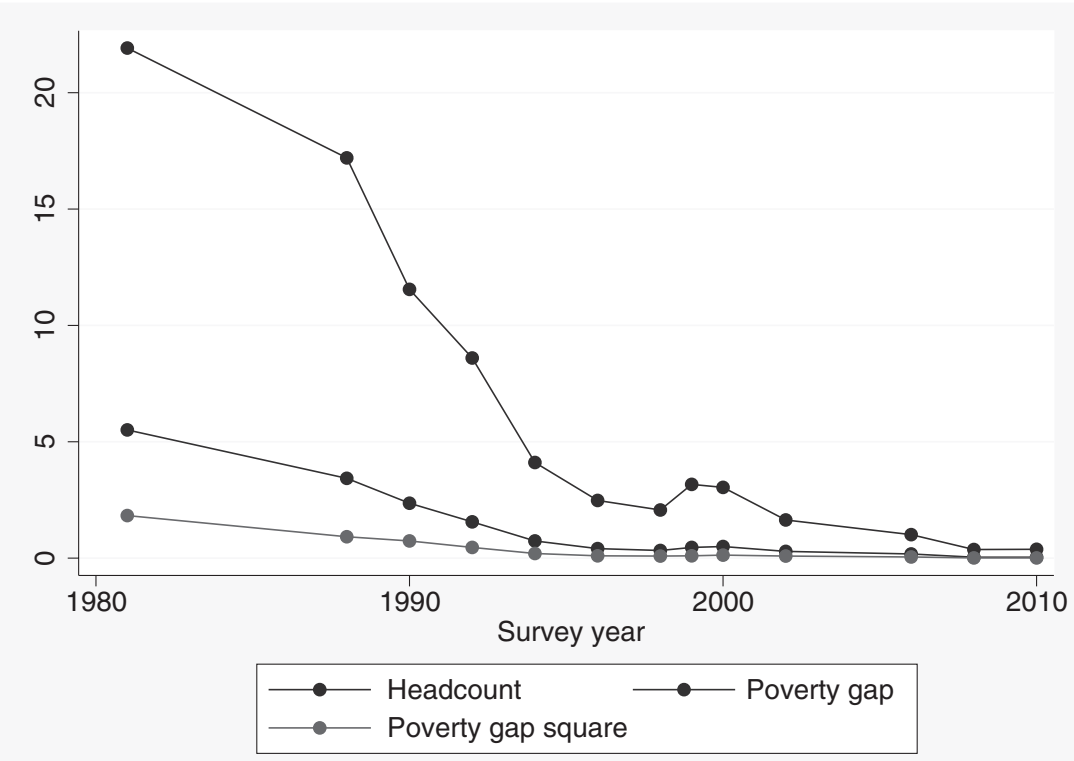

Figure 7.3 Trend of poverty in Thailand 
To understand social instability in Thailand, we need to analyze the dynamics of inequality.

Many countries with similar attributes to Thailand have suffered from social friction due to similar instability. Hayami (2007) referred to these as "middle-income problems." In the discussion that follows, the conflict between the urban and rural sectors is described as the conflict between the agricultural and nonagricultural sectors. In the next section, we survey research that considers the dynamics between the agricultural sector (rural sector) and the nonagricultural sector (urban sector).

\subsection{The relative share of agricultural GDP}

Hayami (2007) analyzes the changes in the role of the agricultural sector and the nonagricultural sector using the discussion in Shultz (1978). Governments in developing countries are assumed to want their countries to become industrialized. The most important problem in such countries is food. Governments try to decrease food prices as much as possible in order to support laborers in the industrialized sector in obtaining food at low prices. The living standards in the rural sector, which is the supply side of the food sector, decreases compared with the living standards in the urban sector, which is the demand side of the food sector. Migration from the rural to the urban sector accelerates because of these policies and promotes industrialization. Government subsidies for food imports, which decrease food prices, also promote this process.

Governments in industrialized countries, on the contrary, pay attention to the living standards of people in the rural sector as well. The supply of food in industrialized countries is very large, and there is usually no food shortage problem. Such governments spend a large share of the budget on subsidizing rural areas because of political pressure from that sector. Consumers in the urban sector in developed countries are rich enough to permit such policies.

Developing and developed countries are characterized by contradictory policy regimes. Developing countries face a food shortage problem, and governments pay more attention to the urban sector in order to accelerate industrialization. Developed countries do not face food shortage problems, and the income level in the urban sector is sufficiently high to allow governments to consider subsidy programs for the rural sector.

The previous discussion suggests that, from the developing stage to the developed stage, there must be a turning point in policy regimes. In the transition phase, governments face difficulties in solving the social friction caused by the contradiction between two opposing policy regimes.

Regarding middle-income problems, Hayami (2007) proposes focusing on the relative incomes of agricultural workers across different stages of economic development. The index can be obtained by the following equation:

$\frac{\text { GDP in agriculture }}{\text { Total GDP }} / \frac{\text { Employment in agriculture }}{\text { Total employment }}$ 


\section{Satoshi Ohira and Atsushi Maki}

Since the index can be modified in the form:

$$
\frac{\text { GDP in agriculture }}{\text { Employment in agriculture }} / \frac{\text { Total GDP }}{\text { Total employment }}
$$

The index uses GDP per worker in the agricultural sector divided by total GDP per person employed in any sector. The index provides the proportion of productivity in the agricultural sector compared to total productivity. Hayami (2007) shows that the index is very high in low-income countries and that it decreases as countries develop. Also, the paper shows that the index is increasing in the data from developed countries. There must be a turning point for the index to change from decreasing to increasing. Hayami (2007), using cross-sectional data, suggests that around the turning point, countries face the middle-income problem.

As an example, we show the evolution of the index in Figure 7.4 for East Asian countries $^{3}$ using data from the World Development Indicators.

If we look at the East Asian countries as a whole, the year 2005 or 2006 is the turning point. Before that time, the index declines, while afterwards it turns upward. The area began facing the middle-income trap around the year 2005 or 2006.

Thailand might be one case that is experiencing the middle-income trap. Since the country succeeded in promoting economic growth in the 1990s, political

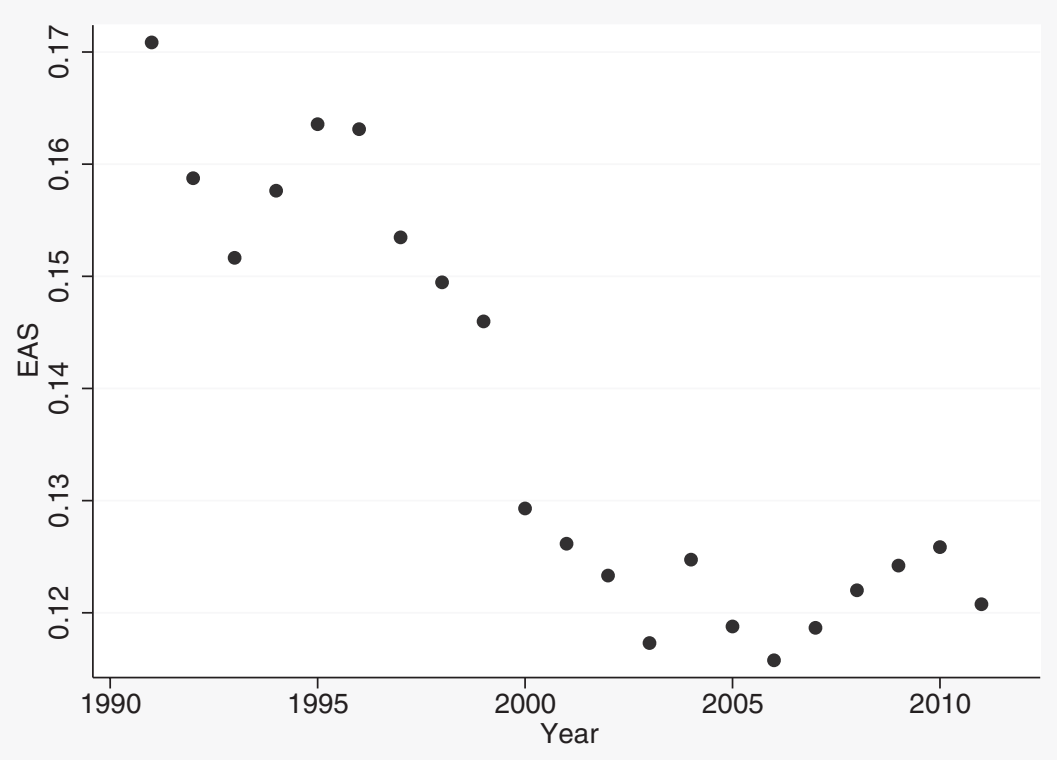

Figure 7.4 Trend in the relative share of agricultural GDP in East Asian countries 
instability has been common due to the struggle between the two political parties. One party represents predominantly urban non-farmers, and the other predominantly rural farmers. One party advocates for the government supporting the agricultural sector, and the other party has the opposite opinion. The instability caused by the controversy between them has been remarkable, especially after the Asian crisis in 1997. This tension suggests that the country is now in the middle-income stage. Inequality between the agricultural and nonagricultural sectors appears to be the cause of the social friction now in Thailand.

We have time series data for the variables relating to this question for Thailand and can show the time series change in the Hayami (2007) index in the country. Figure 7.5 suggests that Thailand became a middle-income country around 1993. The index in Thailand decreased before 1993. After that year, the index began a long-term increase. Figure 7.5 suggests that Thailand reached the turning point around 1993 and that after this year the agricultural sector undoubtedly began a new phase.

We are not sure that the country was in the middle-income stage in 2000, however. Even if we agree with the statement that Thailand was in the middle-income stage in the year 2000, we cannot say that the country was still in the middle-income stage in the year 2013. The Hayami (2007) index increases after 1993. The only exception to this pattern is the period of the Asian economic crisis. It is more natural to see such a dynamic path of a country analyzed using a neoclassical model.

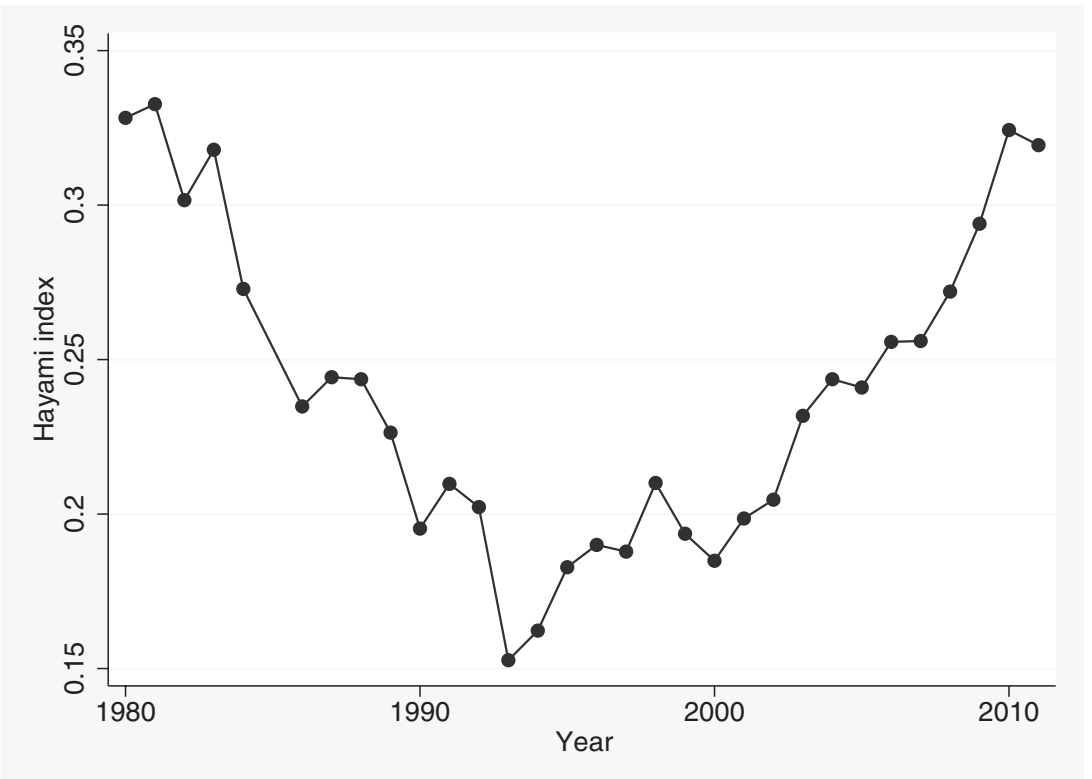

Figure 7.5 Relative incomes of agricultural workers across different stages of economic development: Thailand 
In the following sections, we analyze the types of theoretical models that we can apply to the actual data of Thailand.

\section{Theoretical models}

\subsection{Literature survey}

Political instability due to problems of inequality is a serious obstacle to economic development. Many countries face such issues in the developed stage as well as in the developing stage.

Governments in developing countries promote economic growth by accelerating migration from the agricultural sector to the nonagricultural sector. Migration causes social friction between the rural and urban areas, however. In order to promote industrialization, countries provide food at low prices in urban areas. The government therefore tries to decrease food prices, which in turn burdens farmers in rural agricultural areas. Shultz (1978) summarizes this process and calls it the "food problem." In developed countries, there is sufficient food to supply laborers in urban areas, and there is no food problem.

Gill et al. (2007) argue that economies can become stuck and develop more slowly because of inequality problems in several aspects of the middle-income stage. This problem is known as the "middle-income trap" and has been the subject of a substantial amount of research. Hayami (2007) discusses the trap by focusing on inequality between the agricultural sector and the nonagricultural sector. To mitigate the friction between farmers and non-farmers, government support for the agricultural sector is discussed in many middle-income countries.

Inequality between the agricultural sector and the nonagricultural sector has been discussed for a long time. For developing countries, in which the government tries to promote industrialization, the role of the agricultural sector declines, and agricultural income usually decreases. The role of agriculture in the economy usually decreases in the process as well. Workers in developing countries gradually move from the agricultural sector to the manufacturing sector. Since the manufacturing sector adds more value to finished products, governments in developing countries support industry to promote economic growth. These policies push workers from one sector to another.

Social problems caused by declining income in rural areas have been some of the most serious problems in developing countries. Analyzing the mechanism that explains the dynamics of the role of agriculture is therefore very important, not only out of academic interest but also for actual policy debates.

The first attempt to discuss the dynamics between the agricultural and nonagricultural sectors was in Lewis (1954). The paper divides the economy into two parts: a rural agricultural sector with unlimited surplus labor and an urban industrial sector. In the first stage of economic development, because of the unlimited supply of labor, the wage rate is determined by the subsistence level in rural areas. In urban areas, the wage rate is determined competitively. The wage rate is always higher in urban areas than in rural areas, and the labor force is assumed to be moving from rural to urban areas. The proportion of the population in rural areas 
decreases because of this movement and, at some point, there is no longer surplus labor in rural areas. After this point is reached, the wage rate is determined competitively, which means that the real wage rates in the two areas must be the same due to competitive pressure.

The Lewis model has been modified by several researchers. Ranis and Fei (1961) and Harris and Todaro (1970) are the most well-known examples that try to revise the model for developing stage dynamics in the Lewis model. In these models, movement in the labor force is caused by income differences between the rural agricultural and urban industrial sectors. These wage rate differences are the key factor in the dynamics of economic development. Rural workers migrate to urban areas if there is a wage difference between the areas, and the difference is equalized over time by market forces. Migration from rural to urban areas is not as rapid, even when income differences are very large, however. The factors that suppress migration are therefore often discussed in the literature. Harris and Todaro (1970), for example, assume that employment uncertainty limits workers migrating to urban areas. Workers are not guaranteed employment in urban areas if they migrate, and some workers are unemployed. Because of this uncertainty, some workers hesitate to migrate to urban areas, and the wage rate in urban areas can therefore be higher than that in rural areas.

Other studies assume equilibrium in labor markets in the agricultural and nonagricultural sectors. The real wage rates in the two areas are assumed to always be the same. In this sense, such models are neoclassical. Gollin, Parente, and Regerson (2002), Echevarria (1995, 1997), and Matsuyama (1992) are some examples. In these papers, the wage rate is determined by the principle of supply and demand.

In neoclassical models, the movement of workers is economically rational and inevitable. Changes in consumer preferences are one source of this movement. The main product in the agricultural sector is food. In every stage of economic development, food is necessary to survive. The importance of food decreases when income increases overall, however. Gollin, Parente, and Regerson (2002) and others assume the following type of utility function and describe the decrease in the importance of the agricultural sector.

$$
u=\beta \log \left(c_{t}^{a}-\gamma\right)+\log c_{t}^{m} \quad \text { with } \gamma>0
$$

where $\gamma$ represents the subsistence level of food ( $c^{a}$ and $c^{m}$ denote the consumption of agricultural and manufacturing goods, respectively) for all consumers. By assumption, the demand elasticity of agricultural goods is less than unity, which implies a declining trend of the role of the agricultural sector in the economic development process.

The utility function also implies that the production of agricultural goods is more important than that of manufacturing goods in the first stage of economic development. Because of this fact, there is controversy surrounding the role of the agricultural sector in the first stage of the economic development process. Some researchers have concluded that increases in productivity in the agricultural sector should be advanced for economic growth and that the governments of 
developing countries should therefore try to increase productivity to promote economic growth. Gollin, Parente, and Regerson (2002), for example, construct a simple model of economic growth and, after completing several simulations in the model, conclude that the promotion of agricultural productivity is necessary in order to enhance economic development. This conclusion is consistent with the classical view that the Agricultural Revolution was a necessary step before the Industrial Revolution.

Other studies using open economy models, including Echevarria (1995, 1997) and Matsuyama (1992), come to the opposite conclusion. Government support for the agricultural sector is found to be unimportant and in fact is sometimes harmful to economic development. Instead of supporting the sector, these papers recommend importing food for subsistence and using domestic resources to promote the manufacturing sector as much as possible. Echevarria $(1995,1997)$ examines the effects of international trade on economic growth. These papers construct multi-sector models and show cases in which increases in agricultural productivity are not very important for economic growth. Matsuyama (1992) also examines the problem in an open economy framework with the same type of utility function as Gollin, Parente, and Regerson (2002). Instead of assuming multiple sectors, the paper proposes that there is endogenous technological progress in the manufacturing sector. In the model, the larger the amount of production, the more technological progress in the sector. The proportion of employment in the manufacturing sector increases to a steady-state value on the economic growth path from endogenous technological progress. This means that endogenous technological progress can be a second factor that determines the economic development path.

Thailand experienced a high rate of economic growth in the 1990s. This growth was driven mainly by industrialization in Bangkok and its vicinity, however. The role of the agricultural sector is still important in many areas in the country. This relationship is why the country is now facing the middle-income problem. To avoid the middle-income trap, a solution is needed regarding the government's priorities for support in the rural areas. Constructing a purely theoretical model in and of itself does not help answer this question. Econometric research based on a theoretical model is necessary.

As Gollin (2010) notes, "there is abundant evidence for correlations between agricultural productivity increases and economic growth but little definitive evidence for a causal connection." In this paper, we test a theoretical model using data from Thailand for the years between 2001 and 2009. First, we construct a model of the changes in the agricultural and nonagricultural sectors.

\subsection{General framework}

Even though the discussion on the dynamics between the agricultural and nonagricultural sectors has a long history, there is no theoretical model that explains the phase change in the policy regimes from developing to developed countries. The model that fits economies before the turning point and the model for the 
economies after the turning point might be different. Therefore, in this section, we construct a model that considers the dynamics between the agricultural and nonagricultural sectors generally. After constructing the general model, in Section 4 we modify it for Thailand after that country's turning point.

The model consists of a manufacturing sector $(m)$ and an agricultural sector (a). Total population $L_{t}$ is the source of labor supply to the economy. Labor is divided into two parts: employment in the agricultural sector $N^{a}$ and employment in the manufacturing sector $N^{m}$. Let us denote the proportion of employment in the manufacturing sector of the total population as $n$. Figure 7.6 summarizes the model.

In the following, we construct a system of equations that describes the model. To simplify the discussion, we will neglect capital accumulation.

\section{Production}

First, the technologies in the agricultural sector and the nonagricultural sector are assumed to be:

$$
X_{t}^{m}=M_{t} F\left(N_{t}^{m}\right)
$$

and

$$
X_{t}^{a}=A G\left(N_{t}^{a}\right)
$$

where the terms $X^{m}, X^{a}, N^{m}$, and $N^{a}$ denote the total volume of production and labor employment in the sectors. We assume that the coefficient of the production function in the agricultural sector is constant while the coefficient in the manufacturing sector $M$ increases in the following way:

$$
\dot{M}_{t}=\left(\delta_{0}+\delta X_{t}^{m}\right) \cdot M_{t}
$$

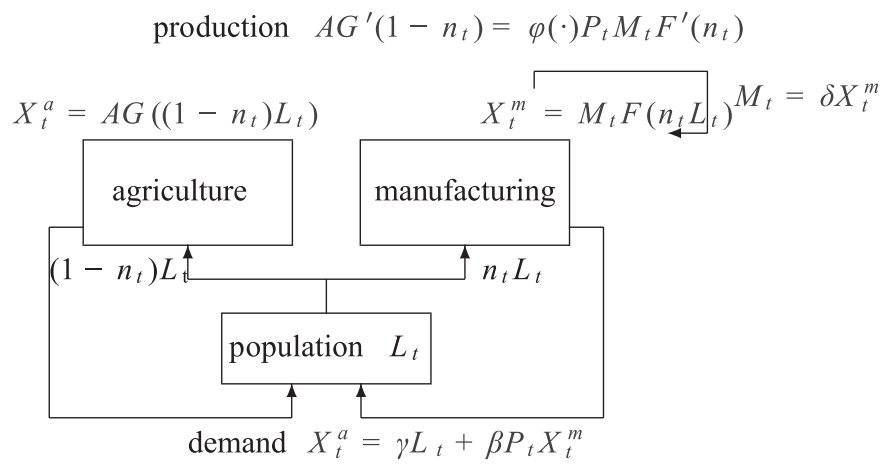

Figure 7.6 The basic framework of the model 


\section{Satoshi Ohira and Atsushi Maki}

where $\delta_{0}$ and $\delta$ are the coefficients. If $\delta_{0}=0$ and $\delta>0$, then the equation is the same as the endogenous technical progress assumption in Matsuyama (1992). If $\delta=0$, then the technical progress in the manufacturing sector is exogenous.

Firms in the two sectors maximize their profits and therefore:

$$
w_{t}^{a}=A G^{\prime}\left(N_{t}^{a}\right)
$$

and

$$
w_{t}^{m}=P_{t} M_{t} F^{\prime}\left(N_{t}^{m}\right)
$$

where $w^{a}$ and $w^{m}$ are the wage rates in each sector.

\section{Labor market equilibrium}

In the discussion of the dynamics between the agricultural sector and the nonagricultural sector, there are two views regarding labor market equilibrium. Neoclassical models assume the market clearing condition, while some other models assume that the clearing condition does not hold in the case of developing countries. Equation (6) describes the general relationship between $w^{a}$ and $w^{m}$ in both the neoclassical model and other models.

$$
\mathfrak{w}_{t}^{a}=\varphi(\cdot) w_{t}^{m}
$$

In the neoclassical equilibrium model, the term $\varphi(\cdot)$ is equal to unity. The variable $\varphi(\cdot)$, however, is not equal to unity if the wage rate equalization is not assumed in the model.

Combining Equations (4), (5), and (6):

$$
A G^{\prime}\left(N_{t}^{a}\right)=\varphi(\cdot) P_{t} M_{t} F^{\prime}\left(N_{t}^{m}\right)
$$

\section{Consumption}

Consumers in this economy have the following utility function:

$$
W=\int_{0}^{\infty}\left[\beta \log \left(c_{t}^{a}-\gamma\right)+\log c_{t}^{m}\right] e^{-\rho t} d t \quad \beta, \gamma, \text { and } \rho>0
$$

The function implies that the demand elasticity of income for agricultural goods is less than unity. The necessary condition for consumption to be optimal is described as follow:

$$
c_{t}^{a}=\gamma L_{t}+\beta P_{t} c_{t}^{m}
$$




\section{Goods market equilibrium}

We assume that the markets for both agricultural goods and nonagricultural goods are in equilibrium.

$$
X_{t}^{a}=C_{t}^{a}
$$

and

$$
X_{t}^{m}=C_{t}^{m}
$$

\section{Model}

Combining the optimal condition for consumers [Equation (9)] and the market clearing condition [Equations (10) and (11)], we obtain:

$$
X_{t}^{a}=\gamma L_{t}+\beta P_{t} X_{t}^{m}
$$

We define the proportion of labors in the nonagricultural sector in the total labor supply:

$$
n_{t}=N_{t}^{m} / N_{t}
$$

Then, by definition, $N_{t}^{a}=\left(1-n_{t}\right) N_{t}$. Using this notation, our model can be summarized by the following five equations $\left[\left(1^{\prime}\right),\left(2^{\prime}\right),(3),\left(7^{\prime}\right)\right.$, and $\left.(12)\right]$ :

$$
\begin{aligned}
& X_{t}^{m}=M_{t} F\left(n_{t} N_{t}\right) \\
& X_{t}^{a}=A G\left[\left(1-n_{t}\right) N_{t}\right] \\
& \dot{M}_{t}=\left(\delta_{0}+\delta X_{t}^{m}\right) \cdot M_{t} \\
& A G^{\prime}\left[\left(1-n_{t}\right) N_{t}\right]=\varphi(\cdot) P_{t} M_{t} F^{\prime}\left(n_{t} N_{t}\right)
\end{aligned}
$$

and

$$
X_{t}^{a}=\gamma L_{t}+\beta P_{t} X_{t}^{m}
$$

where the endogenous variables are $X_{t}^{a}, X_{t}^{m}, \dot{M}_{t}, P_{t}$ and $n_{t}$.

We can derive the movement of the labor force from the agricultural sector to the nonagricultural sector. In other words, the variable $n$ is determined endogenously in the model.

There are two factors that determine the level and the dynamics of $n_{t}$ in the model. The first factor is the change in technology. We assume in our discussion 
that technology in the agricultural sector is constant. The change in technology in the nonagricultural sector is the factor that determines the dynamics of $n_{t}$.

The second factor is consumer preferences. The demand elasticity of income for agricultural goods is less than unity in the model. Consumers in the model tend to prefer nonagricultural goods to agricultural goods when their income increases. Economic development increases demand for nonagricultural goods, and employment in the nonagricultural sector increases through the mechanism of supply and demand.

\subsection{Wage indifference between the sectors}

Harris and Todaro (1970), undoubtedly one of the most well-known papers to analyze the determination of the proportion of the number of laborers in each sector, uses the assumption of wage difference between sectors. The paper constructs a model with an informal sector in urban areas. The wage rate in urban areas is assumed to be constant, and the level of the wage rate is high because of regulation. This means that the wage rate in rural areas is lower than the wage rate in urban areas. It is rational for people in rural areas to migrate to urban areas in such circumstances. Migration is not always successful, however, because of an excess supply of labor in urban areas. In other words, there is a possibility of being unemployed if a person migrates to an urban area. Migration stops when the expected wage rate in urban areas, which is less than the wage rate in urban areas, is equal to the wage rate in rural areas. The situation can be described by setting the term $\varphi$, the wage difference between the agricultural and nonagricultural sectors, to be larger than unity in our model.

Since Harris and Todaro (1970) concentrate on analyzing the role of $\varphi$ in determining $n$, the authors neglect technical progress in the manufacturing/ urban sector, and therefore $\delta_{0}=0$ and $\delta=0$ and $\varphi>1$ in the model.

Adopting the assumptions by Harris and Todaro (1970), our model can be transformed as expressed by the following four equations:

$$
\begin{aligned}
& X_{t}^{m}=M_{t} F\left(n_{t} N_{t}\right) \\
& X_{t}^{a}=A G\left[\left(1-n_{t}\right) N_{t}\right] \\
& A G^{\prime}\left[\left(1-n_{t}\right) N_{t}\right]=\varphi(\cdot) P_{t} \overline{w_{t}^{m}} \\
& X_{t}^{a}=\gamma L_{t}+\beta P_{t} X_{t}^{m}
\end{aligned}
$$

where $\varphi$ is constant ${ }^{4}$ and larger than unity and $\overline{w^{m}}$ is given exogenously. The endogenous variables in the model are $X_{t}^{m}, X_{t}^{a}, P_{t}$, and $n_{t}$. The model is static and there are no dynamics in explaining the movement of $n_{t}$. The proportion $n_{t}$ is determined in each period $t$ given the exogenous variables. 


\subsection{Neoclassical: food problem and income inelasticity}

In a neoclassical model, all markets are always in equilibrium. There is no wage rate difference between the two sectors.

$$
\begin{aligned}
& X_{t}^{m}=M_{t} F\left(n_{t} N_{t}\right) \\
& X_{t}^{a}=A G\left[\left(1-n_{t}\right) N_{t}\right] \\
& \dot{M}_{t}=\left(\delta_{0}+\delta X_{t}^{m}\right) \cdot M_{t} \\
& A G^{\prime} \\
& {\left[\left(1-n_{t}\right) N_{t}\right]=P_{t} M_{t} F^{\prime}\left(n_{t} N_{t}\right)} \\
& X_{t}^{a}=\gamma L_{t}+\beta P_{t} X_{t}^{m}
\end{aligned}
$$

The endogenous variables are $X_{t}^{a}, X_{t}^{m}, \dot{M}_{t}, P_{t}$, and $n_{t}$.

There are two types of this model. One is the traditional neoclassical model that considers the exogenous technical progress. In the model, $\delta$ is assumed to be zero. The rate of technical progress $\delta_{0}$ is predetermined exogenously in the model. In the endogenous model, $\delta$ is assumed to be nonzero. For example, Matsuyama (1992) constructs a model with $\delta>0$ and $\delta_{0}=0$.

\subsection{Classification of the models}

Up to this point, we have summarized the previous discussion on the dynamics of the proportion $n_{t}$, focusing on differences in the assumptions of the parameters $\delta_{0}, \delta, \varphi$, and $\gamma$. The differences are summarized in Table 7.1. The Harris and Todaro model is a specified case of our general model, obtained by setting $\delta_{0}=0$, $\delta=0$, and $\varphi \neq 1$. The neoclassical model is obtained with $\delta_{0}>0, \delta=0, \varphi=1$, and $\gamma>0$. The Matsuyama model is specified with $\delta_{0}=0, \delta>0, \varphi=1$, and $\gamma>0$.

Certainly there are other possibilities. For example, introducing exogenous technical progress into the Harris and Todaro model, we can construct a model with $\delta_{0}>0, \delta=0$, and $\varphi \neq 1$ (Other 1 ). There are no examples among the reviewed models in which $\gamma=0$. Even so, we can assume that $\gamma=0$. Other 2 in

Table 7.1 Classification of the models

\begin{tabular}{lcccc}
\hline Parameter & $\delta_{0}$ & $\delta$ & $\phi$ & $\gamma$ \\
\hline Harris and Todaro & 0 & 0 & $\neq 1$ & Any \\
Neoclassical & + & 0 & 1 & + \\
Matsuyama & 0 & + & 1 & + \\
Other 1 & + & 0 & $\neq 1$ & Any \\
Other 2 & + & 0 & $\neq 1$ & 0 \\
\hline
\end{tabular}




\section{Satoshi Ohira and Atsushi Maki}

Table 7.1 is one such example. In this case, technical progress is exogenous, and there is a wage difference between the sectors.

The validity of the model depends on the country under discussion. In the next section, we discuss the case of Thailand between the years of 2001 and 2009.

\section{Estimation}

\subsection{Model}

In order to estimate the validity of the theoretical model, we now specify the production function as the following exponential form:

$$
F\left(N_{i t}^{m}\right)=M_{i t} N_{i t}^{m \alpha_{1}}
$$

and

$$
G\left(N_{i} t^{a}\right)=A_{i} t N_{i} t^{\left(a \alpha_{2}\right)}
$$

where $\alpha_{1}$ and $\alpha_{2}$ are positive and constant. The subscript it means that the variable refers to province $i$ in time $t$.

Using this specification, the general model discussed in Section 3.2 can be summarized as follows:

$$
\begin{aligned}
& X_{t}^{m}=M_{i t} N_{i t}^{m \alpha_{1}} \\
& X_{t}^{a}=A_{i t} N_{i t}^{a \alpha_{2}} \\
& \frac{\dot{M}_{t}}{M_{t}}=\delta_{0}+\delta X_{t}^{m} \\
& A_{i t} \alpha_{2} N_{i t}^{a \alpha_{2}-1}=\varphi(\cdot) P_{t} M_{i t} \alpha_{1} N_{i t}^{m \alpha_{1}-1}
\end{aligned}
$$

and

$$
X_{t}^{a}=\gamma L_{t}+\beta P_{t} X_{t}^{m}
$$

The model consists of five equations [Equations (13), (14), (15), (16), and (17)]. The endogenous variables are $X_{t}^{a}, X_{t}^{m}, \dot{M}_{t}, P_{t}$, and $n_{t}$.

\subsection{Data}

In the following analysis, we use GDP and employment data published by the National Statistical Office (NSO) of Thailand. We focus on the dynamics of economic growth for the period between 2001 and 2009. Our approach is to use regional GDP and employment data to increase the sample size for the estimation. We have data for seven regions in Table 7.2 for the period. ${ }^{5}$ 
Table 7.2 Regions and provinces in Thailand in the analysis

\begin{tabular}{ll}
\hline Region & Provinces \\
\hline Northeast & Khon Kaen, Udon Thani, Loei, Nong Khai, Mukdahan, Nakhon \\
& Phanom, Sakon Nakhon, Kalasin, Nakhon Ratchasima, \\
& Chaiyaphum, Yasothon, Ubon Ratchathani, Roi Et, Buri Ram, \\
& Surin, Maha Sarakham, Si Sa Ket, Nong Bua lam Phu, Am Nat \\
& Chareon \\
North & Chiang Mai, Lampang, Uttaradit, Mae Hong Son, Chiang \\
& Rai, Phrae, Lamphun, Nan, Phayao, Nakhon Sawan, \\
& Phitsanulok, Kkam Phaeng Phet, Uthai Thani, Sukhothai, Tak, \\
& Phichit, Phetchabun \\
South & Phuket, Surat Thani, Ranong, Phangnga, Krabi, Chumphon, \\
& Nakhon Si Thammarat, Songkhla, Satun, Yala, Trang, Narathiwat, \\
& Phatthalung, Pattani Marat, Songkhla, Satun, Yala, Trang, \\
East & Narathiwat, Phatthalung, Pattani \\
& Chon Buri, Chachoengsao, Rayong, Trat, Chanthaburi, Nakhon \\
& Nayok, Prachin Buri, Sa Keaw \\
West & Buri, Sa Keaw \\
& Ratchaburi, Kachanaburi, Phachuap Khiri Khan, Phetchaburi, \\
Central & Suphan Buri, Samut Songkhram Songkhram \\
Bangkok and & Saburi, Singburi, Chai Nat, Ang Tong, Lop Buri, Phra Nakhon Sri \\
vicinity & Ayuthaya Ayuthaya \\
& Bangkok Metropolis, Samut Prakan, Pathum Thani, Samut Sakhon, \\
& Nakhon Pathom, Nonthaburi \\
& Pathom, Nonthaburi
\end{tabular}

The provinces are divided into seven regions: Northeast, North, South, East, West, Central, and the Bangkok area. Table 7.3 shows the ratio between employment in the nonagricultural sector and total employment between 2001 and 2009. The ratio is very high in the Bangkok area as well as in the East, West, and Central regions. From Table 7.3, we can see that agriculture still plays a large role in the Northeast, North, and South regions.

There are only two sectors in the model: the agricultural sector and the nonagricultural sector. In the actual data, however, there are sectors that do not belong to either the agricultural sector or the nonagricultural sector. Since our main interest is to consider the role of agriculture in the economic development process, we divide the data into agricultural and nonagricultural components. The amount of each variable in the nonagricultural sector can be calculated as the difference between the total and agricultural amounts. For example, nonagricultural GDP is calculated as total GDP minus agricultural GDP. The variables in Table 7.4 are needed for the analysis. All of this information is available in the NSO database.

The sample size is limited, and consistent data are available only for the period between 2001 and 2009. We pool the data in order to increase the degrees of 
Table 7.3 The average ratio between nonagricultural employment and total employment ( $n$, unit: \%)

\begin{tabular}{lccccccccc}
\hline Region & 2001 & 2002 & 2003 & 2004 & 2005 & 2006 & 2007 & 2008 & 2009 \\
\hline Northeast & 41.95 & 41.55 & 42.87 & 44.44 & 44.72 & 43.47 & 44.12 & 44.09 & 46.65 \\
North & 45.64 & 46.06 & 48.46 & 51.65 & 52.23 & 50.42 & 50.67 & 51.72 & 52.63 \\
South & 49.13 & 50.38 & 50.79 & 52.30 & 54.49 & 53.35 & 52.61 & 53.81 & 55.13 \\
East & 63.79 & 62.33 & 64.88 & 68.90 & 71.18 & 69.91 & 69.80 & 69.08 & 70.10 \\
West & 53.99 & 55.94 & 57.54 & 61.07 & 62.25 & 60.15 & 60.06 & 59.31 & 58.93 \\
Central & 67.29 & 68.97 & 69.51 & 69.27 & 70.73 & 72.14 & 72.78 & 73.15 & 73.63 \\
$\begin{array}{l}\text { Bangkok } \\
\text { and vicinity }\end{array}$ & 96.04 & 95.01 & 95.57 & 95.87 & 96.11 & 96.23 & 96.12 & 95.79 & 95.57 \\
\hline
\end{tabular}

Table 7.4 Variables

\begin{tabular}{ll}
\hline Variable & Description \\
\hline$X^{a}$ & Agricultural GDP \\
$X^{m}$ & Nonagricultural GDP \\
$n_{i t}$ & The proportion of employment in the nonagricultural sector \\
$\dot{n}_{i t}$ & The change in $n_{i t}$ \\
$L_{i t}$ & Total population \\
$P_{i t}$ & Price (agricultural GDP deflator/nonagricultural GDP deflator) \\
$\dot{P}_{i t}$ & The change in $P_{i t}$ \\
\hline
\end{tabular}

freedom. First, we construct the change in $n_{i t}$ and $P_{i t}$ or $\dot{n}_{i t}$ and $\dot{P}_{i t}$ for each $i$ and $t$. After that, we pool the observations.

Figure 7.7 describes the change in agricultural and nonagricultural GDP, the GDP deflator, and population in the country as a whole.

From Figure 7.8, we see the increase in prices after the Asian crisis, while the trend reversed to decrease after the year 2000. The declining trend indicates the relative increase in food prices. Government support for rural farmers was behind the trend.

The total population is increasing, ${ }^{6}$ which suggests that the assumption of no population change in Matsuyama (1992) should be changed.

Figure 7.10 shows that the role of the agricultural sector, defined by the ratio between agricultural GDP and nonagricultural GDP, is declining for the whole country. The ratio in 2010 is less than 8 percent. The role of agriculture in this sense is not very high in general. In some regions, like the South, Northeast, North, and West, the ratio is relatively higher.

\subsection{Single equations}

Instead of summarizing the five-equation system with Equations (13), (14), (15), (16), and (17) into a simpler equation system, here we estimate each equation in 

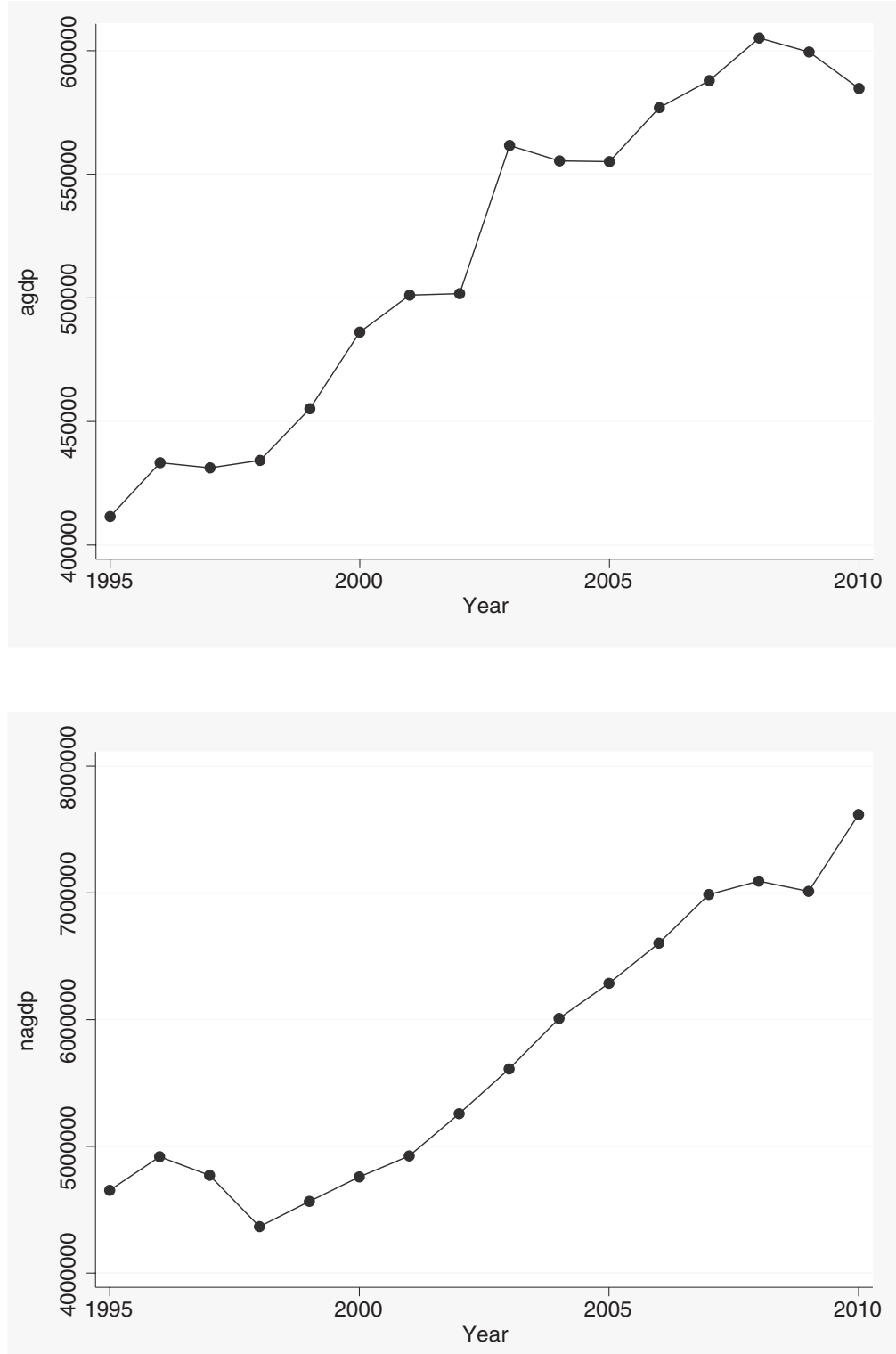

Figure 7.7 Agricultural GDP (left); nonagricultural GDP (whole kingdom) (right) 


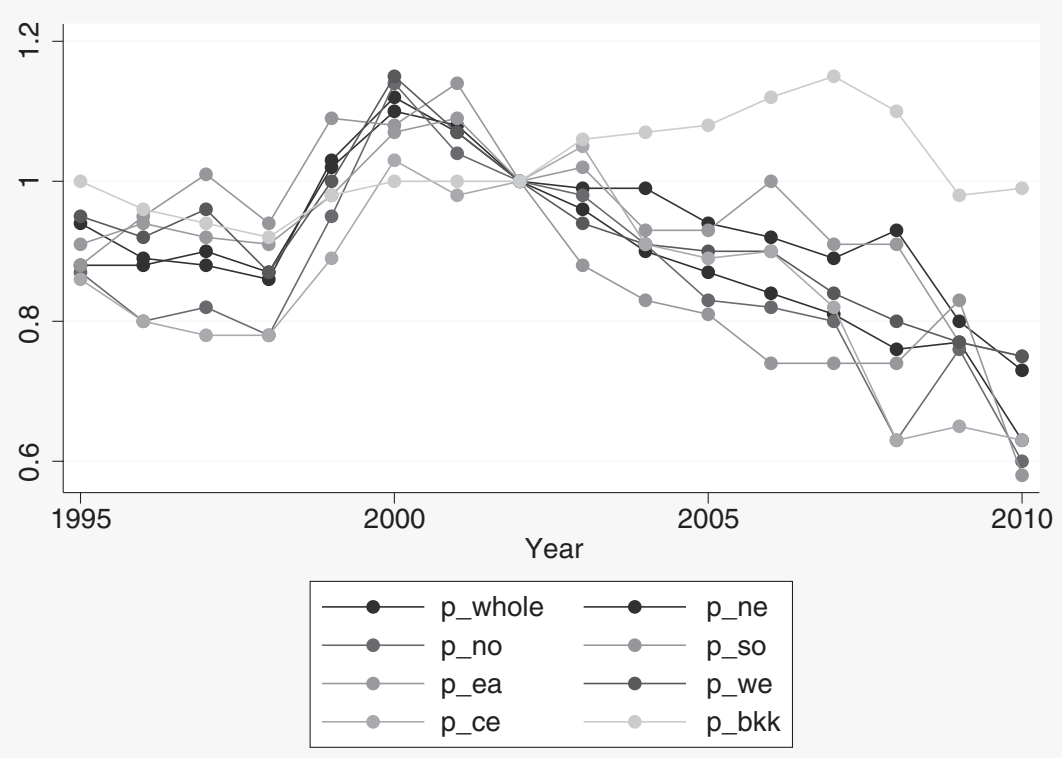

Figure 7.8 The change in prices $\left(\frac{P_{M}}{P_{A}}\right)$

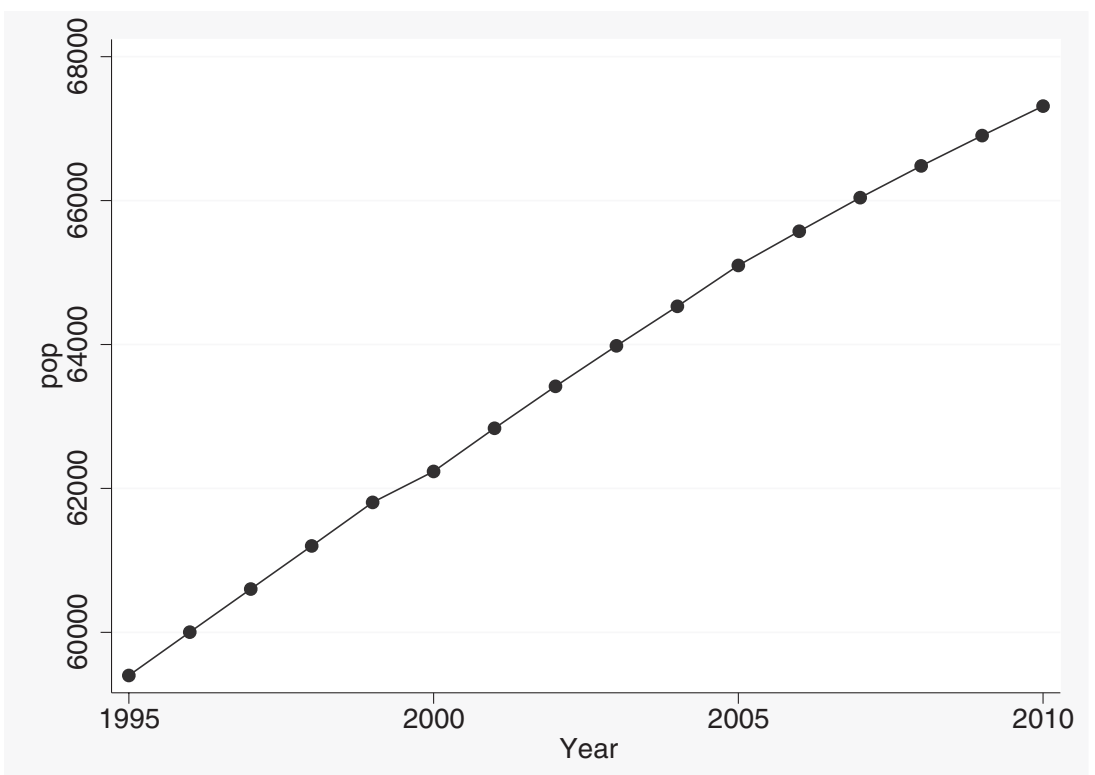

Figure 7.9 Population (whole kingdom) 


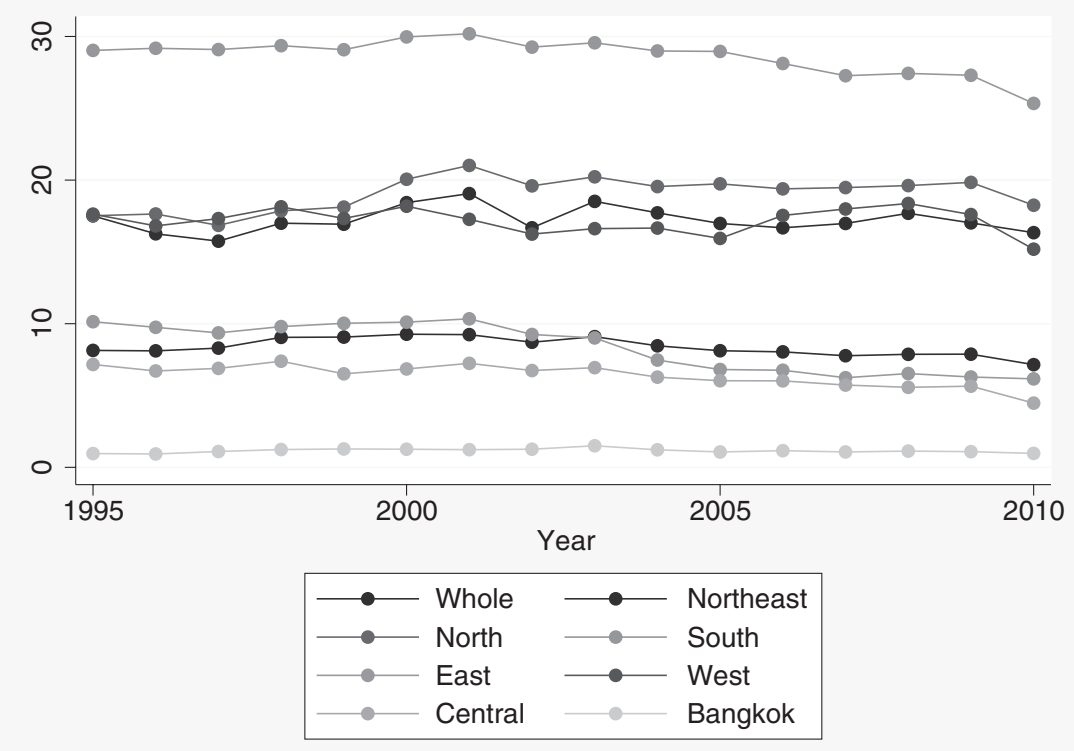

Figure 7.10 The ratio between agricultural GDP and total GDP (unit: \%, whole kingdom)

Table 7.5 Estimation results (production function)

\begin{tabular}{lcllccc}
\hline Dependent & Parameter & Estimate & Error & t-statistic & P-value & Adjusted $\mathrm{R}^{2}$ \\
\hline$X^{m}$ & $\alpha_{1}$ & 0.8469961 & 0.0045837 & 184.78 & 0.000 & 0.5289 \\
$X^{a}$ & $\alpha_{2}$ & 0.6821859 & 0.0030043 & 227.07 & 0.000 & 0.7303 \\
\hline
\end{tabular}

the model separately. By doing so, we ensure that the functional forms are appropriate in estimating the comprehensive equation system.

\section{Production functions}

First, we estimate the production functions:

$$
X_{t}^{m}=N_{t}^{m \alpha_{1}}+\varepsilon^{m}
$$

and

$$
X_{t}^{a}=N_{t}^{a \alpha_{2}}+\varepsilon^{a}
$$

The estimation results are reported in Table 7.5. 

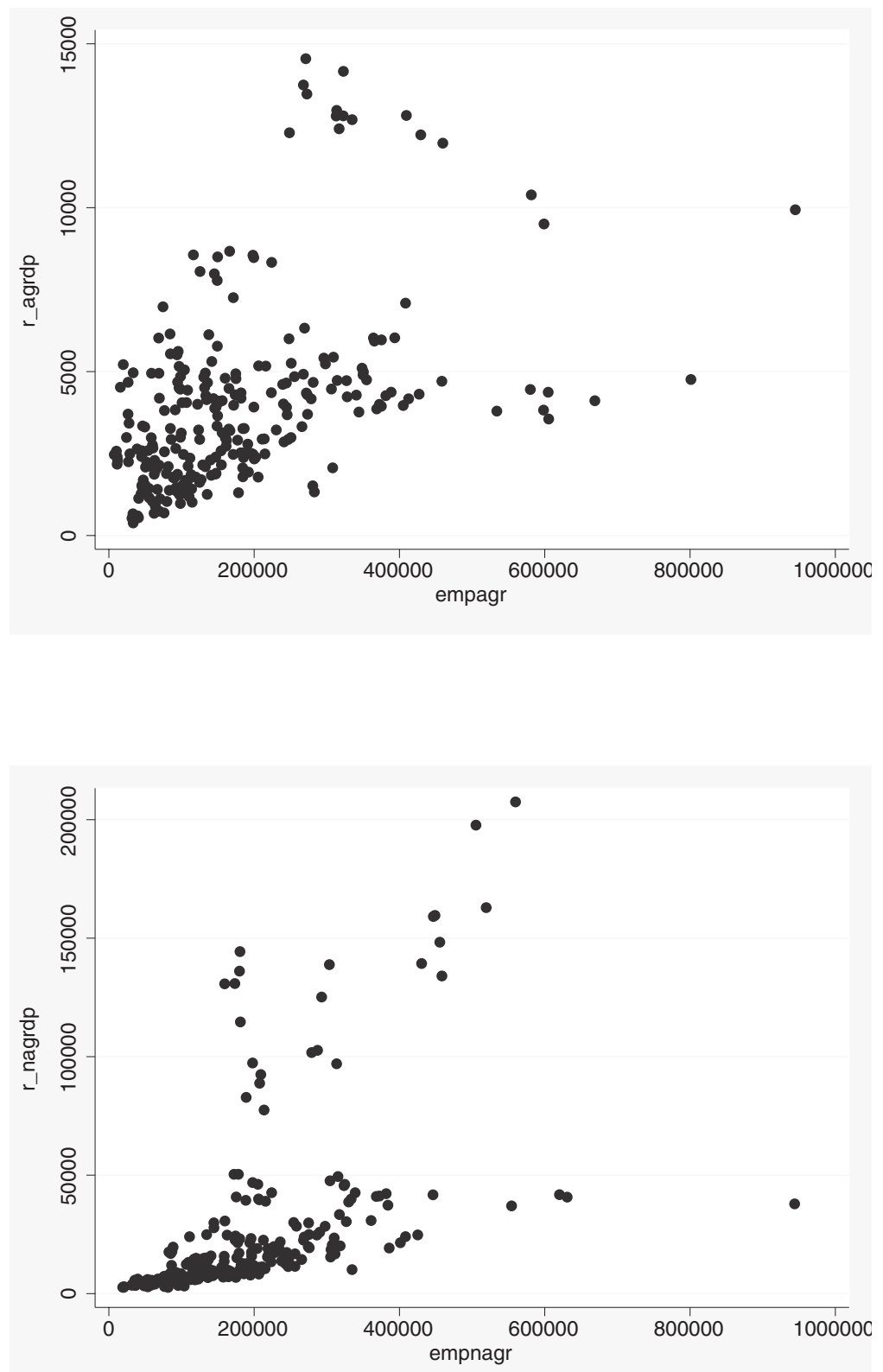

Figure 7.11 Production function 
Figure 7.11 plots the relationship between $N j$ and $X j(j=m$ and $a)$.

It is clear from Figure 7.11 that technologies are not homogeneous among provinces. We find at least two types of provinces in the sample. Therefore, we construct dummy variables $d u m^{j}$ for province $i$ and sector $j$ as follows:

$$
\operatorname{dum}_{i t}^{j}=\left\{\begin{array}{cc}
1 & \text { if } \sum_{t}\left(\begin{array}{cc}
X_{i t}^{j} & \widehat{X} \\
X_{i t}^{j}
\end{array}\right) \geq 0 \\
0 & \text { otherwise }
\end{array}\right.
$$

Putting the variables into Equations (18) and (19), we arrive at the following estimation equations.

$$
\begin{aligned}
& X_{t}^{m}=N_{t}^{m \alpha_{1}}+d u m_{t}^{m}+\varepsilon^{m} \\
& X_{t}^{a}=N_{t}^{a \alpha_{2}}+d u m_{t}^{a}+\varepsilon^{a}
\end{aligned}
$$

The results of the estimation of Equations (20) and (21) are summarized in Table 7.6.

The estimation results are highly improved by introducing dummy variables $d u m^{j}$. In the following discussion, we use the functional forms of (20) and (21) for specifying production technologies in Thailand.

\section{Technical progress}

Next, we consider the functional form of technical progress in the nonagricultural sector. Modifying Equation (13), we obtain

$$
M_{i t}=\frac{X_{t}^{m}}{N_{i t}^{m \alpha_{1}}}
$$

Using Equation (22), we can calculate $M_{i t}$ and plot the relationship between $\dot{M}_{t} / M_{i t}$ and $\left(X^{m}\right)$, which is depicted in Figure 7.12.

It is clear from Figure 7.12 that technological progress in the nonagricultural sector in Thailand is not dependent on the volume of production in the

\begin{tabular}{|c|c|c|c|c|c|c|}
\hline Dependent & Parameter & Estimate & Error & t-statistic & P-value & Adjusted $R^{2}$ \\
\hline$X^{m}$ & $\begin{array}{l}\alpha_{1} \\
d u m_{+}^{m}\end{array}$ & $\begin{array}{l}0.7958131 \\
0.1218704\end{array}$ & $\begin{array}{l}0.0047027 \\
0.0050183\end{array}$ & $\begin{array}{r}169.22 \\
24.29\end{array}$ & $\begin{array}{l}0.000 \\
0.000\end{array}$ & 0.8465 \\
\hline$X^{a}$ & $\alpha_{2}$ & $\begin{array}{l}0.6501537 \\
0.0698945\end{array}$ & $\begin{array}{l}0.0037966 \\
0.0043618\end{array}$ & $\begin{array}{r}171.25 \\
16.02\end{array}$ & $\begin{array}{l}0.000 \\
0.000\end{array}$ & 0.8755 \\
\hline
\end{tabular}
sector. Therefore, we will assume that $\delta=0$ in Equation (15) in the following discussion.

Table 7.6 Estimation results (production function) 


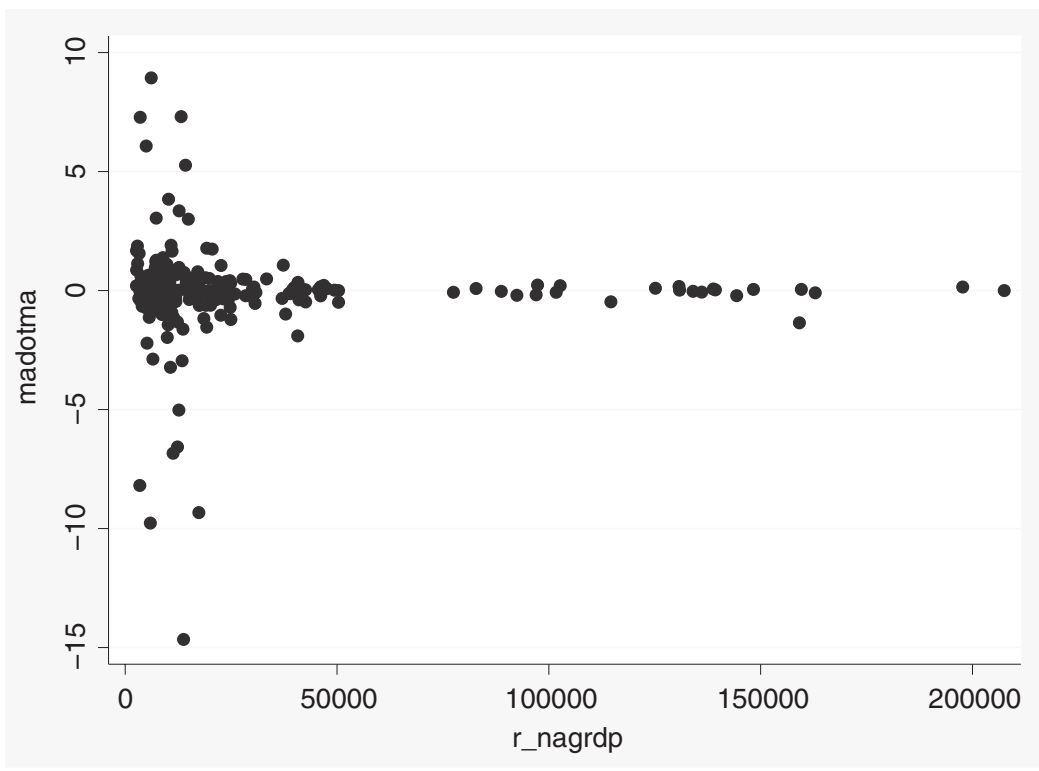

Figure 7.12 Production function

\section{Marginal productivity between sectors}

The key assumption in neoclassical growth models is the wage equalization hypothesis. In such models, marginal productivity in all of the sectors should be equal in equilibrium. Using the results in Table 7.6, we calculate marginal productivities in the agricultural and nonagricultural sectors and test whether $\varphi(\cdot)$ in Equation (16) is equal to unity or not.

Figure 7.13 is the histogram of

$$
\varphi(\cdot)=\frac{P_{t} M_{i t} \alpha_{1} N_{i t}^{m \alpha_{1}-1}}{A_{i t} \alpha_{2} N_{i t}^{i \alpha_{2}-1}}
$$

It is clear from Figure 7.13 that we cannot assume that $\varphi(\cdot)$ is equal to unity. The productivity difference between the two sectors is fairly high.

Now we assume that $\varphi(\cdot)$ depends on $n_{t}$, the proportion of employment in the nonagricultural sector in the total population $L$. We estimate the following equation, which contains the dummy variables in the production functions.

$$
\varphi(\cdot)=b_{0}+b_{1} n_{t}+b_{2} L_{t}+b_{j} d u m_{j}+\varepsilon
$$

The estimation results in Table 7.7 show that the variable $n_{t}$ is the important factor that determines the size of the difference between two marginal productivities. 


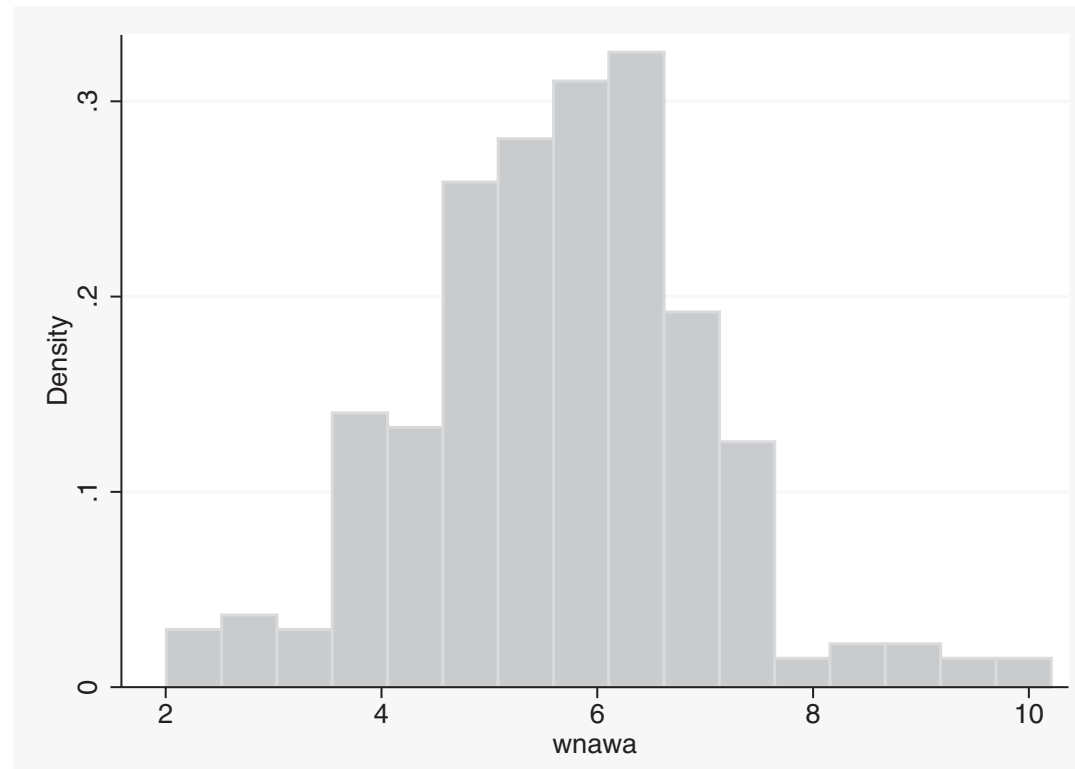

Figure 7.13 Histogram of $\varphi(\cdot)$

Table 7.7 Estimation results (marginal productivity)

\begin{tabular}{llclrlr}
\hline Dependent & Parameter & Estimate & Error & t-statistic & P-value & Adjusted $R^{2}$ \\
\hline$\varphi(\cdot)$ & $n$ & -7.483997 & 0.1999423 & -37.43 & $\mathbf{0 . 0 0 0}$ & 0.8419 \\
& Constant & 9.499624 & 0.1080287 & 87.94 & $\mathbf{0 . 0 0 0}$ & \\
& $n$ & -7.113935 & 0.0921874 & -77.17 & $\mathbf{0 . 0 0 0}$ & 0.9669 \\
& $L$ & $2.12 \times 10^{-6}$ & $6.73 \times 10^{-8}$ & 31.49 & $\mathbf{0 . 0 0 0}$ & \\
& Constant & 8.544771 & 0.0579646 & 147.41 & $\mathbf{0 . 0 0 0}$ & \\
& $n$ & -7.705479 & 0.268358 & -28.71 & $\mathbf{0 . 0 0 0}$ & 0.8424 \\
& dum $^{m}$ & 0.196634 & 0.1203434 & 1.63 & 0.103 & \\
& dum $^{a}$ & -0.0548091 & 0.0732983 & -0.75 & 0.455 & \\
& Constant & 9.606585 & 0.1279606 & 75.07 & $\mathbf{0 . 0 0 0}$ & \\
& $n$ & -7.36301 & 0.1197348 & -61.49 & $\mathbf{0 . 0 0 0}$ & 0.9689 \\
& $L$ & $2.12 \times 10^{-6}$ & $6.53 \times 10^{-8}$ & 32.52 & $\mathbf{0 . 0 0 0}$ & \\
& dum & 0.2204994 & 0.0534912 & 4.12 & $\mathbf{0 . 0 0 0}$ & \\
& dum $^{a}$ & -0.0602543 & 0.0325776 & -1.85 & 0.066 & \\
& Constant & 8.663122 & 0.0638459 & 135.69 & $\mathbf{0 . 0 0 0}$ & \\
\hline
\end{tabular}


Table 7.8 Estimation results (consumer optimization)

\begin{tabular}{lccrrc}
\hline Parameter & Estimate & Error & t-statistic & P-value & Adjusted $R^{2}$ \\
\hline$\gamma$ & 0.0086709 & 0.0004878 & 17.78 & 0.000 & 0.7334 \\
$\beta$ & 0.0172122 & 0.0056851 & 3.03 & 0.003 & \\
$\gamma$ & 0.0060638 & 0.0004082 & 14.86 & 0.000 & 0.8504 \\
$\beta$ & 0.0217813 & 0.0042712 & 5.10 & 0.000 & \\
dum $^{c}$ & $2,687.525$ & 187.3554 & 14.34 & 0.000 & \\
\hline
\end{tabular}

To simplify the discussion, we will assume the following relationship:

$$
\varphi(.)=b_{0}+b_{1} n_{t}
$$

Substituting Equation (24) into Equation (16), we obtain

$$
n_{i t}=\beta_{0}+\beta_{1} \frac{N_{t}^{a \alpha_{21}}}{P_{t} N_{t}^{m \alpha_{1}-1}}
$$

\section{Consumer optimization}

Equation (17) in the system is the condition of consumer optimization. Estimating $\beta$ and $\gamma$ in the equation, we obtain the results summarized in Table 7.8.

There are two results in Table 7.8. The term $d u m^{c}$ in Table 7.8 indicates a dummy variable constructed in the same manner as in the discussion in estimating production functions. In both of the results, parameters $\gamma$ and $\beta$ are significant, and consumer optimization should therefore be included in the estimation of the structural equation system.

Note, however, that the estimates of $\gamma$ are quite small even though the estimates are significant. This suggests that $\gamma$ might be zero. In the discussion of two-sector economic growth, it is usual to assume that $\gamma$ is positive since it implies that the income elasticity of food consumption is less than unity. We need to consider the possibility of the case in which $\gamma$ is equal to zero when we analyze the dynamic path of Thailand over the period.

\subsection{Structural equations}

The discussion in the previous section concludes that our estimation equation model can be summarized by Equations (20), (21), (25), and (17). Applying the data to the nonlinear structural equation system, we obtain the results presented in Table 7.9.

The coefficients of the production function $\alpha_{1}$ and $\alpha_{2}$ are significant, and the values are in a reasonable range. We must note that the estimate of $\beta$ is not in a reasonable range. The negative $\beta$ means that nonagricultural products are inferior goods for consumers.

We also estimate an alternative model in which $\gamma$ is assumed to be zero. The estimation results are summarized in Table 7.10. 
Table 7.9 Estimation results

\begin{tabular}{lclrc}
\hline Parameter & Estimate & Error & t-statistic & P-value \\
\hline$\alpha_{1}$ & 0.7934277 & 0.0047269 & 167.85 & 0.00 \\
$d u m^{m}$ & 0.1236729 & 0.0050336 & 24.57 & 0.000 \\
$\alpha_{2}$ & 0.6544537 & 0.0035421 & 184.76 & 0.000 \\
$d u m^{a}$ & 0.064521 & 0.0041336 & 15.61 & 0.000 \\
$\beta$ & -3.033599 & 0.9022021 & -4.36 & 0.000 \\
$\gamma$ & 0.0173018 & 0.0021253 & 8.18 & 0.000 \\
$\beta_{0}$ & 0.2333333 & 0.0127498 & 18.30 & 0.000 \\
$\beta_{1}$ & 1.384544 & 0.1063509 & 13.02 & 0.000 \\
Number of samples $=264$. & & & \\
$R^{2}$ for $(20)\left(X^{m}\right) 0.8469$, & & & \\
for $(21)\left(X^{a}\right) 0.8756$, & & & \\
for $(25)(p) 0.8606$, and & & & \\
for $(17)(n) 0.6954$. & & & \\
\hline
\end{tabular}

Table 7.10 Estimation results (Matsuyama model)

\begin{tabular}{lllrr}
\hline Parameter & Estimate & Error & t-statistic & P-palue \\
\hline$\alpha_{1}$ & 0.789892 & 0.0040008 & 161.18 & 0.000 \\
$d_{u m}$ & 0.1276095 & 0.0052022 & 24.55 & 0.000 \\
$\alpha_{2}$ & 0.6515393 & 0.0035766 & 182.17 & 0.000 \\
$d_{u m}^{a}$ & 0.0648319 & 0.0040858 & 15.87 & 0.000 \\
$\beta$ & 4.303189 & 0.3013485 & 14.28 & 0.000 \\
$\gamma$ & 0.248136 & 0.0106582 & 23.28 & 0.000 \\
$\beta_{0}$ & 1.182384 & 0.08964 & 13.19 & 0.000 \\
Number of samples $=264$. & & & \\
$R^{2}$ for $(20)\left(X^{m}\right) 0.8463$, & & & \\
for $(21)\left(X^{a}\right) 0.8750$, & & & \\
for $(25)(p) 0.7059$, and & & & \\
for $(17)(n) 0.6673$. & & & \\
\hline
\end{tabular}

All of the results reported in Table 7.10 are reasonable. We can therefore say that the neoclassical growth model with non-unity $\varphi$ basically explains the actual dynamic path of Thailand in the period between 2001 and 2009. The country is in the developing stage in the sense that the wage difference is still high, but it is in the developed stage in the sense that consumer preferences are the key driving force of the agricultural and nonagricultural dynamics.

\section{Conclusion}

Thailand has been facing the middle-income problem, and there have been conflicts between the rural agricultural sector and the urban nonagricultural sector. 
The theoretical model that best explains the current Thailand economy is a hybrid model of a wage-difference model and a neoclassical model.

There is still large wage indifference in Thailand, and this is one of the factors that explain the decline in the role of the agricultural sector in the economic development process. Another important factor in this decline is consumer preference for non-food. When income increases, people prefer more non-food to food. Demand elasticity of food/agricultural products is less than unity.

The endogenous growth model suggests that either supply side factors or endogenous technical progress can be other key factors that explain the declining share of agriculture in GDP. The manufacturing sector adds more value to finished goods than the agricultural sector, and in the model, the advantage becomes larger and larger in the economic development process. Our estimation shows, however, that the supply side effect is not significant. The main factor that causes the middle-income problem can be found in the change in consumer preference, not in the nature of technical progress in the manufacturing sector. To tackle the middle-income trap, we must further investigate the nature of consumer preference and the wage indifference between the sectors.

\section{Notes}

1 Calculation based on the World Development Indicators.

2 Calculation based on the World Development Indicators.

3 American Samoa, Australia, Brunei Darussalam, China, Fiji, Federated States of Micronesia, Guam, Hong Kong Special Administrative Region (SAR), China, Indonesia, Japan, Cambodia, Kiribati, Korea, Lao People's Democratic Republic, Macao SAR, China, Marshall Islands, Myanmar, Mongolia, Northern Mariana Islands, Malaysia, New Caledonia, New Zealand, Philippines, Palau, Papua New Guinea, Democratic People's Republic of Korea, French Polynesia, Singapore, Solomon Islands, Thailand, Timor-Leste, Tonga, Tuvalu, Vietnam, Vanuatu, and Samoa.

4 The value of $\varphi$ is equal to the probability of getting a job in an urban area in the model.

5 For the period that covers the years after 1993, the NSO provides a consistent data set.

6 The population changes are almost the same in every region.

\section{References}

Echevarria, C. (1995), "Agricultural development vs. industrialization: Effects of trade," Canadian Journal of Economics, 28(3), 631-647.

Echevarria, C. (1997), "Changes in sectoral composition associated with economic growth," International Economic Review, 38(2), 431-452.

Gill, I., H. Kharas, D. Bhattasali, M. Brahmbhatt, G. Datt, M. Haddad, E. Mountfield, R. Tatucu and E. Vostroknutova (2007), An East Asian Renaissance - Ideas for Economic Growth. World Bank: Washington, DC.

Gollin, D. (2010), “Agricultural productivity and economic growth," in P. Pingali and R. Evenson (Eds.), Handbook of Agricultural Economics, Vol. 4, Elsevier: Amsterdam. 
Gollin, D., S. L. Parente and R. Rogerson (2002), “The role of agriculture in development," American Economic Review, Papers and Proceedings, 92(2), 160-164.

Harris, J. and M. Todaro (1970), "Migration, unemployment and development: A two-sector analysis," American Economic Review, 40, 126-142.

Hayami, Y. (2007), "An emerging agricultural problem in high-performing Asian economies," World Bank Policy Research Working Paper 4312, World Bank: Washington, DC.

Lewis, W.A. (1954), "Economic development with unlimited supplies of labour," Manchester School of Economic and Social Studies, 22(2), pp. 139-191.

Matsuyama, K. (1992), "Agricultural productivity, comparative advantage, and economic growth," Journal of Economic Theory, 58, 317-334.

Ranis, G. and J.C.H. Fei (1961), "A theory of economic development," The American Economic Review, 51(4), 533-565.

Shultz, T.W., Ed. (1978), Distortions of Agricultural Incentives. Indiana University Press: Bloomington.

World Bank (1993), “The East Asian miracle: Economic growth and public policy," A World Bank policy research report. The World Bank: Washington, DC. 


\title{
8 The possibility of a border economic zone
}

\author{
Asian Golden Quadrangle
}

\author{
Satoko Okuyama
}

\section{Introduction}

In this chapter, we will discuss the possibilities of economic development that may lead to the elimination of poverty in an inland area. Generally speaking, an inland area has a disadvantage in terms of economic development because of its reduced accessibility to other areas. Therefore, the poverty rate of an inland area is apt to stay high. We will consider how to develop such an inland area. We will focus on the Asian Golden Triangle (GT) and Yunnan Province in China. The development of this area's infrastructure has recently rapidly increased, and the liberalization of trade with other countries is expanding. We will explain changes in the economic environment for this area and consider how this may be best utilized.

The GT is a zone bordering Thailand, Myanmar, and Laos. This area, especially Myanmar, is famous for opium products. The residents of this area are poor and earn their living through opium production. One of the reasons for the poverty in this area is its poor accessibility due to its inland location. However, financial and technical support from the Asian Development Bank (ADB), Japan, and China to Thailand, Myanmar, and Laos has helped infrastructure development and thus has improved accessibility to some extent. Owing to the improvement in infrastructure, the accessibility from GT to Yunnan Province in China has also improved. Together with Yunnan Province, a poor area of China, the GT area has recently come to be known as the Golden Quadrangle (GQ).

The economic environment in the GQ is changing along with the improvement of infrastructure. Another positive factor is the expansion of the Free Trade Agreement (FTA) in the Association of Southeast Asian Nations (ASEAN) countries. The ASEAN Free Trade Area (AFTA) is being built and will be completed in 2015. Moreover, ASEAN is expanding the FTA to include other countries, such as China and Japan. Also, foreign direct investment (FDI) into ASEAN has increased recently. An expansion in the manufacturing of a foreign company brings an associated increase in employment, skills, and knowledge about production management and processes. In Thailand, Laos, and Myanmar, the influence of China has recently increased. Because the GQ area is the bordering zone 
of China and ASEAN, the importance of the GQ will increase more and more in the future.

In Section 2, we will trace the impediments to the development of the GQ in terms of geography and history and show the economic data for the GQ and major cities around the GQ. We will also explain the characteristics of the GQ. In Section 3, we will explain the Greater Mekong Subregion (GMS) Program. The GMS Program, which is being implemented by the ADB, helps promote subregional economic cooperation and enhances economic relations among the countries (Thailand, Myanmar, and Laos are also included in the GMS Program). In Section 4, we will discuss the expansion of the free trade area of ASEAN, of which Thailand, Laos, and Myanmar are members. Recently, ASEAN successfully negotiated an FTA with other countries. We will also describe the current position of the FTA. Many foreign companies have already, through ASEAN, created a global supply chain. We will consider how to attract foreign companies into the GQ. In Section 5, we will propose some policies for the development of the GQ area. Finally, we will summarize this chapter in Section 6.

\section{The Golden Quadrangle}

\subsection{Features of the $G Q$}

In this section, we will discuss some basic information relating to the GQ. The most important characteristic of the GQ area is that the four countries all share borders with two of the other countries. Because this area is mountainous, accessibility to big cities is poor. Therefore, the incidence of poverty in the area is comparatively high, and income levels are low.

First, we examine the geographical features of the GT and the GQ. Figure 8.1 shows a map of the GQ. The GT is an area that borders Thailand, Myanmar, and Laos and includes a part of northern Thailand, northwestern Laos, and eastern Myanmar, as well as the Yunnan province of China that lies to the north of the GT, giving the area another border point. Southern Yunnan borders northwestern Laos and eastern Myanmar. This bordering area could be called another GT. The distance between these two border points is about $350 \mathrm{~km}$. The GQ gathers four different countries in a small area.

Let us now look at the border towns around the GQ area. First, we will introduce the border towns around the GT - Thailand, Myanmar, and Laos. The Thai border province is Chiang Rai; the Lao border province is Bokeo; and the border state of Myanmar is Shan, which is also the border state with Yunnan.

The Sai River lies between Thailand (to the south) and Myanmar (to the north). There is a small bridge over the river, which has been used by the people of Thailand and Myanmar since early times. The Thai border town is Mae Sai, while Myanmar's border town is Tachileik. The Mekong River lies between Thailand and Laos; Chiang Khong is the Thai border town, and Houeixay is the Lao border town. These towns are connected by the Fourth Thai-Lao Friendship 


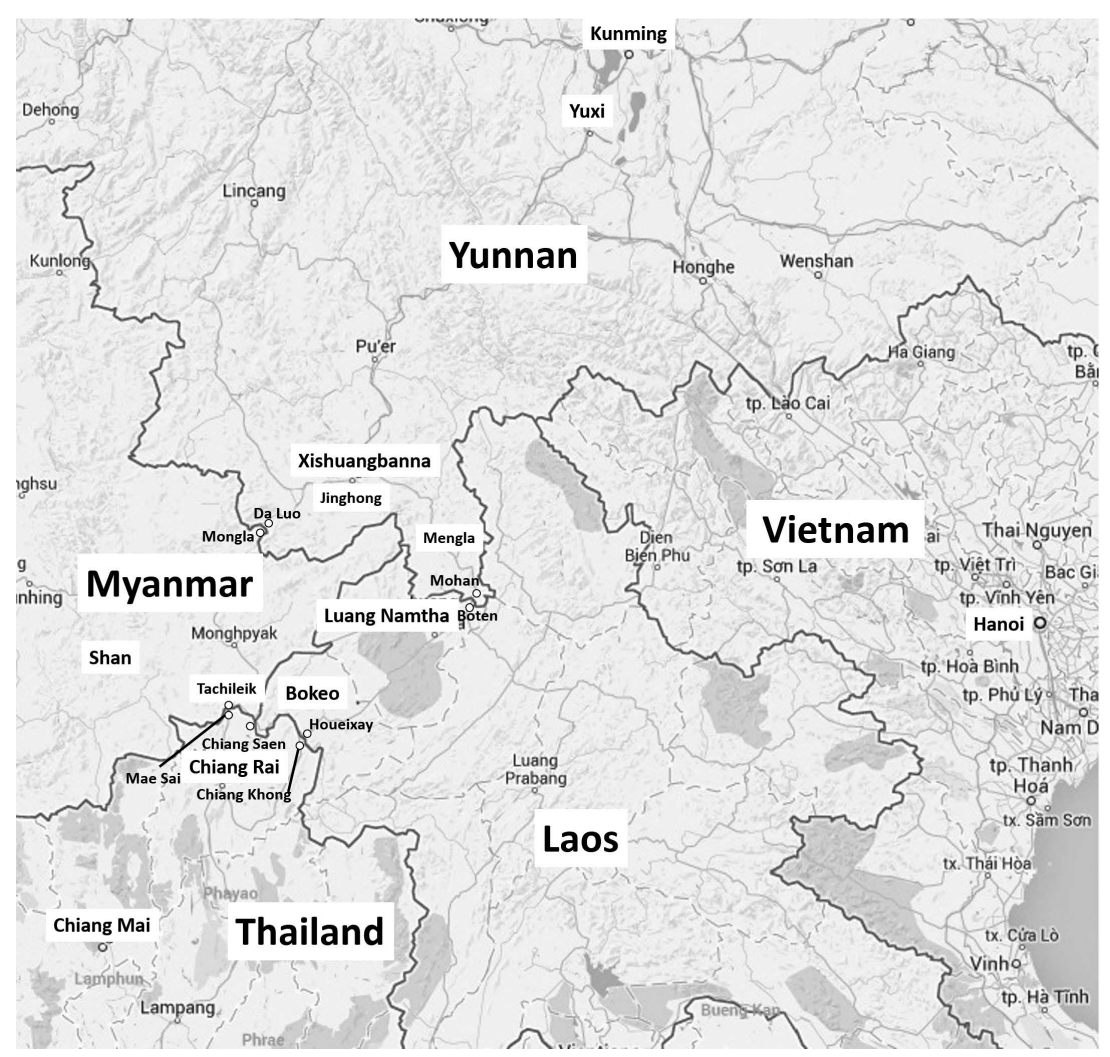

Figure 8.1 The Golden Quadrangle

Source: Adapted from Google Maps.

Bridge. The Sai River and the Mekong River meet at the GT, and this is a famous tourist spot. Although Thailand and Yunnan are not neighbors, people can travel from Jinghong to Chiang Saen by ship along the Mekong River.

Northward of the GT, there is a border between Yunnan, Laos, and Myanmar where Yunnan's border prefecture is Xishuangbanna; the border town with Laos is Mohan, and the border town with Myanmar is Da Luo. The Lao border province is Luang Namtha, and the border town with Yunnan is Boten. Myanmar's border town with Yunnan is Mongla.

Other major cities which are important for the development of the GQ area include Kunming, which is the largest city in terms of population and gross domestic product (GDP) in Yunnan. The North-South Economic Corridor (NSEC), which connects Kunming with Bangkok and Hanoi, is a major economic road. Moreover, railroads between Kunming and Vientiane and Kunming 
and Hanoi are planned. Kunming will be the base point to connect the major cities of ASEAN and southern China. Another important city is Chiang Mai, which is the most central city and has the largest GDP in northern Thailand. For the development of the GT and GQ, these two cities should be the main economic places in the GQ area.

Poor accessibility to the big cities of each country has impeded the development of this area. Table 8.1 lists the distance and travel time by car from the towns of the GQ to the big cities in each country. Bangkok, Yangon, and Vientiane are the largest cities in each country in terms of population and production. Guangzhou is the largest city in Guangdong, which is one of the largest provinces in China and is relatively near the GQ. Hanoi is the capital city of Vietnam. We can see that the GQ area is far away from the big cities, and this is a disadvantage to the development of the industrial sectors. Most of the major industrial areas are near major cities. Moreover, the GQ area has many mountains and rivers and so is isolated from other areas. In addition, as this area is inland and far from the sea, it is inconvenient to transport goods and people overseas.

However, the improvement of the infrastructure in the GQ might change the disadvantage of the countries' location in the GQ to an advantage. We can see that the GQ area can access the four big cities: Bangkok, Yangon, Vientiane, and Hanoi (see Table 8.1). These cities, although they are not close to the GQ, are accessible with improved infrastructure. Together with lower production costs, this might lead to the GQ becoming an industrial area with access to the four big cities. Moreover, these big cities are expected to achieve rapid economic growth.

Second, we examine the historical features of the area. The GT is historically famous for its opium production. In Myanmar, opium production increased between 2007 and 2010 (United Nations Office on Drugs and Crime 2011). In Thailand, however, opium production decreased during the same period because of severe restrictions imposed by the government. The people who live in this area are very poor and rely on opium production to make their living. The Thai government has encouraged people to switch to other profitable crops, such as coffee and tea. However, the situation remains unchanged in Myanmar and Laos.

Conflicts in the GT area serve as another impediment to development. There have been many conflicts near the GT area, as it is essentially a zone bordering Thailand, Laos, and Myanmar. Moreover, Thailand is a capitalist country, while

Table 8.1 Distances between the GQ and the major cities

\begin{tabular}{llll}
\hline From & To & Distance & Time (by car) \\
\hline Mae Sai & Bangkok & $790 \mathrm{~km}$ & 9 hours \\
Tachileik & Yangon & $1,000 \mathrm{~km}(1,186 \mathrm{~km})$ & 13 hours (16 hours) \\
Houeixay & Vientiane & $800 \mathrm{~km}$ & 11 hours \\
Jinghong & Guangzhou & $1,944 \mathrm{~km}$ & 22 hours, 30 minutes \\
Houeixay & Hanoi & $942 \mathrm{~km}$ & 14 hours \\
\hline
\end{tabular}

Source: Google Maps. 
Myanmar and Laos are socialist. During the Cold War era, many conflicts - the most prominent being the Vietnam War - broke out in Indochina.

However, since the end of the Cold War, there has been peace. After the signing of the Paris Peace Agreement in 1991, countries in the Indochina region have largely cooperated with each other. With the ADB's support, ASEAN countries (especially Thailand) have seen considerable infrastructure development and an improved economic environment. With better economic development, the poor in the GT area will be encouraged to take up activities other than opium production, and poverty in the GT area can be decreased.

Any instability in domestic politics also has a dampening effect on economic growth. The military government in Myanmar has suppressed democracy for a long time. The United States, the European Union (EU), and other leading countries imposed trade sanctions on Myanmar that lasted until 2012. The political instability caused economic stagnation. Since 2013, however, the Myanmar military government has advanced democratization, and many countries have removed sanctions against Myanmar. The Myanmar economy is now expected to develop rapidly.

Political instability in Thailand has also depressed the Thai economy. The heated demonstrations that have frequently occurred have caused political stagnation. The Thai Prime Minister was forced out of office, and the Cabinet was also dismissed because of these demonstrations in 2013-2014. In May 2014, the Thai military government was established. This political instability may well make foreign companies wary about investing in Thailand.

Finally, we will explain the various ethnic groups in the GQ and other cultural backgrounds. In Thailand, the proportion of Thai people to the total population is about 85 percent; in Laos, the Lao people's share is about 60 percent; in China, Han Chinese people account for more than 90 percent of the population; and in Myanmar, the Bamar people's share is more than 70 percent. However, there are many kinds of ethnic minorities in each country that have significant populations in the GQ area. This is also one of the significant features of the GQ. Since each ethnic group has their own original traditions and culture, this area is therefore attractive to tourists who like the traditional craft products of ethnic minorities.

In terms of religion, most people from the GQ countries profess to be Buddhist. It should, however, be noted that there are not large differences among religions. Each country has its own mother language. However, it can be said that Thai and Lao are similar. A common religion and similar languages would make creating linkages across the border easier.

\subsection{Economic overview of the $G Q$}

Table 8.2 provides some basic information about the GQ area for Thailand, Laos, Myanmar, and Yunnan (TLMY) and Vietnam. We can see that the population scale is similar among TLMY except for Laos. The population of Laos is $6,256,000$, which is less than one-tenth of that of Thailand $-67,313,000$. In the $\mathrm{GQ}$, Kunming has the largest population, 6,439,000, which is as much as that of 
Table 8.2 Population, land area, and poverty (2010)

\begin{tabular}{|c|c|c|c|c|}
\hline Location and/or Area & $\begin{array}{l}\text { Total } \\
\text { Population } \\
\text { (thousands) }\end{array}$ & $\begin{array}{l}\text { Land area } \\
\text { (thousands } \\
\text { per square } \\
\text { kilometer) }\end{array}$ & $\begin{array}{l}\text { Population } \\
\text { density (persons } \\
\text { per square } \\
\text { kilometer) }\end{array}$ & $\begin{array}{l}\text { Poverty incidence } \\
\text { (\%) (national } \\
\text { standard poverty } \\
\text { incidence) }\end{array}$ \\
\hline $\begin{array}{l}\text { People's Republic of } \\
\text { China }\end{array}$ & $1,340,910$ & $9,600.0$ & 139.7 & 13.1 \\
\hline Beijing & 19,612 & 6.4 & 1166.8 & - \\
\hline Yunnan & 46,016 & 394.1 & 116.6 & - \\
\hline Kunming & 6,439 & 21.5 & 298 & - \\
\hline Xishuangbanna & 1,135 & 19.2 & 57.5 & - \\
\hline $\begin{array}{l}\text { Lao People's } \\
\text { Democratic Republic }\end{array}$ & 6,256 & 236.8 & 26 & $33.9(34.7)$ \\
\hline Vientiane & 769 & 3.9 & 196 & $(16.8)$ \\
\hline Luang Namtha & 164 & 9.3 & 18 & $(22.8)$ \\
\hline Bokeo & 166 & 6.2 & 27 & $(21.1)$ \\
\hline Myanmar & 59,780 & 676.6 & 88 & $(25.6)$ \\
\hline Yangon & 5,440 & 10.2 & 534.9 & $(16.1)$ \\
\hline Shan & 5,660 & 155.8 & 36.3 & $(33.1)$ \\
\hline Shan East & - & - & - & $(46.4)$ \\
\hline Thailand & 67,313 & 513.1 & 131.2 & $0.4(14.4)$ \\
\hline Bangkok & 6,877 & 1.6 & 4297.9 & $(1.7)$ \\
\hline Chiang Rai & 1,214 & 11.7 & 103.7 & $(20.2)$ \\
\hline Chaiang Mai & 1,605 & 20.1 & 79.9 & $(20.2)$ \\
\hline Vietnam & 86,928 & 331.0 & 268.0 & $16.9(14.2)$ \\
\hline Hanoi & 6,562 & 3.3 & $1,961.9$ & $(5.3)$ \\
\hline
\end{tabular}

$-=$ no data.

Notes:

1. Poverty incidence means poverty headcount ratio at $\$ 1.25$ a day (\% of population [PPP]) and is provided by the World Bank Database.

2. The national poverty line of Laos corresponds to the per capita expenditure required to purchase 2,100 Kcal per person per day (Epprecht, Minot, Dewina, Messerli, and Heinimann 2008). The data is calculated based on the Lao expenditure and consumption survey from 2002-2003and the Lao population and housing census from 2005.

3. Myanmar's poverty line is a minimum of food and non-food expenditure based on the consumption patterns of the second quartile of the consumption distribution.

4. The national poverty line of Thailand corresponds to the per capita expenditure required to purchase the calories required per person per day. Bangkok, Chiang Rai, and Chiang Mai's data is from 2002, and Chiang Rai and Chiang Mai's data is the North region's poverty rate.

5 . Vietnam's poverty rate is calculated by the monthly average income per capital per household. The government poverty line is 400,000 dongs (about US $\$ 21$ [calculated by $\$ 1=18,612.9$ dongs]) for the rural area and 500,000 dongs (about US\$26) for the urban area.

Source: PRC data: China Statistical Yearbook (2011); Beijing data: Beijing Statistical Yearbook (2011); Yunnan, Kunming, and Xishuangbanna data: Yunnan Statistical Yearbook (2011); Lao PDR, Vientiane, Luang Namtha, and Bokeo data: Lao Statistical Yearbook (2010); Myanmar data: ADB "Key Indicators for Asia and Pacific 2013," Myanmar Statistical Yearbook (2011), Integrated Household Living Conditions Survey in Myanmar (2009-2010); Thailand, Bangkok, Chiang Rai, and Chiang Mai data: National Economic and Social Development Board (NESDB); Vietnam and Hanoi data: Vietnam Statistical Handbook (2010), (2011), Hanoi Statistical Yearbook (2010). 
Bangkok and Hanoi. Since the total population of TLMY is about $180,000,000$ and the population growth is still high, we can say that the economic potential of the TLMY market is high.

In terms of the population density, Bangkok is very high $\left(4,297.9\right.$ persons $\left./ \mathrm{km}^{2}\right)$; this causes various problems such as bad traffic, environment pollution, and so on. In the GQ, Kunming has the highest population density $\left(298\right.$ persons $/ \mathrm{km}^{2}$ ). On the other hand, Lao's population density $\left(26\right.$ persons $\left./ \mathrm{km}^{2}\right)$ is the lowest in TLMY, and Luang Namtha has the lowest population density in the GQ area (18 persons $/ \mathrm{km}^{2}$ ). Chiang Rai has the second-highest population density (103.7 persons $/ \mathrm{km}^{2}$ ).

Myanmar has the largest land area in TLMY. Its large land area and abundant natural resources are attractive for economic development.

Laos has the highest poverty incidence (33.9 percent), except for Myanmar, using the World Bank's standard (income level below $\$ 1.25$ per day). By national standards, the poverty incidence is 16.8 percent in Vientiane, 22.8 percent in Luang Namtha, and 21.1 percent in Bokeo (Epprecht et al. 2008). In contrast, the poverty incidence is very low in Thailand by the World Bank's standard (0.4 percent). By the national standard, however, the poverty rate is 14.4 percent for the whole country; 1.7 percent in Bangkok; and 20.2 percent in the North area, which includes Chiang Mai and Chiang Rai (NESDB). Although the Thai poverty rate has decreased recently and is lower than the rates of China, Laos, Myanmar, and Vietnam, it remains high in the local area (Jitsuchon and Richter 2007). Myanmar has only the national standard poverty incidence. In Shan East, which is included in the GT area, the poverty rate exceeds the national average (Epprecht, Minot, and Dewina 2011). We could say that the GQ area has a higher poverty rate than each country's average.

Table 8.3 provides the income levels and the economic structure. There is a gap among TLMY. The Thai GDP is the largest among TLMY at $\$ 338$ billion, which is more than double that of Yunnan at $\$ 106.7$ billion and fifty times that of Laos at $\$ 6.7$ billion. Vietnam's GDP is equal to that of Yunnan Province.

Thailand has the highest GDP per capita $(\$ 5,021)$, while Myanmar has the lowest (\$811), which is one sixth that of Thailand. Myanmar and Laos are classified as a low-income country and a lower middle income country, respectively, while Thailand and China are classified as upper middle income countries. As TLMY have different income levels, if these countries reinforce their economic ties, they could construct complementary relationships. For example, in the production process of automobiles, the unskilled labor-intensive process could be located in low-income countries such as Laos and Myanmar, and the skilled labor-intensive process could be located in high-income countries such as Thailand and China. In this way, a firm can separate the production process into narrow areas. Moreover, the differences in the industrial structures of the two countries lead to the dispersion of economic risk.

In the GQ area, Kunming's GDP per capita is the highest $(\$ 4,864)$, and that of Chiang Mai is the second highest $(\$ 3,185)$. On the other hand, Myanmar and Laos are at a very low level $-\$ 811$ and $\$ 1,077$, respectively. We should note that 
Table 8.3 Income levels and economic structure (2010)

\begin{tabular}{|c|c|c|c|c|c|c|}
\hline \multirow{2}{*}{$\begin{array}{l}\text { Location and/ } \\
\text { or area }\end{array}$} & \multirow{2}{*}{$\begin{array}{c}G D P \\
\text { (billions } \\
\$)\end{array}$} & \multirow{2}{*}{$\begin{array}{c}G D P / c a p \\
(\$)\end{array}$} & \multicolumn{3}{|c|}{ Structure of production (\%) } & \multirow{2}{*}{$\begin{array}{l}\text { Export/ } \\
G D P(\%)\end{array}$} \\
\hline & & & Agriculture & Industry & Services & \\
\hline $\begin{array}{l}\text { People's } \\
\text { Republic of } \\
\text { China }\end{array}$ & $5,926.2$ & 4,420 & 10.1 & 46.8 & 43.1 & 26.7 \\
\hline Beijing & 208.5 & 10,630 & 0.9 & 24.0 & 75.1 & 26.6 \\
\hline Yunnan & 106.7 & 2,319 & 15.3 & 44.6 & 40.0 & 7.1 \\
\hline Kunming & 31.3 & 4,864 & 5.7 & 45.3 & 49.0 & 17.0 \\
\hline Xishuangbanna & 2.4 & 2,086 & 27.3 & 29.7 & 42.9 & 3.2 \\
\hline $\begin{array}{l}\text { Lao People's } \\
\text { Democratic } \\
\text { Republic }\end{array}$ & 6.7 & 1,077 & 28.8 & 28.0 & 37.2 & 32.6 \\
\hline Vientiane & 1.5 & 1,320 & 16.6 & 45.0 & 38.4 & - \\
\hline Luang Namtha & - & - & - & - & - & - \\
\hline Bokeo & - & - & - & - & - & - \\
\hline Myanmar & 49.5 & 811 & 36.9 & 26.5 & 36.7 & 13.0 \\
\hline Shan & - & - & - & - & - & - \\
\hline Thailand & 338.0 & 5,021 & 10.5 & 46.9 & 40.1 & $\mathbf{5 7 . 2}$ \\
\hline Bangkok & 98.0 & 14,256 & 0.1 & 18.3 & 18.3 & - \\
\hline Chiang Rai & 2.3 & 1,862 & 33.8 & 12.0 & 49.0 & - \\
\hline Chiang Mai & 5.1 & 3,185 & 21.6 & 16.9 & 53.6 & - \\
\hline Vietnam & 115.9 & 1,334 & 18.9 & 38.2 & 42.9 & 60.2 \\
\hline Hanoi & 37.0 & 2,004 & - & - & - & 61.1 \\
\hline
\end{tabular}

Notes:

1. Vientiane's data is from 2008 and is based on Nolintha (2011).

2. Exports are provided by the International Monetary Fund (IMF), Direction of Trade Statistics (DOT) and calculated by the author.

3. GDP of the People's Republic of China, Beijing, Yunnan, Kunming, and Xishangbanna is calculated at $\$ 1=6.77$ Yuan. GDP of Myanmar is calculated at $\$ 1=802.9$ Kyats. GDP of Thailand, Bangkok, Chiang Rai, and Chiang Mai is calculated at $\$ 1=31.69$ Thailand Bhats (THB). GDP of Vietnam is calculated at $\$ 1=18,612.9$ dong.

Source: PRC data: China Statistical Yearbook (2011); Beijing data: Beijing Statistical Yearbook (2011); Yunnan, Kunming, and Xishuangbanna data: Yunnan Statistical Yearbook (2011); Lao PDR, Vientiane, Luang Namtha, and Bokeo data: Lao Statistical Yearbook (2010); Myanmar data: ADB "Key Indicators for Asia and Pacific 2013," Myanmar Statistical Yearbook (2011), Integrated Household Living Conditions Survey in Myanmar (2009-2010); Thailand, Bangkok, Chiang Rai, and Chiang Mai data: NESDB; Vietnam and Hanoi data: Vietnam Statistical Handbook (2010), (2011), Hanoi Statistical Yearbook (2010).

most of the GQ provinces and cities have lower GDP per capita than the corresponding national level. Particularly in Thailand, there is a large gap in income levels between Bangkok (\$14,256) and Chiang Rai $(\$ 1,862)$.

TLMY have different industrial structures. In Thailand and Yunnan, GDP of industry is larger than agriculture's GDP, while in Myanmar and Laos, GDP of agriculture is larger than industry's GDP. Generally speaking, the productivity 
of industry is higher than that of agriculture. Therefore, if an international specialization is formed and industrialization is advanced in the GQ, it would build up workers' income levels in Myanmar and Laos.

At $\mathbf{5 7 . 2}$ percent, Thailand's export-GDP ratio is the highest in TLMY. The Thai economy depends heavily on foreign countries. In contrast, Myanmar's export-GDP ratio is very low owing to the economic sanctions imposed against it. However, in late 2012, these economic sanctions were almost lifted; therefore, Myanmar's exports are now expected to rise considerably. At 7.1 percent, Yunnan's export-GDP ratio is the lowest in TLMY and lower than that of Beijing, mainly because Yunnan is an inland area and is far away from a trade port. If the railway from Kunming to Hanoi and Vientiane and the highway to Bangkok and Yangon are completed, then we would expect the level of trade from Yunnan to expand.

Figure 8.2 shows the monthly wage of workers and middle managers in the major cities. The wage in Beijing and Bangkok is almost the same, and Vientiane and Hanoi's wage is also almost the same. Vientiane and Hanoi's wage is about one third that of Beijing and Bangkok, and Yangon's worker wage is the lowest - less than half of that of Vientiane and Hanoi. The middle manager wage for Bangkok and Beijing is almost the same and is higher than that of other cities, and Vientiane's middle manager wage is the same as that of Yangon. Hanoi's wage is higher than in the other two big cities.

We compare the average wages between the big cities (Bangkok, Beijing, and Hanoi) and the local cities (Chiang Rai, Chiang Mai, Yunnan, and Lai Chau) in

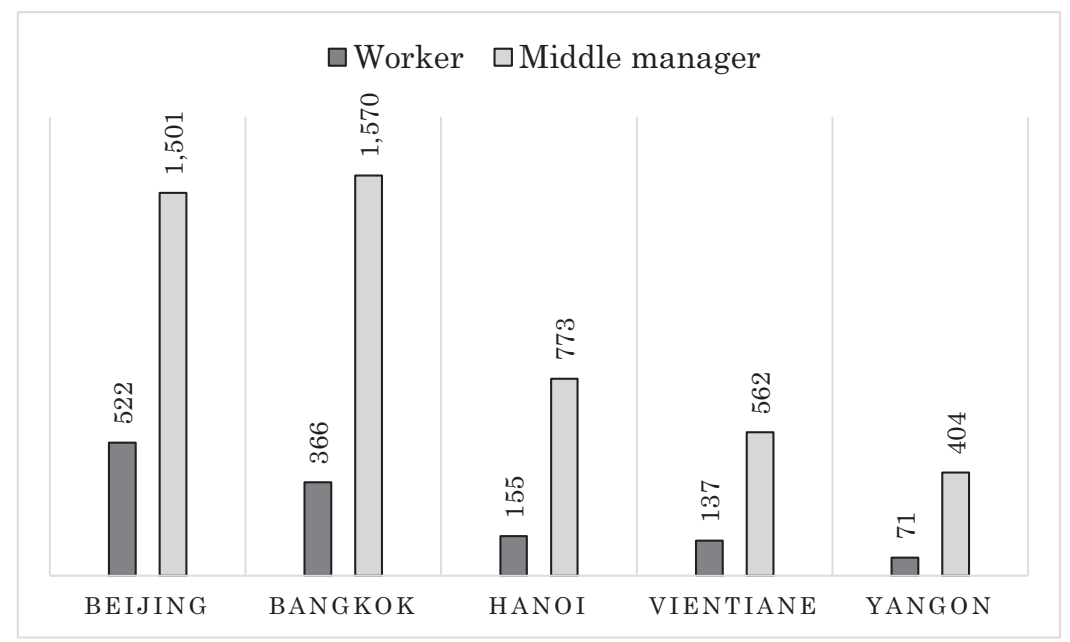

Figure 8.2 Monthly wages of workers and middle managers

Source: Japan External Trade Organization (JETRO) (2014). 
Figure 8.3. Chiang Rai and Chiang Mai's wage is about one third that of Bangkok in Thailand, and Yunnan's wage is about half of that of Beijing in China. Lai Chau is a Vietnamese border province adjacent to Yunnan and Laos; its wage is one fifth of Hanoi's wage. We could guess that the average wage of local cities is lower than in the big cities. Because the GQ area is a local border area, the wages there are lower than in the big cities for each individual country.

From the aforementioned GQ data, there are three significant features in the GQ area and TMLY. The first feature is the difference in the economic structures, such as the scale of GDP, the level of GDP per capita, the structure of production, and the export-GDP ratio. The difference in economic structure creates a difference in comparative advantage. Myanmar and Laos have low-income, agricultural economies but have a comparative advantage of production with unskilled labor. Thailand and Yunnan have middle-income, industrial economies and have a comparative advantage of production with skilled labor. A company can reduce factories' production costs because of this comparative advantage.

The second feature is the difference in wage among TMLY. The wage of Laos and Myanmar is lower than that of Thailand and Yunnan, but their economic systems, such as the financial and trade systems, are inferior compared with those of Thailand and Yunnan. If the movement of labor is opened up, the low-wage labor force of Laos and Myanmar could work in a strong economic system like

(Unit: \$)

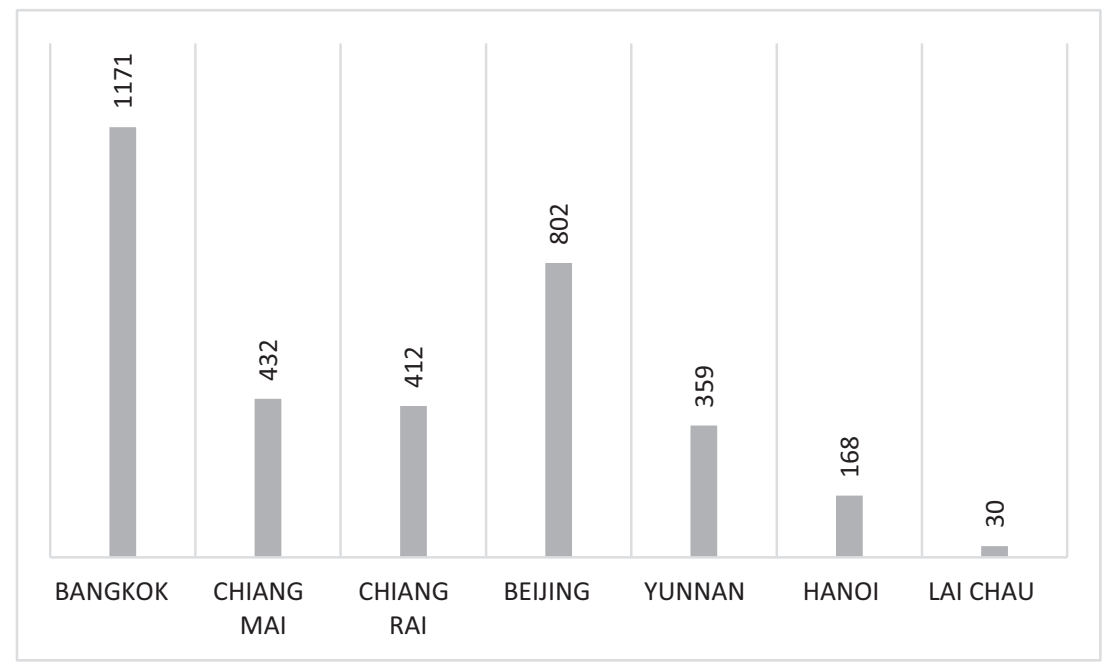

Figure 8.3 Comparing the average monthly wages between big cities and local cities

Source: Thailand in Figures (2012); Statistical Yearbook of Vietnam (2011); China Statistical Yearbook (2011).

Note: Thai data is from 2008; Vietnam's data is from 2010; Chinese data is from 2010. 
the systems in Thailand and China. Moreover, the wage around the GQ is lower than in the big cities of each country, so it makes the GQ attractive as a location for factories.

The third feature is the high poverty incidence. Sadly, the poverty incidence around the GQ is higher than in other areas of each country. This is because of the poor accessibility to the big cities. If their infrastructure is improved and many factories move to the GQ, consumption would increase, leading to higher income levels and a reduction in poverty levels.

\section{Progress of the Greater Mekong Subregion Program}

\subsection{Overview of the GMS Program}

The GMS is a natural economic area bound together by the Mekong River that encompasses 2.6 million $\mathrm{km}^{2}$ and has a combined population of around 326 million. The GMS Program includes Cambodia, China (specifically Yunnan Province and the Guangxi Zhuang Autonomous Region), Laos, Myanmar, Thailand, and Vietnam. It commenced in 1992. The ADB took the initiative to promote the GMS Program. The objective of the Program is to promote subregional economic cooperation and enhance economic relations among the countries. To achieve these objectives, it covers nine priority sectors: agriculture, energy, environment, human resource development, investment, telecommunications, tourism, transport infrastructure, and transport and trade facilitation.

The first priority sector in the Program is the transport infrastructure sector. Many regions of the GMS Program countries lie inland. Therefore, highway construction and improvements to facilitate access among countries are high-priority tasks. This Program brought about the construction of three main economic corridors (see Figure 8.4): the North-South Economic Corridor, which is the most important corridor for the GQ; the East-West Economic Corridor; and the Southern Economic Corridor. These corridors promote trade and improve logistics (ADB 2009). Their routes are detailed in the following sections.

\section{The North-South Economic Corridor (NSEC)}

The NSEC is the backbone of the GMS Program corridor network, as it lies at the center of the region and intersects all the other eight GMS corridors. The NSEC connects Kunming (China) with Bangkok (Thailand) and Kunming (China) with Hanoi (Vietnam) and Haiphong (Vietnam). The Kunming-Bangkok Route separates into two routes (the Laos Route and the Myanmar Route) at Menyang (China) and joins up again at Chiang Rai (Thailand).

The Laos Route runs as follows: Kumming (China, Yunnan Province) to Menyang (China), Boten (Laos), Houayxay (Laos), Chiang Khong (Thailand), Chiang Rai (Thailand) and, finally, Bangkok (Thailand). 


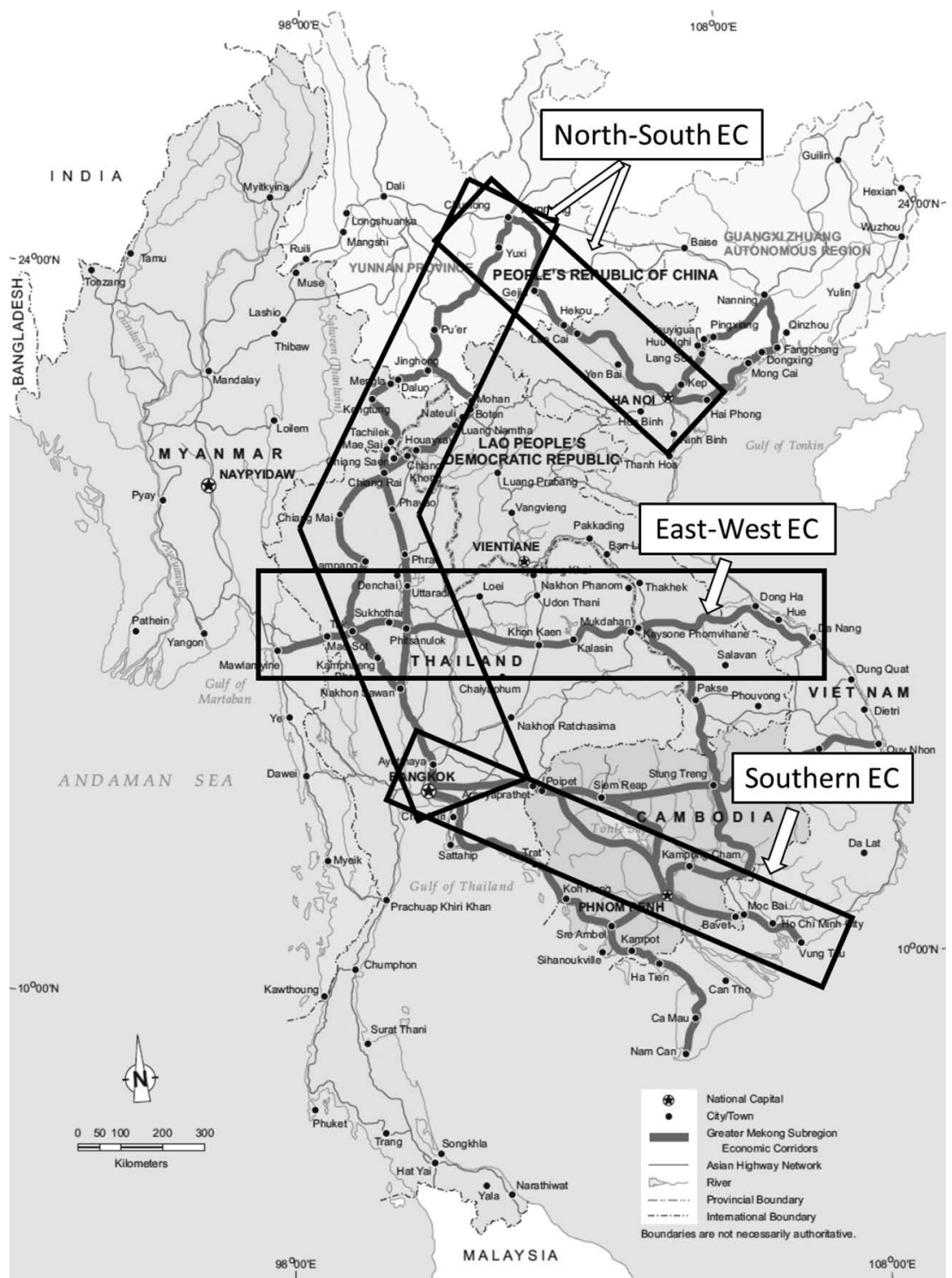

Figure 8.4 Economic corridors being built under the GMS Program Source: The author based this on Asian Development Bank (2010).

The Myanmar Route runs as follows: Kumming (China, Yunnan Province) to Menyang (China), Jinghong (China), Kengtung (Myanmar), Tachileik (Myanmar), Mae Sai (Thailand), Chiang Rai (Thailand) and, finally, Bangkok (Thailand). 
The Kunming-Haiphong Route runs as follows: Kumming (China, Yunnan Province) to Hekou (China, Yunnan Province), Lao Chai (Vietnam), Hanoi (Vietnam) and, finally, Haiphong (Vietnam).

The NSEC project will be close to completion when the Houayxay-Chiang Kong Mekong River Bridge (also known as the Fourth Thai-Lao Friendship Bridge) is built. Therefore, the NSEC nearly runs through the GT and undoubtedly plays an important role for this area.

\section{The East-West Economic Corridor (EWEC)}

The EWEC connects Mawlamyine (Myanmar) and Da Nang (Vietnam) and works as the land bridge of Indochina. The EWEC bisects four of the six GMS Program countries. Its route is as follows: Mawlamyine (Myanmar) to Myawaddy (Myanmar), Mae Sot (Thailand), Mukdahan (Thailand), Kaysone (Laos), Dansavanh (Laos), Lao Bao (Vietnam), and Da Nang (Vietnam).

\section{The Southern Economic Corridor (SEC)}

The SEC links Dawei (Myanmar), Bangkok (Thailand), Phnom Penh (Cambodia), and Ho Chi Minh City (Vietnam). According to many studies, the SEC is likely to become one of the major trade corridors of the GMS Program because this corridor connects big cities. The route is as follows: Dawei (Myanmer) to Bangkok (Thailand), Phnom Penh (Cambodia), Ho Chi Minh City (Vietnam), and Vung Tau (Vietnam).

Moreover, the GMS Program also facilitates the construction of bridges and new airports and the refurbishment of trading ports. This physical infrastructure improves transport in Indochina. The Thai-Lao Friendship Bridges in particular encourage trade between Thailand and Laos. The Second Thai-Lao Friendship Bridge connects Mukdahan Province in Thailand with Savannakhet in Laos on the EWEC. The bridge was opened to traffic in 2006, and the cost of construction was $\$ 70$ million; it was funded by the Japanese government. The bridge drastically reduces the time of transport from Bangkok in Thailand to Hanoi in Vietnam. The Third Thai-Lao Friendship Bridge connects Nakhon Phanom Province in Thailand with Thakhek, Khammouane, in Laos and was opened to traffic in 2011. This third bridge also improves transport between Bangkok and Hanoi by way of Vientiane in Laos.

In order to ensure its smooth implementation, the GMS Program allows projects that are consented to by only two countries (i.e. consensus from all the other countries is not necessary), unless it can also benefit the other countries. Moreover, the Program minimizes red tape as much as possible. The countries have already gathered good momentum, and various discussions about infrastructure, trade rules, and enabling environments to help develop their areas of interest have taken place.

Improvement of the infrastructures of GMS countries substantially facilitates transport in this area. However, the GMS Program needs to improve the software 
infrastructure to facilitate transportation further. The Cross-Border Transportation Agreement (CBTA) agrees to simplify immigration and customs formalities to facilitate the movement of goods and humans over the border in GMS countries. The CBTA was signed in 2007, but the range of applications is limited because of the lack of agreement and preparations for a new system operation in each individual country.

"Single-stop custom inspection" and "single-window custom inspection" are important institutions in the CBTA. Usually, when people transport goods over the border, they have to be checked twice: once at the exporting country and then again at the importing country. Additionally, to cross a border, there are different proceedings at each window with respect to people, goods, and money. A single-window custom inspection would consolidate these proceedings. As trade among the countries is clearly on the rise, the importance of single-stop custom inspection and single-window custom inspection is paramount to assist in facilitating trade between GMS countries.

The GMS Program started in 1992, so it has already been running for more than two decades. Although the improvement of physical infrastructure has been a high priority, the improvement of soft infrastructure plays a role that is as important as physical infrastructure. GMS countries need to develop human resources to improve soft infrastructure. Improvements in physical and soft infrastructure will make the business environment more attractive in the GMS area.

\subsection{Development of the GQ area by the GMS Program}

The GMS Program has also increased development around the GQ area. In this section, we focus on the various projects in the GQ area. In the GQ area, the improvement of physical infrastructure has been implemented preferentially in the same way as other GMS areas (Srivastava and Kumar 2012). One of the most important projects is the NSEC, which connects Kunming (Yunnan Province) to Bangkok (Thailand) and Hanoi (Vietnam). It is the first priority of the GMS Program. Laos, Myanmar, and Yunnan are very mountainous areas, and transportation by road is time consuming and dangerous. There are two routes from Kunming to Chiang Rai (Thailand): the Myanmar Route and the Laos Route. Both routes used to be clay roads, but now most of the route has been paved and expanded, thus helping people traverse the same distance in half the time. Further improvements to the road surface and expansion of traffic lanes are currently underway (Figure 8.5).

The NSEC includes the second Mae Sai Bridge, which has already been constructed between Mae Sai (Thailand) and Tachileik (Myanmar) as part of the GMS Program. This bridge is used by load-carrying vehicles only. Figure 8.6 shows the new customs house in Mae Sai, which introduced single-stop custom inspection. Because the first Mae Sai Bridge was a comparatively smaller bridge, the second bridge will increase the volume of border trade between Thailand and Myanmar.

The Fourth Thai-Lao Friendship Bridge, which was the last big project along the NSEC and opened in December 2013, directly connects road travelers to the 


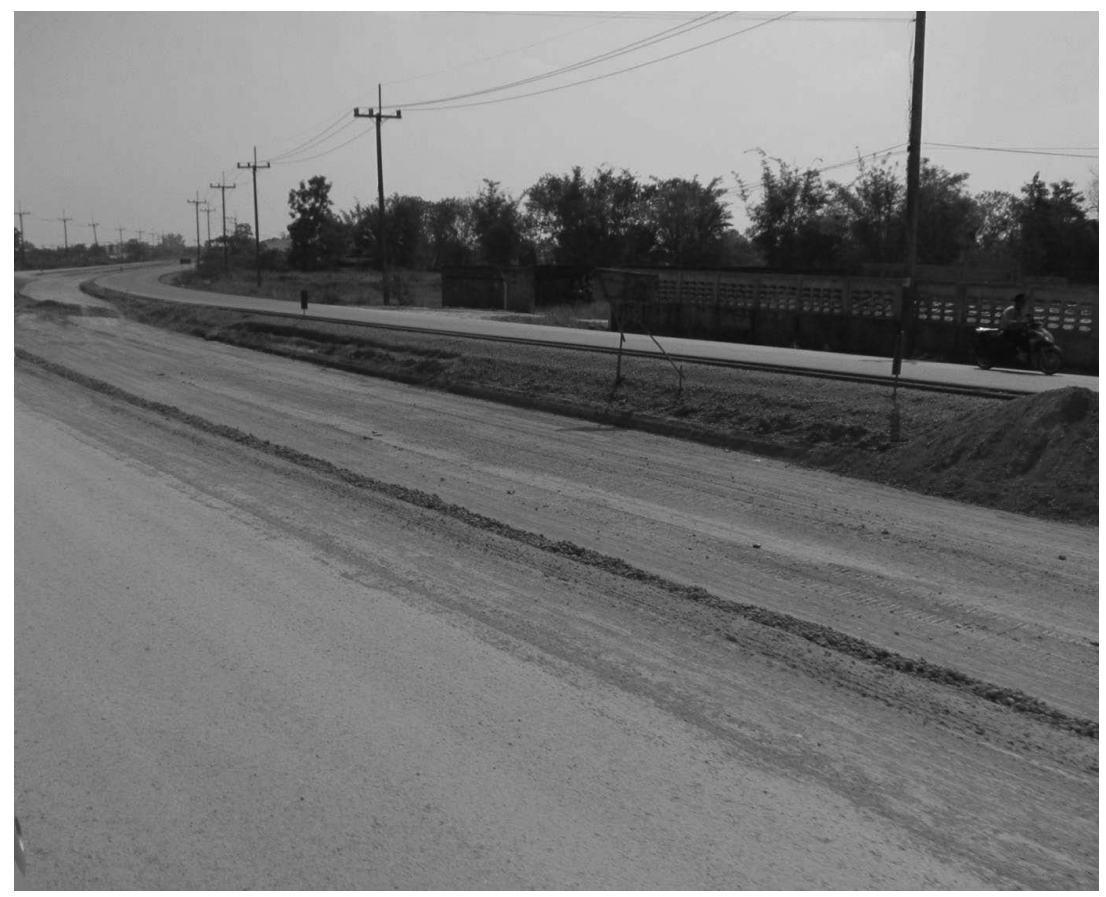

Figure 8.5 Road expansion in Mae Sai

Source: Author.

Laos Route between Kunming (Yunnan) and Chiang Rai (Thailand). The lack of a bridge on the border between Chiang Khong (Thailand) and Houeixay (Laos) over the Mekong River required people to switch from car to ship in order to cross the river. Therefore, this bridge dramatically facilitates transport in this area. The construction cost of the bridge was about 160 million Thai Bahts (THB) and was financed by the Thai and Chinese governments. This indicates the high level of interest of the Chinese government in this area.

The Fourth Thai-Lao Friendship Bridge is expected to stimulate border trade between Thailand and Laos. In fact, the First, Second, and Third Thai-Lao Friendship Bridges have already stimulated border trade. Figure 8.7 shows the border trade volume between Thailand and Laos in the northeastern area of Thailand. The First Thai-Lao Friendship Bridge was constructed in 1994 between Nong Kai in Thailand and Vientiane in Laos, and the trade volume using this first bridge is the largest in the northeastern area in Thailand. In 2007, however, the Second Friendship Bridge was constructed between Mukdahan in Thailand and Savannakhet in Laos, and the trade volume here expanded to become the largest volume between 2011 and 2013. Moreover, in 2011, the Third Thai-Lao 


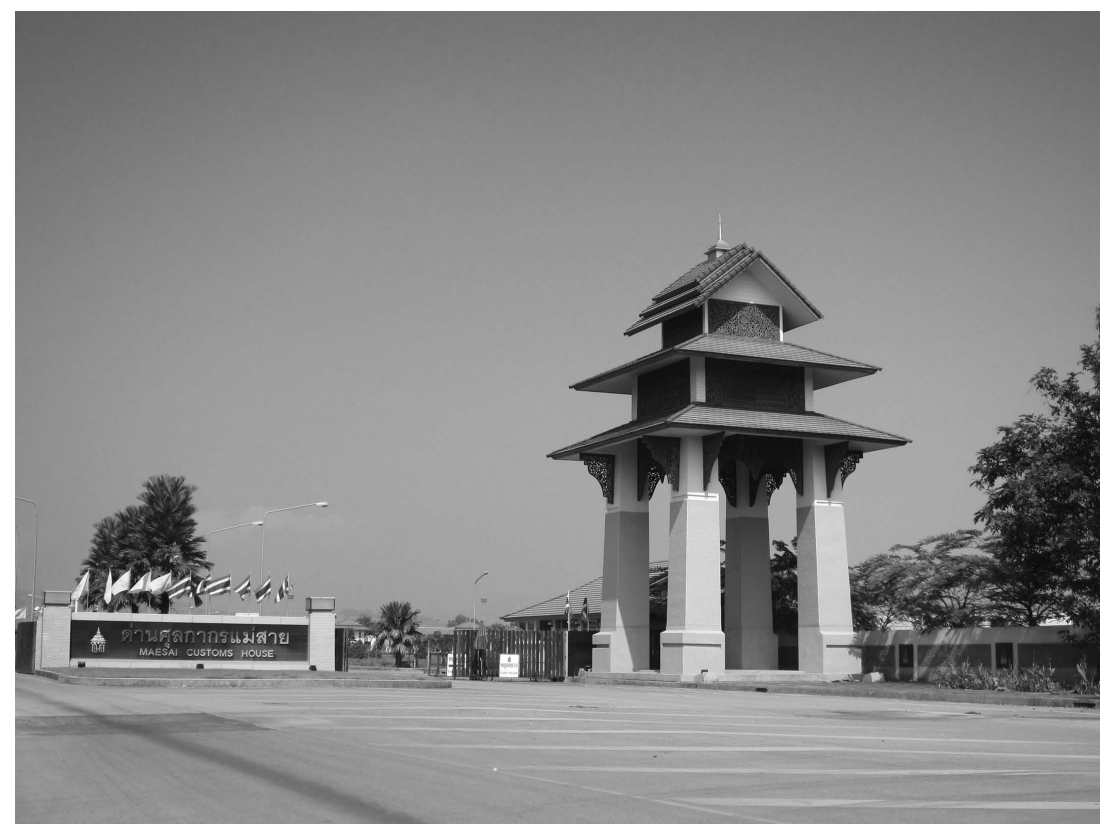

Figure 8.6 The New Mae Sai customs house

Source: Author.

Friendship Bridge was constructed between Nakhon Phanom in Thailand and Khammouane in Laos, and the trade volume of Nakhon Phanom increased 64 percent in 2012 and became the largest volume in 2014.

Figure 8.8 shows the trade volume by region in Thailand. Because the southern area has already been developed and has a large population, the trade volume here is the largest in Thailand (Limskul 2007). The northeastern area had the smallest trade volume in 2003, but in 2012 the trade volume expanded to 7.4 times as much as in 2003. It is believed that the development of infrastructure and the expansion of manufacturing activity contributed to the trade expansions in this area. Conversely, the trade volume of the northern area has stagnated. Infrastructure improvements have not as yet led to any additional trade activity for the northern area.

One of the reasons for the trade stagnation in northern Thailand is its low accessibility around the GQ area. This problem can only be resolved by improvements in infrastructure. Since 1992, the GMS Program has encouraged the improvement of infrastructure. There are three routes for logistics from Kunming to Chiang Rai (Swe and Chambers 2011): the Laos Route, the Myanmar Route, and the Mekong River Route. Because both the Laos and Myanmar Routes are in mountain areas, the expansion and planning of the roads need to 


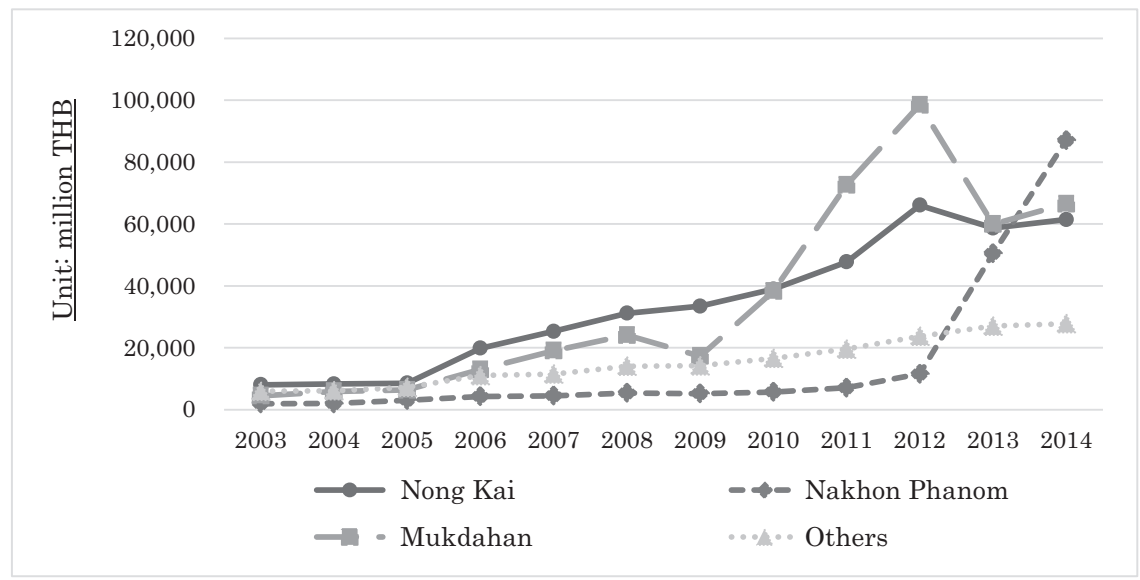

Figure 8.7 Trade volume with Laos by customs in northeastern Thailand

Note: Exchange rate is 39.59 THB (per US\$) at end of 2003 and 32.89 THB at end of 2014. Source: Bank of Thailand, Northeastern Office.

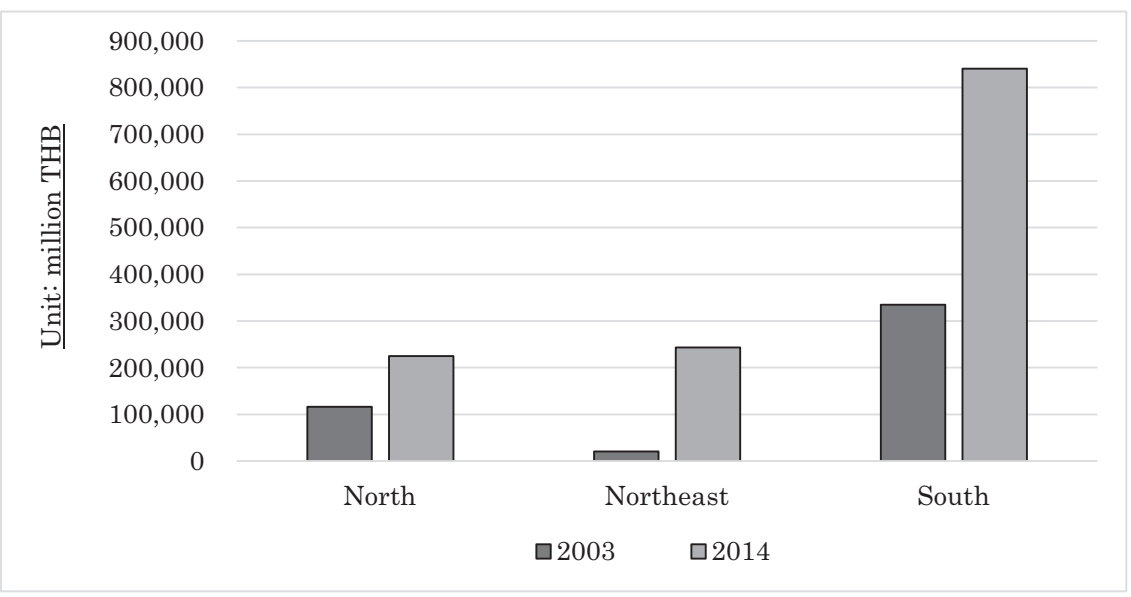

Figure 8.8 Trade volume of Thailand by region

Note: Exchange rate is 39.59THB (per US\$) at end of 2003 and $32.89 \mathrm{THB}$ at end of 2014. Source: Bank of Thailand, Northern, Northeastern, and Southern Offices. 
be effective. The Myanmar Route is unattractive because of political instability and cumbersome bureaucracy. On the other hand, the Mekong River has shallow water, meaning that large vessels cannot run on the river. However, the second Chiang Saen port has been constructed, and this is expected to lead to an expansion of trade between Thailand and Yunnan Province.

\section{Enhancing partnerships with foreign countries}

\subsection{The expansion of FTAs in ASEAN}

During the last decade, many countries have signed FTAs with ASEAN, which has led to substantial tariff cuts and the consequent promotion of trade among these countries. All GMS Program countries are ASEAN members, with the exception of Yunnan Province and the Guangxi Zhuang Autonomous Region. ASEAN aspires to follow in the steps of the EU and achieve its own free trade economic zone called AFTA. AFTA was established in 1993 and included the ASEAN-6 (Thailand, Singapore, Malaysia, Indonesia, the Philippines, and Brunei), which enacted zero tariff rates on virtually all imports by 2010. Tariff cuts for the late-joining countries (Vietnam, Myanmar, Laos, and Cambodia) have been effective since 2006, with the tariffs slated to reduce to zero by the end of 2015. Moreover, ASEAN has already concluded FTAs with Japan, India, Australia, New Zealand, Korea, and China. These FTAs are called ASEAN+1. Moreover, the Regional Comprehensive Economic Partnership (RCEP), which includes ASEAN, Japan, China, Korea, India, Australia, and New Zealand, is currently under negotiation.

In Figure 8.9, we compare GDP of five free trade areas: ASEAN, the RCEP, the North American Free Trade Agreement (NAFTA), the EU, and the Trans-Pacific Partnership (TPP). The TPP has the largest GDP in the five FTA areas. GDP of ASEAN is smaller than one eighth of GDP of the EU. However, GDP of the RCEP is larger than that of NAFTA and the EU.

Moreover, the population of the ASEAN is almost equal to that of NAFTA and the EU (Figure 8.10). This means that the potential growth of ASEAN may exceed that of NAFTA and the EU. Also, the population of the RCEP is 4.29 times as much as the TPP. In terms of population, the RCEP has the largest FTA area in the world. If the RCEP were to be concluded, ASEAN would then include this quite large free trade economic zone.

\subsection{Foreign direct investment in ASEAN}

Recently, many companies have adopted a fragmentation production system whereby the production of products is fragmented across countries. A company adopts this system to produce individual parts of a product in each country. For example, the iPad, a product of Apple Computers, is made in Korea, Japan, Taiwan, and so on. Fragmentation entails subsequent expenditure regarding transportation, communication, tariff duties, and so on. These costs are called service link costs. Infrastructure improvement, through the GMS Program and 
(Unit: billion USD)

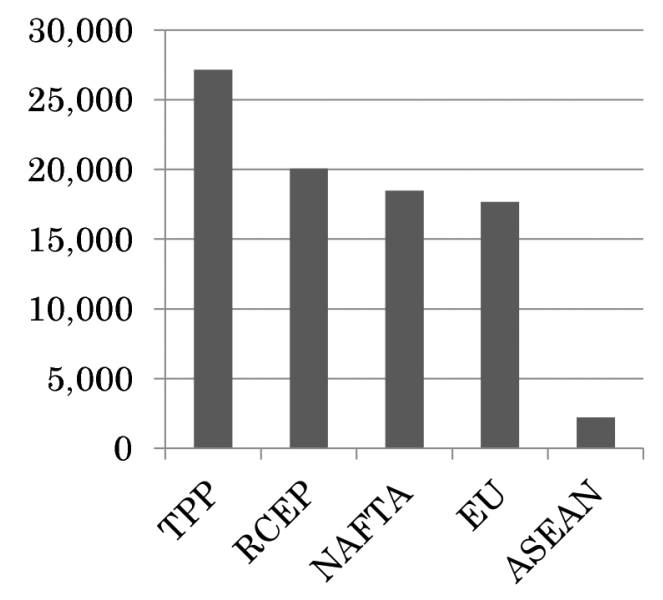

Figure 8.9 Comparing GDP (2011)

Source: IMF, World Economic Outlook (2014).

(Unit: million USD)

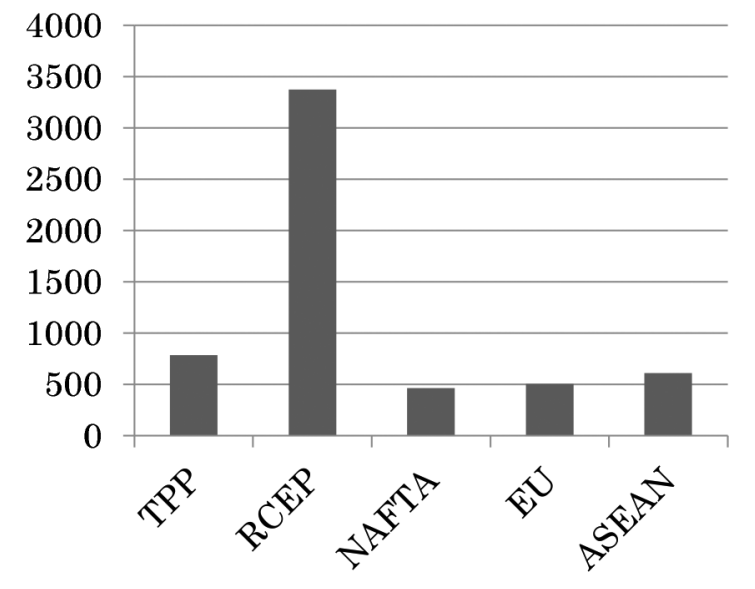

Figure 8.10 Comparing population (2011)

Source: IMF, World Economic Outlook (2014).

the expansion of the FTA network, decreases this service link cost and facilitates the implementation of the fragmentation production system. A stream of a fragmentation system typically comprises many companies from developed countries manufacturing some or all product parts in China and ASEAN countries. 
Figure 8.11 shows FDI to ASEAN between 2008 and 2010. We see an increase in FDI between 2008 and 2010 for all countries/regions. The EU had the largest FDI volume in 2009 and 2010. FDI to Japan and the US was almost the same for all years, and both countries increased FDI to ASEAN. The intraregional investments in ASEAN were higher than those in Japan and the US. In 2010, FDI increased by quite an extent, which could have been a result of the global economic recovery from the financial crisis of 2008.

Figure 8.12 shows the FDI stock of GMS Program countries. The FDI stock of Thailand and Vietnam increased during the 2000s. While the FDI stock of Thailand was the largest (about fifty times the FDI stock of Lao and fifteen times that of Myanmar), it grew at a sluggish pace in 2008, 2009, and 2011. This is probably because of the financial crisis of 2008. Myanmar's FDI, in contrast, grew faster than that of Laos. In 2010, Myanmar's government held the country's first national election in two decades. As the US and other countries recognized this as a step toward democracy, they lifted economic sanctions imposed against Myanmar in 2012 and, consequently, FDI to Myanmar is expected to accelerate.

Figure 8.13 shows the FDI inflow in Thailand, Laos, and Myanmar. We can see that the FDI inflow of Thailand is at a high level during the whole period but has recently stagnated. On the other hand, the FDI inflow of Laos and Myanmar has increased since 2005 .

Figure 8.14 shows the FDI stock-GDP ratio. The GMS Program countries have a high proportion of FDI inflows, which shows the high degree of their dependence on foreign companies. In contrast, the Japanese FDI stock-GDP ratio was only 3.9 percent in 2011. These high FDI numbers and the consequent development of the GMS Program countries can be attributed to their government's policy of opening up their borders to foreign businesses. Thus, the

\section{(Unit: million USD)}

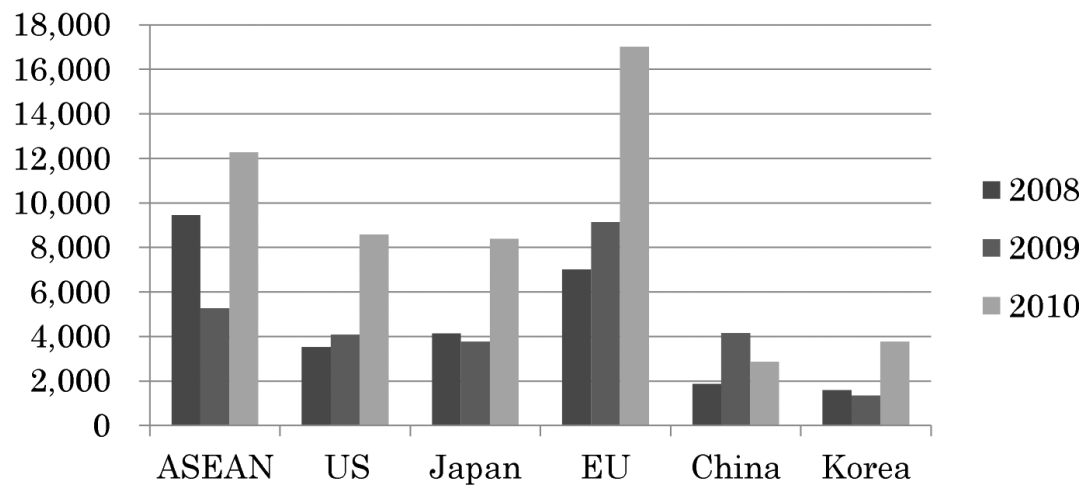

Figure 8.11 FDI inflows to ASEAN by country

Source: ASEAN, Foreign Direct Investment Statistics. 
(Unit: million USD)

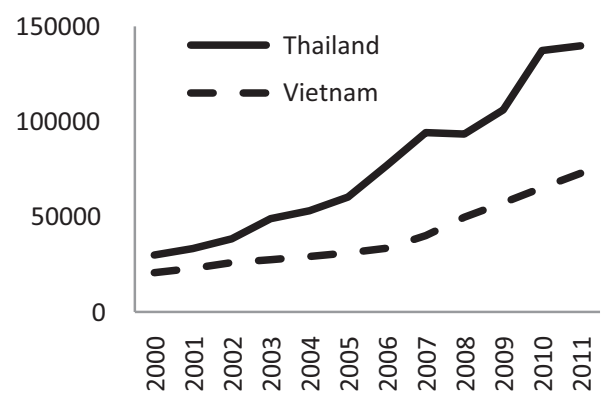

(Unit: million USD)

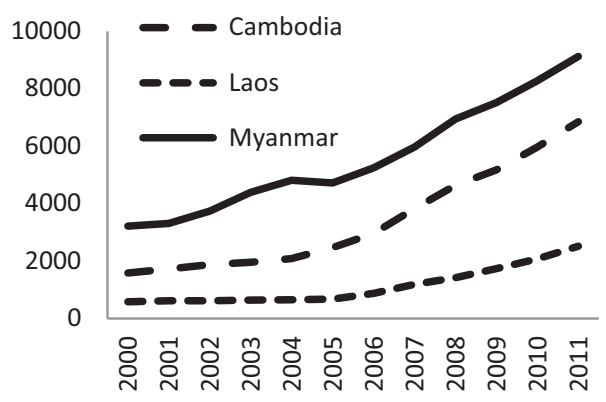

Figure 8.12 FDI stocks of GMS Program countries Source: United Nations Conference on Trade and Development (UNCTAD), UNCTAD STAT.

Note: China is omitted in this graph.

expanding FTA network and the acceptance of foreign companies are important factors for the growth of the economies of GMS Program countries.

\subsection{Rising importance of China in Thailand, Myanmar, and Laos}

In this section, we will discuss the trade partners of Thailand, Laos, and Myanmar (Figure 8.15). Thailand's major export and import partners are ASEAN, China, and Japan. This is because China and Japan are big, and relatively close, consumer markets. Moreover, Japanese companies have recently advanced into Thailand to form a global supply chain (Figure 8.16). As shown in Table 8.3 and Figure 8.15, Thailand's export-GDP ratio is very high, and its trade partners are 
(Unit: million USD)

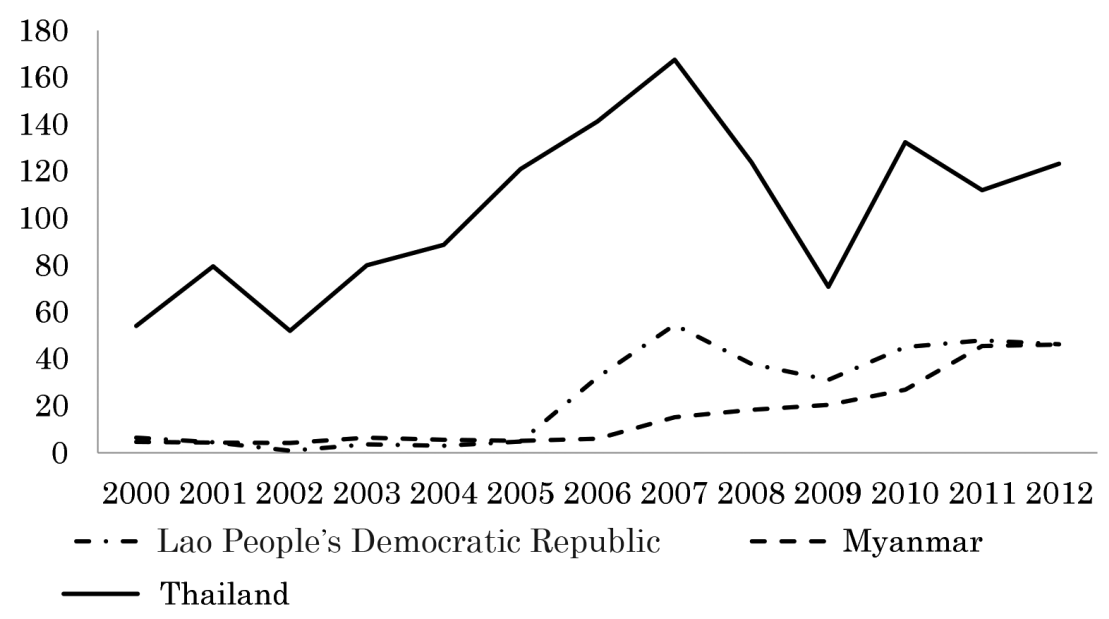

Figure 8.13 FDI inflows in Thailand, Laos, and Myanmar Source: UNCTAD, UNCTAD STAT.

(\%)

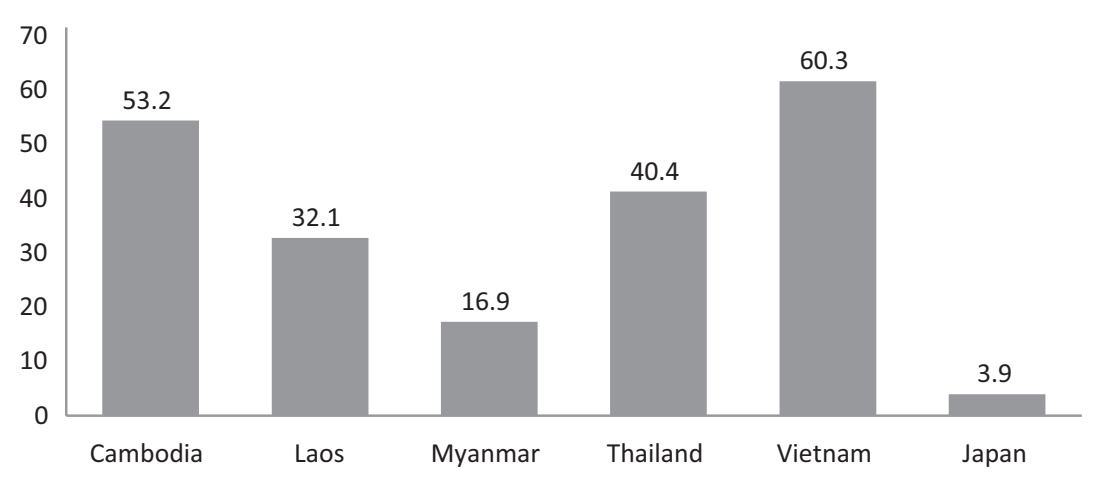

Figure 8.14 FDI stock-GDP ratio (2011) Source: UNCTAD, UNCTAD STAT.

wide ranging. Thailand is becoming the hub of the global supply chain, and the presence of China is increasing there (Figure 8.16).

In Laos and Myanmar, the influence of Thailand and China is very high. The trade share of Thailand and China is over 50 percent in both countries. Myanmar has had economic sanctions imposed on it by Western countries, which increased 

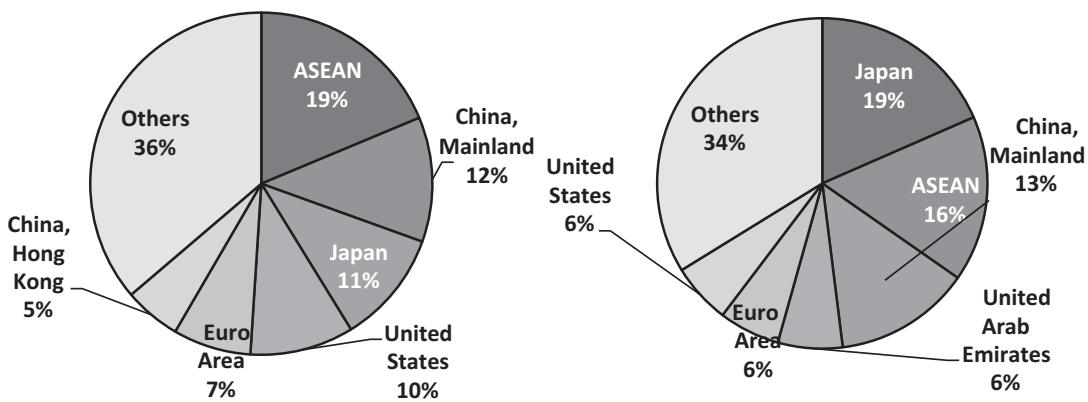

Thailand's Export Share

Thailand's Import Share
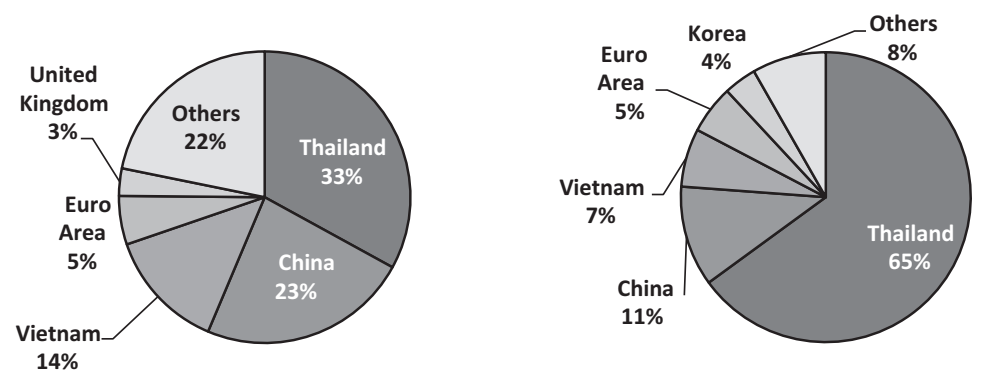

Laos' Export Share

Laos' Import Share
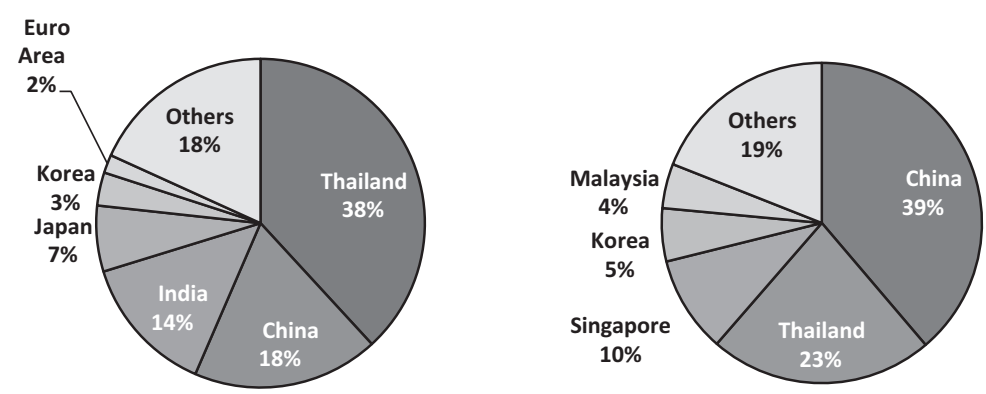

Myanmar's Export Share

Myanmar's Import Share

Figure 8.15 Export and import shares of GT countries (2011)

Source: IMF, Direction of Trade (2013).

the trade share of China rapidly (Figure 8.16). In contrast, the Japanese share of trade has decreased in three countries (Figure 8.17).

In terms of geography, China is an important country for Thailand, Laos, and Myanmar (TML). The progress of the GMS Program and the RCEP will deepen 
$(\%)$

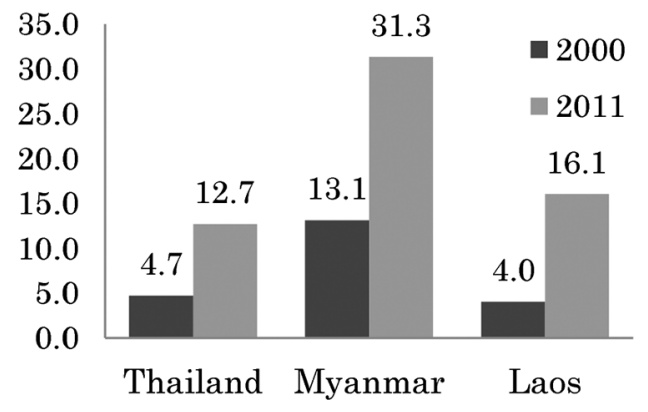

Figure 8.16 China's trade share in Thailand, Laos, and Myanmar

Source: IMF, Direction of Trade (2013).

(\%)

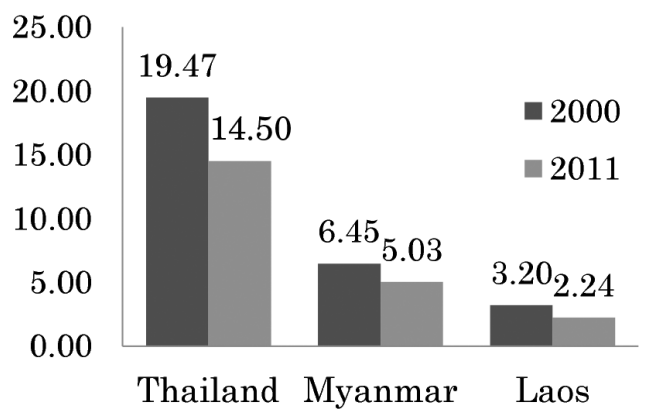

Figure 8.17 Japan's trade share in Thailand, Laos, and Myanmar

Source: IMF, Direction of Trade (2013).

the relationship between TML and China. Additionally, China enjoyed a good economic growth rate during the 2000s, and Chinese GDP ranked second in the world during that decade. Given all these factors, the Chinese influence on TML is likely to intensify in the future.

The development of the GQ area is favorable for China because the Chinese government would like to develop the inland area and reduce the income gap between Beijing and inland rural areas. In fact, some Chinese firms have been operating in the Laos part of the GT area. More Chinese firms are expected to advance into the GQ area in the future. 


\section{Policy recommendations for the development of the GQ}

In this section, we will propose some policies to develop the GQ. In Section 2, we stated that the poverty rate of the GQ area is relatively high and that GDP per capita is low compared to the major cities of the GQ countries. A key reason is accessibility to major cities such as Bangkok and Beijing. We will consider how to conquer this disadvantage for the GQ.

The first policy is the improvement of infrastructure. The disadvantage of the GQ area is its distance from major cities. As we discussed in Section 3, the infrastructure of the GQ has already been improved by the GMS Program. However, there are narrow and rough roads, especially in Myanmar and Laos. The expansion and pavement of the roads will cut down the time that it takes to travel to the big cities. Moreover, the construction of the railroad will also strengthen the transportation power in the GQ. The improvement of soft infrastructure is as important as the hard infrastructure. Single-stop and single-window custom inspection would cut down transportation time drastically these are operated effectively. The development of human resources also plays an important role in the development of soft infrastructure because soft infrastructure, such as single-stop and single-window custom inspection, requires communication skills for joint operation with neighboring countries. The strengthening of human resource development and relationships among GMS countries is needed to operate these systems effectively. A reduction of transportation time will cancel out the disadvantages of the GQ countries.

The second policy is the formulation of the free trade area. The most attractive feature of the GQ area is the close proximity of four countries that have different income levels, development stages, and cultures. This means that countries that have different comparative advantages are gathering in the GQ. We should formulate the free trade area to take advantage of this feature of the GQ.

Recently, many firms adopted fragmentation which distributes the production process with respect to the comparative advantages. For example, an automobile is composed of many components, and an automobile company divides factories by each component depending on the comparative advantage. An automobile company might create a new product or manufacture a complicated engine in Japan and produce the other parts, such as the tires and door panels, in a Southeast Asia country such as Thailand or Malaysia. If the mobility of humans, goods, and money is to be enhanced in the GQ, many fragmentations could be formed in this region. The expansion of the FTAs in ASEAN and the GMS Program has cut service link costs, which is the cost for expanding the production basis. This also encourages the expansion of business in the GQ.

Moreover, in the GQ area, an advanced free economic zone should be formulated. The disadvantage of the GQ area is its distance from major cities. Therefore, small-scale cities in each country should strengthen their economic relationships and form a new economic zone in the GQ area. In the new economic zone, the movement of people, goods, and money is liberalized like in the EU. The 
geographic advantage of the GQ is the close proximity of four countries in a small area with different income levels. In such a location, if an advanced free economic zone could be realized, a global supply chain could be formed in this area.

The formulation of a free economic area would also promote tourist business in the GQ. The GT is already popular as a sightseeing spot - e.g. a casino in Laos is popular for Chinese and Thai people. If the movement of people is liberalized, people could visit four countries freely in several days, and tourist businesses could become successful.

Of course, there are many barriers to the realization of an advanced free trade area. Especially in Myanmar, foreigners cannot move about freely. Therefore, Myanmar's government will not agree to the free trade area at present. Moreover, the drug problem in Myanmar and Laos is also a severe impediment to the liberalization of the movement of goods because this may expand drug trafficking. The eradication of opium production is the immediate priority.

The third policy is the enticement of foreign companies. The formulation of the global supply chain needs advanced product management and great capital resources. It is difficult for a local company to provide these attributes. Therefore, certainly initially, the enticement of foreign companies is important.

Because the Chinese government and companies aim to develop an inland area such as Yunnan Province in China, the advance southward policy to ASEAN areas is important for China. The trade port in Myanmar is nearer than any Chinese trade port. Therefore, Chinese companies have enhanced their influence in ASEAN recently. We think the connection of China and TMLY works well for the GQ area. In fact, some Chinese companies have already made advances in the GQ area.

Some companies from advanced countries such as Japan, the US, and the EU have located offices in big cities such as Bangkok and the surrounding areas. However, if Chinese companies advance more and more in the GQ, other advanced countries' companies would also move aggressively into the GQ. TMLY should create an environment to enhance the FDI of foreign companies.

Finally, political stability is very important for economic development. Political instability delays the development of legal systems and economic agreements that are needed for economic development. Moreover, a foreign company will avoid countries that have political instability. Therefore, political instability needs to be overcome as soon as possible. In fact, political instability in Myanmar has delayed the Myanmar economy severely, and the same issue in Thailand is having a significantly negative impact on the Thai economy. Political instability of one country has a negative impact on all countries in TMLY, the GMS Program countries, and ASEAN.

\section{Conclusion}

In this chapter, we have discussed the possibilities for economic growth in the GQ. The GQ area is located far from the major city of each country, and therefore the poverty rate is comparatively high. Recently, however, owing to the GMS 
Program, the infrastructure of the GMS countries, which include the GQ area, has improved. However, border trade around the GQ has not increased, and the effect of the GMS Program is limited compared with the other areas because of inaccessibility to the big cities. Therefore, the improvement in hard infrastructure is not the only factor needed; improvement in soft infrastructure is also needed. This will come through the development of human resources, simplifying processes and interfusing systems.

In the GQ, there are four countries which have different economic features such as income levels, wage levels, economic structures, and the scale of GDP. This means that the comparative advantage of the GQ is different among TMLY. Moreover, the average wage in the GQ is lower than for other areas. The GQ needs to make full use of these particular characteristics. The area should create an advanced economic zone in which humans, goods, and money can move freely and form a global supply chain in the GQ. For example, a labor-intensive industry could be located in Myanmar or Laos and a capital-intensive industry could be located in Thailand or Yunnan.

It is important to increase the use of FDI in advanced countries' companies that have the know-how to form a global supply chain and great capital resources to assist in its development. If a new economic zone can be developed and foreign companies form a supply chain in the GQ area, jobs will be created, and income levels will be increased in the GQ. The expansion of the ASEAN FTA would also encourage the development of a global supply chain in the GQ.

\section{References}

Asian Development Bank (ADB) (2009), Corridor Chronicles: Profiles of Cross Border Activities in the Greater Mekong Sub-Region. Author: Metro Manila.

Asian Development Bank (ADB) (2010), "Strategy and action plan for the Greater Mekong Sub-Region North-South Economic Corridor," Author: Metro Manila.

Epprecht, Michael, Nicholas Minot and Reno Dewina (2011), Integrated Household Living Conditions Survey 2009-2010, United Nations Development Programme (UNDP) in Myanmar: Yangon, Myanmar.

Epprecht, Michael, Nicholas Minot, Reno Dewina, Peter Messerli and Andreas Heinimann (2008), The geography of poverty and inequality in the Lao PDR, International Food Policy Research Institute and Bern; NCCR North-South: Washington, DC. Japan External Trade Organization (JETRO) (2014), “第24回アジア.オセアニア 主要都市·地域の投資関連コスト比較 [The 24th Survey of Investment Related Costs in Asia and Oceania].” Available from: http://www.jetro.go.jp/world/asia/ reports/07001919 [accessed March 1, 2015]

Jitsuchon, Somchai, and Kasoar Richter (2007), “Thailand's poverty maps: From construction to application," in T. Bedi, A. Coudouel and K. Simler (Eds.), More Than a Pretty Picture: Using Poverty Maps to Design Better Policies and Interventions, World Bank: Washington, DC, 24l-260.

Limskul, Kitty (2007) “A current situation of the East-West Economic Corridor: A case study of Mae Sod border area between the union of Myanmar and the kingdom of Thailand," Working Paper, Chulalongkorn University, Bangkok. 
Nolintha, Vanthana (2011), "Cities, SEZs and connectivity in major provinces of Laos," in M. Ishida (Ed.), Intra- and Inter-City Connectivity in the Mekong Region, Bangkok Research Center, Institute of Developing Economies and Japan External Trade Organization (IDE-JETRO): Bangkok.

Srivastava, Pradeep, and Utsav Kumar (2012), Trade and Trade Facilitation in the Greater Mekong Subregion. Asian Development Bank (ADB): Metro Manila.

Swe, Thein, and Paul Chambers (2011), Cashing In Across the Golden Triangle. Mekong Press: Chiang Mai, Thailand.

\section{Data}

Asian Development Bank (ADB), “Key Indicators for Asia and Pacific 2013," Available from: http://www.adb.org/publications/series/key-indicators-for-asiaand-the-pacific [accessed February 28, 2015]

Association of Southeast Asian Nations (ASEAN), "Foreign Direct Investment Statistics," Available from: http://www.asean.org/news/item/foreign-directinvestment-statistics pacific [accessed February 28, 2015]

Bank of Thailand, Northeastern Office, "Thai - Laos Trade through Customs Houses in the Northeastern Region," Available from: https://www.bot.or.th/English/Sta tistics/RegionalEconFinance/Pages/default.aspx [accessed February 28, 2015]

Bank of Thailand, Northern Office, "Foreign Trade through Customs Houses in the Northern Region," Available from: https://www.bot.or.th/English/Statistics/ RegionalEconFinance/Pages/default.aspx [accessed February 28, 2015]

Bank of Thailand, Southern Office, "Foreign Trade through Customs Houses in the Southern Region," Available from: https://www.bot.or.th/English/Pages/ default.aspx [accessed February 28, 2015]

Beijing Municipal Statistics Bureau, Beijing Statistical Yearbook 2011, China Statistics Press: Beijing.

Epprecht, Michael, Nicholas Minot and Reno Dewina (2011), Integrated Household Living Conditions Survey 2009-2010, United Nations Development Programme (UNDP) in Myanmar: Yangon, Myanmar.

General Statistics Office of Vietnam, "Vietnam Statistical Yearbook 2010," Available from: http://www.gso.gov.vn/default_en.aspx?tabid=515 [accessed August 29, 2014]

General Statistics Office of Vietnam, "Vietnam Statistical Yearbook 2011," Available from: http://www.gso.gov.vn/default_en.aspx?tabid=515 [accessed August 29, 2014]

Government of the Union of Myanmar, Ministry of National Planning and Economic Development, Myanmar Statistical Year Book 2011, Central Statistical Organization: Yangon, Myanmar.

Hanoi Statistical Office, Hanoi Statistical Yearbook 2010, Hanoi Statistical Office: Hanoi, Vietnam.

International Monetary Fund (IMF), "Direction of trade 2013, CD-ROM edition."

International Monetary Fund (IMF), "World Economic Outlook 2014," Available from: http://www.imf.org/external/ns/cs.aspx?id=28 [accessed February 28, 2015]

Lao Statistics Bureau, "Lao Statistical Yearbook 2010," Available from: http://www. nsc.gov.la/ [accessed August 29, 2014] 


\section{Satoko Okuyama}

National Bureau of Statistics of China (2011), China Statistical Yearbook 2011, China Statistics Press: Beijing.

National Economic and Social Development Board of Thailand (NESDB), Office of National Economic and Social Development Board in Thailand. Available from: http://eng.nesdb.go.th/ [accessed March 1, 2015]

National Economic and Social Development Board of Thailand (NESDB), "Thailand's official poverty lines," 2004 International Conference on Official Poverty Statistics: Methodology and Comparability, Manila, Philippines, October 4-6, 2004. Available from: http://www.nscb.gov.ph/poverty/conference/papers/ [accessed March 1, 2015]

Statistical Bureau of Yunnan Province, Yunnan Statistical Yearbook 2011, China Statistics Press: Beijing.

Tera International Company, Thailand in figures 2012, Tera International Company: Bangkok.

United Nations Conference on Trade and Development (UNCTAD), "UNCTAD STAT," Available from: http://unctadstat.unctad.org/EN/Index.html [accessed February 28, 2015]

United Nations Office on Drugs and Crime (2011), "World Drug Report 2011," Available from: http://www.unodc.org/wdr2014/en/previous-reports.html [accessed February 28, 2015] 


\title{
9 Development of the fishery systems in modern Taiwan
}

\author{
Nobutake Koiwa
}

\section{Introduction}

The Taiwanese islands belonged to the Qing dynasty of mainland China for some time. However, Taiwan became part of Japan after the Sino-Japanese War in 1895. Taiwan then became a part of the Republic of China after WWII. Under Japanese rule, the fisheries of Taiwan were modernized, and the foundation of the contemporary fishery systems was laid. ${ }^{1}$

In 1901 in mainland Japan, the government established the Fishery Law, which defined fishery rights and permitted the creation of new fishery associations. Under this new law, only fishers could join fishery associations, and fishery unions were established for merchants and manufacturers of fishery goods. ${ }^{2}$ The Japanese Fishery Law was enacted gradually throughout the country, but the clauses concerning fishery associations were introduced in later revisions of the law. ${ }^{3}$

In Taiwan, regulation of fisheries began in 1912, and adoption of the Japanese Fishery Law came in $1924 .^{4}$ The initial 1912 regulations did not mention fishery associations, meaning that such regulations were not introduced until the Japanese Fishery Law was applied; however, clauses for fishery unions were not included at that time.

The Japanese fishery system had three main characteristics: (1) the fishery rights system, which enabled traditional and local fishery communities to manage the local fishery resources; (2) operation of modern fisheries to avoid conflicts with traditional fisheries; and (3) the establishment of a system that enhanced fishing villages. Because the Japanese Fishery Law allowed the creation of fishery associations in fishing villages, central and local governments were able to assist these villages via the fishery associations.

The first characteristic works well nowadays because fishery activities in local communities are operated and evaluated through coastal fishery resource management strategies. ${ }^{5}$ Of course, there are several other methods of fishery resources management, such as individual quotas (IQs) and total allowable catch (TAC), which are used all over the world, especially in Europe, North and South America, and Oceania. TAC is often operated "Olympic style," where individual boats race to catch as much of the total quota as possible before the fishery closes. ${ }^{6}$ 


\section{Nobutake Koiwa}

The second characteristic was important for the development of modern fisheries. In Japan and neighboring areas, including Taiwan, the Japanese Fishery Law stipulated that modern fisheries operate while avoiding conflict with traditional fisheries. The main purpose of the Fishery Law was to develop fisheries and mediate conflict among fishers. When the Japanese Fishery Law was introduced in Taiwan, these main purposes were carried over.

The third characteristic became important during the serious economic depression of the 1930s. After the Great Depression spread to Japan and neighboring areas, the expectations for fishery associations became enormous, leading to amendments to the Fishery Law to widen the activities of fishery associations.

This paper attempts to clarify the influence that the Japanese fishery system had on the development of fisheries in Taiwan, including how the foundation of Taiwan's fisheries was established and the components that were introduced by Japanese settlers. This paper also discusses the rationale of the Japanese officials in Taiwan, especially Masatsuru Kashiya (樫谷正鶴), who was working in Taiwan’s Fishery Administration.

\section{Introducing Japanese fishery systems in Taiwan}

In 1909, two Japanese fishery experts, Keisuke Shimo and Hidemi Senoo, visited, inspected, and compiled a report about Taiwan's fisheries. The report was published in 1910.7 Shimo was an officer of the Ministry of Agriculture and Commerce, and Senoo was an engineer at the Tokyo Training School of Fisheries. They reported that Taiwan had few good ports to anchor fishing boats and that this resulted in the sluggish development of the fisheries. They calculated the output of fisheries per ri ( $1 \mathrm{ri}=3.75 \mathrm{~km}$ ) of coastline in both Taiwan and Japan in 1909, with catches of 1,977 Japanese yen (JPY)/ri in Taiwan and 8,946 JPY/ ri in Japan; the output in Japan was more than 4.5 times of that in Taiwan.

Though traditional coastal fisheries were operating all over Taiwan, there were a few areas where traditional fisheries were especially prosperous. The northern part near Keelung and the southern part near Tainan and Kaohsiung (Takao) were the centers of traditional fisheries (Figure 9.1), and the Penghu Islands in the western part were also prosperous. Before the Japanese occupation, there were several coastal fisheries using nets, such as sardine fishing using big lift nets and firelights, bonito fishing using set nets, and striped mullet fishing using haul nets. Other targets of coastal fisheries were Japanese Spanish mackerel, yellowtail, flying fish, and shark. There were several traditional nets for waiting for and catching fish, such as round haul nets, gill nets, and lift nets.

Before the Fishery Law was introduced, some Japanese fishers came to Taiwan and began fishing. Those who settled in fishing villages operated offshore fisheries such as spear fishing in the waters off eastern Taiwan. Japanese fishers also settled in the north, especially in the Keelung and Taipei areas. The fishing activities in these areas are given in Table 9.1 and Table 9.2.

The first fishery law in Taiwan was the 1912 Regulation of Taiwan's Fishery. This regulation consisted of 24 main clauses and some additional clauses. Before 
Table 9.1 Data from 1907 for fisheries in Taiwan

\begin{tabular}{lrrrrrrr}
\hline Area & $\begin{array}{l}\text { Full-time } \\
\text { fishing } \\
\text { families }\end{array}$ & $\begin{array}{l}\text { Full-time } \\
\text { fishery } \\
\text { workers }\end{array}$ & $\begin{array}{l}\text { Number } \\
\text { of bamboo } \\
\text { fishing } \\
\text { boats }\end{array}$ & $\begin{array}{l}\text { Number } \\
\text { of wooden } \\
\text { fishing } \\
\text { boats }\end{array}$ & $\begin{array}{l}\text { fotal } \\
\text { boats }\end{array}$ & $\begin{array}{l}\text { Output } \\
\text { (JPY) }\end{array}$ & Main port \\
\hline North & 5,790 & 21,613 & 2,046 & 71 & 2,117 & 360,009 & Keelung \\
Central & 4,037 & 9,659 & 135 & 1,911 & 2,046 & 59,427 & Qungshui \\
South & 8,987 & 22,516 & 17 & 3,806 & 3,823 & 287,984 & Tainan, \\
East & 680 & 2,093 & 162 & 5 & 167 & 7435 & Taitung \\
West & 5,057 & 9,410 & 1,353 & 2 & 1,355 & 72,356 & Penghung \\
\hline
\end{tabular}

Source: Taiwan suisangyo sisatu hukumeisho (A Report about Fisheries in Taiwan).

Table 9.2 Data from 1907 for Japanese fishing vessels operating in Taiwan

\begin{tabular}{lcccc}
\hline Area & Number of vessels & Number of workers & Catch (kin) & Output (JPY) \\
\hline Taipei & 7 & 20 & 29,100 & 6,752 \\
Keelung & 56 & 196 & 204,715 & 31,004 \\
Hsinchu & 3 & 11 & 22,220 & 2,399 \\
A-Kau & 1 & 3 & 375 & 41 \\
Kaohsiung & 2 & 4 & 6,000 & 240 \\
Total & 69 & 234 & 262,410 & 40,436 \\
\hline
\end{tabular}

Source: Taiwan suisangyo sisatu hukumeisho (A Report about Fisheries in Taiwan).

${ }^{*} 1 \mathrm{kin}=0.6 \mathrm{~kg}$.

the regulation was established, traditional customs were applied, and authorities issued permits, for example, to catch whales. ${ }^{8}$ There were several clauses about fishery rights, such as the right to set nets and demarcation of fishing areas. However, exclusive fishery rights were not provided, although the owners of the fishery rights could inherit, sell, and use them as collateral for loans. This regulation lasted for only ten years until 1924 when the Japanese Fishery Law was enforced.

The Fishery Law came into force on February 1, 1924, and contained clauses concerning three types of fisheries: those based on fishing rights, those based on permissions, and those based on open fisheries. The major differences between the old and new fishery laws are listed as follows: ${ }^{9}$

- Legal characteristics of fishery rights: Under the old regulations, fishing rights could be inherited, sold, and used as collateral for loans. The new law also included these regulations but added that the "actual" right and the fishing right could not be divided, changed, or abandoned without the agreement of the rightful claimant.

- Terms of existence of fishing rights: The old regulations allowed fishing rights to be held for 10 years, but the new law allowed rights to be held for 20 years. 


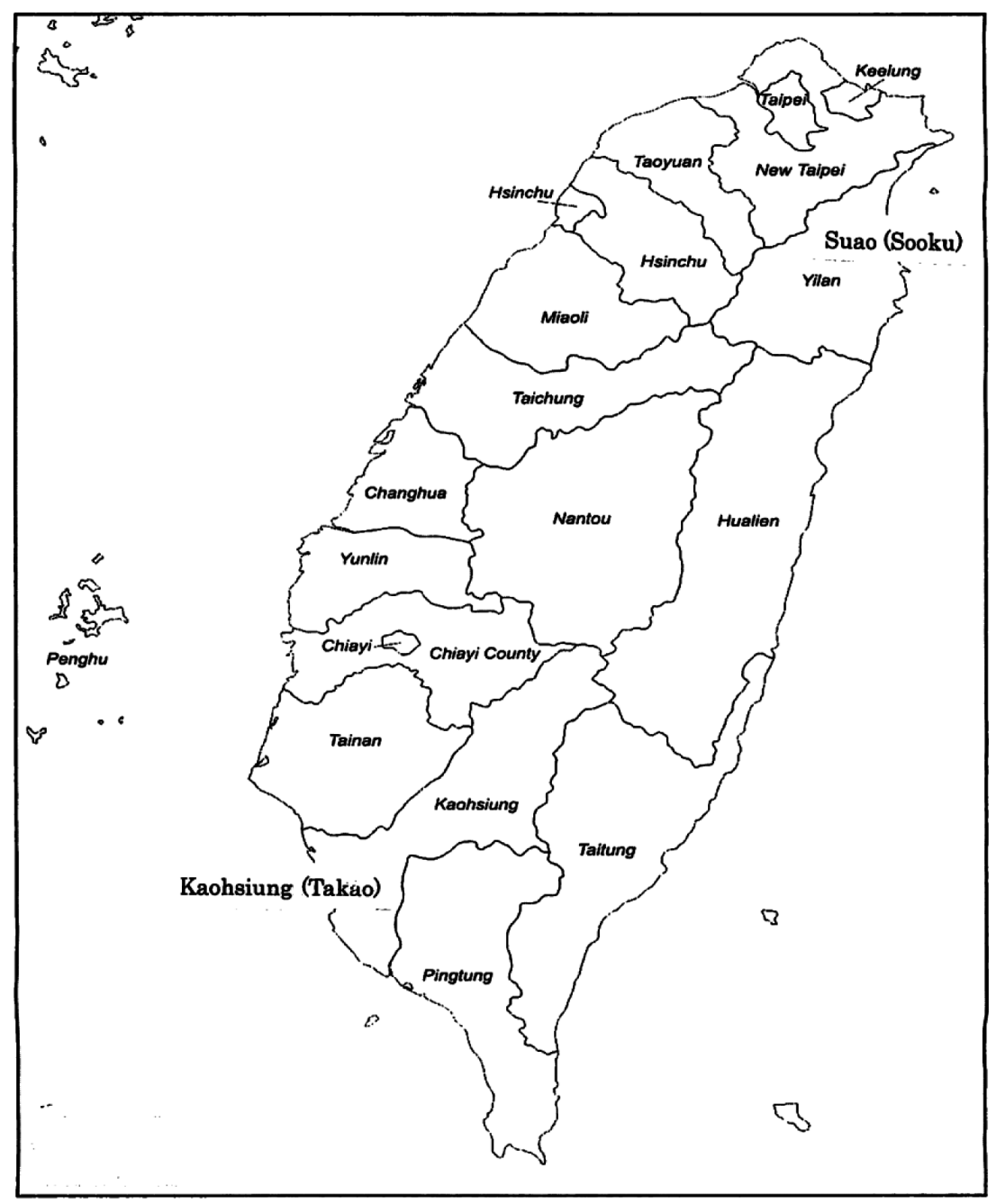

Figure 9.1 Provinces of Taiwan

Source: Taiwan: coasts, divisions, names. http://d-maps.com/carte.php?num_car=648\&lang=en

- Kinds of fishery rights: The old regulations did not provide exclusive fishery rights, but the new law permitted fishery associations to hold exclusive fishing rights in the coastal sea areas where their members lived.

- Kinds of permitted fisheries: The old regulations permitted 15 fisheries (whaling; trawling; sailing trawl net fishing; fishing with diving equipment; coral fishing; beach seine fishing; tateboshi seine fishing; fishing without bait; 
agar collecting; montagne collecting; turban shell fishing; pearl fishing; top shell fishing; hirose shell fishing; and fishing by steamship, sailing ship, and motorboat). The new law permitted nine fisheries (whaling, trawling, fishing with diving equipment, coral fishing, bonito fishing, renji seine fishing, round haul net fishing by motorboat, Danish seine fishing, and drift net fishing by motorboat).

- Regulatory agency: The old regulation was enforced by the Sotokuhu (the governor's office), but the new law was enforced by local governments with some documents submitted to the Sotokuhu for management purposes.

The Japanese Fishery Law was introduced in Taiwan almost in its entirety, as only some clauses concerning fishery unions were excluded. ${ }^{10}$ How, then, did Japanese fishers transfer the techniques which would become part of fishery systems in Taiwan from Japan and assist in developing the fisheries?

After 1910, Japanese fishers were invited to operate offshore and deep-sea fisheries. There were two groups of Japanese fishery workers who came to Taiwan to work in these fisheries. One was a group invited to settle in fishing villages, and the other was a group of entrepreneurs who operated fishery firms and pure fishery workers who were hired by the fishing firms.

These settlers came to Taiwan in accordance with the immigrant policies that the local Taiwanese government introduced in $1910 .{ }^{11}$ In order to improve the fisheries in Taiwan, fishery families were invited to several fishing villages, including Suao in the province of Taipei, two villages in the province of Hsinchu, three villages in the province of Takao, a village in the province of Taichu, as well as several other villages. About 20 fishery families settled in each village. ${ }^{12}$ Most settlers could not operate successfully because of the lack of government support. Even after Suao Port was renovated in 1923, the fisheries had still not developed enough to be viable. In response, the local government of Taipei planned to invite more Japanese settlers to help stimulate the fisheries. From 1926 to 1927, 50 fishery families were invited to immigrate to the Suao area. Most of these families came from Kochi, Ehime, and several other prefectures in Japan. ${ }^{13}$

Around 1913, Japanese fishers began to conduct longline fishing to catch sea bream and yellow porgies. This method of fishing was also practiced by Taiwanese fishers, especially in the Penghu area. Japanese longline fishers first used Japanese-style sailing vessels and then later changed to motorized vessels, while Taiwanese fishers used Chinese-style sailing vessels. Both Japanese and Taiwanese fishers became interested in using modern fishing equipment and motorized vessels, and fishery experiment stations were founded for experts to instruct local fishers on modern techniques. ${ }^{14}$

Offshore and deep-sea fisheries began after 1910, which was also when skipjack fishing began. At first, skipjack fishing was not profitable and fishers were only able to continue fishing with the help of government subsidies. In 1916, when skipjacks were plentiful, the fishery became profitable, and after 1917, subsidies were no longer needed. Experts from the fishery experiment stations tested the use of longlines on their fishing vessels. Because of the tests and recommendations of the 
station experts, longline fishing targeting tuna, spearfish, and sharks also became prosperous. Thus, motorized offshore and deep-sea fisheries became popular in Taiwan. Deep-sea fishing also targeted yellow porgies and allowed for incidental catches of coral. Fishers also targeted coastal areas. The techniques used by the Japanese fishers were gradually transferred to Taiwanese fishers in this manner.

\section{Development of fisheries in modern Taiwan}

The yield of Taiwan's fishery products is shown in Figures 9.2 and 9.3. This information is provided as two separate figures because although the units of kin $(1 \mathrm{kin}=0.6 \mathrm{~kg})$ and $\mathrm{kan}(1 \mathrm{kan}=3.75 \mathrm{~kg})$ can be converted to a common measure, they are used for different types of fish, and kan expresses quantities for several years. In addition, the actual number of fish caught cannot be determined directly from kin or kan values; however, we used mathematical equations to calculate the total number of fish caught for comparison. In general, the total number of fish caught is expressed in kin in Taiwan.

As shown in Figures 9.2 and 9.3, fishery product yields in Taiwan increased after the 1920s. In the first half of the 1930s, yields decreased temporarily but soon recovered. Then, at the beginning of WWII, yields decreased drastically. Although pre-WWII fisheries in Taiwan showed remarkable development, the level of production was not high compared to post-WWII levels, as discussed in the following. Table 9.3 shows the major fisheries in Taiwan in 1925, with skipjacks, sardines, and yellow porgy being the top three fish caught.

In order to fully understand pre-WWII fisheries in Taiwan, the status of the workers must also be considered. Most fishery workers were Taiwanese, and there

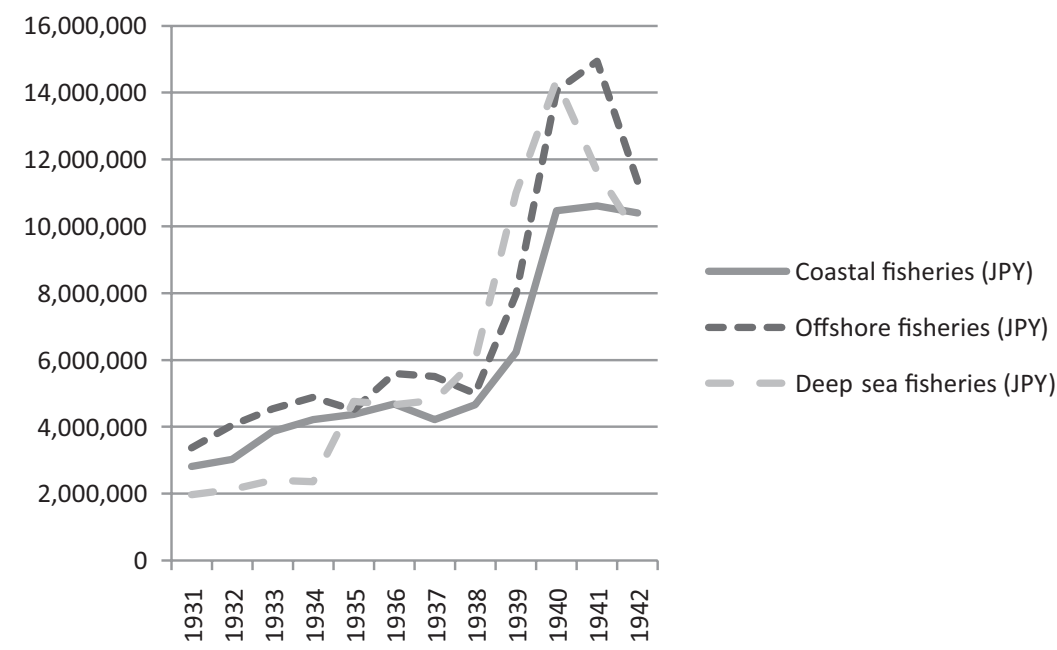

Figure 9.2 Yield of fishery products in Taiwan from 1899 to 1942

Source: Taiwan keizainenpo (Taiwan Economic Yearbook) (1941) (see Appendix 9.Al). 


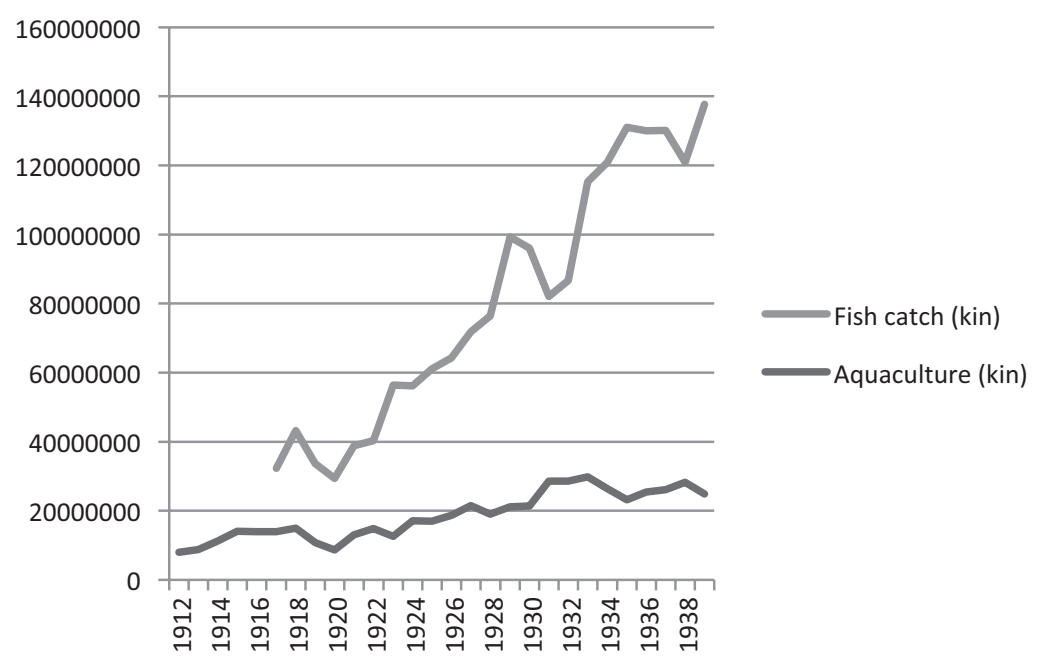

Figure 9.3 Yield of fishery products in Taiwan from 1912 to $1939.1 \mathrm{kin}=0.6 \mathrm{~kg}$. Source: Taiwan keizainenpo (Taiwan Economic Yearbook) (1941) (see Appendix 9.A2).

Table 9.3 Top fish catches in Taiwan in 1925

\begin{tabular}{lc}
\hline Fish & Product value (JPY) \\
\hline Skipjack & $1,515,115$ \\
Sardine & 898,850 \\
Yellow porgy & 839,368 \\
Swordfish & 698,743 \\
Shark & 576,315 \\
Tuna & 474,142 \\
Japanese Spanish mackerel & 414,202 \\
Bullet mackerel & 301,336 \\
Sea bream & 297,537 \\
Striped mullet & 215,992 \\
Flying fish & 180,253 \\
Small yellow croaker & 169,705 \\
Milkfish & 144,572 \\
Horse mackerel & 126,714 \\
Mackerel & 104,333 \\
Other & $1,047,087$ \\
Total & $8,628,947$ \\
\hline
\end{tabular}

Source: Taiwan-bu tokeisho (Statistic Yearbook of Taiwan) No. 29.

were comparatively less Japanese workers (Appendices 9A.3 and 9A.4). Among the Japanese fishery workers, there were many more full-time workers engaged in catching fish than part-time workers. The part-time Japanese workers were 
engaged in seasonal fisheries and had other occupations to supplement their income. However, among the Taiwanese fishery workers, part-time workers were much more common than full-time workers, and these workers were engaged not only in catching fish but also in culturing fish. Some workers were also engaged in processing fish; however, this number was not large.

The local government of Taiwan urged Japanese fishery workers to settle down, but only those who had innovative fishing technology could earn enough money to live comfortably. Therefore, the number of Japanese fishery workers did not increase rapidly. There were also Japanese fishery workers who worked seasonally - for example, some workers from Miyazaki Prefecture, Japan, worked in areas of Taiwan where skipjack fishing was conducted. However, only those who had highly refined techniques were welcomed by the locals.

Fishing vessels were required for successful fisheries. Table 9.4 shows the number of fishing vessels in Taiwan in the 1920s. Most fishing vessels were made of wood, but the number of motorized ships was starting to increase. Because of this modernization, the fishing industry in Taiwan began to develop rapidly.

A handbook of Taiwanese fisheries from 1930 provided some overall statements about the status of the fisheries during that time. ${ }^{15}$ The author wrote the following:

There are many good fishing grounds near Taiwan, but there are only a few good fishery ports. Therefore the main fisheries are fisheries by motor vessels. The main fishery ports in Taiwan are Keelung and Suao (Sooku) in the

Table 9.4 Number of fishing vessels in Taiwan from 1918 to 1929

\begin{tabular}{|c|c|c|c|}
\hline \multirow[t]{2}{*}{ Year } & \multicolumn{2}{|c|}{ Motorized vessels } & \multirow{2}{*}{$\frac{\text { Wooden vessels }^{\dagger}}{\text { Number }}$} \\
\hline & Number & Horsepower & \\
\hline 1918 & 125 & - & 3,853 \\
\hline 1919 & 120 & - & 3,744 \\
\hline 1920 & 160 & - & 4,024 \\
\hline 1921 & 157 & - & 3,893 \\
\hline 1922 & 174 & 5,042 & 3,914 \\
\hline 1923 & 248 & 6,083 & 4,150 \\
\hline 1924 & 391 & 8,176 & 4,385 \\
\hline 1925 & 498 & 9,258 & 4,325 \\
\hline 1926 & 545 & 16,164 & 3,799 \\
\hline 1927 & 561 & 17,618 & 4,051 \\
\hline 1928 & 678 & 23,984 & 4,030 \\
\hline 1929 & 819 & 27,005 & 4,091 \\
\hline
\end{tabular}

Source: Keisuke Shimo (下啓助) and Hidemi Senoo (妹尾秀実) (1910), Taiwansotokubu tokeisho (Statistic Yearbook of Taiwan) Nos. 27-33.

${ }^{*}$ Motorized vessels included steamships and motorboats.

tWooden vessels included Japanese and Chinese vessels. 
northern part, and Kaohsiung (Takao) in the southern part. There are 850 motorized vessels in Taiwan but almost $90 \%$ are in three ports.

The main fisheries in Taiwan were the Danish seine, trawl, skipjack (mainly in Takao), tuna longline, and swordfish harpoon fisheries, as well as coral collecting (mainly in Takao and Suao). ${ }^{16}$

Taiwan's 1941 economic yearbook stated that unlike Japan and Korea, where coastal fisheries were superior to offshore and deep-sea fisheries, deep-sea fisheries in Taiwan were superior to coastal fisheries. ${ }^{17}$ In 1939, the production rate of deep-sea fishing was 75.5 percent, and that of coastal fishing was 24.5 percent. The average rate of deep-sea production from 1931 to 1939 was 69 percent. $^{18}$ The official statistics for the production of offshore fisheries included deep-sea fisheries in accordance with instructions from the local government. ${ }^{19}$ The development of deep-sea fisheries resulted from cultivating new fishing grounds around Taiwan and pioneering the fishing grounds south of Taiwan. This trend in deep-sea fishing is one of the main characteristics of Taiwan's fishery. ${ }^{20}$ However, at the same time that modern fishery techniques were being introduced, coastal fishery was also gradually modernizing; therefore, coastal, offshore, and deep-sea fisheries were developing simultaneously (Table 9.5). Although the growth rates of the fisheries shown in Table 9.5 were higher than that of the nominal gross national expenditure (GNE), the leading sectors of pre-WWII Taiwan were rice farming and sugar planting. ${ }^{21}$

Fisheries declined during wartime but were revived after the war ended. At the beginning of the post-war period, coastal, offshore, and deep-sea fisheries advanced simultaneously, but after 1956, coastal fisheries became stagnant, and

Table 9.5 Total production in Taiwan from 1931 to 1942 by fishing ground

\begin{tabular}{ccccc}
\hline Year & $\begin{array}{l}\text { Coastal fishery } \\
(J P Y)\end{array}$ & $\begin{array}{l}\text { Offshore } \\
\text { fishery (JPY) }\end{array}$ & $\begin{array}{l}\text { Deep-sea } \\
\text { fishery (JPY) }\end{array}$ & $\begin{array}{l}\text { Nominal } \\
\text { GNE/1,000 (JPY) }\end{array}$ \\
\hline 1931 & $2,813,712$ & $3,367,301$ & $1,969,726$ & 881,286 \\
1932 & $3,026,886$ & $4,051,218$ & $2,119,366$ & 899,392 \\
1933 & $3,860,664$ & $4,541,260$ & $2,404,746$ & 913,511 \\
1934 & $4,217,346$ & $4,878,564$ & $2,356,431$ & 964,594 \\
1935 & $4,373,458$ & $4,510,468$ & $4,756,019$ & $1,145,683$ \\
1936 & $4,681,591$ & $5,592,515$ & $4,660,299$ & $1,091,373$ \\
1937 & $4,215,153$ & $5,508,617$ & $4,789,336$ & $1,168,680$ \\
1938 & $4,663,172$ & $4,998,198$ & $6,009,442$ & $1,233,538$ \\
1939 & $6,223,744$ & $7,962,380$ & $10,997,204$ & - \\
1940 & $10,462,442$ & $14,060,928$ & $14,371,029$ & - \\
1941 & $10,612,450$ & $14,940,104$ & $11,643,125$ & - \\
1942 & $10,399,826$ & $11,340,706$ & $9,736,393$ & - \\
\hline Somrce & & &
\end{tabular}

Source: Fishery products: Taiwansotokuhu tokeisho (Statistic Yearbook of Taiwan) Nos. 41-46; nominal GNE: Mizoguchi (1975). 
deep-sea and offshore fisheries advanced quickly. On the other hand, aquaculture progressed gradually (Figure 9.4). ${ }^{22}$

Common data were collected between 1920 and 1925, so we can calculate the relationship between fish catches, the number of fishery workers (Japanese and Taiwanese), and the number of motorized vessels (Table 9.6). ${ }^{23}$

The correlation between fish catches and the number of Japanese fishery workers was strong; therefore, the belief that Japanese fishery workers passed on their fishing techniques has been confirmed. ${ }^{24}$ The correlation between fish catches and the number of motorized vessels was also strong. This reveals that fisheries in Taiwan were led by modernization. The main developing fisheries in the $1920 \mathrm{~s}$ were the deep-sea fisheries around Nanyo.

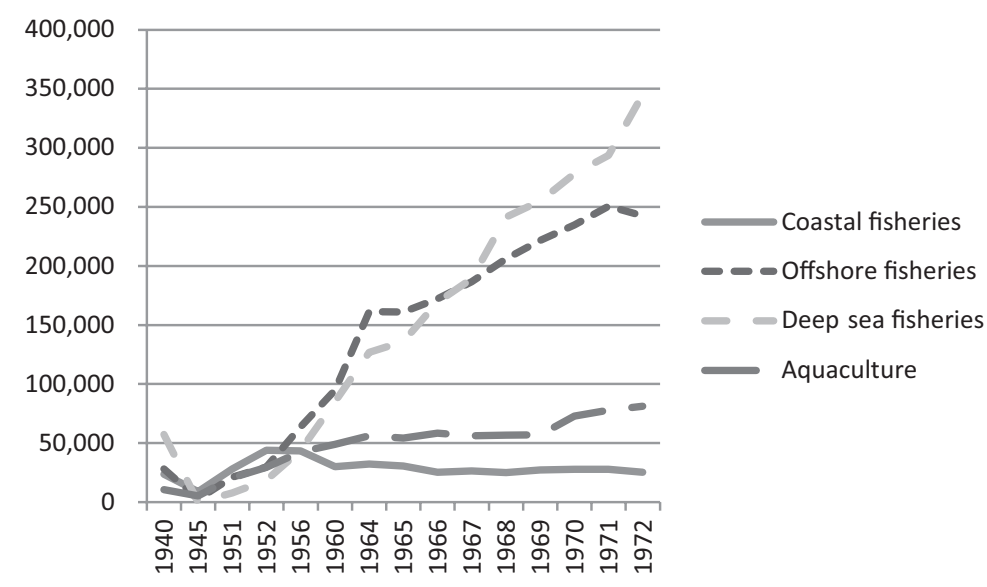

Figure 9.4 Fish catches after 1940 in Taiwan by fishing ground (ton)

Source: Taiwan gyogyo no kenkyu (A Study of Taiwan Fisheries).

Table 9.6 Fish catches and numbers of fishery workers and motorized vessels in Taiwan in the 1920s

\begin{tabular}{ccccc}
\hline Year & Fish catch (kin) & $\begin{array}{c}\text { Full-time Japanese } \\
\text { fishery workers }\end{array}$ & $\begin{array}{c}\text { Full-time Taiwanese } \\
\text { fishery workers }\end{array}$ & $\begin{array}{c}\text { Motorized } \\
\text { vessels }\end{array}$ \\
\hline 1919 & $33,670,301$ & 2,253 & 51,928 & 120 \\
1920 & $29,357,158$ & 2,092 & 41,635 & 160 \\
1921 & $38,844,635$ & 2,220 & 41,003 & 157 \\
1922 & $40,183,688$ & 2,059 & 40,583 & 174 \\
1923 & $56,367,338$ & 3,306 & 46,865 & 248 \\
1924 & $56,116,504$ & 3,464 & 46,869 & 391 \\
1925 & $61,153,501$ & 3,902 & 49,321 & 498 \\
1926 & $64,219,155$ & 4,067 & 50,650 & 545 \\
1927 & $71,788,897$ & 4,776 & 52,038 & 561 \\
1928 & $76,483,188$ & 5,209 & 55,141 & 678 \\
1929 & $99,253,091$ & 6,385 & 53,392 & 819 \\
\hline
\end{tabular}




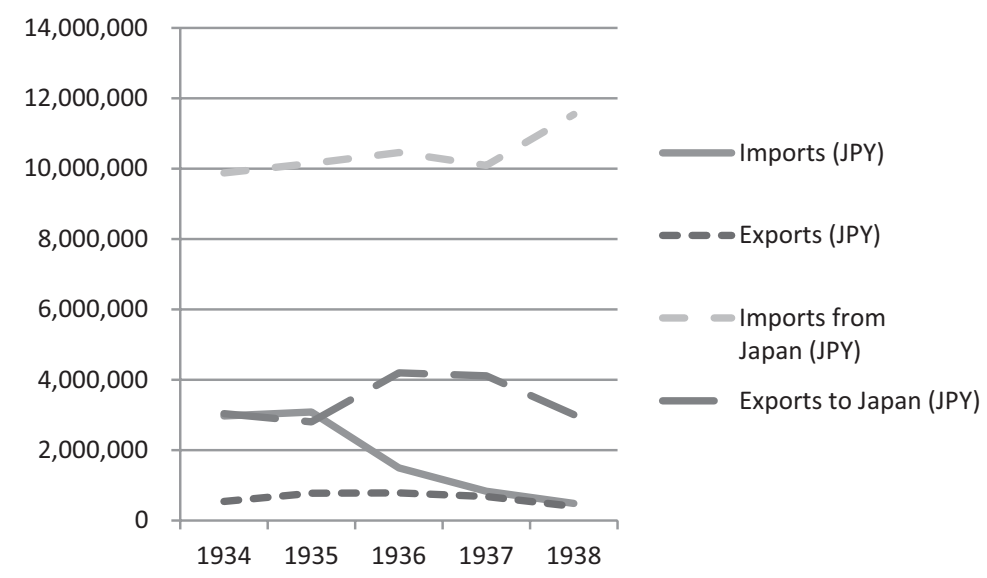

Figure 9.5 Fishery trade data in the 1930s in Taiwan

Source: Taiwan jijo (Circumstances of Taiwan).

Table 9.7 Taiwan's fishery exports (excluding Japan) in 1934 and 1935

\begin{tabular}{rrrrrrr}
\hline Year Value Dried small Dried cod & Salted trout & $\begin{array}{l}\text { Salted } \\
\text { mardine }\end{array}$ & & & Dried squid & $\begin{array}{l}\text { Dried } \\
\text { scallop }\end{array}$ \\
\hline 1934 (kin) & $1,608,193$ & 249,238 & 713,9307 & 46,753 & $1,736,862$ & 385,546 \\
(JPY) & 231,618 & 422,470 & 774,305 & 4,261 & 550,128 & 269,927 \\
1935 (kin) & $1,599,903$ & $2,132,251$ & $8,007,140$ & 106,329 & 923,402 & 476,051 \\
(JPY) & 273,219 & $4,007,36$ & 845,765 & 10,461 & 376,734 & 314,605 \\
\hline
\end{tabular}

Source: Taiwan jijo (Circumstances of Taiwan).

Table 9.8 Taiwan's fishery imports (excluding Japan) in 1934 and 1935

\begin{tabular}{llrr}
\hline Year & Value & Salted trout & Other fish \\
\hline 1934 & (kin) & $6,869,993$ & $5,890,000$ \\
& $(\mathrm{JPY})$ & 317,990 & 32,261 \\
1935 & $(\mathrm{kin})$ & $6,848,161$ & $5,020,000$ \\
& $(\mathrm{JPY})$ & 378,345 & 32,362 \\
\hline
\end{tabular}

Source: Taiwan jijo (Circumstances of Taiwan).

Table 9.9 Taiwan's fishery exports to Japan in 1934 and 1935

\begin{tabular}{llrc}
\hline Year & Value & Fresh fish & Dried skipjack \\
\hline 1934 & (kin) & $11,550,436$ & 634,179 \\
& (JPY) & $2,421,402$ & 444,437 \\
1935 & (kin) & $9,618,743$ & 391,361 \\
& (JPY) & $2,221,756$ & 262,980 \\
\hline
\end{tabular}

Source: Taiwan jijo (Circumstances of Taiwan). 


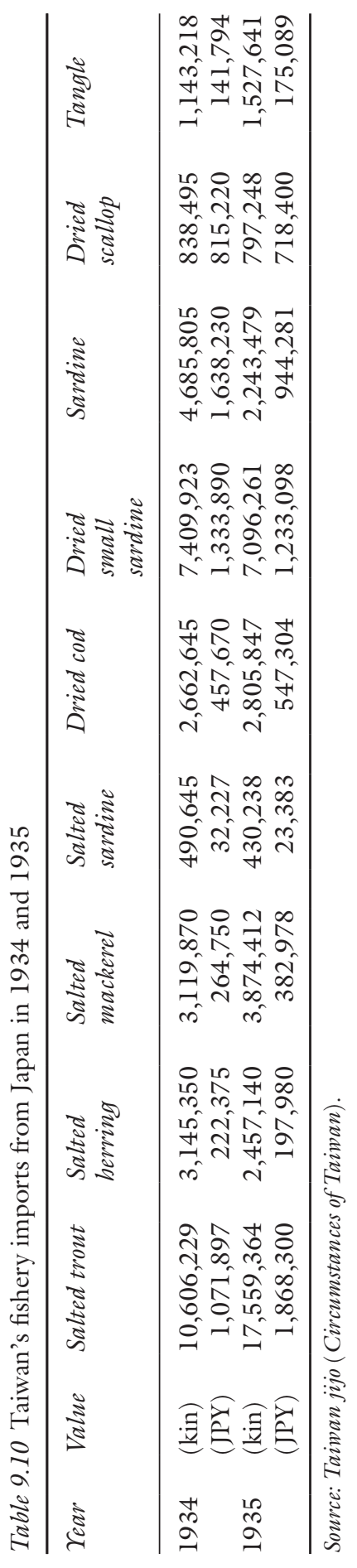


Although fishery activities in Taiwan increased during the 1920s, the pre-WWII fishery trade was quite different from that of post-WWII. Commerce between Taiwan and Japan before the end of WWII was domestic trade, and that after WWII was international. Including commerce with Japan and Korea, fishery imports exceeded exports before the end of WWII; however, this trend reversed after WWII ended.

Fishery trade data before the end of WWII are shown in Figure 9.5. We can see that Taiwan imported many fishery products and exported little fish. Precise import data in 1934 and 1935 are shown in Tables 9.7-9.10.

Fisheries had not developed enough to provide the necessary supply of fish to the Taiwanese people, and Taiwan had to import salted trout, dried small sardines, and other fish from Japan. As a result, fresh fish gradually became the main fishery commodity for export markets, which was made possible by the use of motorized vessels. Table 9.11 shows the amount of fresh fish exported from Taiwan. The main fresh fish exports were tuna and swordfish, which were frozen and exported from Kaohsiung (Takao) and Keelung. ${ }^{25}$

\section{Characteristics of fishery systems in Taiwan}

As previously mentioned, Masatsuru Kashiya was one of the Japanese officials who helped create Taiwan's fishery system. He was born in Kochi, Japan, and served as a local government official in Toyama Prefecture in Japan. Kashiya published a book about the Fishery Law in Toyama in 1901. ${ }^{26}$ In 1910, he was appointed to work as a local government official in Taiwan, where he stayed until 1919, when he was appointed to work as a local government official in Korea.

Kashiya wrote several articles about Taiwan's fishery system. In those articles, he insisted that fishers' associations and unions should not be established in Taiwan because the fishers were unable to appropriately manage such organizations. Instead of these associations and unions, Kashiya said that there should be a

Table 9.11 Taiwan's fresh fish exports to Japan from 1920 to 1929

\begin{tabular}{lrcc}
\hline Year & Quantity $(t)$ & Total value $(J P Y)$ & Price $(J P Y) / t$ \\
\hline 1920 & 256,000 & 204,800 & 0.80 \\
1921 & 250,560 & 207,280 & 0.83 \\
1922 & 335,176 & 236,914 & 0.71 \\
1923 & 992,369 & 471,410 & 0.48 \\
1924 & 590,356 & 348,654 & 0.59 \\
1925 & $1,025,998$ & 541,324 & 0.53 \\
1926 & $1,529,886$ & 791,051 & 0.52 \\
1927 & $2,592,427$ & $1,333,586$ & 0.51 \\
1928 & $3,020,855$ & $1,638,967$ & 0.54 \\
1929 & $4,982,191$ & $2,116,079$ & 0.42 \\
\hline
\end{tabular}

Source: Taiwan suisan yoran (Taiwan Fishery Survey) (1930). 


\section{Nobutake Koiwa}

fisheries organization managed jointly by both the government and the fishers; however, such organizations were not easy to establish. The fishery regulations in place in 1912 were consistent with Kashiya's articles since they were based on the decisions of government officials and the state of the fisheries at the time.

When the Japanese Fishery Law was enforced in Taiwan in 1924, clauses about fishery unions were not included. Fishers were permitted to establish associations but not unions. The new law also affected how fisheries were organized. Fisheries were regulated by government officials, and fishers were encouraged to establish organizations and cooperate with the government in fishery management. This was the principal issue that Kashiya wrote about in his articles. ${ }^{27}$ In mainland Japan, fishery organizations were established to reform fishery policies, and they were expected to act as subcontractors of the government.

Excluding clauses about fishery unions was parallel with Kashiya's claims, but contrary to his opinions, the new Fishery Law did include provisions for fishery associations and exclusive fishing rights. The main reason for this was the amount of time that had passed between Kashiya's articles and when the Fishery Law was established; during this time, fishers' associations became necessary. In 1933, the Japanese government improved the Fishery Law, empowering fishery associations to conduct fishery-related business. This improvement was applied not only in Japan but also in Taiwan and Korea.

In Taiwan, 31 fishery associations were established in 1926, and 62 were established in 1937. ${ }^{28}$ Though fishery associations formed all over Taiwan, the geographical distribution was uneven (Table 9.12).

These fishery associations administrated fishing rights and managed the cooperative marketing of fishery products. They also played a role in stimulating fishing villages affected by the economic depression.

From the viewpoint of the fishers, there were three types of fishery associations in Taiwan: those organized by full-time fishers, those organized by part-time fishers, and those organized by both full-time and part-time fishers. Research on fishery associations conducted by Tamihei Kita was published in fishery magazines in Taiwan. According to Kita's research, some associations were organized by either full-time or part-time fishers, but most were organized by both. ${ }^{29}$ Part-time fishers were engaged in agriculture and other occupations in addition to fisheries. In

Table 9.12 Number of fishery associations in Taiwan in 1930 by area

\begin{tabular}{lc}
\hline Area & Number of fishery associations \\
\hline Taipei & 7 \\
Hsinchu & 5 \\
Taichu & 4 \\
Takao & 16 \\
Penghu & 4 \\
Taito & 1 \\
Total & 37 \\
\hline
\end{tabular}

Source: Taiwan suisan yoran (Taiwan Fishery Survey) (1935). 
1933, the members of one fishery association organized by both full-time and part-time fishers had total annual revenues in the range of 200 to $600 \mathrm{JPY} .^{30} \mathrm{In}$ pre-WWII Taiwan, most fishery association members could not sustain themselves and their families by working in fisheries only.

In addition to fishery associations, fishery organizations were also established in Taiwan and Japan. The fishery organizations which were established in Taiwan are shown in Table 9.13. These regulatory changes became the foundation of the fishery systems in Taiwan.

Table 9.13 Fishery organizations in Taiwan in 1937

\begin{tabular}{|c|c|c|c|c|}
\hline $\begin{array}{l}\text { Organization } \\
\text { name }\end{array}$ & $\begin{array}{l}\text { Date of } \\
\text { foundation }\end{array}$ & $\begin{array}{l}\text { Annual } \\
\text { budget } \\
\text { (JPY) }\end{array}$ & $\begin{array}{l}\text { Special } \\
\text { accounts } \\
(J P Y)\end{array}$ & Main activities \\
\hline $\begin{array}{r}\text { Taiwan Fishery } \\
\text { Organization }\end{array}$ & $\begin{array}{c}\text { August } 11, \\
1928\end{array}$ & 123,325 & - & $\begin{array}{l}\text { Delivering lectures, purchasing } \\
\text { goods, mediating, collecting } \\
\text { sharkskin }\end{array}$ \\
\hline $\begin{array}{l}\text { Taipei District } \\
\text { Fishery } \\
\text { Organization }\end{array}$ & $\begin{array}{l}\text { March 18, } \\
1925\end{array}$ & 128,197 & 73,390 & $\begin{array}{l}\text { Research, encouraging } \\
\text { fisheries, operating a fish } \\
\text { market, operating a marine } \\
\text { radio, giving relief to fishers, } \\
\text { financing the coral fishery }\end{array}$ \\
\hline $\begin{array}{l}\text { Hsinchu District } \\
\text { Fishery } \\
\text { Organization }\end{array}$ & $\begin{array}{l}\text { May 17, } \\
1924\end{array}$ & 37,149 & 14,720 & $\begin{array}{l}\text { Operating a fish market, } \\
\text { financing a fishery business }\end{array}$ \\
\hline $\begin{array}{l}\text { Taichung } \\
\text { District } \\
\text { Fishery } \\
\text { Organization }\end{array}$ & $\begin{array}{l}\text { December } 9 \\
1930\end{array}$ & 20,956 & - & $\begin{array}{l}\text { Delivering lectures, purchasing } \\
\text { goods, coaching and } \\
\text { encouraging fisheries, giving } \\
\text { relief to fishers }\end{array}$ \\
\hline $\begin{array}{l}\text { Tainan District } \\
\text { Fishery } \\
\text { Organization }\end{array}$ & $\begin{array}{l}\text { August 25 } \\
1925\end{array}$ & 20,966 & 1,012 & $\begin{array}{l}\text { Coaching and encouraging } \\
\text { fisheries, operating a fish } \\
\text { market, operating a port, } \\
\text { operating a marine radio, } \\
\text { operating a fishery business, } \\
\text { giving relief to fishers }\end{array}$ \\
\hline $\begin{array}{l}\text { Kaohsiung } \\
\text { Fishery } \\
\text { Organization }\end{array}$ & $\begin{array}{l}\text { August 25, } \\
1924\end{array}$ & 32,802 & 246,168 & $\begin{array}{l}\text { Operating a fish market, } \\
\text { research, encouraging } \\
\text { fisheries, operating a wharf, } \\
\text { giving relief to fishers }\end{array}$ \\
\hline $\begin{array}{l}\text { Taitung District } \\
\text { Fishery } \\
\text { Organization }\end{array}$ & $\begin{array}{l}\text { May 29, } \\
1935\end{array}$ & 24,584 & - & $\begin{array}{l}\text { Operating a fish market, } \\
\text { operating a wharf, } \\
\text { researching fishing grounds }\end{array}$ \\
\hline $\begin{array}{l}\text { Hualien Port } \\
\text { Fishery } \\
\text { Organization }\end{array}$ & $\begin{array}{l}\text { February } 4 \\
1924\end{array}$ & 57,706 & - & $\begin{array}{l}\text { Operating a fish market, } \\
\text { operating a wharf, } \\
\text { researching fishing grounds }\end{array}$ \\
\hline $\begin{array}{l}\text { Penghu District } \\
\text { Fishery } \\
\text { Organization }\end{array}$ & $\begin{array}{l}\text { January } 1 \\
1927\end{array}$ & 218,835 & - & $\begin{array}{l}\text { Operating a fish market, } \\
\text { operating a refrigerator, } \\
\text { coaching and encouraging } \\
\text { fisheries, giving relief to } \\
\text { fishers }\end{array}$ \\
\hline
\end{tabular}

Source: Taiwan jijo (Circumstances of Taiwan) (1937). 
After the Japanese Fishery Law was enacted in Taiwan, some criticized that it was too late because the previous lack of regulation had made the fishery market system poor. When the fishery associations were established, merchants began to settle into fishery markets since this was permitted under the new law. In Japan, fishery associations were expected to conduct fishery-related business, such as marketing and financing, in addition to operating local fishery markets. Similarly in Taiwan, some fishery associations, mainly those in Takao and Tainan Provinces, operated fishery markets and provided financial services. In Taipei, Hsinchu, and Tainan Provinces, fishery organizations, rather than fishery associations, operated fishery markets. ${ }^{31}$ Public bodies also operated fishery markets in many provinces, and in Keelung, a fishery market was also operated by a private company (Table 9.14).

In Japan, fishery organizations were also established after 1921 when the Law of Fishery Organization was created. Fishery organizations coached fishery associations and did not operate fishery markets as they did in Taiwan. The work of selling fish belonged solely to fishery associations. The fact that fishery organizations in Taiwan became relatively important was the result of the thinking and administrative decisions of Sotokuhu officials such as Masatsuru Kashiya as well as the uneven development of the fishery associations.

There were two main reasons why fishery organizations in Taiwan were expected to be responsible for fishery-related business. One was the lack of fishery unions. In Japan, fishery unions were able to perform several administrative tasks concerning fishery product business because the members of these unions were not only fishers but were also merchants and processors of fishery products. The fishery unions inspected the products and held exhibitions. After the Law of Fishery Organization was established, the work of the fishery unions was transferred to fishery organizations in Japan, but the existence of the fishery unions made the tasks of the fishery organizations more administrative than before. In contrast, Taiwan lacked fishery unions, and since fishery organizations did not have a strong administrative function, they were able to focus on fishery-related business.

The second reason was the state of pre-WWII fisheries in Taiwan. The inefficiency of the traditional coastal fisheries was carried over to the uneven

Table 9.14 Number of fishery markets in Taiwan in 1935 by type of operator

\begin{tabular}{|c|c|c|c|c|}
\hline Area & Public bodies & Fishery organizations & Fishery associations & Private companies \\
\hline Taipei & 3 & 2 & 0 & 1 \\
\hline Hsinchu & 1 & 4 & 0 & 0 \\
\hline Taichu & 10 & 0 & 0 & 0 \\
\hline Tainan & 9 & 7 & 7 & 0 \\
\hline Takao & 9 & 1 & 13 & 0 \\
\hline Karenko & 1 & 0 & 0 & 0 \\
\hline Taito & 1 & 0 & 0 & 0 \\
\hline Penghu & 1 & 0 & 0 & 0 \\
\hline
\end{tabular}

Source: Taiwan suisan yoran (Taiwan Fishery Survey) (1935). 
geographical distribution of fishery associations. However, the proactive behavior of the fishery organizations in Taiwan was converted into prosperity for modern fisheries in several areas where fishery associations were established.

\section{Conclusion}

Taiwan's pre-WWII fisheries were not as prosperous as they had been in early modern years. Coastal, offshore, and deep-sea fisheries advanced simultaneously. The belief that Japanese fishers passed on their fishing techniques and knowledge has been confirmed. The correlation between fish catches and the number of motorized vessels was strong, revealing the fact that fisheries in Taiwan were led by modernization. Local government officials in Taiwan did not fully appreciate fishery associations; therefore, these associations were not adequately developed. In 1924, the Japanese Fishery Law came into force in Taiwan, allowing the establishment of fishery associations. Fishery associations were founded gradually as the fisheries developed. When the basic foundation of the fishery associations was built, the government recommended that fishery organizations be created with government support. Membership to the fishery organizations was open to not only fishermen but also fishery merchants and processors. However, when WWII began, the Japanese government introduced wartime policies and regulations, and fishery associations and organizations were combined in both Taiwan and Japan.

Japanese rule ended in Taiwan after WWII, and fishery associations and organizations were restored; however, due to financial stress, fishery associations remained connected to fishery organizations, which were also referred to as fishery associations. Fishery associations in Taiwan have been the main organizations managing fisheries in coastal areas since the end of WWII. Though post-WWII fishery associations in Taiwan have many similarities to those in Japan, one major difference is that membership is not restricted to fishers, and membership is open to transporters and manufacturers of fishery products as well. As stated previously, there are several types of systems to preserve coastal fishery resources. Considering the origin of fishery organizations in Taiwan, it is difficult for them to manage coastal resources without government assistance. ${ }^{32}$

Although some of Taiwan's pre-WWII fisheries developed rapidly, mainly those using motorized vessels, the majority of the fisheries remained undeveloped. As for trade in fishery products, Taiwan was the main market for fishery products from Japan during the pre-WWII era, but this situation changed after the war ended. Post-WWII Taiwan saw drastic advancement of the offshore and deep-sea fisheries and less activity in coastal fisheries.

Presently, the majority of Taiwan's fishery products are exported to international markets. Tuna and other products are exported to Japan and China as well as other countries. With the expansion of the domestic fishery trade after WWII, the role of fishery associations became more substantial because they were permitted to manage local fishery markets. In conclusion, pre-WWII fisheries laid the foundation for the post-WWII fishery systems in both Taiwan and Japan and deeply affected how contemporary fishery systems currently operate in Taiwan. 


\section{Appendix}

Appendix 9A.1 Value of fishery products in Taiwan from 1899 to 1942

\begin{tabular}{|c|c|c|c|c|}
\hline \multirow[t]{2}{*}{ Year } & \multicolumn{4}{|l|}{ Value (JPY) } \\
\hline & Fish catch & Aquaculture & Processed products & Total \\
\hline 1899 & 509,027 & 201,086 & 92,063 & 802,176 \\
\hline 1902 & 538,010 & 655,700 & 143,699 & $1,337,409$ \\
\hline 1907 & $1,464,352$ & 787,212 & 491,037 & $2,742,601$ \\
\hline 1911 & $2,061,251$ & 964,720 & 832,835 & $3,858,806$ \\
\hline 1912 & $1,013,547$ & 756,761 & 271,917 & $2,042,225$ \\
\hline 1913 & $1,551,995$ & 834,435 & 402,626 & $2,789,056$ \\
\hline 1914 & $1,662,656$ & $1,016,965$ & 383,849 & $3,063,470$ \\
\hline 1915 & $1,561,217$ & $1,245,538$ & 390,493 & $3,197,248$ \\
\hline 1916 & $2,102,796$ & $1,381,635$ & 419,207 & $3,903,638$ \\
\hline 1917 & $2,426,388$ & $1,633,774$ & 760,537 & $4,820,699$ \\
\hline 1918 & $4,104,283$ & $2,167,340$ & $1,553,969$ & $7,825,592$ \\
\hline 1919 & $5,057,969$ & $2,422,348$ & $1,424,461$ & $8,904,778$ \\
\hline 1920 & $5,513,121$ & $1,859,981$ & $1,563,731$ & $8,936,833$ \\
\hline 1921 & $5,943,267$ & $2,153,856$ & $1,665,125$ & $9,762,248$ \\
\hline 1922 & $5,989,097$ & $2,130,085$ & $2,200,191$ & $10,319,373$ \\
\hline 1923 & $9,030,651$ & $1,943,565$ & $3,299,514$ & $14,273,730$ \\
\hline 1924 & $9,193,036$ & $3,032,224$ & $3,420,377$ & $15,645,637$ \\
\hline 1925 & $10,031,417$ & $3,166,753$ & $3,581,201$ & $16,779,371$ \\
\hline 1926 & $10,225,692$ & $3,326,298$ & $2,822,618$ & $16,374,608$ \\
\hline 1927 & $10,822,119$ & $3,920,591$ & $2,505,311$ & $17,248,021$ \\
\hline 1928 & $12,670,180$ & $3,401,779$ & $2,706,623$ & $18,778,582$ \\
\hline 1929 & $14,446,265$ & $3,734,684$ & $2,775,420$ & $20,956,369$ \\
\hline 1930 & $11,771,144$ & $3,142,981$ & $1,793,273$ & $16,707,398$ \\
\hline 1931 & $8,482,776$ & $3,047,254$ & $1,524,869$ & $13,054,899$ \\
\hline 1932 & $9,197,468$ & $3,130,800$ & $1,545,164$ & $13,873,432$ \\
\hline 1933 & $10,806,670$ & $3,223,832$ & $1,908,982$ & $15,939,484$ \\
\hline 1934 & $11,452,341$ & $2,890,340$ & $2,290,923$ & $16,633,604$ \\
\hline 1935 & $13,639,945$ & $3,483,582$ & $2,290,741$ & $19,414,268$ \\
\hline 1936 & $14,934,405$ & $4,207,178$ & $2,500,298$ & $21,641,881$ \\
\hline 1937 & $14,513,106$ & $4,545,292$ & $2,324,009$ & $21,382,407$ \\
\hline 1938 & $15,670,812$ & $5,525,265$ & $2,358,530$ & $23,554,607$ \\
\hline 1939 & $25,183,328$ & $6,582,465$ & $3,328,137$ & $35,093,930$ \\
\hline 1940 & $38,894,399$ & $6,644,560$ & $6,719,467$ & $52,258,426$ \\
\hline 1941 & $37,195,679$ & $9,884,055$ & $6,945,417$ & $54,025,151$ \\
\hline 1942 & $31,476,923$ & $11,854,580$ & $7,769,062$ & $51,100,565$ \\
\hline
\end{tabular}

Source: Taiwan keizainenpo (Taiwan Economic Yearbook) (1941). 
Appendix 9A.2 Total fishery products in Taiwan from 1912 to 1939

\begin{tabular}{|c|c|c|c|c|}
\hline Year & Fish catch (kin) & Fish catch (number) & Fish catch (kan) & Aquaculture (kin) \\
\hline 1912 & - & - & - & $7,984,192$ \\
\hline 1913 & - & - & - & $8,715,569$ \\
\hline 1914 & - & - & - & $11,238,075$ \\
\hline 1915 & - & - & - & $14,034,698$ \\
\hline 1916 & - & - & - & $13,884,623$ \\
\hline 1917 & $32,267,588$ & $34,755,812$ & - & $13,973,187$ \\
\hline 1918 & $43,255,970$ & $29,249,508$ & - & $15,003,031$ \\
\hline 1919 & $33,670,301$ & $20,713,902$ & - & $10,819,461$ \\
\hline 1920 & $29,357,158$ & $59,985,454$ & - & $8,633,369$ \\
\hline 1921 & $38,844,635$ & $33,547,884$ & - & $13,048,628$ \\
\hline 1922 & $40,283,688$ & $34,282,977$ & - & $14,832,916$ \\
\hline 1923 & $56,367,338$ & $65,437,008$ & - & $12,599,073$ \\
\hline 1924 & $56,116,504$ & $68,585,825$ & - & $17,104,951$ \\
\hline 1925 & $61,153,501$ & $40,975,204$ & - & $17,001,439$ \\
\hline 1926 & $64,219,155$ & $57,100,576$ & - & $18,717,938$ \\
\hline 1927 & $71,788,897$ & $23,376,408$ & - & $21,470,648$ \\
\hline 1928 & $76,483,188$ & - & - & $18,977,636$ \\
\hline 1929 & $99,253,091$ & - & - & $21,161,382$ \\
\hline 1930 & $95,997,006$ & - & - & $21,344,421$ \\
\hline 1931 & $82,108,883$ & $160,719,108$ & $1,833,692$ & $28,550,352$ \\
\hline 1932 & $86,691,127$ & $129,524,285$ & $2,566,052$ & $28,572,447$ \\
\hline 1933 & $115,274,497$ & $126,513,185$ & $2,390,536$ & $29,827,986$ \\
\hline 1934 & $120,829,266$ & $50,571,683$ & $1,701,234$ & $26,421,635$ \\
\hline 1935 & $131,056,514$ & $40,221,073$ & $3,703,813$ & $23,176,401$ \\
\hline 1936 & $129,969,726$ & $7,395,468$ & $5,328,289$ & $25,375,859$ \\
\hline 1937 & $130,157,794$ & $33,663,337$ & $2,837,879$ & $26,139,122$ \\
\hline 1938 & $120,901,215$ & $96,498,549$ & $1,511,091$ & $28,294,794$ \\
\hline 1939 & $137,720,364$ & $59,017,961$ & $4,861,260$ & $24,855,410$ \\
\hline
\end{tabular}

Source: Taiwan keizainenpo (Taiwan Economic Yearbook) (1941). 


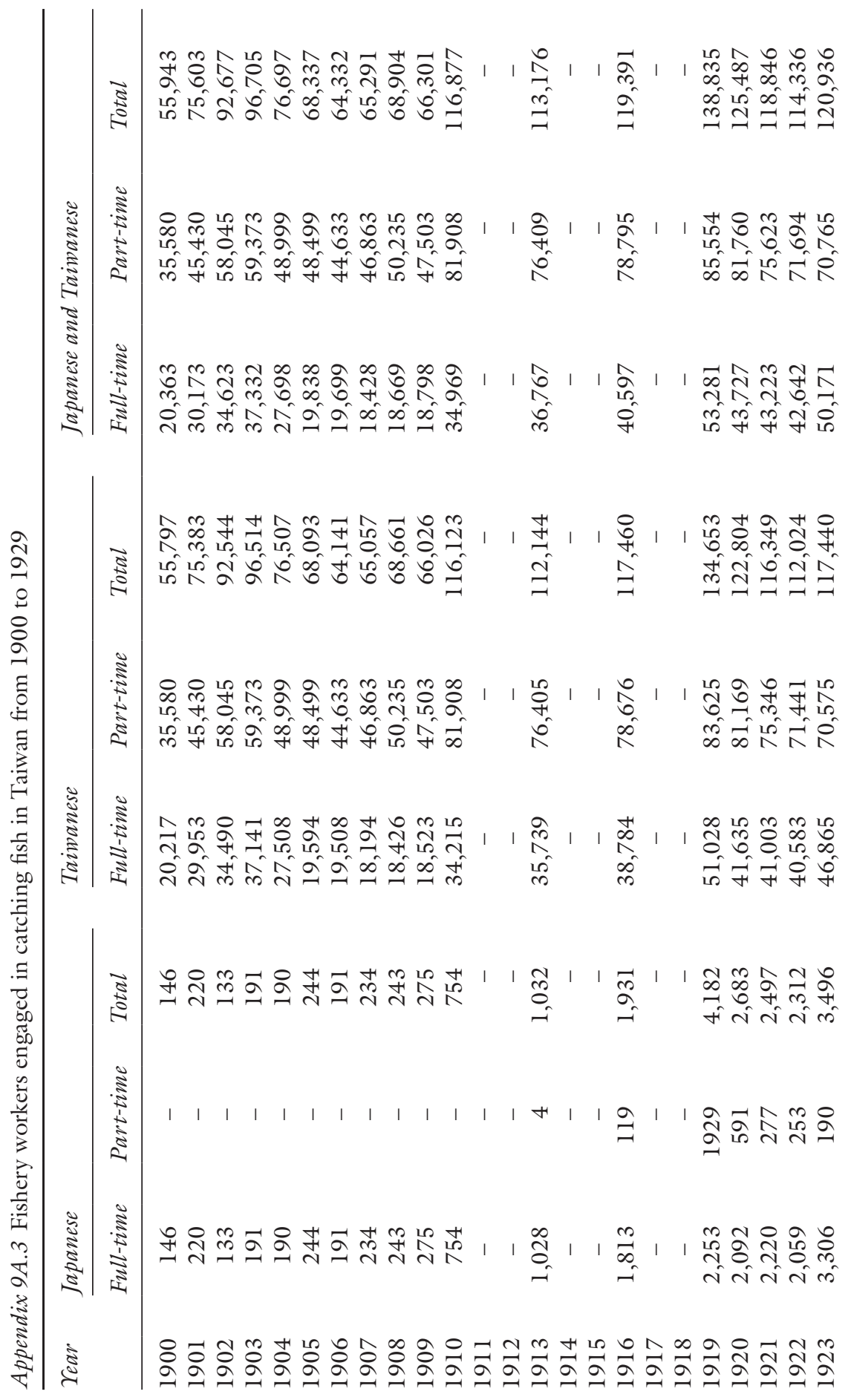




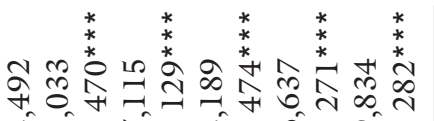

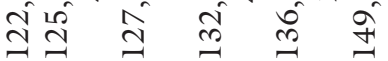

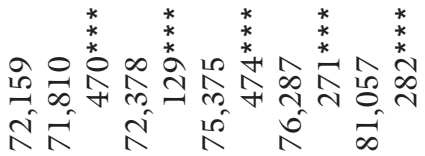

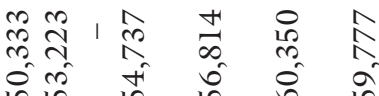

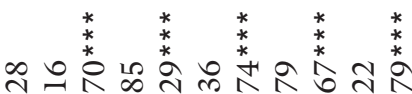

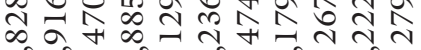

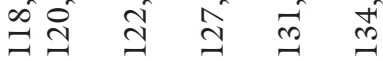

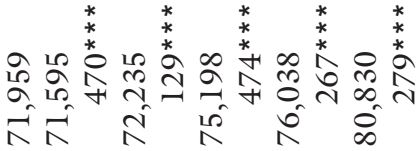

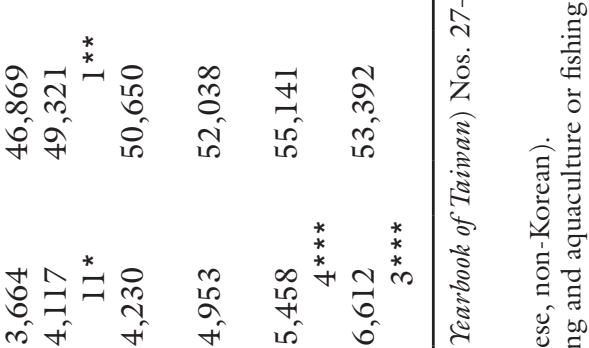

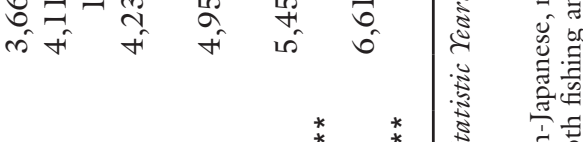

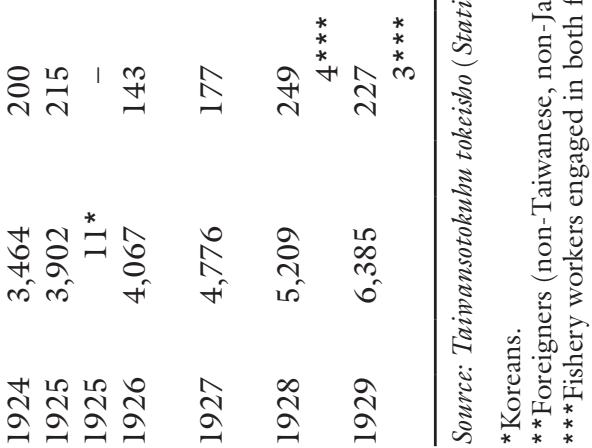




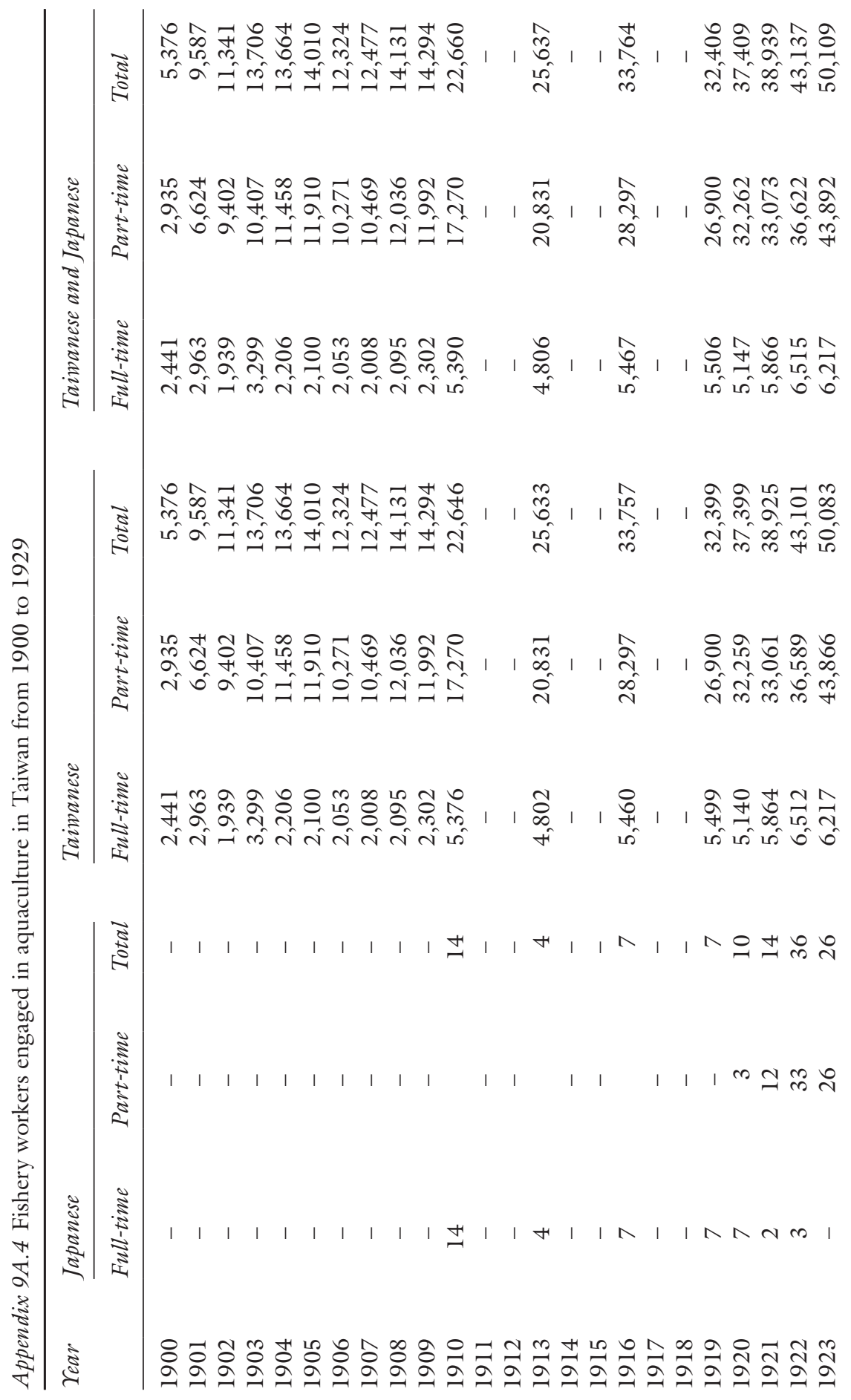




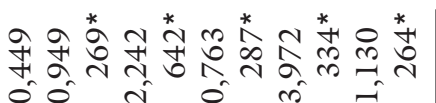

कि कि की की की

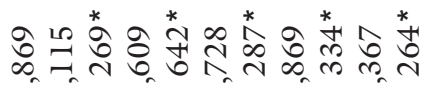

भं

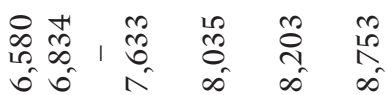

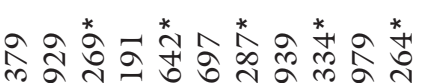

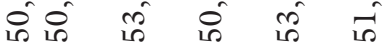

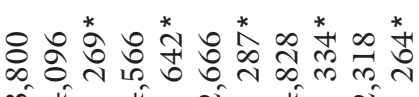

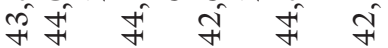

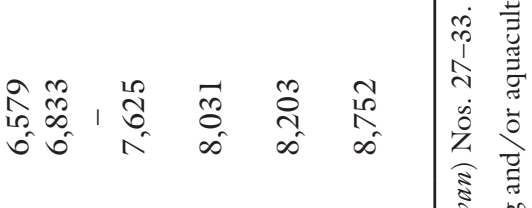

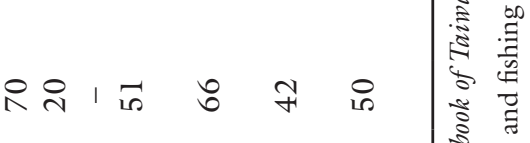

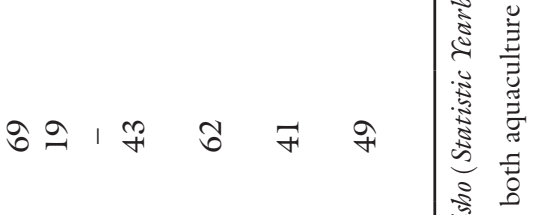

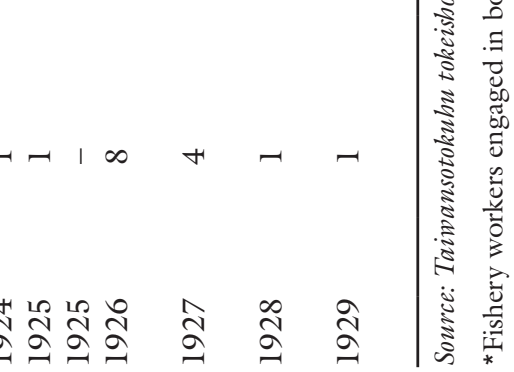




\section{Notes}

1 Alice H. Amsden (1979), "Taiwan economic history: A case study and a challenge to dependency theory," Modern China, 5-3, pp. 343-348.

2 Before the Fishery Law was established, fishery unions were called fishery associations. The Japanese Fishery Law changed the name of these organizations.

3 In Southern Sakhalin, the Japanese government established tentative rules for Sakhalin fisheries in 1905. The Fishery Law was introduced in 1907 and in 1911, the Japanese system of fishery rights was settled, and the complete Japanese law was introduced. Fishery associations were then established in Sakhalin. In Korea, fishery laws were established in 1908 and were similar to the Japanese Fishery Law. However, the Korean Fishery Law did not contain any clauses for fishery associations. After Japan merged with Korea, new fishery orders, including a clause for fishery associations, were established in 1911.

4 Robert S. Pomeroy (1996), "Community-based and co-management institutions for sustainable coastal fisheries management in Southeast Asia," Ocean \& Coastal Management, 27(3), p. 150. There are two methods of community-based resource management: traditional community-based management and co-management operated both by the local community and the government. A government-centralized management system is the opposite of community-based management.

5 Ibid. There are two methods of community-based resource management: traditional community-based management and co-management operated both by the local community and the government. A government-centralized management system is the opposite of community-based management.

6 Gudrun Petursdottir, Olafur Hannibalsson and Jeremy M. M. Turner (2001), Safety at Sea as an Integral Part of Fisheries Management, FAO Fisheries Circular No. 966, Food and Agriculture Organization of the United Nations: Rome.

7 Keisuke Shimo (下答助) and Hidemi Senoo (妹尾秀実) (1910), Taiwan suisangyo sisatu hukumeisho [A Report about Fisheries in Taiwan], Tokyo.

8 Japanese Government (内閣) (1912), Kobunruiju [Collection of Official Documents], National Archives of Japan, Vol. 36, Tokyo.

9 Taipei State Government (1925), Kitataihoku no suisan [Fisheries in Taipei state], Taipei.

10 Japanese Government (内閣) (1912), Kobunruiju [Collection of Official Documents], National Archives of Japan, Vol. 36, Tokyo.

11 Kazuyuki Nishimura (西村一之) (2006), “Taiwan tobu ni okeru gyogyo gijutsu to nihon" [The fishery techniques and Japan in eastern Taiwan], Ajia ahurika gengo bunka kenkyu, 71 .

12 Fisheries Experiment Station of Taipei State (1935), Taipei shu no suisan [Fisheries in Taipei State], Taipei.

13 Ibid; Masahumi Yokemoto (除本理史) (2005), “Senzenki Taiwan ni okeru nihonjin gyogyo imin" [Japanese Fishery Immigrants in Pre-WWII Taiwan], Tokyo keizai daigaku kaisi keizaigaku, 245, pp. 99-101.

14 Yu-Ju Lin (林玉茹) (2011), “Gijutuiten kara chiikikaihatsu he - Kan ei nihonjin gyogyo imin jigyo no tenkai" [From technique transfer to regional development] in Y. Oikawa (老川慶喜) , N. Sunaga (須永徳武) and H. Yagashiro (谷ヶ城 秀吉), Faculty of Economics, Rikkyo University (Eds.), Shokuminchi taiwan no keizai to shakai: Tokyo.

15 Taiwan Suisankai (1930), Taiwan suisan yoran (Taiwan Fishery Survey), Taipei, pp. 14-15.

16 Ibid.

17 Taiwan Keizainenpokankokai (1941), Taiwan keizai nenpo (Taiwan Economic Yearbook) Vol. 1, Kokusai nihonkyokai. 
18 Ibid, p. 201; also see Kenji Fujii (藤井賢二) (2007), “Suisan tokei kara mita Nihon touchiki no Chosen: Taiwan no gyogyo" [On the Fisheries of Korea and Taiwan from the View Point of Fishery Statistics under Japanese Rule], Toyo shiho, 13, p. 103.

19 The statistical yearbook of Taiwan included the production of offshore fisheries as part of deep-sea production. However, offshore production was described separately, so both offshore and deep-sea fishery production can be determined.

20 Ta-Yuan Chen (2006), "Japan and the birth of Takao's fisheries in Nanyo 1895-1945," Working Paper No. 139, Murdoch University: Perth, Western Australia.

21 Toshiyuki Mizoguchi (溝口敏行), (1975), Taiwan chosen no keizai seichou [Economic Growth of Taiwan and Korea], Iwanami Shoten: Tokyo.

22 Bank of Taiwan, Laboratory for Studying Economic Affairs (1974), Taiwan gyogyo no kenkyu [A Study of Taiwan Fisheries], Taipei.

23 Appendix tables; Zhu Pingyi (祝平一) (1998), Taiwan gyogyo shisiryo senhen toukeihen [Collected Papers of Taiwan's Fishery History, Historical Statistics], Taiwansho gyogyo kyoku, Taipei.

24 See the following calculation results:

Calculation results 1

Estimation equation

Fish catch $=\alpha$ (full-time Japanese fishery workers) $+\beta$ (full-time Taiwanese fishery workers)

$+\gamma$ (motorized vessels $)+\delta$

\begin{tabular}{llll}
\hline Variable & Coefficient & Standard error & \multicolumn{1}{c}{ t-statistic } \\
\hline $\begin{array}{l}\text { Full-time Japanese } \\
\text { fishery workers }\end{array}$ & $17,844.21155$ & $4,045.533664$ & 4.410842434 \\
$\begin{array}{l}\text { Full-time Taiwanese } \\
\quad \text { fishery workers }\end{array}$ & -608.2214351 & 353.5438929 & -1.72035662 \\
$\begin{array}{l}\text { Motorized vessels } \\
\delta\end{array}$ & $-10,371.47809$ & $22,396.23976$ & -0.463090153 \\
\hline
\end{tabular}

Calculation results 2

Estimation equation

Fish catch $=\alpha($ motorized vessels $)+\beta$

\begin{tabular}{lrrr}
\hline Variable & Coefficient & Standard error & t-statistic \\
\hline$\beta$ (intercept) & $23,942,653.1$ & $3,579,671.2$ & 6.68 \\
Motorized vessels & $83,697.6$ & $7,829.2$ & 10.69 \\
\hline
\end{tabular}

$R^{2}=0.927$.

25 Taiwan Suisankai (1930), Taiwan suisan yoran (Taiwan Fishery Survey), Taipei, pp. 36-37.

26 Masatsuru Kashiya （樫谷政鶴） (1901), Gyogyouboron [A Study on the Fishery Law], Sakaiinsatsugomeikaisha, Toyama.

27 Masatsuru Kashiya (樫谷政鶴) (1916), “Cho, suisankai no setti wo nozomu” [My Aspiration to Settle Taiwan Fishery Organization], Taiwan suisanzassi, 11, pp. 1-4; Masatsuru Kashiya（樫谷政鶴） (1925), “Koukyu wo yosuru chosen 
suisan mondai no nisan" [A Few Problems in Korean Fisheries to Be Investigated], Chosen no suisan, 11, pp. 1-8; 12, pp. 3-8; 13, pp. 9-13; also see Koji Kita（喜多孝治）(1923), “Gyogyoho to suisankaishaho ni tuite” [On Fishery Law and the Law of Fishery Unions], Taiwan suisanzassi, 88, pp. 3-7.

28 Taiwan Sotokuhu (1927), Taiwan suisan yoran [Taiwan Fishery Survey], Taipei, pp. 162-163; Sing-Hwa Hu (胡興華) (1998), Taiwan gyokaibu [Fisheries Organizations in Taiwan], Taipei, p. 18.

29 Tamihei Kita (1934-1938), "Tonai gyogyo kumiai no gaikyo 1 30" [Outline of Fishery Associations in Taiwan], Taiwan suisanzassi, pp. 232-283.

30 Ibid.

31 Fisheries Experiment Station of Taipei State (1935), Taipei shu no suisan [Fisheries in Taipei State].

32 See Teng-Jeng and Haruhiko Miyazawa (2011), “Taiwan Toko ni okeru sakuraebi gyogyo kanri no tenkai genjo kadai" [The Development, Current Status and Issues of the Sergestid Shrimp-Sergia Lucens-Fisheries Management in Tongkang, Taiwan], Kitanihon gyogyo [Journal of the North Japan Fisheries Economics], 39, pp. 57-82.

\section{References}

Amsden, Alice H. (1979), “Taiwan economic history: A case study and a challenge to dependency theory," Modern China, 5-3.

Bank of Taiwan, Laboratory for Studying Economic Affairs (1974), Taiwan gyogyo no kenkyu [A Study of Taiwan Fisheries], Taipei.

Chen, Ta-Yuan (2006), "Japan and the birth of Takao's fisheries in Nanyo 1895-1945," Working Paper No. 139, Murdoch University: Perth, Western Australia.

D-maps.com. Taiwan: coasts, divisions, names. http://d-maps.com/carte.php?num_ car $=648$ \&lang $=$ en $[$ accessed September 10, 2014]

Fisheries Experiment Station of Taipei State (1935), Taipei shu no suisan [Fisheries in Taipei State], Taipei.

Fujii, Kenji (藤井賢二) (2007), “Suisan tokei kara mita Nihon touchiki no Chosen: Taiwan no gyogyo" [On the Fisheries of Korea and Taiwan from the View Point of Fishery Statistics under Japanese Rule], Toyo shibo, 13, 98-114.

$\mathrm{Hu}$, Sing-Hwa (胡興華) (1998), Taiwan gyokaibu [Fisheries Organizations in Taiwan], Taipei.

Japanese Government (内閣) (1912), Kobunruiju [Collection of Official Documents], National Archives of Japan, Vol. 36, Tokyo.

Kashiya, Masatsuru (樫谷政鶴) (1901), Gyogyouboron [A Study on the Fishery Law], Sakaiinsatsugomeikaisha, Toyama. Kashiya, Masatsuru (樫谷政鶴) (1916), “Cho, suisankai no setti wo nozomu” [My Aspiration to Settle Taiwan Fishery Organization], Taiwan suisanzassi, 11, 1-4.

Kashiya, Masatsuru （樫谷政鶴）(1925), “Koukyu wo yosuru chosen suisan mondai no nisan" [A Few Problems in Korean Fisheries to Be Investigated], Chosen no suisan, 11, 1-8; 12, 3-8; 13, 9-13.

Kita, Koji (喜多孝治) (1923), “Gyogyoho to suisankaishaho ni tuite” [On Fishery Law and the Law of Fishery Unions], Taiwan suisanzassi, 88, 3-7.

Kita, Tamihei (1934-1938), "Tonai gyogyo kumiai no gaikyo 1 30" [Outline of Fishery Associations in Taiwan], Taiwan suisanzassi, 232, 62-71; 283, 15-22.

Lin, Yu-Ju （林玉茹） (2011), “Gijutuiten kara chiikikaihatsu he - Kan ei nihonjin gyogyo imin jigyo no tenkai” [From Technique Transfer to Regional Development], 
in Y. Oikawa (老川慶喜), N. Sunaga (須永徳武) and H. Yagashiro (谷ヶ城秀吉), Faculty of Economics, Rikkyo University (Eds.), Shokuminchi taiwan no keizai to shakai, Nihon keizaihyouronsha: Tokyo.

Mizoguchi, Toshiyuki (溝口敏行), (1975), Taiwan chosen no keizai seichou [Economic Growth of Taiwan and Korea], Iwanami Shoten: Tokyo.

Nishimura, Kazuyuki（西村一之） (2006), “Taiwan tobu ni okeru gyogyo gijutsu to nihon" [The Fishery Techniques and Japan in Eastern Taiwan], Ajia aburika gengo bunka kenkyu, 71, 120-145.

Petursdottir, Gudrun, Olafur Hannibalsson, and Jeremy M. M. Turner (2001), Safety at Sea as an Integral Part of Fisheries Management, FAO Fisheries Circular No. 966, Food and Agriculture Organization of the United Nations: Rome.

Pomeroy, Robert S. (1996), "Community-based and co-management institutions for sustainable coastal fisheries management in Southeast Asia," Ocean \& Coastal Management, 27(3), 143-162.

Shimo, Keisuke (下啓助) and Hidemi Senoo (妹尾秀実) (1910), Taiwan suisangyo sisatu hukumeisho [A Report about Fisheries in Taiwan], Tokyo.

Taipei State Government (1925), Kitataiboku no suisan [Fisheries in Taipei State], Taipei.

Taiwan Keizainenpokankokai (1941), Taiwan keizainenpou (Taiwan Economic Yearbook), Taipei.

Taiwan Sotokuhu (1923), Taiwan-hu tokeisho [Statistic Yearbook of Taiwan] No. 27, Taipei.

Taiwan Sotokuhu (1927), Taiwan suisan yoran [Taiwan Fishery Survey], Taipei.

Taiwan Sotokuhu (1934), Taiwan jijou [Circumstances of Taiwan], Taipei.

Taiwan Suisankai (1930), Taiwan suisan yoran [Taiwan Fishery Survey], Taipei.

Teng-Jeng, Huanga and Miyazawa Haruhiko (2011), "Taiwan Toko ni okeru sakuraebi gyogyo kanri no tenkai genjo kadai" [The Development, Current Status and Issues of the Sergestid Shrimp-Sergia Lucens-Fisheries Management in Tongkang, Taiwan], Kitanihon gyogyo [Journal of the North Japan Fisheries Economics], 39, 57-82.

Yokemoto, Masahumi (除本理史) (2005), “Senzenki Taiwan ni okeru nihonjin gyogyo imin" [Japanese Fishery Immigrants in Pre-WWII Taiwan], Tokyo keizai daigaku kaisi keizaigaku, 245.

Zhu, Pingyi (祝平一) (1998), Taiwan gyogyo shisiryo senhen toukeiben [Collected Papers of Taiwan's Fishery History, Historical Statistics], Taiwansho gyogyo kyoku, Taipei. 


\title{
10 Conclusion
}

\author{
Atsushi Maki
}

Less rhetoric, more realism.

Jorgenson (2014)

In the present monograph, we presented a variety of topics related to developing countries. The empirical validity of the quadratic Engel curve in a developing country was the key finding in Chapters 2 and 3. Because of the existence of the quadratic Engel curve, we have to reconsider the distinction between necessities and luxuries and the role of in-kind consumption. The quadratic Engel curve shows interesting characteristics regarding the income elasticity of demand for food - namely, in the phase of an increasing Engel's coefficient, food becomes an income-elastic item and is classified as a luxury good. This observation contradicts the standard concept for food items - namely, that food is income inelastic and is classified as a necessity.

The differentiation between necessities and luxuries is important in analyzing consumption patterns in developing countries. We tested the validity of the Törnqvist-Wold hypothesis regarding the classification of necessities and luxuries in consumer demand theory in considering the relationship between price and income elasticities. As examined in Chapter 2, almost all items are classified as necessities in developed countries such as Japan, while in developing countries certain items such as automobiles are considered luxuries. In Japan, before the high economic growth era in the 1960s, automobiles were classified as a luxury item, while after the high economic growth era in the 1970s, automobiles became classified as a necessity. Such changes are explained empirically by using the Törnqvist-Wold hypothesis. The classification of necessities and luxuries is important in terms of government tax policy in order for the government to promote wealth redistribution.

We also tested the validity of New Economics of Labor Migration (NELM) theory using the micro-data set of the Philippines in Chapter 5. Regarding the stability of NELM theory, there were a couple of counter-examples proposed by the researchers. In the present analysis using the Philippines data, one out of three characteristics of NELM theory is accepted, while others are rejected by the 
data. Let us return to the results: we observe that (1) very poor families are less likely to send their members to foreign countries; (2) remittances reduce poverty; and (3) remittances increase inequality. The second observation is consistent with NELM theory, while the first and third observations are inconsistent with NELM theory.

We also tested the Harris-Todaro model and endogenous growth models using the Thailand data in Chapter 7. The theoretical model that best explains the current Thailand economy is a hybrid model of a wage-difference model and a neoclassical model. This conclusion is consistent with the observation that the country is now facing the middle-income trap. Many countries that are in the transitional period from the developing to the developed stage face political and social instability because of this problem.

The middle-income trap during the development process in Thailand carries policy implications. We argue that the competing political and economic interests of rural and urban Thais stem from the structural shift from the agriculture sector to the manufacturing and services sectors. Policies that target mitigating the socio-economic fallout of this shift are imperative to promote political stability, a necessary condition to reignite growth momentum.

In analyzing the economic growth of the fishery industry in Taiwan in Chapter 9, it is clear that legal and institutional changes were crucial to the growth in Taiwan's fishery industry in addition to advances in fishery technology.

Returning to our main themes of poverty, inequality, and growth, growth reduces poverty as a whole, while it has ambiguous effects on inequality whether or not it narrows. When the variance of income distribution increases in accordance with economic development, the degree of inequality may increase. This can be adjusted through government redistribution policies.

The World Bank systematically collects data sets on developing countries regarding poverty, inequality, and growth. It reports that due to economic growth in developing countries, extreme poverty has decreased monotonically over time, the Gini coefficient has decreased, and the poverty gap between developed and developing countries has also narrowed.

On the other hand, although extreme poverty rates have fallen everywhere, the number of poor people in low-income countries (LICs) (as defined by the World Bank) has increased. Thus, while the number of extremely poor individuals has declined in middle-income and high-income countries (including India and China), it has increased in LICs. This means that poor households in LICs remain relatively worse off despite decreases in extreme poverty (cf. Olinto, Beegle, Sobrado, and Uematsu 2013).

Government policy plays an important role in poverty reduction and decreasing inequality in developing countries. While governments in developing countries are primarily responsible for alleviating poverty and inequality, they need assistance from international institutions. 
In order to address these critical issues, we propose the following for consideration:

(1) The effect of education is important to facilitate dissemination of technology and promote poverty reduction. The benefits of education may appear only gradually, but promoting access to schooling must be a development priority;

(2) Our research confirms the necessity of adapting our methods, analysis, and policy prescriptions to local conditions that reflect the historical, traditional, cultural, and religious context. We need to fine-tune economic policy according to factors other than aggregate indicators such as per capita gross domestic product (GDP) or the Gini coefficient;

(3) Regarding poverty problems, political stability is crucial. Instability, war, and displacement upend the best economic policies and amplify existing problems of poverty and inequality. Economic growth, the opportunities it generates, and effective distribution of the fruits of that growth are critically important to promote political stability. In this regard, corruption is a widespread malady that undermines development, stability, and international contributions;

(4) Weather changes have taken place because of global warming. The consequences of adverse weather changes and an increase in natural disasters reduce economic prospects in developing countries which lack disaster resilience and capacity to cope with flooding, earthquakes, volcanic eruptions, and other disasters such as the recent Ebola epidemic and other pandemics.

Our research confirms the importance of systemic stability to development. The system includes not only the economic system (markets) but also political systems and natural conditions. In economic analysis, the stability of the system means that exogenous factors are stable. The economic system in developing countries is fragile and vulnerable to external shocks. Developed countries benefit from legal, institutional, and market systems that serve as shock absorbers that are not as robust in developing nations, where immature institutions are not reliable stabilizers and have limited capacity to mitigate external shocks.

Let us give one example concerning poverty reduction. In developing countries, the main industry is agriculture, and the amount of production is strongly affected by weather conditions, while in developed countries the main industry is manufacturing, and output is far less affected by weather conditions. Considering these conditions, we compare developed and developing countries regarding the effect on poverty from various causal factors divided into economic, political, and environmental variables. The target variable, poverty reduction, is related to economic growth as an economic factor, the possibility of regime change around democratic government and autocratic government as a political factor, and weather as an environmental effect. The following is a table that explains the different effects of reducing poverty between developed and developing countries. 


$\begin{array}{lll}\text { Target } & \text { Reduction of poverty } \\ { } } & \text { Developed countries Developing countries }\end{array}$

(1) Economic factor

Income or growth rate of income

Prices or inflation rate

Regime change

(3) Environmental factor

Weather conditions

Tsunami

Note: $(+)$ indicates a positive effect on poverty reduction; $(-)$ indicates a negative effect on poverty reduction; $(0)$ indicates no effect on poverty reduction; (?) indicates ambiguous though small effect on poverty reduction; and (??) indicates ambiguous though large effect on poverty reduction.

We focus on the role of economic models using the previous table. This relationship is described in the following table with respect to the difference between developed and developing countries.

Economic models

(1) Economic factor (systematic part in economics)

Developed countries

Developing countries

Exactly explained based on economic theory Exactly explained based on economic theory

(2) Political factor (disturbance specified by stochastic distribution)

Developed countries

Variance of the stochastic distribution is 0

Developing countries

Variance of the stochastic distribution is large

(3) Environmental factor (disturbance specified by stochastic distribution)

Developed countries

Developing countries

Variance of the stochastic distribution is small

Variance of the stochastic distribution is large

Note: Political and environmental factors are treated as a stochastic disturbance term, and the variance of the disturbance term including political and environmental factors is larger in developing countries than in developed countries because of the difference between the (0), (?), and (??) effects in the previous table.

From the previous tables, it is clear that when we obtain a reasonable solution regarding poverty reduction in developing countries, we have to consider factors other than economic factors. Though it is not easy to construct a suitable economic development model, we will extend the existing model in order to obtain suitable policy implications for developing countries.

With nearly one fifth of the world population still below the poverty line, it is crucial to do so.

\section{References}

Jorgenson, Dale W. (2014), “Abenomics," Asia Nikkei Newspaper, Available from: http://asia.nikkei.com/print/article/13173 
Olinto, Petro, Kathleen Beegle, Carlos Sobrado and Hiroki Uematsu (2013), "The state of the poor: Where are the poor, where is extreme poverty harder to end, and what is the current profile of the world's poor?" Economic Premise, World Bank, Available from: http://wwwwds.worldbank.org/external/default/WDSContent Server/WDSP/IB/2013/10/11/000333037_20131011145101/Rendered/ PDF/818010BRI0EPl20Box0379844B00PUBLIC0.pdf 


\section{Index}

Page numbers in italic format indicate figures and tables.

ad hoc expenses 140

adult equivalence scale $13,15-16,21$, $46,50-2,68$

agricultural workers $87,96,157,159$

agriculture sector: economic growth and

161; GDP related to $110,157-60$,

170-1, 173; income inequality and

160; introduction to 7; labor force

characteristics 94 ; productivity in

176-7; support for 162 ; see also

informal economy/sectors; wage/

earnings

ASEAN Free Trade Area (AFTA) 182, 199

Asian crisis 154, 159, 170

Asian Development Bank (ADB) 130, 131, 182, 186, 192

Asia's Golden Quadrangle (AGQ): conclusion about 207-8; conflicts in 185-6; description of 8,182 ; distances between major cities and 185; economic overview of 186-92; export and import shares 204; features of 183-92; GMS Program and 192-9; income levels 188-9; infrastructure development in 182, 185,206 ; map of 184 ; partnership with foreign countries and 199-205; policy recommendations for 206-7; population of 187,188 ; poverty in 192

Association of Southeast Asian Nations (ASEAN) 129, 182, 183, 186, 199-205

Autonomous Region in Muslim Mindanao (ARMM) 107, 111
Banten: agriculture and nonagricultural sectors in 77,79 ; case study $91-8$; economy growth in $76-7,91$; employment by occupation in 97 ; labor force characteristics 93-6; labor productivity in 80 ; working poverty rate in $84-5$

basic needs poverty line 13, 15, 16, 65

caloric intake 13, 15, 40

case study for Yogyakarta and Banten 91-8

casual workers $83-8,99$

celestial mechanics 1,2

China, rising importance of 202-5

coastal fisheries $211,212,213,220$, 227,229

Colombo Consumer Price Index (CCPI) 142

commodities: demand functions and 12, 23-9; total and price elasticities for 38

conditional mean estimating function 19,56

consumer behavior: cross-price elasticities and 11; Engel's Law and 45, 67; in Vietnam and Philippines 46-55

consumer optimization 178 consumption expenditure: amount of 47-9; Engel's coefficient and 141-2 contributing family workers 75,76 cram schools 146

Cross-Border Transportation Agreement (CBTA) 195

cross-price elasticities $11,32-7$ 
data analysis 15-23

deep-sea fisheries 215-16, 219-20, 227

demand functions: estimating $11-12$,

23-9; linear expenditure system 30;

quadratic expenditure system 30-1

developed countries 154, 157, 158, 238, 240-1

developing countries see specific countries developing member countries (DMCs) 73

DI Yogyakarta see Yogyakarta

durable household goods 140, 141

earnings see wage/earnings

East-West Economic Corridor (EWEC) 194

economic growth: agriculture sector and 161; estimation results $168-79$; migration and 161; political stability and 207; in Thailand 7, 154-60, 162; theoretical models 160-8; in Yogyakarta and Banten 76-7, 91 economic models 241

economic sanctions 190, 201, 203

education: impact of 130,240 ; level of 146

elasticity of demand see income elasticity of demand; price elasticity of demand elderly households 143, 144, 148, 149, 150

employment: nature of 91-3;

nonagricultural and total 170 ; by occupation $96-7$; poverty rate by 84-5; type of enterprise and 97-8; wage/earnings by 82

endogenous growth model 180, 239

Engel curve: conclusion about 40-1, 238; introduction to 4 ; in Tanzania 11, 13, 19, 22, 66-7; total expenditure elasticity and 4, 10-11; very poor households and 4,13 ; in Vietnam and Philippines 55-7, 66

Engel's coefficient: consumption expenditure and 141-2; by elderly household 149; of family nuclei 147; in-kind consumption and 53; movement of 13, 17; of Sri Lanka 138-40; total expenditure and 18, 46; very poor households and 53-4; in Vietnam and Philippines 52

Engel's Law: consumer behavior and 45,67 ; data analysis and 15-23; food expenditure and 10,67; introduction to 4 ; validity of 13,45 enterprises: formal $75,77,92$; informal $74,76,77,92$; type of $97-8$

enumeration areas (EAs) 107-8

equivalence scale see adult equivalence scale

Estate sector 133, 136, 139-40, 142, 144,146

expenditure(s): distribution of 137-41;

Gini coefficient 139; HIES and

136-50; of specific households 143-9

family income see income

Family Income and Expenditure Survey

(FIES) 106-7, 111, 112, 122

fish catches 217, 220, 227, 228, 229

fishery industry/system: associations and organizations 224-7; conclusion about 239; data from 1907 213; development of 216-23; exports and imports 221-3; features of 223-7; introduction to 8, 211-12; Japanese 212-16; trade data 221, 223; unions related to 224,226

Fishery Law see Japanese Fishery Law fishery products: in Taiwan 219; value of 228-9; yield of 216,217

fishery workers 96, 97, 213, 215-18, $230-3$

fishing vessels $213,215,218,220,227$

food consumption expenditures 15, 16, 65

food costs 140

food expenditure: Engel's Law and 10, 67; food poverty line and 15, 16, 65; Gini coefficient and 55; total expenditure elasticity and 10-11, 21

Food Stamp Program (FSP) 45

foreign direct investment (FDI) 182, 199-203, 208

formal employment/sectors: competition for 99 ; concept of 80 ; gap between informal and 76-83; labor productivity in 81

Fourth Thai-Lao Friendship Bridge $183,184,194,195,196$

Free Trade Agreement (FTA) 182-3, 199-200, 206

free trade areas: formulation of 206-7; GDP of 199,200

Gini coefficient: adult equivalence scale and 46, 52; expenditure 139; of household income 129, 137; income inequality and $51,53-5,109$; in-kind 
consumption and 51, 55; migration probability and 113; theoretical 124-5; of urban and rural sectors 136 Gini index 109, 156

Golden Quadrangle (GQ) see Asia's Golden Quadrangle (AGQ) goods market equilibrium 165-6 government subsidy programs 44,45 , 157,215

Greater Mekong Subregion (GMS) Program: EWEC and 194; foreign direct investment and 202; GQ area development by 195-9, 207-8; NSEC and 192-4; objective of 192; SEC and 194-5 gross domestic production (GDP): AGQ and TLMY region 189-91; agricultural 110, 157-60, 170-1, 173; of free trade areas 199, 200; growth rate of 129,154 ; nonagriculture 79 , $170-1$; by sector and industry 78 gross regional domestic product (GRDP) 77, 80, 98, 99

gross valued added (GVA) 5, 77, 79

Harris-Todaro model 7, 154, 161, 166-7, 239

Hayami index 159

household expenditure see expenditure(s)

Household Expenditure and Income Survey (HIES): income and expenditure and 136-50; overview of $131-5$

households income see income

household unincorporated enterprises with at least some market production (HUEMs) 101-2

income: of agricultural workers 159 ; distribution of 136-7; education impact on 130; HIES and 136-50; remittances and 112; sources of 108 , 125; of specific households 143-9

income elasticity of demand $46,58,62$, $66,67,238$

income inequality: agriculture and nonagricultural sectors and 160; distribution of 109-10; Gini coefficient and 51, 53-5, 109; poverty profile and $107-11$; remittances and 107-11, 121-5; in Sri Lanka 130, 150; in Thailand 154-7 income levels 188-9

Indonesia see Banten; Yogyakarta industry: contribution to GDP by 78 ; of economic activity 96; in Indonesia $76-7$; labor productivity by 81 ; productivity of 189,190

informal economy/sectors: case study 91-8; conceptual framework 75; conclusion about 98-9; description of 74, 76; gap between formal and 76-83; introduction to 73 ; nonagriculture sector and 79 ; policy implications 99-100; poverty and 83-91; productivity in 79-81; relevance of 92-3

informal employment: households engaged in 83,87 ; introduction to 5 ; in nonagriculture field 94 ; significance of 92 ; structure of 95 ; wage/earnings for 82

informal workers 73-4, 80, 87, 96, 99, 101

infrastructure development: in AGQ region 182, 185, 206; GMS Program for 192, 194-5, 197; in Sri Lanka $129-31,143$

in-kind and cash transfers 44,45

in-kind consumption: conclusion about 68; consumer behavior and 46-55; Engel curve and 55-7; Engel's coefficient and 53; Gini coefficient and 51, 55; implications of 65-8; introduction to 4, 5; in Philippines 63-4; QUAID system and 57-63; role of 44,64 ; sources of 45 ; in Vietnam 63-4

in-kind non-food consumption 47,48

in-kind transactions $44,45,63-6$

International Conference of Labor Statisticians (ICLS) 74, 75, 76

inverse U-shaped Engel curve see Engel curve

Japanese Fishery Law 211-15, 224, 226, 227

Japanese fishery system: features of 211 ; introducing 212-16

Kepler stage 1, 9

kernel regression 56-9, 119

labor force: Estate sector 139; by gender and sector 93-6

Labor Force Survey (LFS) 101, 102 
labor market equilibrium 164

labor productivity: by industry 81 ; for informal sector 79-81; see also productivity

Laos: poverty in 188; rising importance of China in 202-5; trade volume with 198; see also Asia's Golden Quadrangle (AGQ)

Law of Fishery Organization 226

Law of Universal Gravitation 1, 3

least absolute error (LAE) estimator 21 , 60

Lewis model 153, 161

linear expenditure system (LES) demand function 12, 29-32

living standards $14,40,41,65,140-1$, 157

logistic regression model 112-19

longline fishing 215,216

low-income countries (LICs) 158, 188, 239

luxuries: classification between necessities and 35; conclusion about 238; defined 32,41 ; elasticity of demand and 37 ; representation of 35-6

Mae Sai Bridge 195, 196

Mae Sai customs house 197

marginal productivity 176-7

market clearing condition 164, 165

Matsuyama model 167, 179

middle-income problems 157, 159, 179-80, 239

migration: determinants of $111-19$; economic growth and 161 ; logistic regression model of 112-19; per capita income and 118 ; poverty index and 114; probability of 113 ; remittances and 104-5; wage rates and 166

“moderately poor" households 87,88 , 91

Myanmar, rising importance of China in 202-5

Myanmar Route 193, 199

necessary goods/necessities:

classification between luxuries and 35; conclusion about 238 ; defined 32 , 41 ; elasticity of demand and 37 ; food category 22 ; representation of $35-6$; see also luxuries neoclassical model 154, 164, 167, 239

new economics of labor migration

(NELM) theory: claims of 105 ;

conclusion about 238-9; implications

of 5-6; remittances and 105-6,

$111-12$

Neyman allocation 135

nonagriculture sector: employment and 170 ; GDP related to $79,170-1$;

households engaged in 83,87 ;

income inequality and 160; informal sector production in 79 ; labor force characteristics 94 ; poverty rate and 87; productivity in 176-7; in

Yogyakarta and Banten 77-9

non-durable household goods 133, 140 non-food category 55, 65, 66

nonparametric regression $13,19,20$, $40,55-7$

non-poor households $13,16,17,18$, 19,41

North American Free Trade Agreement (NAFTA) 199

North-South Economic Corridor (NSEC) 184, 192-4

nuclear families 143, 144, 146, 148

occupation, employment by $96-7$

Official Development Assistance (ODA) 130-1

Official Poverty Line (OPL) 142

offshore fisheries 212, 215-16, 219-20, 227

opium production 182, 185, 186, 207

ordinary least-squares (OLS) regression $14,22-3,60-2$

Organization for Economic

Co-operation and Development

(OECD) 50, 51, 52

overseas Filipino workers (OFWs) 6, 104 own-account workers $75,90,91$

own-price elasticity: for commodities 38 ; consumer behavior and 11 ; demand functions and 23-9; Engel curve and 4; estimating 14; necessities and luxuries and 32-6

Oxford equivalence scale $50,51,52$

per capita income: determinants of 123 ; migration and 118 ; percentage and average 113 ; remittances and 115 , 122; theoretical 124

per capita scale 50,51 
Philippines: all households in 58 , 70 ; consumer behavior in 46-55; Engel curves in 55-7, 66; Engel's coefficient in 52 ; income elasticity of demand in 62 ; in-kind consumption in 63-4; very poor households in 49, 54, 59; see also remittances

political instability/stability: economic growth and 207; poverty reduction and 240; in Thailand 155-6, 186

poor households: defined 16; poverty rate of 87-91; total expenditure classes and 17

population: AGQ region 187, 188; land area and 186-8; of Sri Lanka 132

poverty: in AGQ region 192; determinants of 120 ; distribution of 110; GDP and 110; income inequality and 107-11; informal sectors and 76, 83-91; in Laos 188; migration and 114; reduction in 142-3, 239-41; remittances effects on 119,121 ; in Thailand 154-7, 188

poverty index $106,112,114$

poverty line: calculation of 87,142 ; defined 126; family income and 119, 121 ; types of 65

poverty ratios $87,88,89,142$

pre-WWII fisheries 216, 223, 226, 227

price elasticity of demand $4,14,41$

price-independent generalized logarithmic (PIGLOG) 13, 19, 58 prices, increase in 170,172

primary sampling units (PSUs): defined 107; EAs and 107-8; HIES and 133, 135; HUEMs and 101-2

production function $163,173-6,178$ productivity: of industry 189,190 ; in nonagriculture field 176-7; wage/ earnings and $82-3$

quadratic almost ideal demand (QUAID) system: estimation results 22, 60-2; introduction to 10; in-kind consumption and 57-63; PIGLOG and 13,19 ; total expenditure elasticity and 23

quadratic expenditure system (QES) demand function $12,29-32$

remittances: conclusion about 125 ; determinants of receiving 116 ; effects of 119-25; families receiving 112 ; income inequality and 107-11, 121-5; introduction to $5-6$; migration and 104-5, 111-19; NELM theory and 105-6, 111-12; per capita income and 115,122 rural sectors 136, 139, 142, 155, 157 rural workers 89,161

Samurdhi program 143 secondary sampling units (SSUs) 135 Second Thai-Lao Friendship Bridge 194, 196

service link costs 199, 206

single-stop custom inspection and single-window custom inspection 195,206

skipjack fishing 215,218

soft infrastructure 195, 206, 208

Southern Economic Corridor (SEC) 194-5

square root scale $50,51,52$

Sri Lanka: civil war in 128-9; distributions of households in 133-4; HIES in 131-5; income and expenditure and 136-50; income inequality in 130,150 ; infrastructure development in 129-31, 143; introduction to 128 ; level of education in 146; ODA for 130-1; population of 132

standard of living 14, 40, 41, 65, 140-1, 157

structural equations 178-9

subsidy programs $44,45,157,215$

Taiwan: fishery production in 219; provinces of 214; see also fishery industry/system

Tanzania: Engel curve in 11, 13, 19, 22, 66-7; household budget survey 15

Thailand: economic growth in 7 , 154-60, 162; FDI inflows in 201, 203; GDP per capita 188; income inequality in 154-7; introduction to 153-4; political instability in 155-6, 186; poverty in 188; regions and provinces in 169; rising importance of China in 202-5; trade volume of 197, 198; see also Asia's Golden Quadrangle (AGQ)

Thailand, Laos, Myanmar, and Yunnan (TLMY): income levels 
188; industrial structures 189-90; population and land area $186-8$

Third Thai-Lao Friendship Bridge 194, 196, 197

Törnqvist-Wold hypothesis: conclusion about 238; empirical findings 36-40; empirical validity of 12 ; for necessities and luxuries 32-6; purpose of 11,15 total expenditure elasticity: demand functions and 23-9; elasticity of demand and 39; Engel curve and 4, 10-11; estimating 14; food expenditure and 21; QUAID system and 23; for very poor households 13 total gross value added (GVA) 5, 77, 79

total household expenditure 47,48 , 49

unemployment rates 7, 129

unpaid family workers $74,86,88$

urban households 89

urban sector $142,144,155,157$

very poor households: basic statistics 48-9; classification of 16; defined 16; Engel curve and 4, 13; Engel's coefficient and 53-4; migration and 105-6; in Philippines 49, 54, 59 ; poverty rate of $87-91$; total expenditure elasticity for 13
Vietnam: all households in 56, 69; consumer behavior in 46-55; Engel curves in 55-7, 66; Engel's coefficient in 52 ; income elasticity of demand in 62 ; in-kind consumption in 63-4; very poor households in $48,53,57$

wage/earnings: between big and local cities 191; by class of workers 90; economic growth and 161 ; for informal employment 82 ; migration and 166; productivity and $82-3$; of workers and managers 190; see also income

Walras' Law 20, 50, 59

weather changes 240,241

Working-Leser demand functions 12 , $14,23,32$

working poor $83,86,87,99$

working poverty rate: calculation of 83 ; conclusion about 99 ; by employment status $84-5$

World Bank 129-31, 154, 188, 239

Yogyakarta: agriculture and nonagricultural sectors in 77,79 ; case study 91-8; economy growth in $76-7,91$; employment by occupation in 96; labor force characteristics 93-6; poverty rate in $84-5$; productivity in 80 